Prepared in cooperation with the U.S. Department of Transportation Federal Highway Administration

Office of Project Development and Environmental Review

\title{
Methods for Evaluating Potential Sources of Chloride in Surface Waters and Groundwaters of the Conterminous United States
}

Open-File Report 2015-1080 



\section{Methods for Evaluating Potential Sources of Chloride in Surface Waters and Groundwaters of the Conterminous United States}

By Gregory E. Granato, Leslie A. DeSimone, Jeffrey R. Barbaro, and Lillian C. Jeznach

Prepared in cooperation with the U.S. Department of Transportation Federal Highway Administration

Office of Project Development and Environmental Review

Open-File Report 2015-1080 


\title{
U.S. Department of the Interior SALLY JEWELL, Secretary
}

\section{U.S. Geological Survey \\ Suzette M. Kimball, Acting Director}

\author{
U.S. Geological Survey, Reston, Virginia: 2015
}

For more information on the USGS - the Federal source for science about the Earth, its natural and living resources, natural hazards, and the environment-visit http://www.usgs.gov/ or call 1-888-ASK-USGS.

For an overview of USGS information products, including maps, imagery, and publications, visit http://www.usgs.gov/pubprod/.

Any use of trade, firm, or product names is for descriptive purposes only and does not imply endorsement by the U.S. Government.

Although this information product, for the most part, is in the public domain, it also may contain copyrighted materials as noted in the text. Permission to reproduce copyrighted items must be secured from the copyright owner.

Suggested citation:

Granato, G.E., DeSimone, L.A., Barbaro, J.R., and Jeznach, L.C., 2015, Methods for evaluating potential sources of chloride in surface waters and groundwaters of the conterminous United States: U.S. Geological Survey Open-File Report 2015-1080, 89 p., http://dx.doi.org/10.3133/ofr20151080.

ISSN 2331-1258 (online) 


\section{Acknowledgments}

The authors thank the many people who provided information for the report or reviewed this report. Susan Jones and Marcel Tchaou of the Federal Highway Administration, Rachel Herbert of the U.S. Environmental Protection Agency, Henry Barbaro of the Massachusetts Department of Transportation, and John Clune, Michael Como, Jonas Casey-Williams, and Kevin Breen of the U.S. Geological Survey provided thoughtful and thorough technical and editorial reviews of this report. Patricia Cazenas of the Federal Highway Administration identified the research need and provided information and guidance for the design of the study. Kirk Smith of the U.S. Geological Survey provided much of the information and data that were used to examine the potential representativeness of grab-sampling efforts and to evaluate automatic monitoring methods. 



\section{Contents}

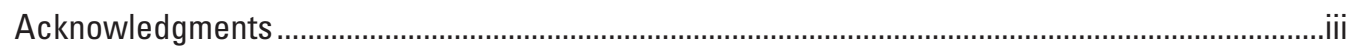

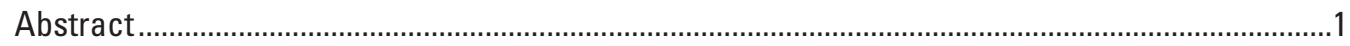

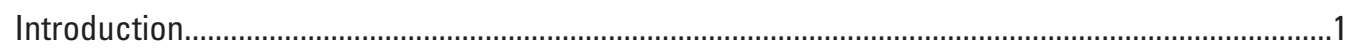

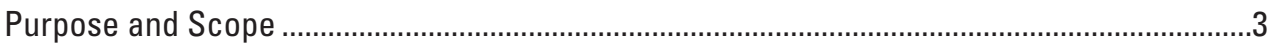

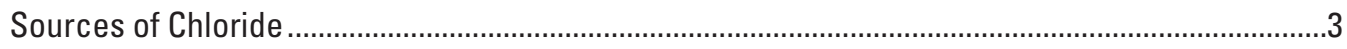

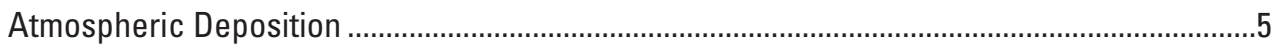

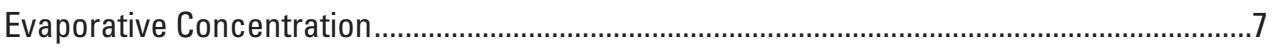

Deep Saline Groundwater ................................................................................................

Chemical Weathering of Soil and Rock...............................................................................

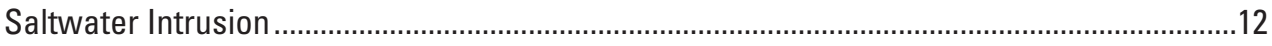

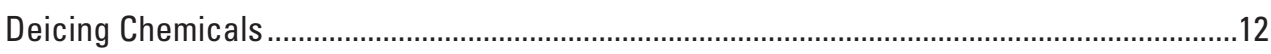

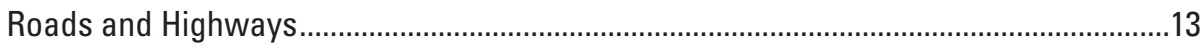

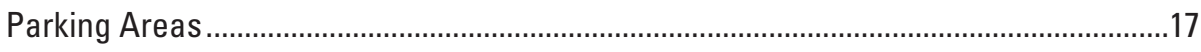

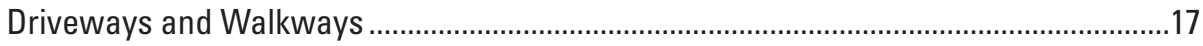

Storage and Handling Sites ...................................................................................18

Dust Control and Stabilization of Unpaved Roads...............................................................18

Water Treatment and Wastewater ....................................................................................19

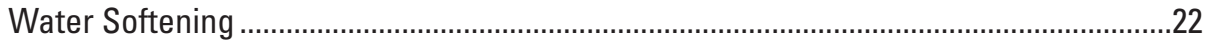

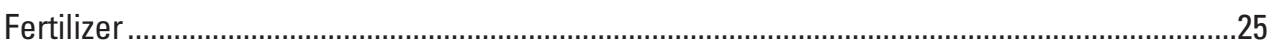

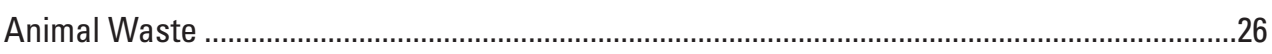

Irrigation

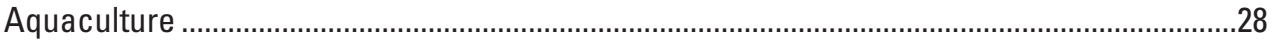

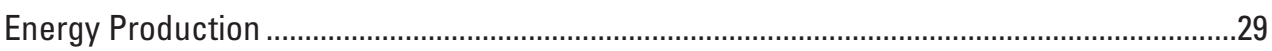

Landfills, Incineration, and Composting...........................................................................

Constructing a Chloride Budget for a Watershed ………..........................................................3

Watershed Characterization ..................................................................................................3

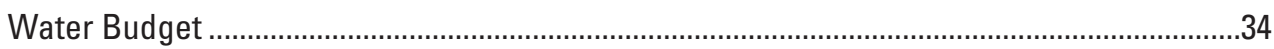

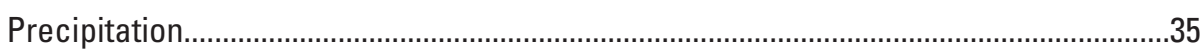

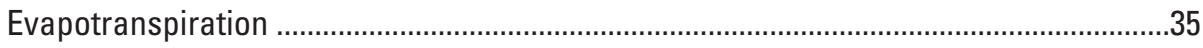

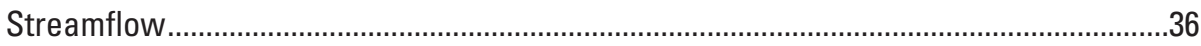

Human Water Use.....................................................................................................

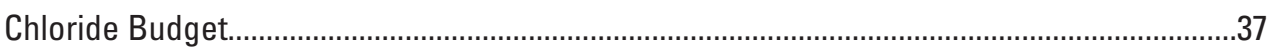

Monitoring Chloride in the Environment ..............................................................................3

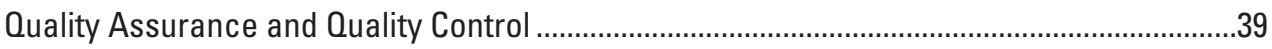

Use of Ionic Conductance for Monitoring Chloride ................................................................40

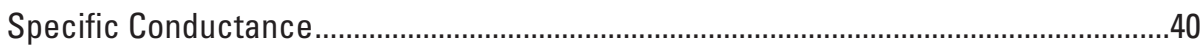

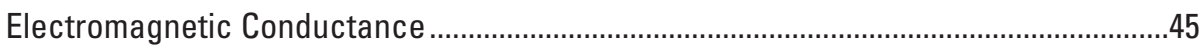

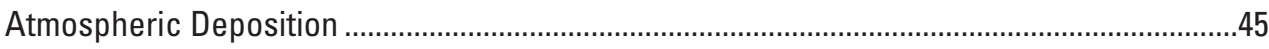

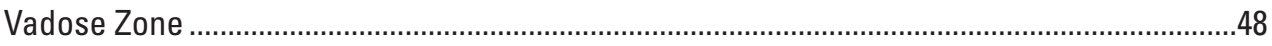

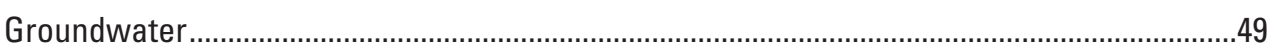

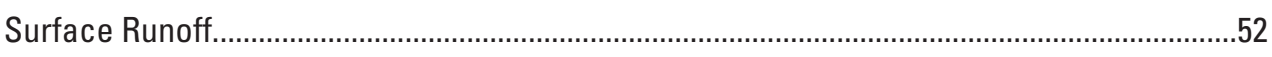

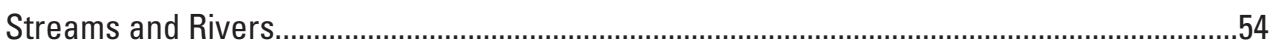




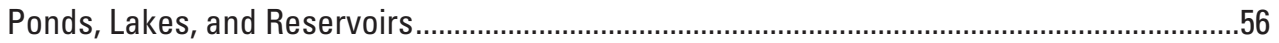

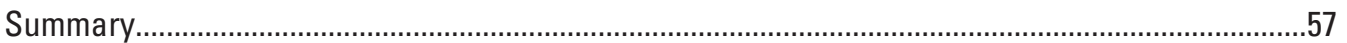

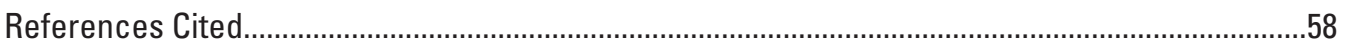

\section{Figures}

1. Scatterplots showing correlations among the population density, imperviousness, and road density values for 8,470 gaged drainage basins in the U.S. Geological Survey Geospatial Attributes of Gages for Evaluating Streamflow (GAGES II) database.

2. Maps showing annual mean concentration and annual rate of deposition of chloride in precipitation (wet deposition) in the conterminous United States, 2011.........6

3. Graphs showing relation between distance from the coast and $A$, annual mean concentration (precipitation-weighted) and $B$, annual rate of deposition of chloride in precipitation (wet deposition) in the conterminous United States, 2011 ......................7

4. Map showing the depth to saline groundwater in the conterminous United States ........8

5. Scatterplot showing chloride and total dissolved solids concentrations in deep saline groundwater in data compiled by Feth and others (1965).

6. Map showing generalized areal extent of geologic deposits of rock salt and other evaporites in the conterminous United States

7. Graph showing instantaneous and event-mean chloride concentrations estimated from specific-conductance measurements and measured event-mean chloride concentrations in pavement runoff collected from 0ctober 1, 2005, through September 30, 2007, at U.S. Geological Survey monitoring station 423027071291301 on State Route 2 near Littleton, Massachusetts

8. Pie chart showing public road area, by percentage of total lane miles identified by functional system

9. Graph showing annual load of chloride added to the wastewater stream from ionexchange water softeners.

10. Map showing number of oil- and gas-related wells in the United States by eightdigit hydrologic unit code.

11. Map showing major areas of unconventional oil and gas development in the United States

12. Diagrams showing components of a water budget for $A$, a stream basin and $B$, an aquifer system.

13. Flowchart showing environmental reservoirs and pathways for the storage and transport of water and solutes from deicing operations

14. Graph showing empirical equations for adjusting the calculated specific conductance to a measured specific conductance for a sodium chloride solution.......43

15. Diagrams showing $A$, principles of borehole logging of electromagnetic conductivity and $B$, a surface survey of terrain conductivity .

16. Flowchart showing conceptual categorization of the components of atmospheric deposition with respect to their deposition properties and flux detection methods ......46

17. Graphs showing induction logs and water-quality data collected on July 25, 1991, from well clusters B1 (upgradient from the highway) and B2 (downgradient of the highway) along the same groundwater flow path, State Route 25, southeastern Massachusetts. 
18. Graph showing range of chloride concentrations estimated from specificconductance values measured at 1-minute intervals in highway runoff during runoff events with one or more estimated values that exceed the 230-milligramsper-liter criterion continuous concentration for chloride in receiving waters at U.S. Geological Survey monitoring station 423027071291301 along State Route 2 in Littleton, Massachusetts, during the period from November 28, 2005, to May 3, 2006

19. Graphs showing records of flow and specific conductance during $A$, fall and $B$, winter storm runoff at U.S. Geological Survey streamgage 01104455, Unnamed Tributary 1, Stony Brook Reservoir watershed, Massachusetts, water year 2007. .55

\section{Tables}

1. Estimates of enrichment concentrations of chloride in wastewater made by using background concentrations and wastewater concentrations ..........................................21

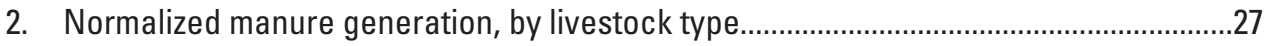

3. Molecular weight and equivalent ionic conductance at infinite dilution for selected ions commonly measured in water samples. 


\section{Conversion Factors}

Inch/Pound to SI

\begin{tabular}{|c|c|c|}
\hline Multiply & By & To obtain \\
\hline \multicolumn{3}{|c|}{ Length } \\
\hline inch (in.) & 2.54 & centimeter $(\mathrm{cm})$ \\
\hline foot $(\mathrm{ft})$ & 0.3048 & meter $(\mathrm{m})$ \\
\hline mile (mi) & 1.609 & kilometer $(\mathrm{km})$ \\
\hline \multicolumn{3}{|c|}{ Area } \\
\hline acre & 4,047 & square meter $\left(\mathrm{m}^{2}\right)$ \\
\hline acre & 0.4047 & hectare (ha) \\
\hline square foot $\left(\mathrm{ft}^{2}\right)$ & 0.09290 & square meter $\left(\mathrm{m}^{2}\right)$ \\
\hline square mile $\left(\mathrm{mi}^{2}\right)$ & 259.0 & hectare (ha) \\
\hline square mile $\left(\mathrm{mi}^{2}\right)$ & 2.590 & square kilometer $\left(\mathrm{km}^{2}\right)$ \\
\hline \multicolumn{3}{|c|}{ Volume } \\
\hline gallon (gal) & 3.785 & liter $(\mathrm{L})$ \\
\hline gallon (gal) & 0.003785 & cubic meter $\left(\mathrm{m}^{3}\right)$ \\
\hline million gallons (Mgal) & 3,785 & cubic meter $\left(\mathrm{m}^{3}\right)$ \\
\hline cubic foot $\left(\mathrm{ft}^{3}\right)$ & 0.02832 & cubic meter $\left(\mathrm{m}^{3}\right)$ \\
\hline \multicolumn{3}{|c|}{ Flow rate } \\
\hline cubic foot per second $\left(\mathrm{ft}^{3} / \mathrm{s}\right)$ & 0.02832 & cubic meter per second $\left(\mathrm{m}^{3} / \mathrm{s}\right)$ \\
\hline gallon per minute (gal/min) & 0.06309 & liter per second $(\mathrm{L} / \mathrm{s})$ \\
\hline gallon per day (gal/d) & 0.003785 & cubic meter per day $\left(\mathrm{m}^{3} / \mathrm{d}\right)$ \\
\hline million gallons per day (Mgal/d) & 0.04381 & cubic meter per second $\left(\mathrm{m}^{3} / \mathrm{s}\right)$ \\
\hline inch per year (in/yr) & 25.4 & millimeter per year (mm/yr) \\
\hline \multicolumn{3}{|c|}{ Mass } \\
\hline pound, avoirdupois (lb) & 0.4536 & kilogram (kg) \\
\hline grain & 0.01543 & milligram \\
\hline ton, short $(2,000 \mathrm{lb})$ & 0.9072 & megagram (Mg) \\
\hline ton per year (ton/yr) & 0.9072 & megagram per year $(\mathrm{Mg} / \mathrm{yr})$ \\
\hline ton per year (ton/yr) & 0.9072 & metric ton per year \\
\hline
\end{tabular}

Temperature in degrees Celsius $\left({ }^{\circ} \mathrm{C}\right)$ may be converted to degrees Fahrenheit $\left({ }^{\circ} \mathrm{F}\right)$ as ${ }^{\circ} \mathrm{F}=\left(1.8 \times{ }^{\circ} \mathrm{C}\right)+32$.

\section{Datum}

Vertical coordinate information is referenced to the North American Vertical Datum of 1988 (NAVD 88) or the National Geodetic Vertical Datum of 1929 (NGVD 29).

Horizontal coordinate information is referenced to the North American Datum of 1983 (NAD 83). 


\section{Supplemental Information}

Specific conductance is given in microsiemens per centimeter at 25 degrees Celsius $\left(\mu \mathrm{S} / \mathrm{cm}\right.$ at $\left.25^{\circ} \mathrm{C}\right)$.

Concentrations of chemical constituents in water are given in milligrams per liter (mg/L).

Concentrations of hardness in water commonly are are given in grains per gallon (gr/gal). There are 7,000 grains per avoirdupois pound. One $\mathrm{gr} / \mathrm{gal}$ is equivalent to $17.11806 \mathrm{mg} / \mathrm{L}$.

A lane mile is defined as an area 12 feet wide and 1 mile long.

\section{Abbreviations}

$\begin{array}{ll}\text { AU } & \text { animal unit } \\ \text { BMP } & \text { best management practice } \\ \text { CASTNET } & \text { Clean Air Status and Trends Network } \\ \text { DOT } & \text { department of transportation } \\ \text { EMC } & \text { event-mean concentration } \\ \text { EPA } & \text { U.S. Environmental Protection Agency } \\ \text { FHWA } & \text { Federal Highway Administration } \\ \text { ITFM } & \text { Intergovernmental Task Force on Monitoring Water Quality } \\ \text { NADP } & \text { National Atmospheric Deposition Program } \\ \text { NPDES } & \text { National Pollutant Discharge Elimination System } \\ \text { NTN } & \text { National Trends Network } \\ \text { NWIS } & \text { National Water Information System } \\ \text { Ppm } & \text { parts per million } \\ \text { OA } & \text { quality assurance } \\ \text { OC } & \text { quality control } \\ \text { SPMS } & \text { special purpose monitoring station } \\ \text { tcf } & \text { trillion cubic feet } \\ \text { TDS } & \text { total dissolved solids } \\ \text { TIA } & \text { total impervious area } \\ \text { TMDL } & \text { total maximum daily load } \\ \text { USGS } & \text { U.S. Geological Survey } \\ \text { WSI } & \text { winter severity index }\end{array}$





\title{
Methods for Evaluating Potential Sources of Chloride in Surface Waters and Groundwaters of the Conterminous United States
}

\author{
By Gregory E. Granato, Leslie A. DeSimone, Jeffrey R. Barbaro, and Lillian C. Jeznach
}

\section{Abstract}

Chloride exists as a major ion in most natural waters, but many anthropogenic sources are increasing concentrations of chloride in many receiving waters. Although natural concentrations in continental waters can be as high as 200,000 milligrams per liter, chloride concentrations that are suitable for freshwater ecology, human consumption, and agricultural and industrial water uses commonly are on the order of 10 to 1,000 milligrams per liter. "Road salt" frequently is identified as the sole source of anthropogenic chloride, but only about 30 percent of the salt consumed and released to the environment is used for deicing. Furthermore, several studies in Southern States where the use of deicing salt is minimal also show anthropogenic chloride in rising concentrations and in strong correlation to imperviousness and road density. This is because imperviousness and road density also are strongly correlated to population density. The term "road salt" is a misnomer because deicers applied to parking lots, sidewalks, and driveways can be a substantial source of chloride in some catchments because these land covers are comparable to roadways as a percentage of the total impervious area and commonly receive higher salt application rates than some roadways. Other sources of anthropogenic chloride include wastewater, dust control on unpaved roads, fertilizer, animal waste, irrigation, aquaculture, energy production wastes, and landfill leachates. The assumption that rising chloride concentrations in surface water or groundwater is indicative of contamination by deicing chemicals rather than one or more other potential sources may preclude the identification of toxic, carcinogenic, mutagenic, or endocrine-disrupting contaminants that are associated with many sources of elevated chloride concentrations. Once the sources of anthropogenic chloride in an area of interest have been identified and measured, water and solute budgets can be estimated to guide decisionmakers to identify and apply potential mitigation measures that can reduce the problem.

Scientists, engineers, regulators, and decisionmakers need information about potential sources of chloride, water and solute budgets, and methods for collecting water-quality data to help identify potential sources. This information is needed to evaluate potential sources of chloride in areas where chloride may have adverse ecological effects or may degrade water supplies used for drinking water, agriculture, or industry. Knowledge of potential sources will help decisionmakers identify the best mitigation measures to reduce the total background chloride load, thereby reducing the potential for water-quality exceedances that occur because of superposition on rising background concentrations. Also, knowledge of potential sources may help decisionmakers identify the potential for the presence of contaminants that have toxic, carcinogenic, mutagenic, or endocrine-disrupting effects at concentrations that are lower by orders of magnitude than the chloride concentrations in the source water. This report is a comprehensive synthesis of relevant information, but it is not the result of an exhaustive search for literature on each topic. The potential adverse effects of chloride on infrastructure and the environment are not discussed in this report because these issues have been extensively documented elsewhere.

\section{Introduction}

Chloride exists as a major ion in most natural waters (Feth, 1981; Hem, 1992; Sharp and Draper, 2013). Chloride concentrations in continental waters range from less than 1 to more than 200,000 milligrams per liter (mg/L). In comparison, the concentration of chloride in seawater is about $19,300 \mathrm{mg} / \mathrm{L}$, and the concentration of saturated brine is about $220,000 \mathrm{mg} / \mathrm{L}$. Chloride in natural continental waters comes from precipitation and chemical weathering. Natural concentrations in water from the same geologic formations can vary by orders of magnitude. Chloride concentrations in igneous rocks are very low, but concentrations in sedimentary rocks can be greater than 1,000 parts per million (ppm). Once chloride is dissolved in water, it generally travels with the water without reacting with other solutes or sediments. The only practical ways to remove it from the water are through ion exchange, reverse osmosis, or distillation. 
Chloride concentrations are increasing in surface water and groundwater in many parts of the United States (Rose, 2007; Steele and Aitkenhead-Peterson, 2011; Lindsey and Rupert, 2012). Deicing salts commonly are identified as the primary driver for these trends and are linked to adverse effects in receiving waters (for example, Jaworski and Hetling, 1996; Environment Canada, 2001; Godwin and others, 2003; Jackson and Jobbagy, 2005; Howard and Maier, 2007; Kelley and others, 2008; Mullaney and others, 2009; Corsi and others, 2010a,b; Medalie, 2012; Cañedo-Argüelles and others, 2013). However, from 1990 through 2010 the estimated amount of chloride in salt used for deicing ranged from about 19 to 39 percent of the annual chloride consumption, averaging about 31 percent of national annual chloride consumption (Kelly and Matos, 2013). About 70 percent of the salt consumed and dispersed to the environment each year is from sources other than deicing chemicals (Kostick, 1993; Kelly and Matos, 2013). These sources include chemical synthesis, agricultural production, food processing, industrial processes, and water treatment (Kelly and Matos, 2013). Furthermore, studies that comprehensively investigate potential sources of chloride other than deicing indicate that wastewater, agriculture, and other sources can also be substantial contributors (for example, Knuth and others, 1990; Panno and others, 2006; Whittemore, 2007; Kelly and others, 2010; Steele and Aitkenhead-Peterson, 2011). For example, Steele and Aitkenhead-Peterson (2011) showed a strong positive relationship between the mean annual sodium and chloride flowing out in waters discharging from a basin and the percentage of urban land cover and impervious surface area in the humid subtropical Dallas-Fort Worth region. They identify wastewater effluent as the single largest contributor and note that estimates of urban loadings were similar to the estimates in northern watersheds that are commonly attributed to deicing salts. Gregory and Calhoun (2007) found that chloride concentrations had strong correlations ( 0.76 to 0.87 ) with urban indicators such as population, imperviousness, and road density in Georgia and Alabama. Similarly, Rose (2007) identified increasing sodium, chloride, and other related chemicals with increasing development near Atlanta, Georgia, and attributed this correlation to leaking sewers and septic tanks as a diffuse source of these chemicals. Furthermore, there is evidence that increasing adverse effects on the ecology of receiving waters may be a result of many hydrologic and water-quality issues that occur with increasing development. For example, Coles and others (2012) demonstrated that no single factor related to stream hydrology, habitat, or chemistry was universally important in explaining responses of biological communities to urban development in many areas of the United States.

The assumption that rising chloride concentrations in surface water or groundwater is indicative of contamination by deicing chemicals rather than one or more other potential sources may preclude the identification of toxic, carcinogenic, mutagenic, or endocrine-disrupting contaminants that are associated with many of the other sources of elevated chloride concentrations. Investigators focused on deicing salts may miss potential effects of other chloride sources because the costs and logistical requirements needed to expand the scope of an investigation to include monitoring of many other potential contaminants are large. Analysis of specific conductance and chloride, the most commonly monitored constituents when deicing salts are expected to be the source of contaminants, costs tens of dollars; adding nutrients and metals can increase analysis costs by an order of magnitude, and a single sample that is analyzed for organic chemicals, hormones, and pharmaceuticals can cost about a thousand dollars (Kirk Smith, U.S. Geological Survey, oral commun., July 2014). Furthermore, the sample-collection and processing protocols for such chemicals can cost more, by orders of magnitude, than the cost of collecting specific-conductance and chloride data.

Identifying all the potential sources of chloride is important because many anthropogenic sources of chloride can be associated with other chemicals that have adverse effects at concentrations that are orders of magnitude lower than the water-quality guidelines for chloride. These guidelines are $250 \mathrm{mg} / \mathrm{L}$ for drinking water, $230 \mathrm{mg} / \mathrm{L}$ for the chronic aquatic life criterion concentration, and 860 $\mathrm{mg} / \mathrm{L}$ for the acute aquatic life criterion concentration (U.S. Environmental Protection Agency, 1988, 1992b). For example, wastewaters contain nutrients, bacteria, viruses, hormones, pharmaceuticals, fire retardants, plasticizers, insect repellants, pesticides, fungicides, and many other chemicals (Vaughn and others, 1983; Kolpin and others, 2002; Sprague and Battaglin, 2004; U.S. Environmental Protection Agency, 2009; Hunt and others, 2010; Deo and Halden, 2013). Fertilizers used in agricultural, suburban, and urban areas can contribute chloride and nutrients; application of fertilizers is commonly associated with application of herbicides, pesticides, and fungicides (National Agricultural Statistics Service, 2011; Carey and others, 2012, 2013). Animal waste, as a point source at animal-feeding operations or as a diffuse source when spread on fields, is a source of chloride, nutrients, hormones, pharmaceuticals, bacteria, and viruses (Ruhl, 1999; Hooda and others, 2000; Arnon and others, 2008; Showers and others, 2008). Irrigation water contains chloride and other contaminants, evapotranspiration can concentrate contaminants, and infiltration of excess irrigation water in agricultural suburban and urban areas may mobilize nutrients, herbicides, pesticides, fungicides, selenium, and other constituents (Wagner and others, 1996; Seiler, 1997; Seiler and others, 1999; Paul and others, 2007). Return flows from oil and gas development wells commonly contain high concentrations of chlorides as well as radioactive constituents and hundreds of organic chemicals that may be toxic, carcinogenic, mutagenic, or endocrine disrupting (Kharaka and others, 2005; Zielinski and Budahn, 2007; Colborn and others 2010; Wilson and Van Briesen, 2013; Kassotis and others, 2014; Vengosh and others, 2014). Landfill leachates also contain chloride and a host of other chemicals, including nutrients, pesticides, organic chemicals, and pharmaceuticals 
(El-Fadel and others, 1997; Kjeldsen and others, 2002; Ward and others, 2002; Kulikowska and Klimiuk, 2008; Buszka and others, 2009, Canton and others, 2010; Ford and others, 2011; Varank and others, 2011; Pastor and Hernández, 2012). Although urban and highway runoff also contain nutrients, metals, and many different organic chemicals (including unexpected wastewater chemicals), deicing chemicals are relatively pure, and the deicing process does not contribute many of these constituents in proportion to the chloride load (Driver and Tasker, 1990; Granato, 1996; Lopes and Dionne, 1998; Granato and Cazenas, 2009; Smith and Granato, 2010).

Contrary to conventional wisdom, deicing may not be the primary source of chloride in some cases. For example, Eisen and Anderson (1979) investigated chloride in wells downgradient of a highway in an urban area and found that leaking sewer pipes were the likely source of contaminants. Knuth and others (1990) investigated the source of chloride in residential wells surrounded by three heavily salted roads (including a multilane interstate) in northeast Ohio; however, they found that the source of chloride was from return flows from a nearby gas well. Izbicki (2000) measured elevated specific conductance and chloride in several publicsupply wells along the Blackstone River in Massachusetts. Topographic analysis and conventional wisdom would suggest that the source of chloride was deicing salts from two State highways that are within 600 feet (ft) of the well and a large mall within 1,000 ft of the well. However, Izbicki's hydrogeological investigation revealed that a highly transmissive gravel layer connecting the well field to the river bottom was the source of contaminated water to the wells. During low flows, the Upper Blackstone Water Pollution Abatement District wastewater-treatment plant is the primary source of water in the Blackstone River near these wells. In this case, the "road salt" assumption would not protect the public from the host of wastewater contaminants, such as pharmaceuticals, that are not identified in commonly used drinking-water analyses (Reif and others, 2012).

\section{Purpose and Scope}

The purpose of this report is to provide information about potential sources of chloride, water and solute budgets, and methods for collecting water-quality data to help identify potential sources of chloride in the surface waters and groundwaters of the conterminous United States. This study was done by the U.S. Geological Survey (USGS), in cooperation with the Federal Highway Administration (FHWA), because scientists, engineers, regulators, and decisionmakers need this information for the evaluation of potential sources of chloride in areas where chloride may have adverse ecological effects or may degrade water supplies used for drinking water, agriculture, or industry. Knowledge of potential sources can help decisionmakers identify the best mitigation measures to reduce the total background chloride load, thereby reducing the potential for water-quality exceedances caused by superposition on rising background concentrations. Also, knowledge of potential sources may help decisionmakers identify the potential for the presence of contaminants that have toxic, carcinogenic, mutagenic, or endocrine-disrupting effects at concentrations that are lower by orders of magnitude than the chloride concentrations in the source water.

This report is a comprehensive synthesis of relevant information, but it is not an exhaustive literature search for each topic. As a synthesis, the report is a compilation of information that is needed to help researchers improve the interpretation of results from the many chloride studies that focus exclusively on deicing chemicals. Information and examples from the literature that are needed to assess potential sources of chloride are discussed. The potential adverse effects of chloride on infrastructure and the environment are not discussed in this report because these issues have been extensively documented elsewhere (for example, Transportation Research Board, 1991; Environment Canada, 2001; Mussato and others, 2007; Corsi and others, 2010a,b; Cañedo-Argüelles and others, 2013).

\section{Sources of Chloride}

There are many natural and anthropogenic sources of chloride in the waters of the United States. Natural sources include atmospheric deposition, evaporative concentration of precipitation, deep saline groundwater, and chemical weathering. Saltwater intrusion at supply wells is an example of a natural source of chloride that is introduced into the freshwater realm by human action. In this case, the chloride contamination occurs from pumping at coastal wells or deep irrigation wells above deep saline groundwater. Anthropogenic sources include deicing chemicals, chlorides used for dust control and stabilization, water treatment and wastewater, agricultural sources, energy production, and landfills. Kostick (1993) quantifies the relative magnitudes and the fate of the salt that was consumed in the United States during 1990. Kelly and Matos (2013) provide annual consumption rates by category, which can be used to assess the magnitudes of various sources. Deicing chemicals, commonly identified with the misnomer "road salt," are identified as the primary source of chloride in many studies; since 1990, however, salt used for deicing chemicals represents only about 31 percent of the salt consumed each year (Kelly and Matos, 2013). Many of the "road salt" studies neglect other sources because chloride concentrations are correlated to road density or imperviousness. However, these measures also are highly correlated to population density (fig. 1). Although these relations, shown on logarithmic scale, have considerable scatter at very low population densities, these relations demonstrate that population density, road density, and imperviousness covary in developed areas. Other measures of development indicating various potential 

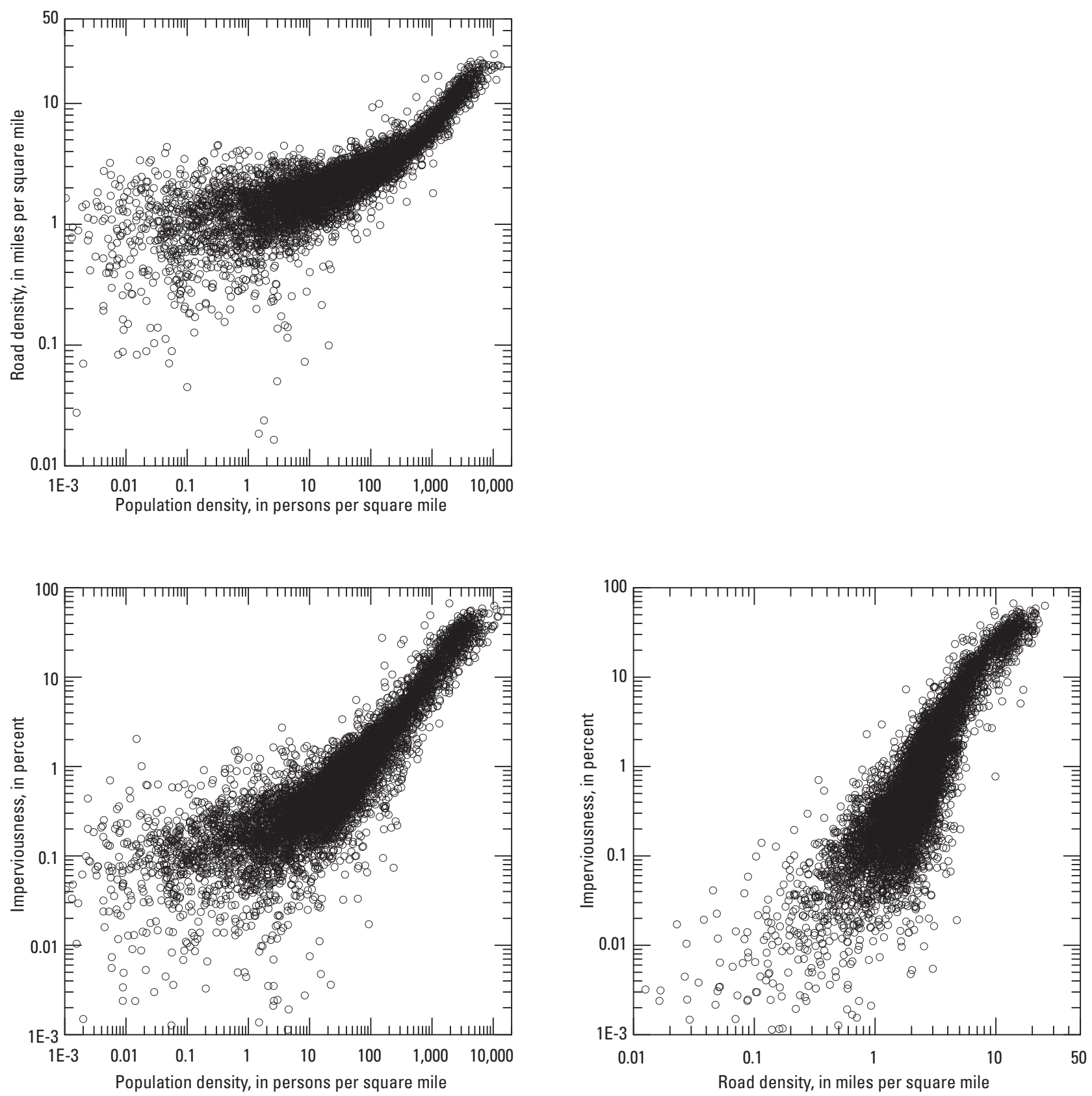

Figure 1. Correlations among the population density, imperviousness, and road density values for 8,470 gaged drainage basins in the U.S. Geological Survey Geospatial Attributes of Gages for Evaluating Streamflow (GAGES II) database (Falcone, 2011). 
anthropogenic sources of chloride also are correlated to population and imperviousness (Coles and others, 2004; Granato, 2010b). Although most of the agricultural sources are not expected to be correlated with population density, fertilizer use on suburban and urban green spaces also may be a source of chloride. Knowledge and quantification of all potential sources may lead to better decisions about potential mitigation strategies.

\section{Atmospheric Deposition}

Atmospheric deposition, which includes wet (rain, ice, fog, and snow) and dry (dust and gas) deposition, is a ubiquitous source of chloride to surface waters and groundwaters. The ocean is the single largest natural source of sodium and chloride ions, containing about 46 quadrillion short tons of salt (Kostick, 1993). Seawater normally has a chloride concentration near $19,000 \mathrm{mg} / \mathrm{L}$. Chloride is present in the atmosphere in aerosols from sea spray, the minute droplets of seawater that form from breaking waves (Graedel and Keene, 1996; Gong and others, 1997a,b; Seinfeld and Pandis, 2006). Chloride concentrations from the oceans are greatest along the coast, decreasing rapidly with increasing distance inland (Feth, 1981). Volcanic emissions, wind suspension of mineral aerosols from soils or in urban areas, fossil fuel combustion, and biomass burning also contribute chloride to the atmosphere; but these sources are much smaller than sea spray at the global scale (Graedel and Keene, 1996; Keene and others, 1999). Magmatic gases from volcanoes, fumaroles, and geysers are also considered sources and have been recorded to produce between 1,100 and 1,430,000 short tons of chloride each year (Feth, 1981). Aerosol chloride and gaseous hydrogen chloride, which is produced from aerosol chloride, are highly soluble and are rapidly removed from the atmosphere through wet and dry deposition. Consequently, wet and dry atmospheric deposition are typically significant components of chloride inputs to watersheds, especially in areas where anthropogenic sources are absent or minimal.

Concentrations of chloride in wet deposition (rain, ice, fog, and snow) have been monitored as part of the National Atmospheric Deposition Program/National Trends Network (NADP/NTN) since 1978, and these data are well suited for the calculation of chloride loads to watersheds from atmospheric deposition (Lamb and Bowersox, 2000; National Atmospheric Deposition Program, 2012). Maps and data for concentrations and rates of wet deposition, including interpolated, gridded data across the conterminous United States, are available at the NADP/NTN Web site (http://nadp.sws.uiuc.edu/NTN). More than 200 sites are monitored, with at least one site in every State; most sites have at least 10 years of record; and sites are located away from urban areas or point sources. Precipitation volumes and precipitation chemistry are measured at these sites, with weekly samples.
Chloride concentrations in wet deposition are highest along the coasts and relatively low in the interior of the United States, reflecting the influence of sea spray as the dominant source at the continental scale (Munger and Eisenreich, 1983). In 2011, annual mean precipitation-weighted concentrations in wet deposition ranged from 0.03 to $3.1 \mathrm{mg} / \mathrm{L}$ at NADP/NTN sites; concentrations were highest at sites along the eastern and southeastern coasts (fig. 2). Rates of chloride deposition in wet deposition ranged from 0.014 to 10 short tons per square mile and were similarly highest along the eastern and southeastern coasts as well as in the Northwest. High deposition rates in the Northwest result from the high rates of precipitation in that region as well as proximity to the coast (fig. 3). Concentrations and deposition rates decrease rapidly with distance from the coast (fig. 3; Feth, 1981). At inland NADP/NTN sites located 100 miles (mi) or farther from the coast, concentrations were less than one-sixth of the high concentrations along the coasts and deposition rates were less than 0.5 percent of the deposition rates along the coasts.

Chloride concentrations in dry deposition are less well known than concentrations in wet deposition. Through dry deposition, gases or particles settle, adhere, or are absorbed directly onto surfaces (vegetation, soil, water, or others) without precipitation (U.S. Environmental Protection Agency, 2013b,d); subsequent precipitation can wash the dry-deposited gases or particles into runoff. Dry deposition can be measured directly, by using surrogate surfaces and collectors that do not sample during precipitation events, or indirectly from atmospheric concentrations and modeled depositional processes. The complex factors that influence dry deposition, such as atmospheric turbulence, surface characteristics and orientation, and particle or gas properties, make measurements difficult, fluxes highly variable, and data difficult to extrapolate (Lovett and others, 1997; Colman and others, 2001). Dry deposition is monitored in the United States by the Clean Air Status and Trends Network (CASTNET), which is operated by the U.S. Environmental Protection Agency (EPA) and others, at about 90 rural sites in the United States and Canada. The CASTNET network focuses on the components of acid deposition; data for chloride are available at monitoring sites but are not routinely mapped (http://epa.gov/castnet; AMEC Environment and Infrastructure, 2013).

An alternative to operating a robust monitoring network, which can be difficult and expensive, is to provide planninglevel estimates of bulk deposition by applying correction factors to the NADP wet-deposition data. The literature indicates that wet deposition commonly accounts for about 60 to 90 percent of the bulk deposition total for many constituents (Vet and others, 1988; Peters and Ratcliffe, 1998; Thimonier, 1998; Staelens and others, 2005; Balestrini and others, 2007; Izquierdo and Avila, 2012).

Estimates of chloride inputs to watersheds from dry deposition are variable. Seinfeld and Pandis (2006) suggest that inputs in dry deposition can be about equal to inputs in wet deposition and may even exceed wet-deposition rates in arid regions. This finding is consistent with measured rates 
A. Precipitation-weighted annual mean chloride concentration

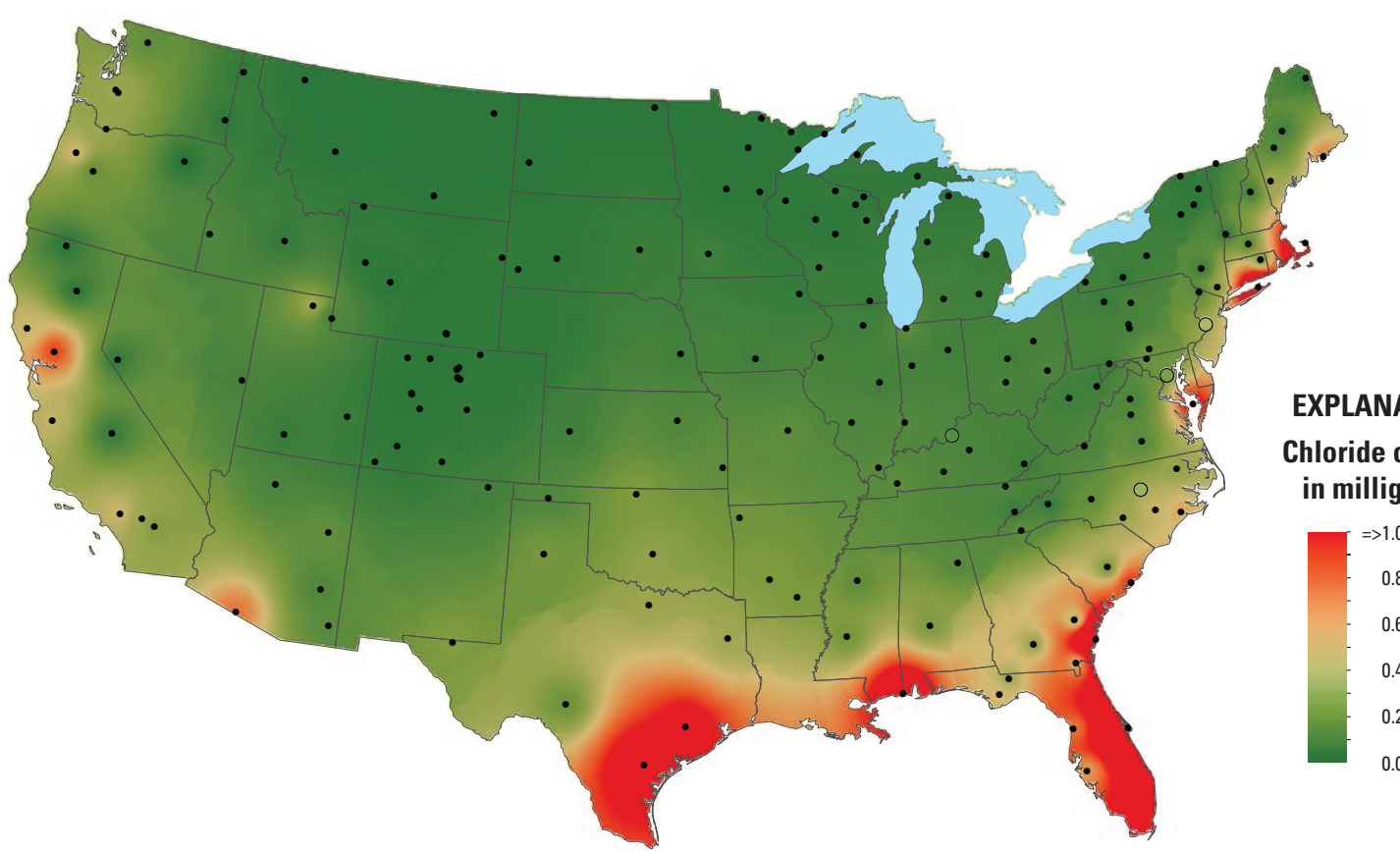

B. Annual rate of chloride wet deposition

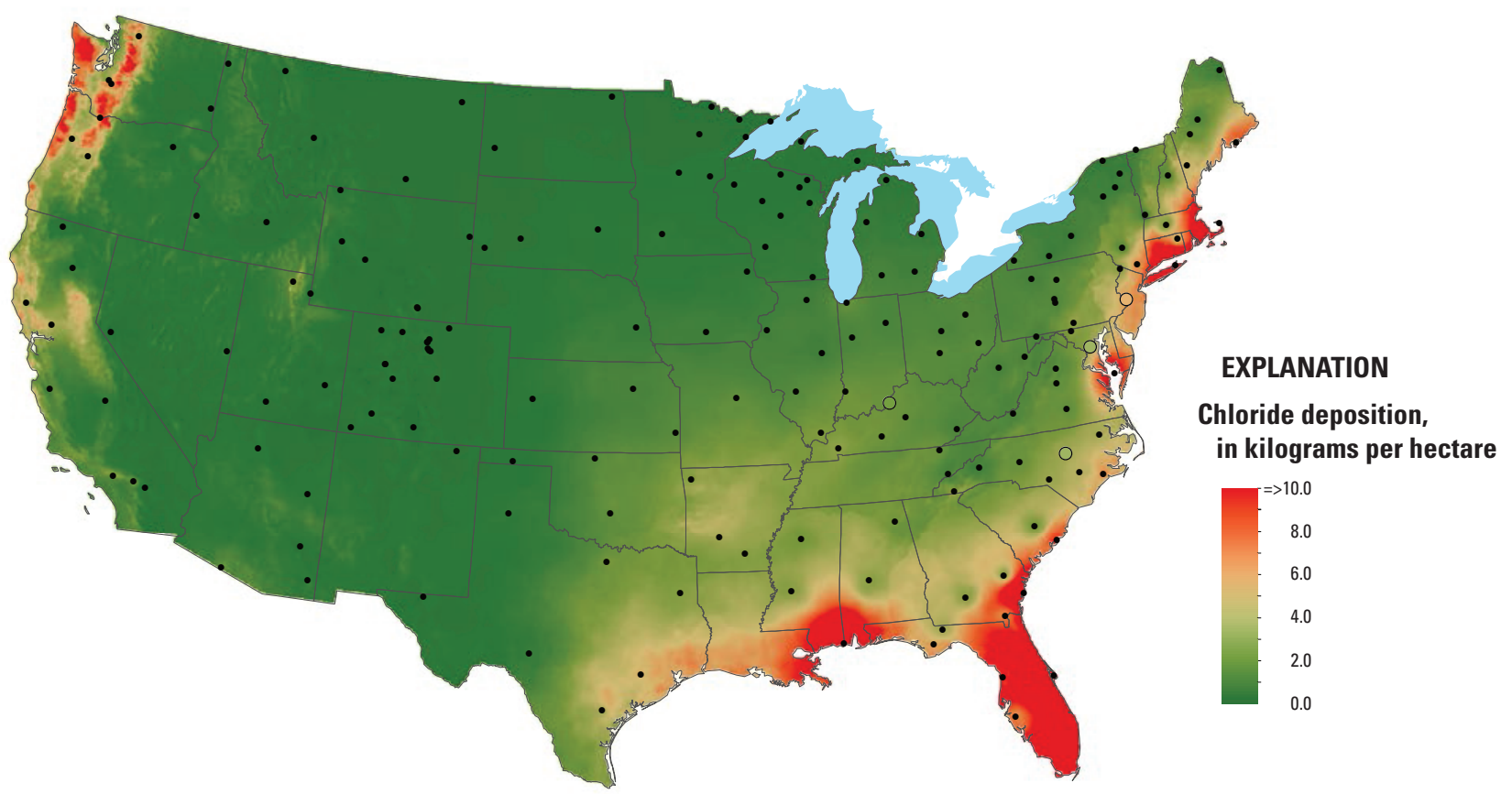

Figure 2. Annual mean concentration and annual rate of deposition of chloride in precipitation (wet deposition) in the conterminous United States, 2011. A, Precipitation-weighted annual mean concentration. B, Annual rate of wet deposition. Black dots represent sites at which concentration was measured; open circles designate urban sites. Data are from National Atmospheric Deposition Program (2012). 
A. Annual mean chloride concentration

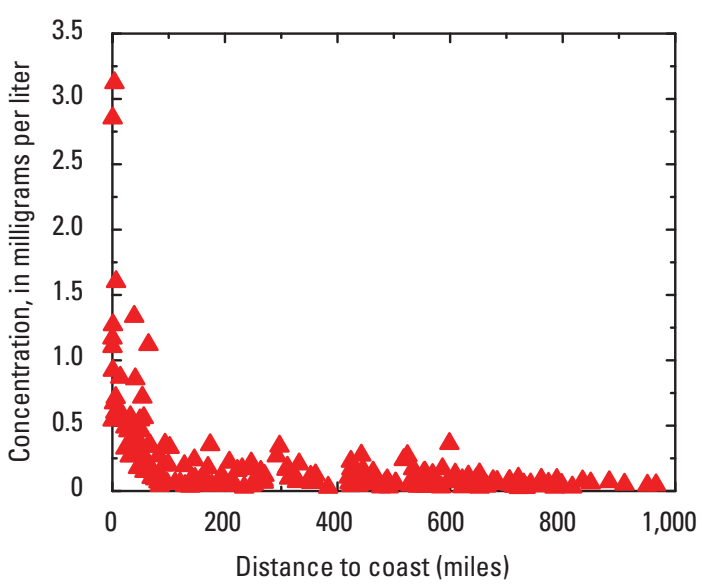

B. Annual rate of chloride wet deposition

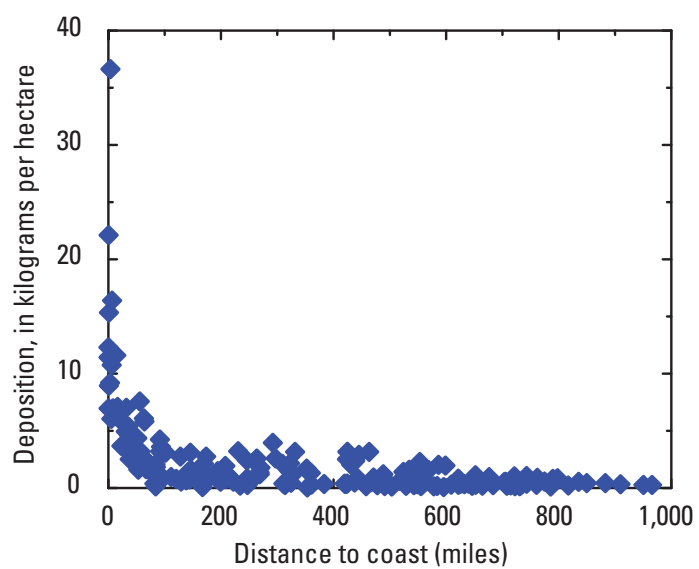

Figure 3. Relation between distance from the coast and $A$, annual mean concentration (precipitation-weighted) and $B$, annual rate of deposition of chloride in precipitation (wet deposition) in the conterminous United States, 2011. Data are from National Atmospheric Deposition Program (2012).

of dry deposition of chloride at eight urban sites in central Arizona, which ranged from about two-fifths to more than twice the rates of wet deposition of chloride (Hope and others, 2001), and the dry-deposition rate of chloride at a forested site in the Adirondack Mountains of New York, which was more than one-third of the wet-deposition rate of chloride (Shepard and others, 1989). Urban areas, in particular, may have higher rates of dry deposition, from nonmarine sources of aerosol particulates and dust, than wet deposition (Lovett and others, 2000). In contrast, dry-deposition rates of chloride at 80 CASTNET sites between 2007 and 2008 averaged about 2.5 percent of wet-deposition rates (data from http://epa.gov/castnet) and were estimated at 2.4 percent of wet-deposition inputs at a rural site in southeastern New York.

In relatively undeveloped areas where the effects of human activities are minimal, inputs of chloride from atmospheric deposition may account for a large fraction of the total loads carried by streams or of the total concentrations in groundwater, but estimates are highly variable (Feth, 1981; Peters, 1984; Steele and Aitkenhead-Peterson, 2011). This fraction is likely to be larger near the coasts and smaller in basins with significant geologic sources of chloride, such as evaporite deposits (see "Chemical Weathering on Soil and Rock"). In basins affected by deicing chemicals and other anthropogenic chloride sources, atmospheric deposition is estimated to contribute less than 10 percent-and in some cases only 1 or 2 percent - of total chloride inputs (Howard and Haynes, 1993; Colman and others, 2001; Nimiroski and Waldron, 2002; Kelly and others, 2008; Novotny and others, 2009; Kelly and others, 2010; Steele and Aitkenhead-Peterson, 2011).

\section{Evaporative Concentration}

Evaporative concentration, which occurs when water evaporates, leaving a higher concentration of solutes behind, is not a loading source, but it does increase the concentration of chloride in natural waters. In closed basins that have no drainage outlet, such as the Great Salt Lake and the Basin and Range area where potential evapotranspiration equals or exceeds precipitation, much of the available water will evaporate, leaving the solutes (including chloride) behind (Weiskel and others, 2007). In areas where water is imported or extracted for irrigation, evaporative concentration can be a major source of salinization. Sanford and Selnick (2013) estimated the fraction of precipitation lost to evapotranspiration nationwide from 1971 to 2000 by using a regression equation based on precipitation, temperature, and land cover. Their estimates range from about zero inches (in.) for some areas of the humid Northwest to about 1.29 in. for arid areas that use surface water or groundwater to irrigate crops.

Estimates of evaporative concentration may provide an estimate for the lower bound of natural concentrations in groundwater and surface water in the absence of other sources of chloride. For example, Jackson (1905) developed contour maps of chloride concentrations in New England and New York from data that were available from the late 1800 s to early 1900 s. These values, which predate many but not all anthropogenic sources, are close to values that would be estimated by using local estimates of bulk deposition and Sanford and Selnick's (2013) evapotranspiration values. There are some geologic sources of salt in New York that affect concentrations on the map, but the soils, sediment, and 
bedrock of New England are not a major source of chloride in natural waters, so many concentrations there are low. The chloride concentrations shown on the map by Jackson (1905) are about twice the atmospheric deposition concentrations reported by the National Atmospheric Deposition Program for 2011 in New England and New York (National Atmospheric Deposition Program, 2012), which is consistent with the evapotranspiration rate of about 50 percent of precipitation estimated by Sanford and Selnick (2013).

\section{Deep Saline Groundwater}

Saline groundwater (total dissolved solids [TDS] greater than $1,000 \mathrm{mg} / \mathrm{L}$ ) lies underneath fresh groundwater in at least two-thirds of the conterminous United States, and chloride is a major constituent of these saline waters (fig. 4) (Feth and others, 1965; Alley, 2003). In some cases, deep saline groundwater originated as the interstitial seawater that was buried with sediments when they were deposited in the geologic past (connate water); in others, it resulted from the interaction of meteoric water, recharged thousands or tens of thousands of years ago, with subsurface rocks and sediments or from the interaction of more recently recharged meteoric water with highly soluble evaporite salts (Frape and others, 2003; Kharaka and Hanor, 2003; van Weert and others, 2009). The precise origins of deep saline groundwater can be difficult to determine and can include the mixing of waters from different sources and fractionation processes (Land and
Prezbindowski, 1981; Grasby and Betcher, 2002; Frape and others, 2003).

Chloride concentrations in deep, saline groundwater can be extremely high and range widely. Concentrations averaged $3,190 \mathrm{mg} / \mathrm{L}$ (median $370 \mathrm{mg} / \mathrm{L}$ ) from about 900 analyses compiled by Feth and others (1965) and ranged from less than 10 to $206,000 \mathrm{mg} / \mathrm{L}$ (fig. 5). Chloride was the dominant anion (constituting more than 50 percent of major anions) in more than one-third of all analyses and was the dominant anion in nearly all samples with more than 20,000 mg/L TDS (Feth and others, 1965; Feth, 1970).

The compilation of Feth and others (1965; fig. 4) is still the best representation of saline groundwater at the national scale in the United States (Alley, 2003; Dennehy, 2004). However, this compilation depicts saline groundwater in rocks and sediments that were considered capable of producing water for supply (well yields greater than 7 gallons per minute [gal/min]) because it was focused on saline groundwater as a developable resource. Thus the areas identified are typically sedimentary basin rocks. More recently, the presence of deep saline groundwater is increasingly being recognized in crystalline (igneous and metamorphic) rocks, with chloride concentrations that range from several hundred to more than $100,000 \mathrm{mg} / \mathrm{L}$ (Frape and Fritz, 1982; Frape and others, 2003). Because of the very low permeability of deeply buried crystalline rocks, deep saline groundwater in these rocks is more likely than deep saline groundwater in sedimentary basin

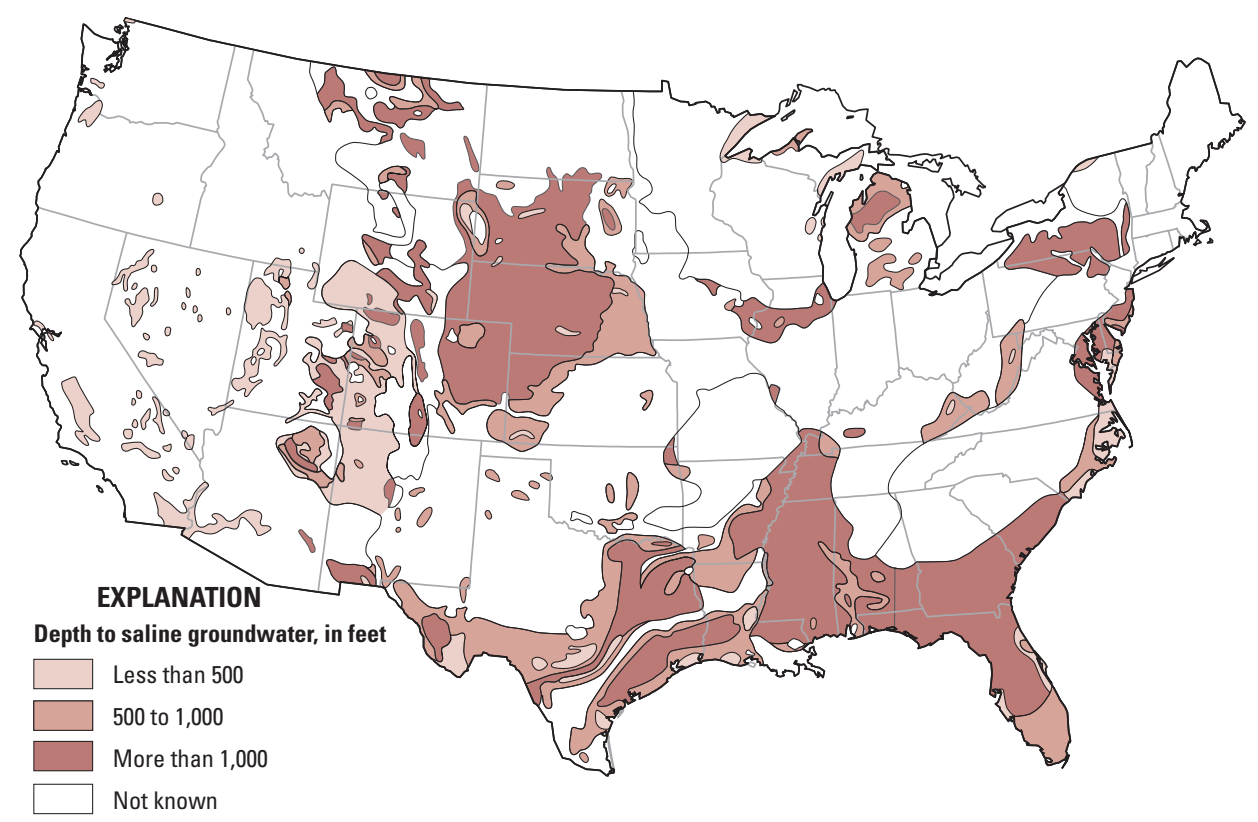

Figure 4. The depth to saline groundwater in the conterminous United States. Modified from Feth and others (1965) and Alley (2003). 


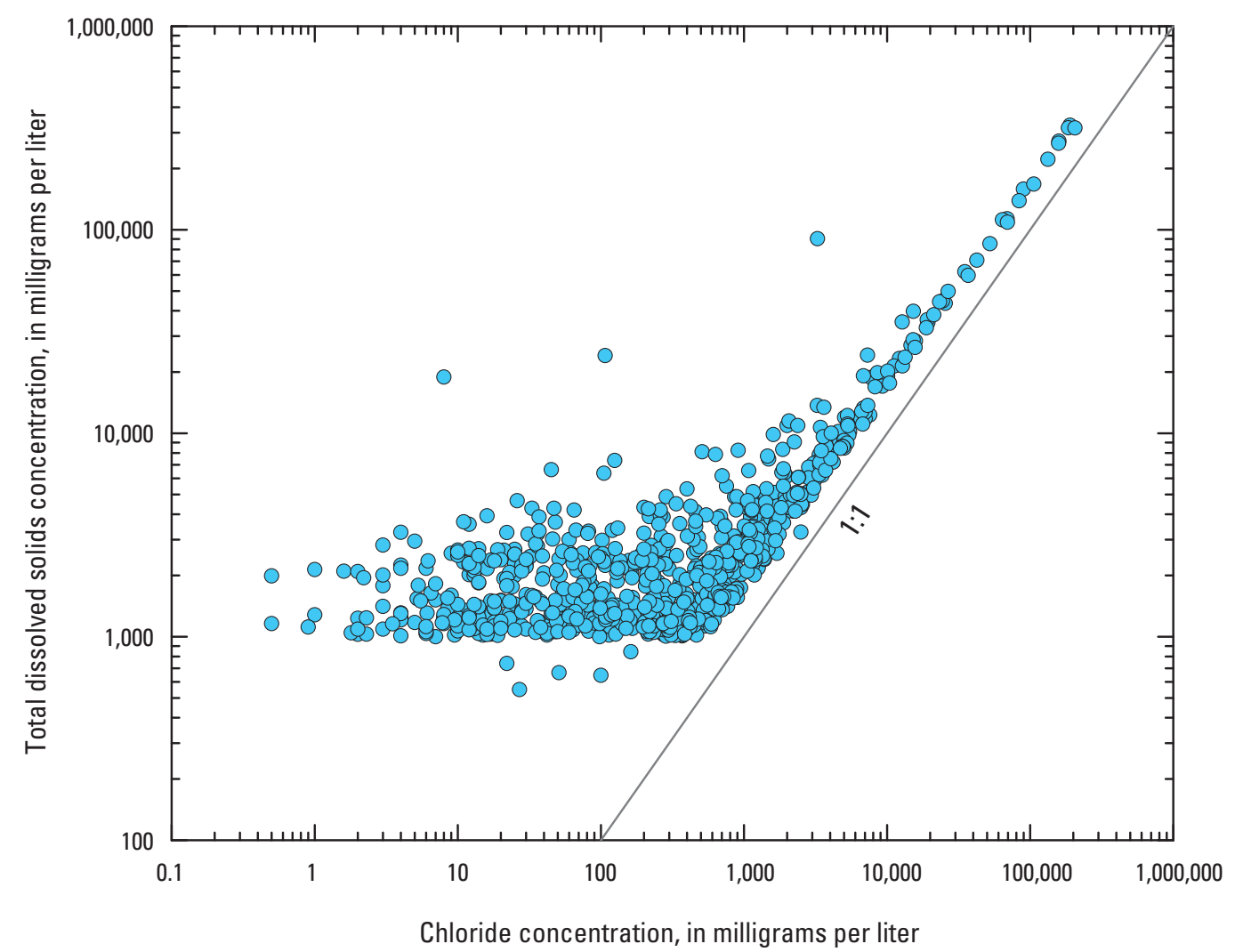

Figure 5. Chloride and total dissolved solids concentrations in deep saline groundwater in data compiled by Feth and others (1965).

rocks to be permanently isolated from the active meteoric water cycle.

Deep saline groundwater can be a source of chloride to surface waters and shallow groundwaters in diverse hydrogeological settings. Deep saline groundwater emerges at springs and in shallow groundwater when it travels upward to inland discharge areas of large, regional groundwater-flow systems (Hitchon and others, 1969; Grasby and Betcher, 2002; Panno and others, 2006; Harvey and others, 2007). For example, saline springs in Missouri represent discharge from the deeply buried Western Interior Plains aquifer system (Jorgensen and others, 1993). Upward flow of deep saline groundwater may result from geologic structural features, such as faults and the configuration of the bedrock surface beneath basin-fill deposits; these features contribute to the discharge of deep saline groundwater into the Rio Grande River in Arizona (Plummer and others, 2004; Kirk and others, 2009). Faults are also integral to the discharge of deep saline groundwater at springs in diverse settings such as Upstate New York (Saratoga Springs) and the mountains of California's Coast Ranges (Unruh and others, 1992; Siegel and others, 2004).

\section{Chemical Weathering of Soil and Rock}

Chemical weathering of rocks and soil minerals can contribute chloride to surface waters and groundwaters. The amount of chloride depends on the lithology and hydrology of the drainage basin. Chloride is the least abundant of the major ions in nearly all types of rocks, except in the sedimentary rocks formed by evaporation (evaporites). Typical concentrations of chloride in the mineral structure are 100 to $300 \mathrm{ppm}$ in igneous rocks, 140 to $170 \mathrm{ppm}$ in shales, 10 to $15 \mathrm{ppm}$ in sandstones, and 150 to $300 \mathrm{ppm}$ in limestones (Kuroda and Sandell, 1953; Bowen, 1966; Horn and Adams, 1966); these concentrations are 10 to 100 times lower than the concentrations of the other major-ion constituents of surface waters and groundwaters (Hem, 1992). Biesecker and Leifeste (1975) showed that total dissolved concentrations in stream base flow draining unaltered basins across the United States depended on the local geology and the total annual runoff in the basin. Although the maximum base-flow concentrations generally decreased with increasing annual streamflow, the effect of hydrology was most important on the least soluble 
rock types. Consequently, the chemical weathering of minerals in rocks and soils may be a relatively small source of chloride to natural waters, compared to the magnitude of weathering processes for other major ions, except in basins and aquifers where evaporites are present.

The small quantities of mineral chlorine in igneous and metamorphic rocks are present as impurities in the common silicate rock-forming minerals biotite and hornblende; in chlorapatite and sodalite, which are less common but have higher chlorine content; in fluid inclusions in feldspar, quartz, and other silicate minerals; and in solid solution in volcanic glass (Kuroda and Sandell, 1953; Best, 1982). Chlorine in the mineral sodalite contributes to the higher chlorine content of some syenites, which are quartz-poor igneous rocks otherwise similar to granite (Hulburt and Klein, 1977; Kuroda and Sandell, 1953; Johns and Huang, 1967). Although relatively rare compared to other igneous rocks, syenites (and phonolites, their extrusive equivalent) are in many parts of the United States - they are mapped in geologic formations in 22 States (U.S. Geological Survey, 2013a,b). Chemical weathering of these minerals, typically by hydrolysis, releases the chlorine as chloride (Feth, 1981). In non-evaporite sedimentary rocks, including most shales, sandstones, and limestones, the mineral form of chlorine is not well known, but chlorine may be present in unweathered silicate minerals or as residual interstitial seawater. The chlorine content of deep, buried shales of marine origin may be higher than shales at land surface because the chlorine in rocks near land surface is readily leached by circulating groundwater (Johns and Huang, 1967; Hem, 1992). Marine shales that release appreciable amounts of chloride during weathering were estimated to constitute only 3 percent of all shales at land surface worldwide by Maybeck (1987).

Contributions of chloride to natural waters from rock weathering in watersheds that are underlain by igneous, metamorphic, or non-evaporite sedimentary rocks commonly are considered negligible (for example, Claassen and Halm, 1996; Novotny and others, 2009). In fact, several analytical methods in hydrology and geochemistry make use of this assumption, including the chloride mass-balance method for calculating groundwater recharge rates and the calculation of silicate rock-weathering rates from dissolved ion concentrations in river water (Wood and Sanford, 1995; Gaillardet and others, 1999; Oliva and others, 2003; Zhu and others, 2003). The negligible contribution of igneous and metamorphic rocks to chloride inputs in the Hubbard Brook experimental watershed in New Hampshire was demonstrated with 10 years of annual budgets, in which chloride inputs from precipitation were nearly balanced by outputs in streamwater (Likens and Bormann, 1995; Lovett and others, 2005). More commonly, data from which to calculate inputs from rock weathering are very sparse. Kelly and others (2008) estimated chloride inputs from rock weathering in a rural New York watershed by using a stream chloride sample from 1905, which predates anthropogenic sources in the watershed. In this watershed, estimated inputs from rock weathering were less than inputs from atmospheric deposition and were about 1 percent of total modern (2008) inputs to the watershed, which also include road deicing, sewage, and water softeners. Similarly, Norton and Friedman (1985) used chloride concentrations in remote streams to estimate inputs from rock weathering in Yellowstone National Park, for comparison with chloride contributions from geothermal waters and anthropogenic sources. In both these examples, stream concentration data were chosen to minimize chloride contributions from sources other than rock weathering; the stream concentrations, however, may also include chloride inputs from other sources upstream of the sampling location or, conversely, may be affected by unknown chloride sinks such as vegetative uptake (Lovett and others, 2005).

Evaporites are sedimentary rocks that were deposited by evaporation of seawater, saline lakes, or saline pore water. Evaporites formed of halite - sodium chloride $(\mathrm{NaCl})$ - are one of two primary rock types formed (calcium sulfate minerals - gypsum or anhydrite - compose the other type). Geologic deposits of rock salt underlie parts of 25 States (fig. 6); these are typically regionally extensive layered deposits that are hundreds of feet thick and may lie hundreds or thousands of feet below land surface (Smith and others, 1973; Ege, 1985; Johnson and others 1989). In the Gulf Coast region, thick salt deposits also occur in dome-like structures that resulted from the plastic flow of salt upward from lower layered deposits. The thick, deep geologic rock salt deposits were formed in shallow inland seas and depositional basins in the Paleozoic and Mesozoic eras. More recently formed salt deposits occur in hot, dry basins of Western States, called playas or dry lakes, where rates of evaporation and transpiration are greater than water inflows from precipitation, surface-water runoff, and groundwater discharge (Pierce and Rich, 1962; Eugster, 1980; Rosen, 1994). Great Salt Lake, Death Valley, and the Salton Sea are large, well known playas with halite-containing evaporites, but there are numerous others - many less than a few square miles in area - in California, Nevada, Utah, Arizona, New Mexico, southeastern Oregon, and western Texas. Salt deposits in playas may form thin crusts on the land surface or layers several feet or tens of feet thick that extend below land surface (Pierce and Rich, 1962; Rosen, 1994; Wood and Sanford, 1995).

Evaporites, which are highly soluble, can contribute large quantities of chloride to surface water and shallow groundwater that come into contact with them. This occurs largely in the western regions of the United States, where the thick geologic deposits of rock salt are close to land surface (within 10s or 100s of feet of land surface rather than thousands; Ege, 1985), where playa evaporites are present, and where the climate is dry. Chloride concentrations in rivers and groundwater affected by dissolution of evaporites have been reported to range from several hundreds to more than $1,000 \mathrm{mg} / \mathrm{L}$ in the western United States and Canada (Jordan and others, 1964; Hitchon and others, 1969; Gustavson and others, 1982; Macfarlane and others, 1990; Thomas and others, 1996; Hibbs and Merino, 2007; Tuttle and Grauch, 


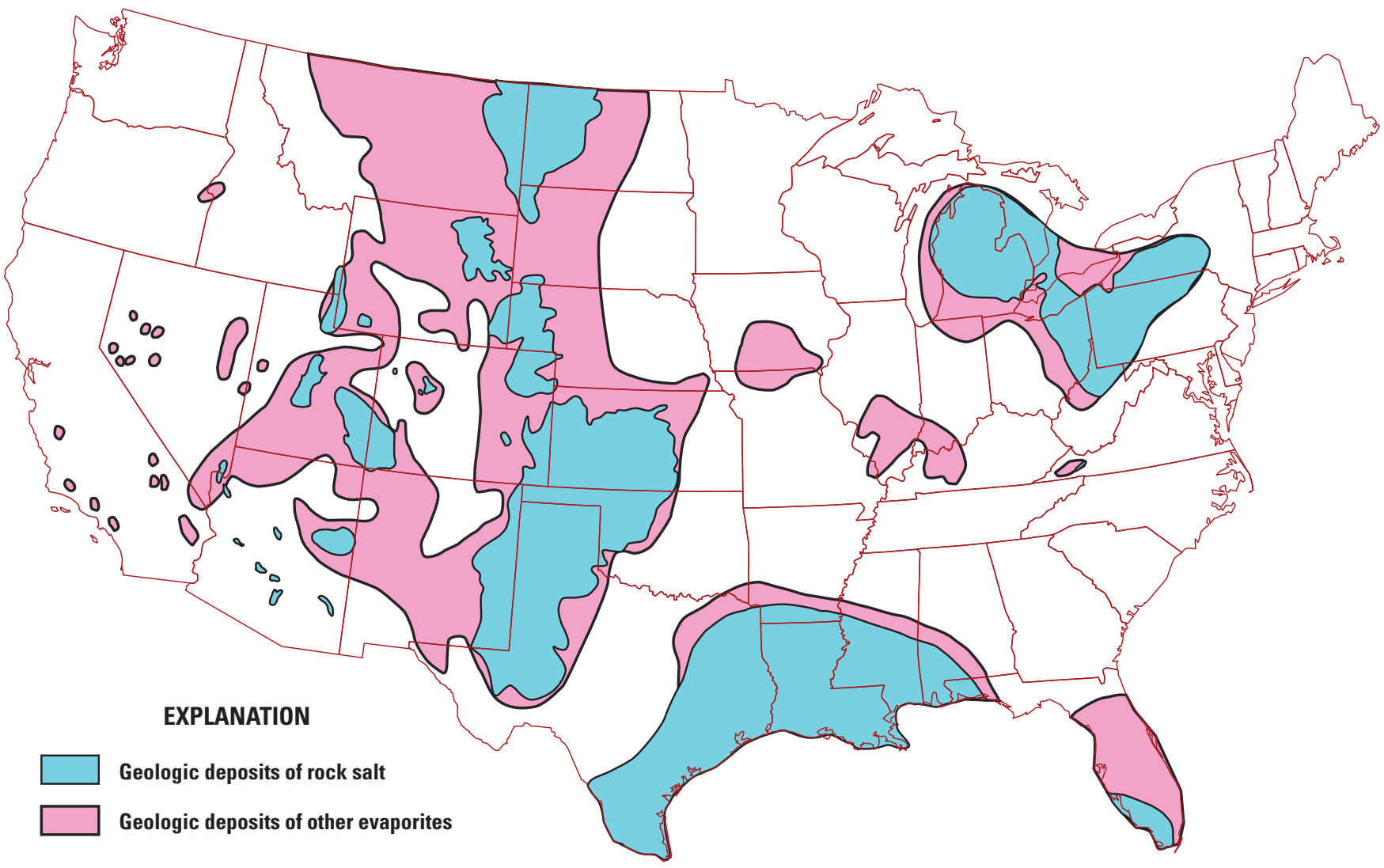

Figure 6. Generalized areal extent of geologic deposits of rock salt and other evaporites in the conterminous United States. Geologic deposits of rock salt are buried deposits several hundred to several thousand feet below land surface. Evaporite deposits near land surface in playas or dry lakes, which may be present in the western United States in areas where precipitation is less than potential evapotranspiration, are not shown. Extent of rock salt and other evaporate deposits modified from Pierce and Rich (1962), Ege (1985), Johnson and others (1989), Johnson (1997), and Rauzi (2002).

2009; Gootee, 2013). The high chloride concentrations in rivers in these areas reflect inflow, from saline seeps and springs along river valleys, of groundwater that dissolved halite as it flowed through bedded subsurface evaporite deposits. Chloride concentrations in saline springs exceed $10,000 \mathrm{mg} / \mathrm{L}$ and may exceed 100,000 mg/L (Hitchon and others, 1969; Feth, 1981; Johnson, 1981). In the Gulf Coast region, salt domes provide another pathway for the development of chloride-rich groundwater (Ranganathan and Hanor, 1988; Hamlin, 2006). Salt domes extend upwards from deeply buried evaporite deposits into freshwater aquifers. Direct dissolution of halite at the dome margins can impart high concentrations of dissolved chloride to adjacent, shallow groundwater under some conditions (Hamlin and others, 1988). In the humid eastern United States, geologic deposits of rock salt are buried thousands of feet below land surface, and halite in the limited outcrops of these rocks was dissolved by precipitation and groundwater flow long before the current era.
However, saline springs, exploited commercially in colonial times, are in many Eastern States, including New York, Michigan, Ohio, and Illinois (Doerr and others, 1994; Hansen, 1995; Illinois Department of Natural Resources, 2009); the geologic origins of the chloride in these springs typically is not known but may be related to deep rock salt deposits or saline connate groundwater.

Rock weathering may contribute large chloride inputs to groundwater and surface waters in basins where evaporites are present (Feth, 1981; Tuttle and Grauch, 2009). For example, Van Denburgh and Feth (1965) reported that chloride export loads from the Pecos River Basin in New Mexico, which is underlain by large areas of evaporites, were 60 times greater than the chloride loads from precipitation. Chloride loads in excess of precipitation inputs can be attributed to evaporite dissolution but also may have other minor geologic sources (for example, geothermal waters) or anthropogenic sources. In the absence of anthropogenic sources, weathering rates 
can be calculated by comparing concentrations in rivers from upstream and downstream locations (Chafin and Butler, 2002). Natural rates of chloride release to groundwaters and surface waters from rock weathering of evaporites can be increased by irrigation in arid basins, through enhanced dissolution of evaporite minerals in the unsaturated zone by excess irrigation water (Ghassemi and others, 1995).

\section{Saltwater Intrusion}

Saltwater intrusion can contribute to elevated chloride concentrations in coastal aquifers. Historically, saltwater intrusion was primarily caused by groundwater withdrawals (Barlow and Wild, 2002; Barlow, 2003; Barlow and Reichard, 2010; Conrads and others, 2013). Currently and in the future, intrusion is expected to increase because of increasing inundation and infiltration as sea levels rise (Thieler and Hammar-Klose, 1999, 2000a,b; Tomaszewski, and Lovelace, 2007; Rice and others, 2011; Conrads and others, 2013; Langevin and Zygnerski, 2013; Prinos, 2014). Saltwater intrusion and associated problems with salinization of coastal aquifers affect water quality in some areas of the United States, Mexico, and Canada (Barlow and Reichard, 2010). However, saltwater intrusion commonly is localized to the vicinity of pumping wells. Pumping at wells may cause intrusion laterally from the ocean; upward from deeper, more saline groundwater; or downward from coastal waters (Barlow and Reichard, 2010). Because saltwater intrusion is a complex process, which depends on the hydrogeology of the area, the location and pumping rates of supply wells, and other factors, much of the available information cannot be extrapolated to different locations. Groundwater models such as SEAWAT have been developed by the USGS to inform understanding of the relation between hydrogeology and the location of supply wells, their pumping rates, and other factors on the potential effects of intrusion (Langevin, 2009; Langevin and Zygnerski, 2013). Barlow (2003) provides information about saltwater intrusion and the methods of hydrologic monitoring and analysis used to identify and quantify intrusion.

\section{Deicing Chemicals}

In many areas chlorides from deicing salts may be a primary source of chloride in receiving waters. From 1990 through 2010, the estimated amount of chloride used for deicing application in the United States ranged from about 5 to 15 million short tons of sodium chloride, with an average annual of 10 million short tons (Kelly and Matos, 2013). Thus, deicing salt was about 19 to 39 percent of the annual chloride consumption and was, on average, about 31 percent of national chloride consumption from 1990 through 2010. Additional amounts of chloride were released from other deicing chemicals, but annual usage volumes are expected to be much lower than the sodium chloride volumes but cannot easily be quantified because nationwide loading data are not compiled for deicers other than sodium chloride (Mussato and others, 2007).

Four types of deicers and sand commonly are used to increase traction on roadways, parking lots, and walkways (Salt Institute, 1991; Ohrel, 2000, Mussato and others, 2007; Michigan Department of Transportation, 2006; Rubin and others, 2010; Massachusetts Department of Transportation; 2012; Fay and others, 2013). With the exception of sand, these chemicals are used to lower the freezing point of water so that ice and snow can be removed from the paved surfaces. The primary chloride-based deicers are $\mathrm{NaCl}$, calcium chloride $\left(\mathrm{CaCl}_{2}\right)$, magnesium chloride $\left(\mathrm{MgCl}_{2}\right)$, and much less commonly potassium chloride $(\mathrm{KCl})$. Organic deicers include calcium magnesium acetate (known as CMA) and less commonly potassium acetate (known as KA). Sodium chloride commonly is used by State departments of transportation (DOTs) because it is effective for most conditions and costs about half as much as the other chloride-based deicers and about an order of magnitude less than the organic deicers. $\mathrm{CaCl}_{2}, \mathrm{MgCl}_{2}$, or mixtures of these chemicals with $\mathrm{NaCl}$, are used when pavement temperatures are extremely low because $\mathrm{NaCl}$ loses its effectiveness at low temperatures. Private contractors may use a higher percentage of $\mathrm{CaCl}_{2}$ and $\mathrm{MgCl}_{2}$, especially if they are using salt-plus contracts, which provide for the price of deicers plus a profit on the amount used (Dindorf and Fortin, 2008; Fortin and Dindorf, 2012; Fu and others, 2013). Increasingly, brines made from the chloridebased deicers are used for anti-icing before snow or ice events or for prewetting solids for application to roads, parking lots, or walkways. Most of the proprietary deicers use corrosion inhibitors and agricultural or industrial byproducts blended with either the chloride or acetate deicers.

Sand is sometimes considered as an alternative to chloride-based deicers, but sand is not as effective and also has adverse environmental effects. Sand is not as effective as chemical deicers because it does not melt ice; is rapidly dissipated by traffic (Mussato and others, 2007; Rubin and others, 2010; Massachusetts Department of Transportation, 2012); causes air-pollution problems; is associated with metals, nutrients, and organic chemicals in runoff; and is associated with adverse ecological effects (Buckler and Granato, 1999; Granato and others, 2002; Mussato and others, 2007; Rubin and others, 2010; Smith and Granato, 2010; Massachusetts Department of Transportation, 2012). Also, use of sand incurs heavy maintenance costs such as road sweeping and sand removal from catch basins, storm sewers, and structural best management practices (BMPs) (Mussato and others, 2007; Rubin and others, 2010; Massachusetts Department of Transportation, 2012).

The concentration of chloride in runoff and meltwater from impervious areas that have been treated with deicing salts and nearby pervious areas receiving plowed snow, runoff, splash, spray, or aerosols from paved areas is expected to be much greater than local background concentrations (for example, Howard and Haynes, 1993; Granato and Smith, 1999a; Kunze and Sroka, 2004; Lundmark and Olofsson, 
2007; Corsi and others, 2010a,b; Smith and Granato, 2010). For example, figure 7 shows instantaneous (1-minute) and event-mean chloride concentrations estimated from specificconductance measurements and measured event-mean chloride concentrations in pavement runoff collected from October 1, 2005, through September 30, 2007, at USGS monitoring station 423027071291301 on State Route 2 near Littleton, Massachusetts. There are 90,665 instantaneous concentrations, ranging from about 0.11 to about $26,500 \mathrm{mg} / \mathrm{L}$ of chloride, with a median of $11.8 \mathrm{mg} / \mathrm{L}$ and an average value of $525 \mathrm{mg} / \mathrm{L}$. In comparison, the maximum chloride concentration of a saturated brine solution at near freezing temperatures is about $220,000 \mathrm{mg} / \mathrm{L}$. About 12.7 percent of the instantaneous runoff values from this highway are greater than or equal to the criterion continuous (chronic) concentrations of $230 \mathrm{mg} / \mathrm{L}$, and about 7.6 percent are above the criterion maximum (acute) concentration of $860 \mathrm{mg} / \mathrm{L}$ (U.S. Environmental Protection Agency, 1988). However, because highway runoff only occurs during about 8.6 percent of the time within this two-year period, the time-based exceedances of the chronic and acute criteria are about 1.1 and 0.65 percent of the time, respectively. In comparison, the 147 estimated event-mean concentrations (EMCs) range from 1.79 to $10,700 \mathrm{mg} / \mathrm{L}$, with a median of about $36 \mathrm{mg} / \mathrm{L}$ and a mean of about $544 \mathrm{mg} / \mathrm{L}$. About 20 percent exceed the chronic criterion and about 12 percent exceed the acute criterion. In comparison, the 18 measured EMCs range from 6 to $10,700 \mathrm{mg} / \mathrm{L}$ of chloride, with a median of about $22 \mathrm{mg} / \mathrm{L}$ and a mean of about $779 \mathrm{mg} / \mathrm{L}$. About 27 percent exceed the chronic criterion, and about 15 percent exceed the acute criterion. Again, because the total duration of all the runoff events is much shorter than the entire two-year period, the percentage of time during which the exceedances occur is much less than the percentage of samples that exceed a given criterion. This dataset is from a high-priority bare-pavement site, and it has higher concentrations and a greater percent of exceedances than other sites in Massachusetts (Smith and Granato, 2010).

\section{Roads and Highways}

Although roads and highways commonly are identified as the primary source of chloride in the environment (with the term "road salt" being the most commonly used misnomer for deicing chemicals), roads may not be the predominant source of chloride in some land-use areas because roadway surfaces may represent less than 50 percent of the paved area. Wigmosta and others (1994) estimated that roadways were about 63 percent of the total imperviousness and about 86 percent of the paved imperviousness in a residential land-use area with a total impervious area (TIA) equal to 28 percent. However, Arnold and Gibbons (1996) indicate that roadways represent 5,35 , and 64 percent of paved areas in commercial, multifamily residential, and high-density residential land-use areas, respectively. Slonecker and Tilley (2004) examined the components of imperviousness in
11 watersheds in 5 areas of the country with impervious areas ranging from about 9 to 45 percent of their total drainage areas. They found that, on average, roadways comprised about 29 percent of the TIA and 43 percent of the paved area. Trowbridge (2007) indicated that, on average, private roads, State roads, and municipal roads comprised about 5 , 8 , and 36 percent, respectively, of the paved areas in four watersheds in New Hampshire that were subject to a chloride total maximum daily load (TMDL) analysis. Roy and Shuster (2009) estimated that driveways, streets, and parking areas comprised 24.6, 22.7 and 12.3 percent of the TIA in their study area, respectively. Therefore, considering the additional (but unquantified) area of sidewalks, streets represent less than 38 percent of the paved portion of their study area. In the Cambridge drinking-water source area in Massachusetts described by Smith (2014), municipal roads are about 11 to 82 percent of the paved area in different subbasins and are, on average, about 41 percent of the paved area. In this basin, which includes two of the primary highways in Massachusetts, State-maintained roads are about 0 to 52 percent of the paved area in different subbasins and are, collectively, about 22 percent of the paved area in the entire drinking-water source area.

Roadway deicing-load estimates commonly are reported as pounds per lane mile for individual applications and short tons per lane mile for annual application (Church and others, 1996). A lane mile is defined as an area of 12 -foot width and 1-mile length. In many cases, local roads are assumed to be two lanes wide, but road widths may vary with land use. In rural and mountainous areas, lane widths may be less than the 12-foot standard. For example, Kelting and others (2012) examined potential effects of deicing on mountain lakes in the Adirondacks in New York; they used width factors of 1.5 for local town and county roads, 2 for State routes and U.S. highways, and 4 for interstate highways. State DOTs commonly apply deicing chemicals only to the travel lanes and report these values as the application rate. However, lane-mileage figures may include the width of paved borders and breakdown lanes (Church and others, 1996), so application rates over the TIA should be reduced accordingly. For example, State Route 25 in southeastern Massachusetts is a six-lane divided highway and has 8.33 lane miles per mile of highway because of the extra area of the borders and breakdown lanes (Church and others, 1996). The borders and breakdown lanes commonly are deiced by the spread of applied salt and brine from the travel lanes, and snow and ice are removed by plowing. If the current application rate of 240 pounds (lb) per lane mile (Massachusetts Department of Transportation, 2012) were applied on the highway, the nominal rate would be $3.78 \mathrm{lb}$ per 1,000 square feet $\left(\mathrm{ft}^{2}\right)$, but the effective rate over the entire impervious area would be less, at $2.73 \mathrm{lb}$ per $1,000 \mathrm{ft}^{2}$.

The Federal Highway Administration (2012) estimated that there was 8,606,003 lane miles of roadway surface in the United States in 2010. Most of this roadway area (about 65.4 percent) was classified as local roads, which are in most 


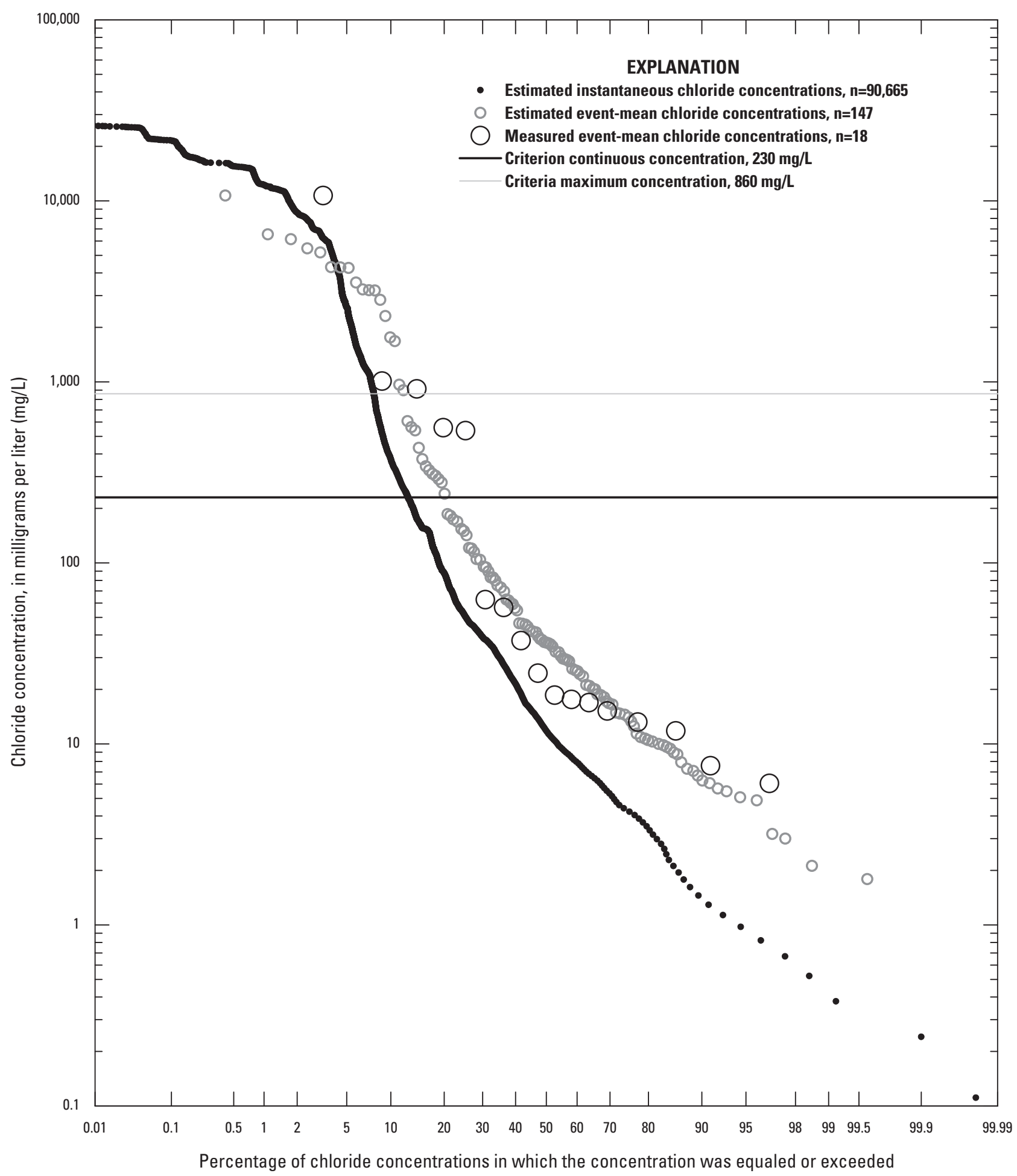

Figure 7. Instantaneous and event-mean chloride concentrations estimated from specific-conductance measurements and measured event-mean chloride concentrations in pavement runoff collected from October 1, 2005, through September 30, 2007, at U.S. Geological Survey monitoring station 423027071291301 on State Route 2 near Littleton, Massachusetts. Chloride concentrations were estimated from specific conductance by using the regression relation documented by Smith and Granato (2010). 
cases municipal or county roads (fig. 8). The next category is collector roads, which are designed to connect the local roads for travel over short to mid-distances at subhighway speeds. About 19 percent of the Nation's roadways are classified as collectors. Collector roads may be local, county, or State roads. Arterial roads are defined as higher speed long-distance roads with some access control. Arterial roads include interstate highways (2.5 percent), freeways and expressways (0.8 percent), and other arterials (12.2 percent). Arterial roads commonly are operated by State DOTs or similar transportation authorities. As indicated in figure 8, because of their prevalence and areal extent, small improvements in local deicing techniques may have a large effect on chloride loading.

Deicing application rates can be used with weather data to estimate roadway loads. Historically, the Salt Institute (1991) clear pavement standard of $250 \mathrm{lb}$ per lane mile, with an average of four applications per storm, was widely used. Mussato and others (2007) indicate that current anti-icing rates are about 25 to $130 \mathrm{lb}$ per lane mile for light icing conditions, 100 to $200 \mathrm{lb}$ per lane mile for light to heavy snow, and 75 to
$400 \mathrm{lb}$ per lane mile for freezing-rain events. They indicate that deicing salt application rates are about 97 to $136 \mathrm{lb}$ per lane mile for light icing conditions, 136 to $253 \mathrm{lb}$ per lane mile for light snow, 253 to $331 \mathrm{lb}$ per lane mile for heavy snow or freezing-rain events. The Massachusetts Department of Transportation (2012) reported that their application rate policy was $240 \mathrm{lb}$ per lane mile, which is on the low end of the range for New England States (240 to $300 \mathrm{lb}$ per lane mile). The Madison Wisconsin Salt Use Subcommittee (2006) indicates that application rates on local streets in that city are on the order of $150 \mathrm{lb}$ per lane mile. Fortin and Dindorf (2012) indicate that application rates may be 40 to $200 \mathrm{lb}$ per lane mile if the salt is prewetted and 50 to $375 \mathrm{lb}$ per lane mile if dry salt is used.

Deicing-chemical loading rates depend on the level of service designated for each road class by the organization controlling deicing operations (Wisconsin Department of Transportation, 2009). Levels of service define the desired road condition, which may include no deicing, clear center, bare wheel path, bare lane, or bare pavement. The desired road condition affects the number of times deicers are applied

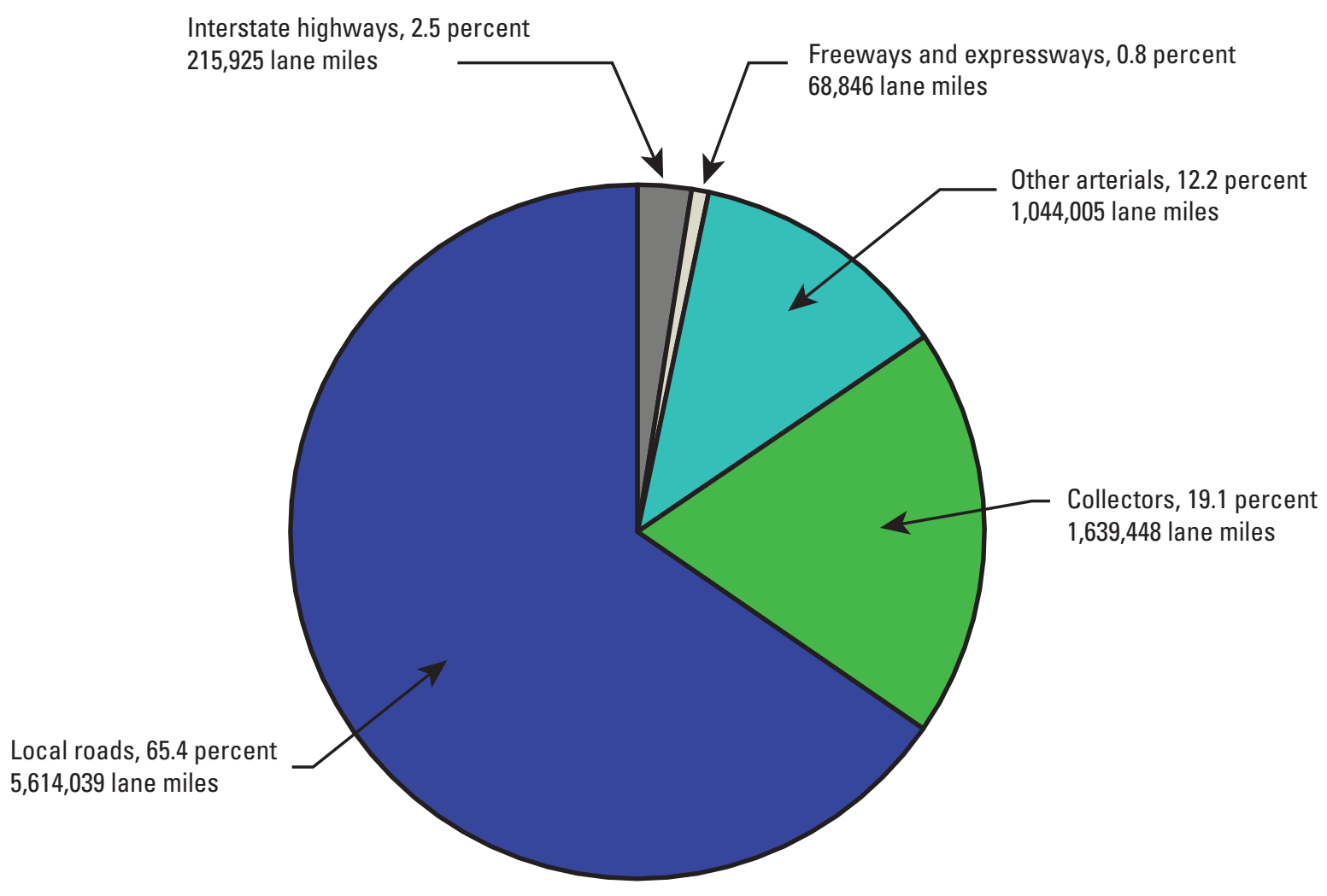

Figure 8. Public road area, by percentage of total lane miles identified by functional system. Data are from Federal Highway Administration (2012). 
during each storm or freeze event. Half of the agencies responding to the Wisconsin Department of Transportation (2009) survey indicated that level of service was dependent on traffic volume or the importance of selected corridors. Definitions of the levels of service also commonly include the time required to reach the desired road condition, which also affects the number of times deicers are applied during each storm (Wisconsin Department of Transportation, 2009; Rubin and others 2010; Minnesota Department of Transportation, 2011; Sproul and Adams, 2011; Massachusetts Department of Transportation, 2012; Sproul and Adams, 2013).

Loading studies commonly apportion deicing applications by using a single annual usage estimate for different roadway applicators and different land uses, but such estimates have limited value because there is wide variability in use from year to year (Sander and others, 2007; Stefan and others, 2008; Mullaney and others, 2009; Barr Engineering Company, 2010; Environment Canada, 2012; Kelting and others, 2012). For example, Granato (1996) noted that application rates to State Route 25 in southeastern Massachusetts varied by a factor of 350 percent of the minimum value over six winter seasons (1990 to 1995). Denner and others (2010) noted that statewide average annual deicing applications by the Vermont transportation agency varied by a factor of about 260 percent of the minimum value from 1981 to 2005. Brown and others (2011) noted that loading rates varied by about 205 percent of the minimum value along Interstate 95 in southeastern Connecticut for the 2008-9 winter season. Similar interannual variations have been noted in many cases (for example, Minnesota Department of Transportation, 2011; Massachusetts Department of Transportation, 2012; Sproul and Adams, 2011, 2013). Although recommended application rates may remain constant from year to year, calibrated spreaders, the number of applications needed, and the mix of chemicals used commonly are adjusted to suit the temperature and the amount and type of precipitation (Salt Institute, 1991; Mussato and others, 2007; Rubin and others, 2010; Minnesota Department of Transportation, 2011; Massachusetts Department of Transportation, 2012; Sproul and Adams, 2011, 2013).

Because large variability in annual loading rates is caused by differences in winter weather, annual usage estimates may not be readily transferable from place to place if there are substantial differences in climate, or even from place to place within a given State. However, use of a winter severity index (WSI) may help establish a historical record of loading rates or be used to adjust available loading data to local conditions. State DOTs commonly use various winter severity indexes to do hindcasting in attempts to interpret year-to-year variability and variability in loading rates within a State or region. WSI values commonly are based on factors such as the daily minimum and maximum temperatures, the daily snowfall, the number of snowfall events each month, the amount of freezing rain, the number of freezing rain events, and the duration of winter events (Transportation Research Board, 2004; Minnesota Department of Transportation, 2011; Environment Canada, 2012; Massachusetts Department of Transportation,
2012; Sproul and Adams, 2011, 2013). WSI values have been shown to be a useful tool in evaluating the performance of salt reduction measures as implemented by, for example, the Massachusetts Department of Transportation (2012), which indicated that 95 percent of the variability in the year-to-year statewide salt usage could be explained by differences in winter severity.

Use of historical application rates may overestimate current rates, and current rates may underestimate historical loadings to surface water and groundwater. State highway departments, in cooperation with the FHWA, are researching and adopting many different methods to maintain the desired level of service while minimizing the volume of deicer used (Ketcham and others, 1996; Transportation Research Board, 2004; Michigan Department of Transportation, 2006; Mussato and others, 2007; Fortin and Dindorf, 2012; Massachusetts Department of Transportation, 2012; Federal Highway Administration, 2013). Anti-icing is the practice of applying a small amount of deicing chemical (usually a sprayed-on brine solution) to the road in advance of an expected storm event. Anti-icing is effective because it prevents or retards the bond between ice and pavement with much less deicer than it would take to melt off bonded ice and snow. The Massachusetts Department of Transportation (2012) indicates that an antiicing application may result in a loading rate of about $70 \mathrm{lb}$ of salt per lane mile, which is about 29 percent of the standard Massachusetts loading rate of $240 \mathrm{lb}$ of salt per lane mile. Anti-icing measures may replace the use of deicing for many small events and on days where frost or icing is expected as temperatures drop after a winter rain or melt event. Prewetting is the practice of spraying the solid deicer with liquid brine to start the melting reaction and reduce the proportion of deicer that may bounce off the road. Zero-velocity spreader technology matches the dispersal of salt to the groundspeed of the deicing vehicle; this technology also minimizes the amount of deicer that bounces off the roadway (Nantung, 2001). Road-weather information systems use an array of sensors, including precipitation, air temperature, road temperature, and sometimes Web cameras, so that road managers can implement anti-icing measures and optimize application rates and the time between applications. Such measures can substantially reduce the total annual application rates, but such reductions can be masked by interannual variability caused by differences in weather. DOTs sometimes use the WSI to adjust for this variability to examine the effects of best practices. For example, using the WSI adjustment, the Massachusetts Department of Transportation (2012) concluded that their application-reduction techniques resulted in a 23-percent decrease in chemical use in the winter of 2010-11 in comparison to earlier winters of comparable severity. Similar improvements in application rates also may reduce loadings to municipal roads, parking lots, and walkways if municipal and commercial applicators receive training and adopt these technologies (Fortin and Dindorf, 2012). 


\section{Parking Areas}

Parking areas may represent a large component of the deicing load in suburban and urban areas because parking is a large component of the TIA, expected levels of service are high, and deicing-chemical loading rates can be high. Exum and others (2005) estimate that there are about 70,000,000 offstreet parking spaces in the United States. Arnold and Gibbons (1996) indicate that parking areas comprise 48 percent of paved areas in multifamily residential land-use areas and 88 percent of paved areas in commercial land-use. Slonecker and Tilley (2004) examined the components of imperviousness in 11 watersheds, in 5 areas of the country, with impervious areas ranging from about 9 to 45 percent of the total drainage area. They found that, on average, parking lots comprised about 25 percent of the TIA. Similarly, Roy and Shuster (2009) estimated that about 12 percent of the TIA was parking lots in the Shepherd Creek watershed, Hamilton County, Ohio. Trowbridge (2007) indicated that parking lots comprised 6 to 61 percent of the paved area in four watersheds in New Hampshire that were subject to a chloride TMDL. In the Cambridge drinking-water source area in Massachusetts, described by Smith (2014), parking lots represent 13 to 75 percent of the paved area in different subbasins; on average, they represent 36 percent of the paved area. In many cases, parking lots receive high levels of deicing service. Fu and others (2013) surveyed more than 100 private applicators and found that 34 percent of large and 18 percent of small commercial customers wanted parking areas to be free of ice and snow 24 hours per day. They also found that 59 percent of large and 18 percent of small commercial customers wanted parking areas to be free of ice and snow at the start of the day.

Deicing loads from parking lots commonly are estimated from roadway application rates because private application rates are not commonly published (Trowbridge 2007; Kelley and others, 2008; Trowbridge and others, 2010; Barr Engineering Company, 2010). The Madison Wisconsin Salt Use Subcommittee (2006) estimates that commonly used commercial application rates are between 6 to $14 \mathrm{lb}$ per $1,000 \mathrm{ft}^{2}$ (about 407 to $873 \mathrm{lb}$ per lane mile) per application. Sassan and Kahl (2007) obtained application data from schools and private contractors; they provided application rates that range from 0.18 to $9.38 \mathrm{lb}$ per $1,000 \mathrm{ft}^{2}$ (equivalent to 11 to $595 \mathrm{lb}$ per lane mile) with a most probable value of $3 \mathrm{lb}$ per $1,000 \mathrm{ft}^{2}$ (equivalent to $190 \mathrm{lb}$ per lane mile) per application. These self-reported rates, however, are lower than most other values in the literature. For example, Fu and others (2013) indicate that average application rates commonly are about $20 \mathrm{lb}$ per $1,000 \mathrm{ft}^{2}$ and range between 12 and $30 \mathrm{lb}$ per $1,000 \mathrm{ft}^{2}$ (equivalent to a range of 760 to $1,900 \mathrm{lb}$ per lane mile). Omer and others (2014) indicate that application rates may be between 8.3 and $56 \mathrm{lb}$ per $1,000 \mathrm{ft}^{2}$ (equivalent to a range of 525 to $3,548 \mathrm{lb}$ per lane mile) per application. In comparison, Dindorf and Fortin (2008) indicate that rates as low as 0.75 to $3 \mathrm{lb}$ per $1,000 \mathrm{ft}^{2}$ (equivalent to a range of 19 to $190 \mathrm{lb}$ per lane mile) per application may be possible for trained operators who are using calibrated spreaders and anti-icing techniques. These rates, however, do not include the brine that is spread before the storm. The deicing application rates for parking areas that are shown in the literature are about 2 to 18 times greater than the rates suggested by Dindorf and Fortin (2008) and about 2 to 4 times greater than commonly used highway application rates (Mussato and others, 2007).

\section{Driveways and Walkways}

Deicing-chemical contributions from driveways and walkways commonly are not identified as a separate source area. It is commonly assumed that the area of driveways and walkways is negligible, the participation rates are low for deicing activities on these surfaces, and the loading rates on them are low. However, studies indicate that applications to these areas may be disproportionate to their size because applications can greatly exceed the needed amount (Dindorf and Fortin, 2008; Environment Canada, 2012; Fu and others, 2013; Omer and others, 2014). Not many studies on imperviousness quantify the area of driveways and walkways; most available data are from residential areas (Granato, 2010a,b). For example, Arnold and Gibbons (1996) indicate that sidewalks comprise $6.7,12$, and 16 percent of paved areas in commercial, high-density residential, and multifamily residential land-use areas, respectively. They also indicate that driveways comprise 24 percent of paved areas in high-density residential areas. Lee and Heaney (2003) characterized impervious surfaces in a medium-density single-family residential area in Colorado with a TIA value of about 26 percent. They did field surveys of impervious areas and found that driveways and sidewalks accounted for 21 and 7 percent of the impervious area in the neighborhood, respectively. Slonecker and Tilley (2004) did an analysis of the components of imperviousness in five areas of the country and found that, on average, driveways and sidewalks accounted for about 9 and 3 percent of the TIA and about 5 and 14 percent of the paved area, respectively. Roy and Shuster (2009) estimated that driveways and sidewalks accounted for 25 and 6 percent of the impervious area. Wigmosta and others (1994) estimated that driveways were about 11 percent of the TIA and about 25 percent of the paved impervious area in a residential land use area.

Driveways and walkways in residential areas are most likely deiced manually. Information about levels of service and manual deicing rates are not readily available in the literature. When such loads are estimated, it is commonly done on the basis of sales data for prepackaged deicers (for example, Stefan and others, 2008; Sander and others, 2007; Barr Engineering Company, 2010). Among the households that use commercial snow-removal services, 46 percent of customers expect to be deiced only on demand, 44 percent expect clear pavement in the morning, and 10 percent want continuously clear pavement all winter long ( $\mathrm{Fu}$ and others, 2013). However, homeowners who use commercial 
deicers probably expect a higher level of service than if the homeowner was doing the deicing. When deicing chemicals are applied, manual application rates are likely to be much higher than rates from a calibrated spreader. For example, Schueler (2005) described "a handful per square yard" as a recommended application rate to minimize the use of deicers; based on a small sample $(\mathrm{n}=6)$, this rate is equivalent to about $25.7 \mathrm{lb}$ per $1,000 \mathrm{ft}^{2}$ (equivalent to $1,920 \mathrm{lb}$ per lane mile) per application. Currently, commercial application rates for driveways and walkways probably are comparable to rates of 6 to $20 \mathrm{lb}$ per $1,000 \mathrm{ft}^{2}$ (equivalent to about 448 to $1,490 \mathrm{lb}$ per lane mile) described for parking areas (Madison Wisconsin Salt Use Subcommittee, 2006; Omer and others, 2014).

However, if commercial deicing companies adopt training programs, calibrated spreaders and anti-icing techniques, rates as low as 0.75 to $3 \mathrm{lb}$ per $1,000 \mathrm{ft}^{2}$ (equivalent to about 56 to $224 \mathrm{lb}$ per lane mile) may be obtainable (Dindorf and Fortin, 2008). More data are needed, but driveways and walkways should not be ignored in loading estimates, and knowledge of applications to these areas represents an opportunity to reduce chloride loads by public education.

\section{Storage and Handling Sites}

Historically much of the salt stockpiled for winter use was stored outside, but by the 1970s outside storage was recognized as a source of chloride to the environment, and indoor storage and handling became more prevalent (U.S. Environmental Protection Agency, 1974). Although most large State DOT storage facilities are covered, many commercial and local-government storage facilities in the United States continue to be unsheltered and lack controls to reduce salt runoff (Meegoda and others, 2004). To mitigate this problem, the State of Maine requires that all private and public storage facilities be registered, and the State provides funding and technical assistance to build shelters (Rubin and others, 2010). In 1999 there were 674 registered sand/salt storage areas in Maine, two-thirds of which were uncovered (Rubin and others 2010). Uncovered salt piles may produce highly saline runoff. For example, Ostendorf and others (2012) observed a monthly averaged dissolved chloride concentration of $13,000 \mathrm{mg} / \mathrm{L}$ in runoff from a salt storage facility in Massachusetts that featured outdoor delivery and loading of salt trucks. One inch of rainfall produces approximately 0.6 gallons (gal) of brine per square foot of stockpiled salt (Joint Departments of the Army, Navy, and Air Force, 1995). In addition, outside storage of salt creates crusts and lumps, making the salt more difficult to work with and leading to loss of product. For large stockpiles, losses can reach one-eighth of the initial weight of the pile per inch of rainfall each year (Joint Departments of the Army, Navy, and Air Force, 1995).

In the absence of control measures, runoff from "road salt" storage and handling areas can be a significant source of chloride to surface water and groundwater (Trowbridge, 2007; Ostendorf and others, 2006; Ohno, 1990; Wilcox, 1986). In large, heavily developed watersheds, individual salt piles may contribute only a small percentage of the total chloride load to streams in comparison to other sources such as deicing of parking lots, roads, and highways (Trowbridge and others, 2010), but salt piles can be potent point sources that have substantial local effects on adjacent surface waters and can produce plumes of highly saline groundwater. Ohno (1990) measured elevated chloride concentrations in wetlands adjacent to four outdoor salt storage facilities in east-central Maine. Runoff resulted in chloride concentrations up to $13,500 \mathrm{mg} / \mathrm{L}$ in surrounding wetlands, and average elevated concentrations were about 400 times greater than background levels at the four sites. Ostendorf and others (2006) sampled 43 monitoring wells in 12 clusters installed around a former outdoor storage area in Massachusetts that was in operation from the 1960s to the mid-1980s. Concentrations of chloride in groundwater ranged from 70 to $11,300 \mathrm{mg} / \mathrm{L}$. The authors estimated that approximately 0.3 percent of the chloride stored at the site (4,400 kilograms) entered the groundwater-flow system each year. In most instances the long-term legacy of improper storage of salt stockpiles is elevated chloride concentrations in groundwater and streams compared to background conditions.

Uncovered salt piles and poor handling practices are the anthropogenic sources that can be mitigated most readily. Generally the best method for minimizing runoff from salt storage facilities is for all delivery, storage, loading, and equipment-maintenance activities to take place inside a building (Salt Institute, 2006; Meegoda and others, 2004; U.S. Environmental Protection Agency, 1999a). Material storage and handling in shelters minimizes the loss of salt to dissolution and the contamination of soil, groundwater, and water resources from runoff. Outside areas should be underlain by impermeable material such as concrete or asphalt and contain runoff control measures. Even for facilities that are completely enclosed, truck and equipment maintenance generates saline water that requires proper disposal (Meegoda and others, 2004). Thus the use of BMPs for salt storage facilities involves minimizing the generation of liquid wastewater as well as controlling its runoff to the environment. Meegoda and others (2004) proposed a management strategy in which saline wastewater is reused. Runoff from storage and maintenance facilities is collected, treated, stored, and the brine is then reused the following winter for anti-icing of road surfaces and prewetting of dry salt.

\section{Dust Control and Stabilization of Unpaved Roads}

It is estimated that there are about 1.7 million miles of unpaved road in the United States and that about 25 percent of these roads are treated with stabilizers and (or) dust suppressants (Sanders and Addo, 1993; Piechota and others, 2004; Gesford and Anderson, 2007). Use of chloride-based dust suppressants can affect surface-water and groundwater quality (Hull and Bishop, 2003, 2004; Robertson and others, 2013). For example, Robertson and others (2013) noted 
chloride enrichment of shallow groundwater on the order of $100 \mathrm{mg} / \mathrm{L}$ downgradient of a campground that was using $\mathrm{CaCl}_{2}$. Stabilizers and dust suppressants have been used on the Nation's unpaved roads since the early part of the 20th century (Burggraf and others, 1932; Fay and Kociolek, 2009; Kestler, 2009). Dust suppressants also are used on mining sites, construction sites, campgrounds, agricultural fields, livestock facilities, disturbed vacant land, landfills, and in steel mills (Piechota and others, 2004; Robertson and others, 2013). Stabilizers and dust suppressants are used to reduce air pollution and sediment runoff into streams (Bolander and Yamada, 1999; Hull and Bishop, 2003, 2004; Gesford and Anderson, 2007; Kestler, 2009). Stabilizers and dust suppressants also increase the life of a roadway. For example, Sanders and Addo (2009) indicated that about 2.59 short tons of dust were mobilized from an untreated roadway pervehicle-mile per-day per-year, and this rate was reduced to 1.49 short tons if sodium chloride was used or 1.04 short tons if calcium chloride or magnesium chloride was used as a dust suppressor on the road. Monlux and Mitchell (2006) indicated that chloride-based road treatments increase the time between regrading by a factor of 4 to 57 times.

Many different chemicals are used for road stabilization and dust suppression, but magnesium chloride, calcium chloride, sodium chloride, and mixed brines are the most commonly used materials (Piechota and others, 2004; Fay and Kociolek, 2009; Kestler, 2009; Sanders and Addo, 2009; Rubin and others, 2010; Jones and others, 2013). Calcium chloride is slightly more effective than magnesium chloride, but because magnesium chloride has a lower cost, it is the most commonly used material (Kestler, 2009; Sanders and Addo, 2009; Jones and others, 2013). Sodium chloride is not as effective as magnesium chloride or calcium chloride for dust control and road stabilization; therefore it is not commonly used. However, oil- and gas-field brines, which are primarily sodium chloride, commonly are used for dust suppression in oil and gas production areas (Janiczek, 2005; Lynch, 2010; Wilson and Van Briesen, 2012; Pennsylvania Department of Environmental Protection, 2013; Hladik and others, 2014).

Chloride compounds are used because they absorb water from the atmosphere to keep the roadway moist to hold the fine particles together (Sanders and Addo, 1993; Bolander and Yamada, 1999; Fay and Kociolek, 2009; Kestler, 2009; Jones and others, 2013). The chloride compounds are either sprayed on as a liquid; applied to the road surface as flakes or solids with prewetting and, if necessary, post-wetting with water; or spread as a solid, mixed into the first inch of material, then compacted (Sanders and Addo, 1993; Piechota and others, 2004; Jones and others, 2013). Two to four applications each year are considered necessary to maintain the road (Piechota and others, 2004; Gesford and Anderson, 2007; Kestler, 2009). Reported loading rates for magnesium chloride range from about 3.0 to 12 tons, with an average of about 7.1 tons of $\mathrm{MgCl}_{2}$ per lane mile (12-ft width) per application (Piechota and others, 2004; Gesford and Anderson, 2007; Kestler, 2009).
Similarly, reported loading rates for calcium chloride range from about 2.9 to 19 tons, with an average of about 8.9 tons of $\mathrm{CaCl}_{2}$ per lane mile (Piechota and others, 2004; Gesford and Anderson, 2007; Kestler, 2009). Assuming that about $447,000 \mathrm{mi}$ of two-lane unpaved road are treated twice per year with equal parts $\mathrm{MgCl}_{2}$ and $\mathrm{CaCl}_{2}$, this would result in an annual load of about 13.6 million tons of chloride-based suppressant and about 10,900,000 tons of chloride. Thus chloride loadings from $\mathrm{CaCl}_{2}$ and $\mathrm{MgCl}_{2}$ for road stabilization are comparable to the chloride loading rates from $\mathrm{NaCl}$ used for deicing chemicals in 2010, as reported by Kelly and Matos (2013).

\section{Water Treatment and Wastewater}

Chloride in wastewater may come from a variety of discharges from residential, commercial, and industrial sources and from remnants of chemical addition throughout the processes of drinking-water treatment for coagulation, water softening, and disinfection. Chloride may also be introduced to the environment via wastewater. Choride is added to wastewater from human biological excretion, food waste, personal care products, detergents, chlorine-based cleansers, and bleach. Water-softening systems also add chloride to the wastewater stream. Choride also is added for disinfection of wastewater and as a component of other wastewater chemicals. Chlorination of wastewaters may contribute a substantial load of chloride into waters where wastewater is discharged. This discussion will focus on chloride concentrations in municipal and self-supplied residential water supplies. In many areas these sources are an important part of the water and chloride budget that should be considered and quantified. Nationally, industrial, mining, and nonhousehold water uses were a substantial proportion of the total annual water use in 2005 (Kenny and others, 2009). If withdrawals for thermoelectric cooling water, agriculture, and aquiculture are excluded, municipally supplied, industrial, and mining water uses were about 28,25 , and 3.4 percent of annual withdrawals in 2005, respectively (Kenny and others, 2009). Data on chloride concentrations in such wastewater discharges, however, are more likely to vary substantially according to the commercial, industrial, or mining processes that would produce chloride in the waste stream. For example, Hladik and others (2014) compared wastewater from a municipal plant and a commercial plant processing waste from oil and gas mining that were both discharging to the same stream; the municipal effluent had chloride concentrations of about $40 \mathrm{mg} / \mathrm{L}$, whereas the commercial plant had effluent concentrations of about $8,200 \mathrm{mg} / \mathrm{L}$. Nationwide, some chloride concentrations from municipal plants are measured or reported; however, these concentrations may be influenced by oil and gas mining waste if the waste is allowed to discharge to that municipal treatment plant. For example, Kenny and others (2009) indicate that nonhousehold water use represented about 42 percent of public-supply withdrawals in 2005 ; commercial 
and industrial facilities that are on public water supply also may be on the public wastewater system. Information about various dischargers in a watershed of interest may be identified by using the EPA Permit Compliance System and Integrated Compliance Information System databases in Envirofacts (U.S. Environmental Protection Agency, 2012b, 2014b). These databases can be used to search for dischargers by using a combination of facility name, National Pollutant Discharge Elimination System (NPDES) permit number, geographic location, facility industrial classification, and chemicals on the permit. Even though almost all discharges will contain some form of chloride, the list of chemicals on the permit for a given facility may not include chloride if is not a constituent of interest. If water-use data are not available for such facilities, then coefficients for estimating commercial, industrial, or mining organizations may be available (for example, Barlow and others, 2009). Concentrations and loads of chloride from such sources will need to be measured, or estimated, from the known effluent quality from similar sites for which chloride data are available.

Although concentrations of chlorides in municipal wastewater and septic-system discharges are not commonly of the same order of magnitude as concentrations from other potential sources, withdrawal and use of water for municipal and self-supplied household use can represent a substantial portion of the local and regional water budget (Weiskel and others, 2007). Therefore, annual loads from these sources, which commonly are discharging wastewater to surface water and groundwater every day, may be substantial (Peters and Turk, 1981; Minnesota Pollution Control Agency, 1999; Panno and others, 2006, 2007; California Regional Water Quality Control Board, 2008; Heinz and others, 2008; Carollo Engineers, Inc., 2009; Novotny and others, 2009; Kelly and others 2010; Kelly and others, 2012). The increased concentrations and loads of chloride from such sources can accumulate in surface-water and groundwater resources, thereby increasing the potential number of waterquality exceedances as chloride from other sources is added to the elevated receiving-water concentrations. Kenny and others (2009) estimated that, nationally, public water supplies withdrew 44,200 million gallons per day (Mgal/d), household use was $25,600 \mathrm{Mgal} / \mathrm{d}$, and other uses were about 18,600 Mgal/d in 2005. About 258 million people were on public supplies (about 86 percent of the population). In comparison, self-supplied household withdrawals were about 3,830 Mgal/d, serving 42.9 million people (about 14 percent of the population) in that year. Kenny and others (2009) estimated that, in 2005, public-supplied household water use was 99 gallons per day (gal/d) per person, selfsupplied household water use was $89 \mathrm{gal} / \mathrm{d}$ per person, and the population-weighted average was $98 \mathrm{gal} / \mathrm{d}$ per person.

To evaluate the magnitude and location of sources of chloride to surface water and groundwater (especially municipal and private wells), the locations of these sources must be identified. Municipal wastewater-treatment systems commonly are viewed as point sources where they discharge to surface water or groundwater. However, these systems also may be diffuse sources because sewage-line exfiltration can be substantial, wastewater is increasingly used for irrigation, and disposal of sewage sludge to the land surface or to landfills can create unexpected point or diffuse sources separate from the recognized wastewater-treatment-plant outfall (German, 1990; Gaggiani, 1991; Rutsch and others, 2006; Rose, 2007; Chisala and Lerner, 2008; Katz and Griffin, 2008; Garrison and others, 2011; Katz and others, 2011; Schirmer and others, 2013). For example, in a review of sewer-system exfiltration, Rutsch and others (2006) indicate that leakages to local groundwater can be on the order of 1 to 20 percent of dry-weather sewage flows. Lerner (2002) estimated that about 10 to 30 percent of sewer pipes leak into local groundwaters. Chisala and Lerner (2008) indicate that exfiltration rates can range from about $6 \times 10^{-6}$ to about 1.5 gallons per second per mile of sewer, with a median of 0.02 gallon per second per mile, depending on age and construction materials. These exfiltration rates represent annual values that range from about 188 to $47,000,000$ gallons per mile. Therefore, sewage exfiltration may be a substantial source of chloride in groundwater and base flow and may be contributing to rising concentrations.

Wastewater exfiltration may be misattributed to other sources because the prevalence of sewers is expected to increase as road density and imperviousness also increase. For example, Steele and Aitkenhead-Peterson (2011) show a strong positive relationship between the mean annual watershed exports of sodium and chloride and the percentage of urban land cover and impervious surface area in the humid subtropical Dallas-Fort Worth region. They identify wastewater effluent as the single largest contributor and note that estimates of urban salt exports were similar to the estimates from northern watersheds that are commonly attributed to deicing salts. Similarly, Rose (2007) identified increasing sodium, chloride and other related chemicals with increasing development near Atlanta, Georgia and attributed this correlation to leaking sewers and septic tanks as a diffuse source of these chemicals.

Septic systems also may be a diffuse source of chloride in public water-supply areas. Although about 14 percent of the U.S. population is on private water supply it is estimated that about 20 percent of the 26.1 million American households use private wastewater disposal (increasingly septic) systems (U.S. Environmental Protection Agency, 2008). About 50 percent of these systems are in rural areas, 47 percent are in suburban areas, and 3 percent are in central cities (U.S. Environmental Protection Agency, 2008).

Flow rates of water and wastewater are needed to estimate concentrations and loads of chlorides in an area of interest. Kenny and others (2009) estimated that household water use is about $100 \mathrm{gal} / \mathrm{d}$ per person. However, some of that amount is used outdoors for watering lawns and gardens, washing cars, and other purposes (Barlow and others, 2009; Garrison and others, 2011; Kenny and Juracek, 2012). Most outdoor use occurs in the warm seasons, and in some areas the magnitudes of outdoor uses from year to year are correlated to 
precipitation (Barlow and others, 2009; Kenny and Juracek, 2012). Most outdoor-use water in public-supply areas has been treated and chlorinated. Much of the outdoor-use water may be lost to evapotranspiration, but some flows to storm sewers or infiltrates to groundwater. Barlow and others (2009) indicate that summertime water-use values may be about 1.1 to 1.4 times greater than winter values. The U.S. Department of Defense (2012) uses wastewater rates of $100 \mathrm{gal} / \mathrm{d}$ per person for facilities, $83 \mathrm{gal} / \mathrm{d}$ per person for single-family housing, $69.4 \mathrm{gal} / \mathrm{d}$ per person for multifamily housing, and $30 \mathrm{gal} / \mathrm{d}$ per shift for workers. Benefield (2002) did a literature review of residential flow rates for septic-system design across the 50 States and found that these rates ranged from 30 to $150 \mathrm{gal} / \mathrm{d}$ per person, with an average of $69 \mathrm{gal} / \mathrm{d}$ per person and a median of $71 \mathrm{gal} / \mathrm{d}$ per person to be discharged as wastewater. Benefield (2002) observed that large houses and affluent households were listed on the top of the septic-discharge range in many States.

Estimates of concentrations of chloride in wastewaters also are needed to estimate loads from wastewater and the potential effects on receiving waters. Many wastewater concentrations are available in the literature, but these concentrations are not commonly transferable from one place to another because of differences in the background concentrations. Enrichment concentrations, which are the differences between concentrations of wastewater and source water, however, indicate increases in chloride concentrations that may be caused by drinking-water chlorination, human waste, consumer products, and potentially chlorination of wastewaters. Values for public wastewater-treatment plants also may include sources from commercial waste, food processing, and industrial waste. Some of the following results may include the effects of water-softening on chloride concentrations in wastewater. Water softening, because it can be a large source of chloride, is covered in the next subsection. The examples in this paragraph do not knowingly include chloride from water softening. Chloride enrichment estimates made by subtracting background concentrations from septicsystem and wastewater-plant values reported in the literature are shown in table 1. Estimated enrichment values range from 0.5 to $710 \mathrm{mg} / \mathrm{L}$ of chloride in the septic-effluent studies and range from 30 to 279 in the wastewater-effluent studies. The median of central tendency numbers for estimated enrichment concentrations in septic-system studies is about $75 \mathrm{mg} / \mathrm{L}$; the median of central tendency numbers for wastewater-effluent studies is about $100 \mathrm{mg} / \mathrm{L}$; and the combined median is about $82 \mathrm{mg} / \mathrm{L}$ chloride. In comparison, the EPA onsite wastewatertreatment-systems manual provides an estimate of $70 \mathrm{mg} / \mathrm{L}$,

Table 1. Estimates of enrichment concentrations of chloride in wastewater made by using background concentrations and wastewater concentrations.

[Enrichment estimates are made by subtracting background concentrations from wastewater concentrations. The potential range is calculated by subtracting the reported minimum background values from the maximum wastewater values. The central tendency is calculated by subtracting reported medians or averages as appropriate. --, did not define]

\begin{tabular}{|c|c|c|}
\hline Reference & $\begin{array}{c}\text { Potential range, } \\
\text { in milligrams per liter }\end{array}$ & $\begin{array}{c}\text { Central tendency, } \\
\text { in milligrams per liter }\end{array}$ \\
\hline \multicolumn{3}{|c|}{ Septic effluent } \\
\hline Alhajjar and others, 1990 & 0.5 to 710 & 59 to 112 \\
\hline Harman and others, 1996 & 34 to 198 & 116 \\
\hline Patterson, 1997 & 67 to 101 & 88 \\
\hline Robertson and others, 2013 & 30 to 84 & 75 \\
\hline Wilhelm and others, 1996 & -- & 54 \\
\hline Yates, 1985 & -- & 50 \\
\hline \multicolumn{3}{|c|}{ Wastewater effluent } \\
\hline German, 1990 & 30 to 80 & 51 \\
\hline Hladik and others, 2014 & -- & 30 \\
\hline Hyer, 2007, and Fairfax County Water Authority, 2014 & -- & 49 \\
\hline Katz and Griffin, 2008 & 54 to 70 & -- \\
\hline Kelly and others, 2010 & 101 to 279 & 129 to 163 \\
\hline Ronen and Magaritz, 1985 & -- & 100 \\
\hline Vengosh and Keren, 1996 & -- & 125 \\
\hline Vengosh and Pankratov, 1998 & 85 to 168 & -- \\
\hline
\end{tabular}


with a range of 37 to $110 \mathrm{mg} / \mathrm{L}$, to represent expected chloride concentrations in septic systems (U.S. Environmental Protection Agency, 2002).

Establishing accurate estimates for chloride in wastewater is important because human use can represent a large component of the chloride loads in some basins. Godwin and others (2003) estimated a chloride load of 12 kilograms per year per person from human excreta and household waste, which would be 33,949 milligrams per day (mg/d). If this mass is divided by the median of $71 \mathrm{gal} / \mathrm{d}$ per person from values reported for septic-system permitting in Benefield (2002), then the resulting chloride concentration would be only about $126 \mathrm{mg} / \mathrm{L}$. Trowbridge (2007) used a textbook value of $50 \mathrm{mg} / \mathrm{L}$ from Tchobanoglous and others (1991) to estimate the chloride load from wastewater; this estimate was used to help formulate a TMDL in New Hampshire. Mullaney and others (2009) estimated wastewater chloride concentrations by using the recommended daily adult sodium intake of $2,300 \mathrm{mg} / \mathrm{d}$ to estimate a chloride load of $3,547 \mathrm{mg}$ chloride per day. If this mass is divided by Benefield's (2002) water-use estimate, then the result would be only about $13 \mathrm{mg} / \mathrm{L}$. Steele and Aitkenhead-Peterson (2011) determined that the chloride estimate by Mullaney and others (2009) only accounted for about 11.6 percent of the chloride in the Texas wastewaters. Similarly, chloride data on source water and finished drinking water from the Fairfax County Water Authority (2014) indicate that chlorination may add about 8 to $12 \mathrm{mg} / \mathrm{L}$ chloride to public supplies that use surfacewater supplies, which would be comparable to the $13 \mathrm{mg} / \mathrm{L}$ estimate for wastewater provided by Mullaney and others (2009). In comparison, Kelley and others (2008) estimated $9,035 \mathrm{mg} / \mathrm{d}$ for excretion, $24,914 \mathrm{mg} / \mathrm{d}$ for consumer products, and $1,999 \mathrm{mg} / \mathrm{d}$ for wastewater chlorination. Using an estimated flow of $71 \mathrm{gal} / \mathrm{d}$ per person, these loads would result in concentrations of about $126 \mathrm{mg} / \mathrm{L}$ for septic systems and about $134 \mathrm{mg} / \mathrm{L}$ chloride for chlorinated wastewater effluents. Comparisons among these numbers and the estimate developed in this report indicate that some studies may be overestimating the deicing-chemical contribution to receiving waters, especially if chloride from water softeners also is discharged to the waste stream.

\section{Water Softening}

Water softening is commonly mentioned as a source of chloride in effluent from septic systems and wastewatertreatment plants (Thomas, 2000; Panno and others, 2006, 2007; Trowbridge, 2007; Kelley and others, 2008; Mullaney and others, 2009). Municipal drinking-water treatment plants may use chemical precipitation or ion-exchange systems to reduce hardness (Peavy and others, 1985; Driscoll, 1986). Most home and commercial systems, however, use ionexchange systems because these systems are relatively simple to install and operate (Thomas, 2000; New Hampshire Department of Environmental Services, 2008, 2009; Kelley and others, 2008; Michigan Department of Environmental
Quality, 2014). Water softening is used to reduce the hardness of water, which is commonly defined as the sum of calcium (Ca) and magnesium $(\mathrm{Mg})$, expressed as an equivalent concentration of $\mathrm{CaCO}_{3}$ in $\mathrm{mg} / \mathrm{L}$. In the water-treatment industry, hardness is commonly expressed as grains of $\mathrm{CaCO}_{3}$ per gallon; 1 grain per gallon equals $17.12 \mathrm{mg} / \mathrm{L}$ (Driscoll, 1986; Hem, 1992). Actual hardness, however, also would include the hydrogen ion and polyvalent metal ions (such as iron and manganese), but these ions commonly exist at much lower concentrations than $\mathrm{Ca}$ and $\mathrm{Mg}$ in potable water sources (Hem, 1992; New Hampshire Department of Environmental Services, 2008). Water with less than $60 \mathrm{mg} / \mathrm{L}$ as $\mathrm{CaCO}_{3}$ of hardness is generally considered "soft," and water with more than $120 \mathrm{mg} / \mathrm{L}$ as $\mathrm{CaCO}_{3}$ of hardness is generally considered "hard" (Hem, 1992). However, this distinction depends on the intended water use. For example, although the World Health Organization indicates that hardness concentrations of $500 \mathrm{mg} / \mathrm{L}$ would be acceptable, public water suppliers commonly reduce hardness below $100 \mathrm{mg} / \mathrm{L}$, with a target value of about $80-85 \mathrm{mg} / \mathrm{L}$ as $\mathrm{CaCO}_{3}$ for domestic consumption (Driscoll, 1986; Hem, 1992). Hardness concentration-targets for boiler-feed water and textile processing are less than $20 \mathrm{mg} / \mathrm{L}$, for paper processing and laundering are less than or equal to $50 \mathrm{mg} / \mathrm{L}$, for producing canned goods are less than or equal to $75 \mathrm{mg} / \mathrm{L}$, and for other food processing commonly are less than or equal to $250 \mathrm{mg} / \mathrm{L}$ as $\mathrm{CaCO}_{3}$ (Driscoll, 1986; Hem, 1992). However, water softeners are sold as water-treatment units even in areas with relatively soft waters (for example, Rhode Island Department of Environmental Management, 2012).

Water hardness in surface water and groundwater varies substantially across the country. Britton and others (1983) provide a map of hardness in surface water at 345 stations in the major watersheds of the United States during 1976, with a histogram showing the number of stations in each hardnessconcentration range. Granato and others (2009) obtained 107,210 samples from 7,281 surface-water monitoring stations with paired streamflow and hardness concentrations from the USGS National Water Information System (NWIS). Concentrations in these streamflow samples ranged from 1 to $110,000 \mathrm{mg} / \mathrm{L}$ as $\mathrm{CaCO}_{3}$. The average hardness value for the 84 level III ecoregions in the conterminous United States ranged from 8.5 to 2,760 , with a median ecoregion value of about $222 \mathrm{mg} / \mathrm{L}$ as $\mathrm{CaCO}_{3}$. Water-quality transport curves, which are regression equations for predicting concentrations (or loads) from measured flow, developed from these data consistently indicated reductions in hardness with increasing streamflow. These analyses indicate that concentrations in groundwater sources would commonly be higher than indicated by these surface-water concentrations. DeSimone (2009) analyzed data for total hardness in 2,160 domestic wells in principal aquifers of the United States; only about 25 percent of these domestic-supply wells had concentrations less than or equal to $76.2 \mathrm{mg} / \mathrm{L}, 50$ percent had concentrations greater than or equal to $162 \mathrm{mg} / \mathrm{L}$, and 25 percent had concentrations greater than or equal to $267 \mathrm{mg} / \mathrm{L}$ as $\mathrm{CaCO}_{3}$. 
DeSimone (2009) indicated that hard and very hard water occurred in principal aquifers with rock types that are relatively soluble and that contain calcium- and magnesiumbearing minerals, such as some glacial, basaltic-rock, sandstone and carbonate-rock, and carbonate-rock aquifers.

Ion-exchange systems commonly adsorb calcium and magnesium (the primary components of hardness), iron, and manganese by replacing sodium ions on the ion-exchange media and then using sodium chloride (or potassium chloride) brine solutions to recharge the media with sodium. This process generates a brine solution containing chloride; the calcium, magnesium, iron, and manganese ions previously captured by the media; and excess sodium ions needed to recharge the media. This brine may be discharged to surface water or groundwater from a municipal wastewater-treatment plant or discharged to groundwater from a local septic system or dry well. In some areas the brine solution may be discharged to storm sewers or ditches on the land surface that may empty into local streams or be recharged to groundwater (Thomas, 2000). The U.S. Census Bureau (2011) indicates that about 75 percent of households used a municipal sewer system and 25 percent used onsite disposal in 1990. However, households with home treatment systems may not necessarily discharge softener backwash to the municipal sewer system (for example, Michigan Department of Environmental Quality, 2014). Nationally, estimated salt use for water treatment has been variable from year to year during the 1990-2010 period, with an average of about 1.22 million tons of salt, which represents about 2 percent of the annual consumption (Kelly and Matos, 2013). Some of the annual potash consumption includes the use of $\mathrm{KCl}$ for water softening, but Kelly and Matos (2013) do not categorize potash consumption. However, use of $\mathrm{KCl}$ is relatively limited because it has a lower hardness-removal capacity and is more expensive than $\mathrm{NaCl}$ (New Hampshire Department of Environmental Services, 2008; McEachern and others, 2009; Michigan Department of Environmental Quality, 2014).

The concentration and load of chloride from water softening depends on the local hardness, the amount of softening achieved, and the efficiency of the treatment systems. A water softener operating at theoretical 100-percent efficiency would remove 5,995 grains of hardness per pound of $\mathrm{NaCl}$, and it would remove a maximum of 4,708 grains of hardness per pound of $\mathrm{KCl}$ (Michaud, 2002a,b). The California State Legislature (2005) has specified that water softeners used in the State must meet allowable rated standards of efficiency: 2,850 grains of hardness per pound of $\mathrm{NaCl}$ before January 2000, 3,350 before January 2002, and 4,000 thereafter. However, the actual performance of a water softener is a function of the hardness of incoming water, the size of the system, the amount of salt used, the method (manual, time-based or flow-based), frequency of recharge (Michaud, 2002a,b; Harrison and Michaud, 2005; McEachern and others, 2009; Culligan International Company, 2012), and the age of the system (Michaud, 2002b). If a water softener is set on a timer, rather than on a flow-based measurement, it may commonly recharge the ion-exchange bed more frequently than needed. For example, Thomas (2000) indicated that the wastewater from resin-regeneration would have a chloride concentration of about $21,935 \mathrm{mg} / \mathrm{L}$ and would be composed of about 68 percent $\mathrm{NaCl}, 22$ percent $\mathrm{CaCl}_{2}$ and 10 percent $\mathrm{MgCl}_{2}$. In the absence of other $\mathrm{NaCl}$ sources in the wastewater stream, this concentration represents an efficiency of only about 577 grains of hardness per pound of $\mathrm{NaCl}$. Ionexchange beds are designed to remove all the hardness in the treated water; if some residual hardness is desired then some of the incoming water will bypass the unit and be mixed in downstream. An estimate of the chloride concentration in the average waste effluent (rather than the backwash volume) can be estimated as follows:

$$
C l=C F \times \frac{\left(H_{L}-H_{D}\right)}{E F_{e s t}},
$$

where

$$
\begin{aligned}
& \mathrm{Cl} \text { is the effective addition of chloride to the } \\
& \text { average wastewater composition in } \mathrm{mg} / \mathrm{L} \text {; } \\
& C F \text { is the conversion factor, which is } 4,245.7 \text { for } \\
& \mathrm{NaCl} \text { and 3,328.1 for } \mathrm{KCl} \text { salt; } \\
& H_{L} \quad \text { is the local hardness concentration in } \\
& \text { milligrams per liter as } \mathrm{CaCO}_{3} \text { (including } \\
& \text { the concentration of iron and manganese } \\
& \text { expressed as } \mathrm{CaCO}_{3} \text { ); } \\
& H_{D} \quad \text { is the desired hardness concentration in } \\
& \text { milligrams per liter as } \mathrm{CaCO}_{3} \text {; and } \\
& E F_{\text {est }} \quad \text { is the estimated operating efficiency factor of } \\
& \text { the water softener unit in grains of } \mathrm{CaCO}_{3} \\
& \text { per pound of salt. }
\end{aligned}
$$

If the exchange efficiency is $2,000,3,000$, or 4,000 grains per pound, about $2.2,1.4$, and $1.1 \mathrm{mg} / \mathrm{L}$ chloride, respectively, will be added to the wastewater stream for each milligram per liter of hardness that is detained in the ion-exchange bed between brine cycles.

Although these normalized concentrations seem small, the total softening load in a basin could be substantial. For example, if the hardness in an area is $162 \mathrm{mg} / \mathrm{L}$ as $\mathrm{CaCO}_{3}$ (the national median identified by DeSimone, 2009) and the target is $70 \mathrm{mg} / \mathrm{L}$ (Driscoll, 1986; Hem, 1992), then the hardness to be removed would be $92 \mathrm{mg} / \mathrm{L}$ as $\mathrm{CaCO}_{3}$. Assuming an efficiency of 2,000 grains per pound, the softening chloride concentration would be about $195 \mathrm{mg} / \mathrm{L}$. Kenny and others (2009) estimate that, nationally, the domestic self-supplied water use rate is $89 \mathrm{gal} / \mathrm{d}$ per person, the domestic publicsupplied water use rate is $99 \mathrm{gal} / \mathrm{d}$ per person, and the population-weighted average is $98 \mathrm{gal} / \mathrm{d}$ per person. Using the average rate of $89 \mathrm{gal} / \mathrm{d}$ per person, the annual load of chloride from water softening would be about $58 \mathrm{lb}$ per year $(\mathrm{lb} / \mathrm{yr})$ per person (fig. 9). If the utility or consumer does not use a bypass valve, then the full $162 \mathrm{mg} / \mathrm{L}$ would be detained by the softener and the annual load of chloride from water softening would be about $103 \mathrm{lb} / \mathrm{yr}$ per person. 


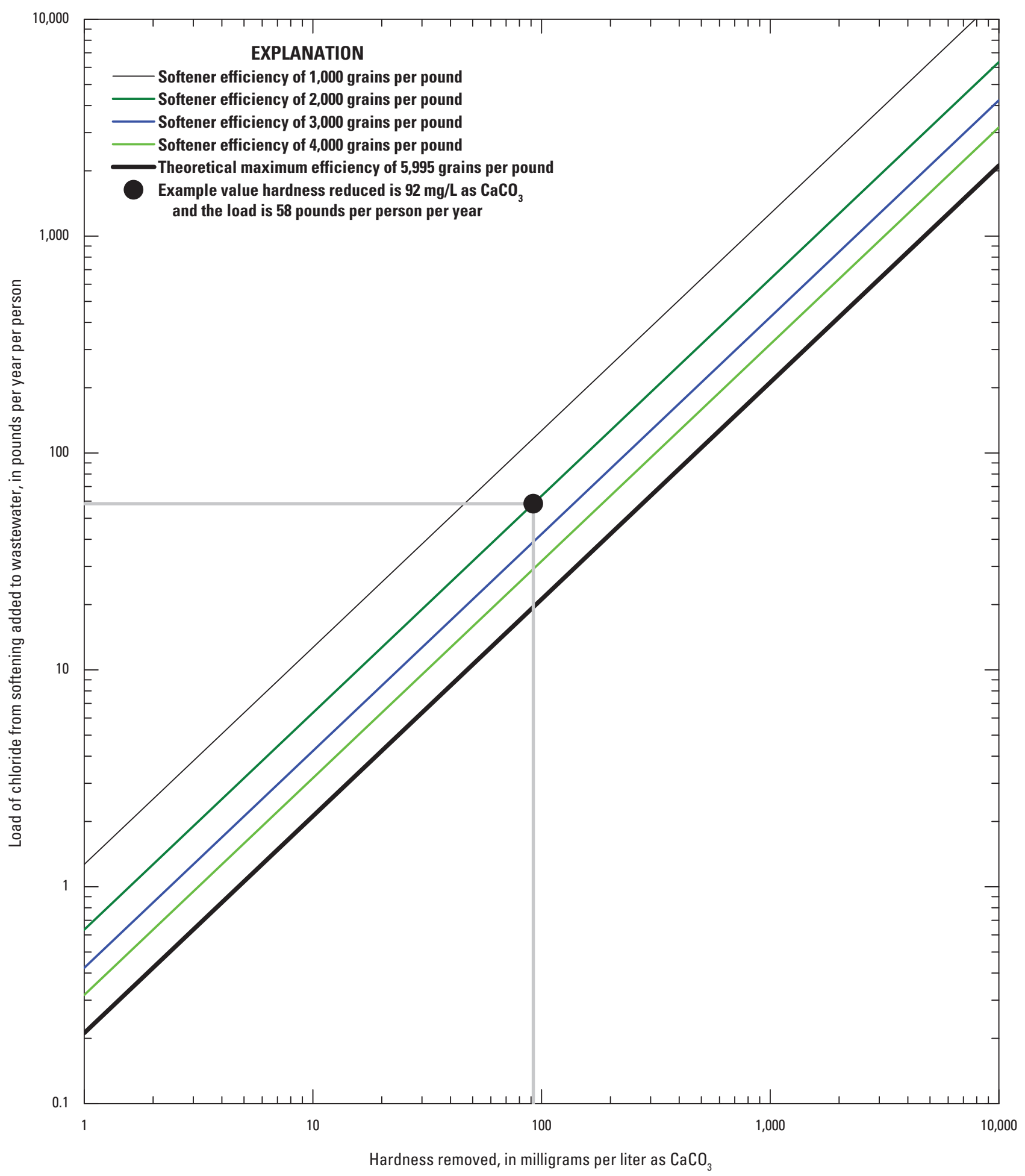

Figure 9. Annual load of chloride added to the wastewater stream from ion-exchange water softeners. The load is calculated by using the estimated national average of annual domestic water-use of 98 gallons per day per person (Kenny and others, 2009). $\mathrm{mg} / \mathrm{L}$, milligrams per liter. 
Salt-based ion-exchange systems also are being adopted to treat nitrate problems in water supplies (DeSilva, 2003). These systems also use an ion-exchange resin, but in this case, the resin is designed to adsorb the nitrate anion. The chloride in the brine is exchanged for the nitrate, which is flushed to waste during the brine cycle. Treatment of increasing nitrate problems from increased wastewater loads, animal waste, and nitrogen-based fertilizers (all of which also are sources of chloride) may increase the prevalence of salt-based nitratetreatment systems, which could accelerate the accumulation of chloride in a basin.

\section{Fertilizer}

Commercial fertilizers may be a substantial source of chloride in agriculture, and the application of fertilizers to turf in suburban and urban areas also may contribute to the total anthropogenic chloride load. Hamilton and Helsel (1995) noted that potassium and chloride from fertilizers was "significantly elevated" in groundwater beneath the agricultural areas in five regions of the United States. In a study of 10 rural lakes in rural Wisconsin, McGinley (2008) estimated that chloride from fertilizer was 22 to 77 percent of the annual loads to the lakes (with a median of 62 percent); chloride from residential wastewater was 0 to 40 percent (with a median of 7 percent); and chloride from road deicing was 0 to 18 percent (with a median of 0 percent). Similarly, Kraft and others (2008) examined groundwater quality in Wisconsin and found that increasing chloride concentrations were similar to nitrate concentrations and that both were associated with pesticide concentrations in groundwater. Kelly and others (2010) estimated that chloride from fertilizer was about 1.8 percent of the annual chloride load to the Illinois part of the Illinois River Basin. Fertilizer also may be a source of chloride to turf grass in suburban and urban areas; the Louisiana State University Agricultural Center (2007) indicates that turf grass may need 14 to 28 tons of potash per square mile per year. Carey and others (2013) did not look at the potential contribution of chloride from fertilizers, but they did note that average concentrations of total nitrogen, total phosphorus, and dissolved phosphorus in urban streams were 44, 95, and 122 percent greater, respectively, than in forested streams. Similarly, Dennehy and others (1998) documented elevated concentrations of nutrients and fertilizers in urban areas of the South Platte River Basin. In a statistical analysis of groundwater quality across the country, Lindsey and Rupert (2012) noted that a larger percentage of the urban land-use networks had increases in chloride and nitrate concentrations than the agricultural land-use networks they examined. Given the substantial amount of chloride in fertilizers, these fertilizers may be a substantial component in an urban chloride budget.

Chloride from fertilizer comes primarily from muriate of potash, a $\mathrm{KCl}$ mineral that is also known as sylvite (Armstrong and Griffin, 1998; Searls, 2000). The term "potash" also may refer to potassium sulfate (sulfate of potash), potassium magnesium sulfate (sulfate of potash magnesia), potassium magnesium chloride, and potassium nitrate (Armstrong and Griffin, 1998; Jasinski and others, 1999, Schulte and Kelling, 1999; Searls, 2000; Stone, 2009). Muriate of potash represents about 95 percent of potash used in the United States (Armstrong and Griffin, 1998; Jasinski and others, 1999, Searls, 2000; California Fertilizer Foundation, 2011). Potash is used as a source of soluble potassium and is, with fixed nitrogen and soluble phosphorus, one of the three primary plant nutrients (Armstrong and Griffin, 1998; Searls, 2000). About 81 percent of potash is used by agriculture; the remainder is used in oil-well-drilling mud, aluminum recycling processes, a steel heat-treating process, metal electroplating, snow and ice melting, and water softening (Searls, 2000). Nationally, potash use climbed sharply until about 1975 and has plateaued and varied with agricultural markets through 2011 (Kelly and Matos, 2013). On average, from 1990 through 2011, the amount of chloride in potash consumption was about 13 percent of the chloride in salt consumption and about 45.5 percent of chloride in deicingsalt consumption based on the data reported by (Kelly and Matos, 2013).

Potash is reported on the basis of its oxide $\left(\mathrm{K}_{2} \mathrm{O}\right)$ equivalent content (Armstrong and Griffin, 1998; Searls, 2000; North Carolina Department of Agriculture and Consumer Services, 2012; Kelly and Matos, 2013). Muriate of potash is expected to be greater than or equal to 95 percent pure $\mathrm{KCl}$ (Searls, 2000). Fertilizer is sold on the basis of the percentage of the three major components (nitrogen, phosphate, and potash as $\mathrm{K}_{2} \mathrm{O}$ ). As such, fertilizer labeled as 5-20-20 would be composed of 5-percent nitrogen, 20-percent phosphate, and 20-percent potash as $\mathrm{K}_{2} \mathrm{O}$. The proper mix depends on the soil and the crop (Bundy, 1985; Armstrong and Griffin, 1998; Schulte and Kelling, 1999; Fixen and others, 2006; California Fertilizer Foundation, 2011; National Agricultural Statistics Service, 2013). Stoichiometrically, the chloride content in muriate of potash reported as $\mathrm{K}_{2} \mathrm{O}$ is about 0.78 , but because muriate of potash is not 100-percent pure, a conversion of about 0.76 commonly is used to calculate chloride from the reported $\mathrm{K}_{2} \mathrm{O}$. If a combination of potash compounds is being used, this fraction would have to be adjusted accordingly.

Several methods may be used to estimate chloride from potash in an area of interest. Fertilizer application rates commonly are calculated from county-level sales data collected by the U.S. Department of Agriculture (for example, Battaglin and Goolsby, 1995; Searls, 2000; Ruddy and others, 2006; Kelly and others, 2010). Application rates also may be calculated on the basis of crop cover and likely amounts of fertilizer used for different crops (for example, Bundy, 1985; Louisiana State University Agricultural Center, 2007; National Agricultural Statistics Service, 2011, 2013).

Nationally, the mass of chloride used in fertilizer is comparable to the mass used in deicing salt; an assumption that all measured chloride is from deicing salt may be incorrect. The phosphorus and nitrogen associated with 
chloride from fertilizer may cause eutrophication at concentrations that are two or more orders of magnitude lower than the water-quality guidelines for chloride (Greene and others, 1994; Hamilton and Helsel, 1995; Harned and others, 1995; Mueller and Helsel, 1996; Stites and Kraft, 2001). Similarly, the pesticide and herbicide contamination associated with crop and turf management may cause adverse effects at concentrations that are more than four orders of magnitude lower than the water-quality guidelines for chloride (Greene and others, 1994; Harned and others, 1995; Munn and others, 2006; National Agricultural Statistics Service, 2011). In comparison, data from the National Agricultural Statistics Service (2011) indicate that pesticide applications may be on the order of 1 to 5 percent of fertilizer-chloride applications by mass.

\section{Animal Waste}

Animal waste may be a substantial source of nutrients, chloride and other constituents to surface water and groundwater in agricultural areas and may be a contributing source in suburban areas where homeowners keep horses and livestock (Gilbertson and others, 1981; Schepers and Francis, 1982; Bundy, 1985; Ruhl, 1999; Kellog, 2000; Krapac and others, 2000; Karr and others, 2001; Miller and others, 2004; Rodvang and others 2004; Israel and others, 2005, Panno and others, 2005, 2006; Toetz, 2006; Burkart and Stoner, 2007; McMahon and others, 2007; Kelly and others, 2010; Kelly and others, 2012; Castillo and others, 2013; U.S. Environmental Protection Agency, 2013c). Runoff or infiltration from animal holding areas can be a point source of contaminants. Discharge or leakage from animal-waste storage or treatment facilities also may be a point source of contaminants. Land spreading manure for fertilizer commonly creates a diffuse source of contaminants. Even use of land for grazing may increase chloride concentrations and loads in comparison to those from ungrazed lands because livestock are a source of chloride. For example, Schepers and Francis (1982) noted a 78-percent increase in chloride in runoff from grazing land with livestock in comparison to grazing land without livestock. The concentrations and potential effects of nutrients from manure have been the focus of most manure-related studies. Estimates of the ratio of chloride to total nitrogen in manure range from 3:1 to 17:1 according to data presented by Miller and others (2004), Zublena and others, (2012), and Wells (2014). These ratios may indicate the magnitude of the potential effect of manure on chloride concentrations and loads in areas without chloride data.

Care and maintenance of livestock is resource intensive. Kelly and Matos (2013) indicate that about 1.4 million short tons of chloride was consumed for use in agricultural animal feeds annually from 1990 through 2010, and about 1.3 million short tons of chloride was consumed for this purpose in 2005. Kenny and others (2009) estimate that 2,140 Mgal/d was used in 2005 for livestock operations, including livestock watering, cooling, and wash-down water. The U.S. Department of Agriculture reports manure production normalized to animal unit, which is the number of average animals whose live weight sums to $1,000 \mathrm{lb}$ (table 2; American Society of Agricultural and Biological Engineers, 2006; U.S. Department of Agriculture, 2009; U.S. Environmental Protection Agency, 2013c). In 2007 about 78 million animal units (AU) of cattle produced about 921 million short tons of manure; 9 million AU of swine produced about 921 million short tons of manure; and 6 million AU of poultry produced about 921 million short tons of manure (U.S. Department of Agriculture, 2009; U.S. Environmental Protection Agency, 2013c).

Estimates of chloride concentrations and loads are needed to assess animal waste as a source of chloride in an area of interest. An initial estimate for the chloride concentration in manure would be about $400 \mathrm{mg} / \mathrm{L}$, based on the water used for livestock operations (Kenny and others, 2009) and the salt consumed to make animal feeds (Kelly and Matos, 2013). However, Meyer and Inson (2007) indicate that livestock commonly receive most of their sodium and chloride from drinking water and excrete 68 to 87 percent of their daily consumption in manure. This concentration is estimated by assuming that the entire amount estimated by Kenny and others (2009) was used for watering livestock, that the water used was free of chloride, and that the salt added to the feed was the only source of chloride. Panno and others (2005) sampled horse and hog waste, indicating that the chloride concentrations in horse waste sample was $400 \mathrm{mg} / \mathrm{L}$ and that the concentrations in three hog waste samples ranged from 794 to 1,980 with a mean of $1,028 \mathrm{mg} / \mathrm{L}$. Similarly, Miller and others (2004) reported that the maximum chloride concentration in cattle-feedlot runoff, which should approximate the manure concentration, was $1,048 \mathrm{mg} / \mathrm{L}$. Data reported by Zublena and others (2012) indicates that dairy manure is about $1,650 \mathrm{mg} / \mathrm{L}$ and is diluted to 726 in liquid manure and $274 \mathrm{mg} / \mathrm{L}$ in lagoon sludge. Similarly, Ruhl (1999) indicates that chloride concentrations in waste lagoons are about $225 \mathrm{mg} / \mathrm{L}$. McQuillan (2007) indicates that dairy wastewater ranges from 200 to $1,000 \mathrm{mg} / \mathrm{L}$. Wells (2014) estimated that chloride concentrations in poultry manure are about $6,000 \mathrm{mg} / \mathrm{L}$. In arid areas, manures may have maximum chloride concentrations as high as 30,000 to $60,000 \mathrm{mg} / \mathrm{L}$ (University of Arizona Cooperative Extension, 1991). Although chloride concentrations in manure of other animals are not readily available, they may be estimated by using the nutrient requirements of different animals that are published by the National Research Council Committee on Animal Nutrition $(1994,2000,2001,2007 a, b, 2012)$ or by Berger and Cunha (2006). The specific gravity of manure is about 1.0 (Canessa and Hermanson, 1994; American Society of Agricultural and Biological Engineers, 2006; U.S. Environmental Protection Agency, 2013c); the volume of manure produced per animal can be calculated from data and information on the tonnage of manure produced. The U.S. Department of Agriculture (2009, 2014b,c) census of agriculture provides information on animal populations and 
Table 2. Normalized manure generation, by livestock type.

[An animal unit (AU) is the normalized mass of 1,000 pounds of live animal(s). USDA, U.S. Department of Agriculture; -- not documented]

\begin{tabular}{|c|c|c|c|c|}
\hline \multirow[b]{2}{*}{ Animal type } & \multicolumn{2}{|c|}{ USDA (2009) } & \multicolumn{2}{|c|}{ Canessa and Hermanson (1994) } \\
\hline & Animals per AU & $\begin{array}{c}\text { Manure generation, } \\
\text { in tons per year per AU }\end{array}$ & Animals per AU & $\begin{array}{l}\text { Manure generation, } \\
\text { in tons per year per AU }\end{array}$ \\
\hline Beef cattle & 1. & 11.5 & 1. & 11.3 \\
\hline Beef stocker & -- & -- & 2. & 10.6 \\
\hline Dairy cows & 0.74 & 15.24 & 0.71 & 15.7 \\
\hline Heifers and dairy calves & 1.82 & 12.05 & 1. & 15.7 \\
\hline Steers, calves, and bulls & 1.64 & 10.59 & 1. & 11.5 \\
\hline Horses & -- & -- & 1. & 9.3 \\
\hline \multicolumn{5}{|l|}{ Swine } \\
\hline Swine, breeders & 2.67 & 6.11 & 3.6 & 7.7 \\
\hline Swine, market & 9.09 & 14.69 & 6.7 & 15.3 \\
\hline Sheep & -- & -- & 10. & 7.3 \\
\hline \multicolumn{5}{|l|}{ Poultry } \\
\hline Chickens, layers & 250. & 11.45 & 250. & 11.75 \\
\hline Chickens, broilers & 455. & 14.97 & 500. & 15.5 \\
\hline Turkeys, for slaughter & 67. & 8.18 & -- & -- \\
\hline Turkeys, hens for breeding & 50. & 8.18 & -- & -- \\
\hline
\end{tabular}

manure production that may be used to estimate chloride loads. For example, Battaglin and Goolsby (1995), Kellog and others (2000), and Ruddy and others (2006) used such data to produce estimates of nutrient inputs to the land surface from manure. McMahon and others (2007) estimate loads of nutrients in wastewater from livestock facilities that have NPDES permits. This method is useful if chloride data are included in the permits.

\section{Irrigation}

Irrigation, which is the diversion of surface water or groundwater to foster plant growth, is a source of increasing chloride concentrations and (or) loads because evapotranspiration concentrates chloride in the waters that are diverted. Irrigation is anthropogenic intensification of the evaporative-concentration mechanisms discussed in the section "Evaporative Concentrations"; that information also may be useful for examining irrigation as a source of elevated chloride concentrations at a site of interest. Also, natural rates of chloride release to groundwaters and surface waters from rock weathering of evaporites can be increased by irrigation in arid basins, through enhanced dissolution of evaporite minerals in the unsaturated zone by excess irrigation water (Ghassemi and others, 1995). If irrigation water is from a within-basin source, concentrations will increase, but because of water losses the loads will not necessarily increase. If, however, water is imported for irrigation, then it is likely (unless the imported water has much lower chloride concentrations than the local water) that concentrations and loads will increase. Irrigation also has other potential adverse effects on water quality because intentional or unintentional excess irrigation waters are likely to carry nutrients, herbicides, and pesticides through the vadose zone and into tile drains or the underlying groundwater (Saffigna and Keeney, 1977; Ritter and others, 1993; Stites and Kraft, 2001; Seiler and others, 2003; Burkart and Stoner, 2007; Carey and others, 2013). As with potash fertilizer, misattribution of chloride from irrigation to deicing chemicals may preclude more detailed investigations, which may reveal presence of other chemicals with more adverse effects than chloride.

Kenny and others (2009) define irrigation as water that is used to sustain plant growth, provide frost protection, apply chemicals, control weeds, prepare fields, cool crops, harvest crops, suppress dust, and leach salts from the root zone. They also include water lost in conveyance as part of 
the irrigation totals. In 2005, total irrigation withdrawals were about 128,000 Mgal/d and represented 62 percent of water use for non-thermoelectric cooling (Kenny and others, 2009). About 85 percent of these irrigation withdrawals occurred in 17 conterminous Western States, but a substantial amount of water was used for irrigation in all 50 States (Kenny and others, 2009). In suburban and urban areas, irrigation commonly is used for lawns, golf courses, parks, nurseries, cemeteries, and other landscaped areas (Bent and others, 2009; Ivahnenko, 2009; Johnson and Belitz, 2012). Irrigation for crops, turf, and urban and suburban green spaces can be large, even in the humid East and Northeast (Fanning and others, 2001; Satti and others, 2004; Bent and others, 2009; Levin and Zarriello, 2013). Agricultural irrigation volumes in an area of interest may be estimated by using databases developed by the U.S. Department of Agriculture (2010, 2014a) that indicate the location and magnitude of agricultural irrigation in the United States.

Leaching is needed in all irrigated areas to prevent excessive salts, caused by the evapotranspiration of irrigation water, from accumulating in the root zone (Canessa and Hermanson, 1994; Natural Resources Conservation Service, 2001). In the more humid areas, natural precipitation that occurs between dry periods commonly is sufficient to prevent long-term salinization of soils. In semi-arid and arid areas, however, excess irrigation volumes are needed to leach dissolved solids from the root zone so that evapotranspiration does not salinize topsoils (Rhoads, 1992; Canessa and Hermanson, 1994; Konikow and Person, 1985; Natural Resources Conservation Service, 2001). In these areas the excess irrigation that is needed is calculated by using the salinity of the irrigation water and the sensitivity of the plants being irrigated (Rhoads, 1992; Natural Resources Conservation Service, 2001).

Chloride concentrations can increase spatially and temporally as irrigation water and the solutes are carried down the stream and (or) the groundwater gradient as chloride accumulates along the flow path (Konikow and Person, 1985; Hudak, 2000; Steele and Aitkenhead-Peterson, 2011; Moyer and others, 2013). Because chloride enrichment depends on local water quality, imported water quality, irrigation volumes, and evapotranspiration rates, the potential effects of irrigation may be difficult to establish without data. NWIS (http://waterdata.usgs.gov/nwis) provides ready access to millions of water-quality analyses from almost 400,000 sites nationwide (U.S. Geological Survey, 2014b) and so may be a source of data for evaluating irrigation as a source. Measurement and modeling of all parts of an irrigated streamaquifer system is necessary to define the problem because the cycle of irrigation, consumptive use, deep percolation, and return flow from surface drainage, tile drains, and groundwater discharge increases salinity slowly over many years as chloride moves from irrigation water, through the soil, and into surface water and groundwater (Konikow and Person, 1985; Crandall, 2000).

\section{Aquaculture}

Aquaculture may be a substantial source of chloride in areas that receive discharges from Aquaculture to surfacewater or groundwater resources. The U.S. Environmental Protection Agency (2012a, 2014b) maintains geographical and discharge information about aquaculture facilities that are subject to NPDES regulations. Aquaculture production primarily occurs in ponds and flow-through raceways and less commonly in closed-recirculation tanks (Kenny and others 2009; Lovelace, 2009). In these systems it is necessary to use controlled feeding, sanitation, and harvesting procedures. Even small increases in chloride concentrations may result in large loads because aquaculture operations use large volumes of water. Nationally, Kenny and others (2009) estimated that about $8,780 \mathrm{Mgal} / \mathrm{d}$ was being used for aquaculture and that about 78 percent of this water was from surface-water sources. This water-use volume is minor on a national scale, but such operations can be the major water use in some areas (Swann, 1992; Kidd and Lambeth, 1995; U.S. Environmental Protection Agency, 2004; Lovelace, 2009; Swann, 2014). For example, Swann (2014) indicates that a minimum rate of 13 gallons per minute per acre is commonly used for ponds and that flow rates of about $500 \mathrm{gal} / \mathrm{min}$ are used for raceways. Water requirements for single-pass raceways can be as high as 30,000 to 42,000 gallons per pound of fish produced (U.S. Environmental Protection Agency, 2004). Swann (2014) indicates that recirculating systems also may withdraw and release large volumes of water and estimates that a small, 100,000-gal-capacity water recirculating operation could release $10,000 \mathrm{gal} / \mathrm{d}$. Chloride is added to the water and waste stream for water treatment and disinfection. In some cases, groundwater with chloride concentration in excess of surface waters may be used and discharged, For example, Kidd and Lambeth (1995) indicate that fish farmers can use waters with high salinity (up to $500 \mathrm{mg} / \mathrm{L}$ ) and may add sodium chloride to fish ponds to control or prevent fish disease. Data from the census of aquaculture can provide information about the types of operations and the source of process water in different areas (U.S. Department of Agriculture, 2014d).

Increasingly, aquaculture operations are incorporating disinfection practices (Boyd, 2008; Yanong and Erlacher-Reid, 2012; Hill and others, 2013). Failure to control predators, parasites, pathogens, and fungi in water and equipment may lead to reduced productivity or, in some cases, mandatory depopulation of an entire facility. High doses of chlorine commonly are used to disinfect surface-water supplies, water in recirculating systems, and effluent to be discharged to receiving waters (Yanong and Erlacher-Reid, 2012). High doses also are used to disinfect facilities, equipment, and holding ponds (Boyd, 2008; Yanong and Erlacher-Reid, 2012; Hill and others, 2013; El Gamal, 2014). These doses commonly are on the order of 20 to $50 \mathrm{mg} / \mathrm{L}$ chloride to achieve the minimum-residual dose (Boyd, 2008; Hill and others, 2013; El Gamal, 2014). However, residual chlorine is toxic to fish, so it must be removed by processes such as 
aeration, the use of chemicals such as sodium thiosulfate, or, less commonly, filtration through activated charcoal (Bills and others, 1993; Buttner and others, 1993; Boyd, 2008; Hill and others, 2013; El Gamal, 2014). Use of chlorine and other chloride-containing disinfectants results in increased chloride concentrations in the water or waste stream discharged to surface waters or groundwaters.

Other chloride-containing compounds may be used to treat inflows, process waters, and wastewaters. For example, use of aluminum chloride or ferric chloride for coagulationflocculation of suspended solids and associated nutrients may add a residual of about $40 \mathrm{mg} / \mathrm{L}$ chloride to recycled water or effluent (Ebeling and others, 2004). Chloride also is added to process waters in ratios of about 6 parts chloride to 1 part nitrogen to counteract ammonia or nitrite toxicity (Swann, 1992; Boyd, 1998).

\section{Energy Production}

More than 4 million oil and gas wells have been drilled in the United States over the past 150 years (fig. 10) (Susong and others, 2012). Salt is an important component of drilling fluids used in the oil and gas industries (Kostick, 1993). The mined salt used by the petroleum industry increased from about 550,000 short tons in 1990 to $2,767,000$ short tons in 2011; these values represent chloride loads equal to 325,000 and 1,632,000 short tons, respectively (Kelly and Matos, 2013). During this period the salt consumed by the petroleum industry increased from about 1 to 5 percent of annual salt consumption in the United States (Kelly and Matos, 2013). The production of oil and gas also is accompanied by production of large volumes of saline formation water (brine or produced water). Brines extracted from deep geologic formations are defined as fluids having total dissolved solids (TDS) concentrations greater than 350,000 mg/L (Kalkhoff, 1993), and these brine concentrations can exceed $450,000 \mathrm{mg} / \mathrm{L}$ in some parts of the United States (Otton, 2006). Chloride concentrations in oil-field brines have been reported as being in the range from 10,000 to $200,000 \mathrm{mg} / \mathrm{L}$ (Kharaka and others, 2005; Li and others, 2006; Whittemore, 2007; Barbot and others, 2013). The amount of brine produced along with oil and gas varies widely and is at least 2 parts brine to 1 part oil in conventional oil wells (Gleason and Tangen, 2014). However, much higher ratios (up to 20 to 1 ) have been reported, and the fraction of

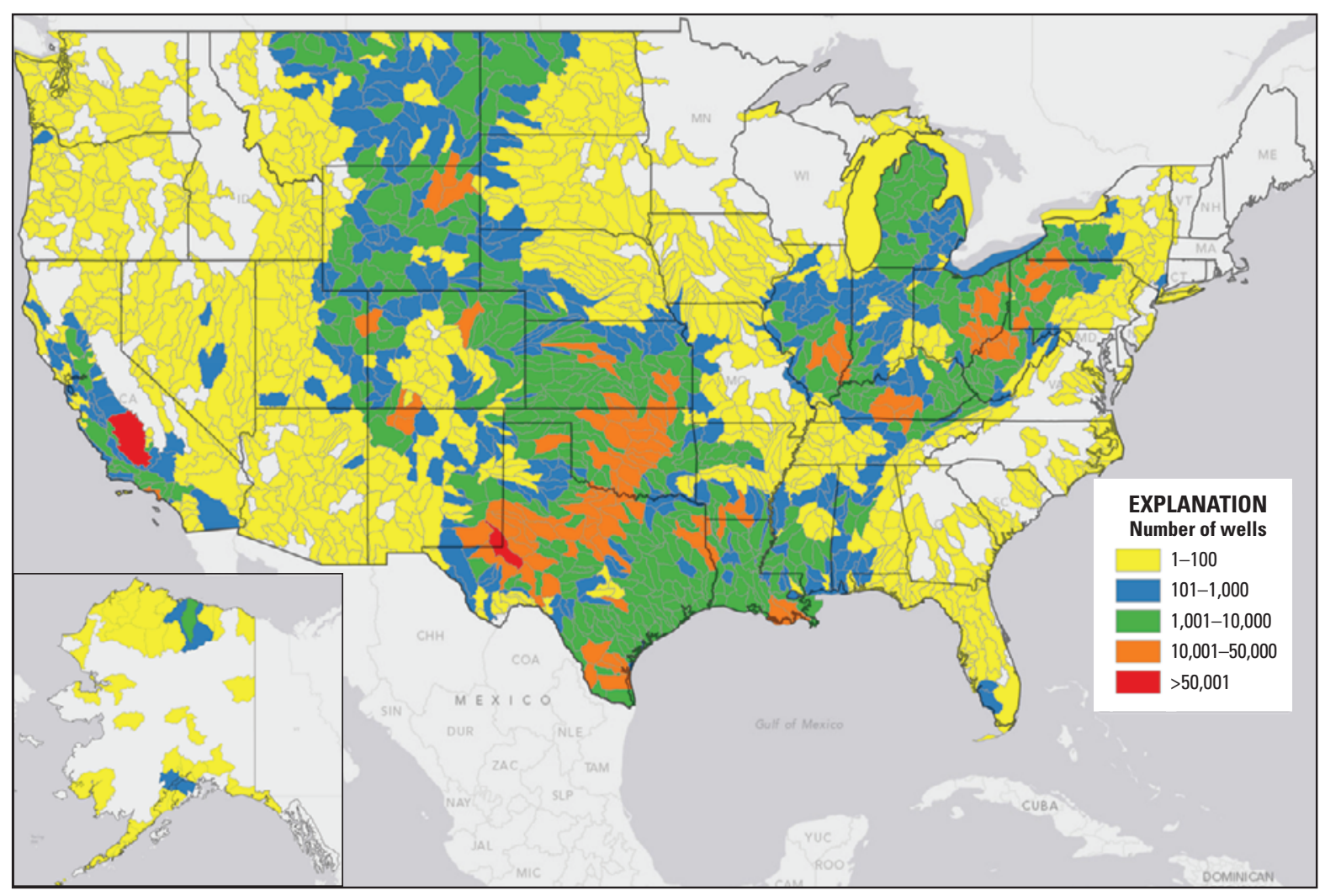

Figure 10. Number of oil- and gas-related wells in the United States by eight-digit hydrologic unit code. Modified from Susong and others (2012). 
brine generally increases as the amount of recoverable oil or gas declines. Wanty (1997) estimated that for each barrel of crude oil produced, approximately 10 barrels of water are also produced. The total national volume of produced water from conventional oil and gas production was estimated to be approximately 21 billion barrels in 2007 (Clark and Veil, 2009). If an average of $50,000 \mathrm{mg} / \mathrm{L}$ chloride (Whittemore, 2007) is representative of chloride in this water, the chloride load from this volume would be about seven times greater than the apparent consumption of chloride in salt consumed within the United States in 2007 (Kelly and Matos, 2013). Produced water is the largest byproduct by volume of oil and gas exploration and production. In 2007, Texas, California, Wyoming, Oklahoma, and Kansas accounted for 75 percent of the total volume of produced water (Clark and Veil, 2009). Much of this water may be reinjected for deep-well disposal, but some may be dispersed to the environment by discharge to surface water, stored in surface impoundments, used for irrigation, or spread on roads (Wilson and Van Briesen, 2012; Hladik and others, 2014). For example, the New York State Department of Environmental Conservation (Lynch, 2010) and the Pennsylvania Department of Environmental Protection (2013) consider the use of such brines for dust control and road stabilization on unpaved roads to be a "beneficial use." Similarly, the Michigan Department of Environmental Quality allows use of oil-field brines for ice and dust control and for soil and road stabilization (Janiczek, 2005).

The handling and disposal of brine from older oil and gas fields has resulted in legacy contamination of water resources (groundwater and surface water) throughout the United States. Historically brines were disposed into deep geologic units by use of disposal wells, or brines were discharged directly into surface waters or unlined evaporation pits (Gorman, 1999; Gleason and others, 2011). These disposal methods led to surface scarring and groundwater and surface-water contamination with highly saline water in many parts of the United States (Pettyjohn, 1971; Kalkhoff, 1982; Thamke and Craigg, 1997; Suro, 1992; Hudak, 2003; Kharaka and others, 2005; Otton, 2006; Paine and others, 2007; Rice and others, 2007; Gleason and Tangen, 2014; Sando and others, 2014). In many areas, chloride contamination from past disposal practices has persisted for decades (Gorman, 1999). For example, Petronila Creek, a small stream on the Texas coastal plain, contains elevated TDS (up to $15,100 \mathrm{mg} / \mathrm{L}$ ), chloride, and sulfate concentrations caused mainly by past discharge of oil-field brine into ditches and pits (Paine and others, 2007; Shipley, 1991). Significant oil and gas exploration and production took place in the area between 1935 and 1982. Production attributed to the Clara Driscoll and North Clara Driscoll oil fields totaled 19.7 million barrels between 1935 and 1982. The amount of formation brine that accompanied oil production is unknown but probably equaled or exceeded the volume of produced oil. The salinity of the formation brines in the area is high; chloride concentrations of 36,500 to $55,700 \mathrm{mg} / \mathrm{L}$ were reported for the produced brines (Shipley, 1991). The Railroad Commission of Texas prohibited the disposal of brine to ditches and streams in 1987, but past disposal practices into ditches and pits have produced extensive subsurface salinization zones that appear to provide a continuing source of salinity to the stream (Paine and others, 2007). Other examples of persistent salt contamination resulting from oil and gas production are provided by Gleason and others (2011), Kharaka and others (2005), and Kalkhoff (1982). Thus chloride loads in groundwater discharging to streams may be a source of chloride in much of the country, including many areas where deicing chemicals are used (fig. 10).

Abandoned oil and gas wells that are not plugged properly can also be conduits by which brine can reach the surface or contaminate shallow freshwater aquifers (Gorman, 1999; Suro, 1992). Produced brines were often forcefully reinjected into inactive wells for disposal and to improve recovery in nearby active wells. If not plugged properly, pressurized brine can migrate upward and become a long-term source of contamination from salinity, radioactivity, and heavy metals. The EPA estimated that there are approximately 1.2 million abandoned wells in the United States, of which about 200,000 are not properly plugged (Suro, 1992). In the 1960s and 70s, increasing recognition of the adverse effects of past brine disposal practices on water resources led to enactment of Federal and State regulations to limit or prohibit disposal to unlined pits, surface waters, and abandoned wells; to improve procedures for abandoning wells; and to improve design standards and monitoring requirements for new injection wells (Gorman, 1999). Nonetheless, risks to water resources from brines coproduced with oil and gas remain. Possible surface and subsurface sources of contamination from modern exploration and production operations include leaks or unintentional releases from aboveground storage tanks or holding ponds, drilling-fluid migration prior to casing installation, failed casing seals, induced subsurface migration pathways, and transportation-related releases such as breaks in pipelines (Gleason and Tangen, 2014; Susong and others, 2012).

Unconventional shale gas and shale oil production, in which hydraulic fracturing techniques are used to improve recovery volumes, has increased greatly in recent years. Between 2000 and 2010, shale gas increased from 2 to 23 percent of United States gas production (U.S. Department of Energy, Energy Information Administration, 2011, 2012a,b). Nationally, twenty shale gas and shale oil deposits have been discovered in the lower 48 States as of 2012 (fig. 11; Susong and others, 2012; U.S. Department of Energy, Energy Information Administration, 2011). The total volume of technically recoverable gas from these shale deposits is estimated to be 750 trillion cubic feet (tcf), of which 63 percent is in the Northeast (55 percent [ $410 \mathrm{tcf}$ ] in the Marcellus Shale alone), 13 percent is in the Gulf Coast, 8 percent is in the Mid-Continent, 10 percent is in the Southwest, and 6 percent is in the Rocky Mountain region (U.S. Department of Energy, Energy Information Administration, 2011). Shale oil resources from a subset of these deposits are estimated to total 24 billion barrels. 


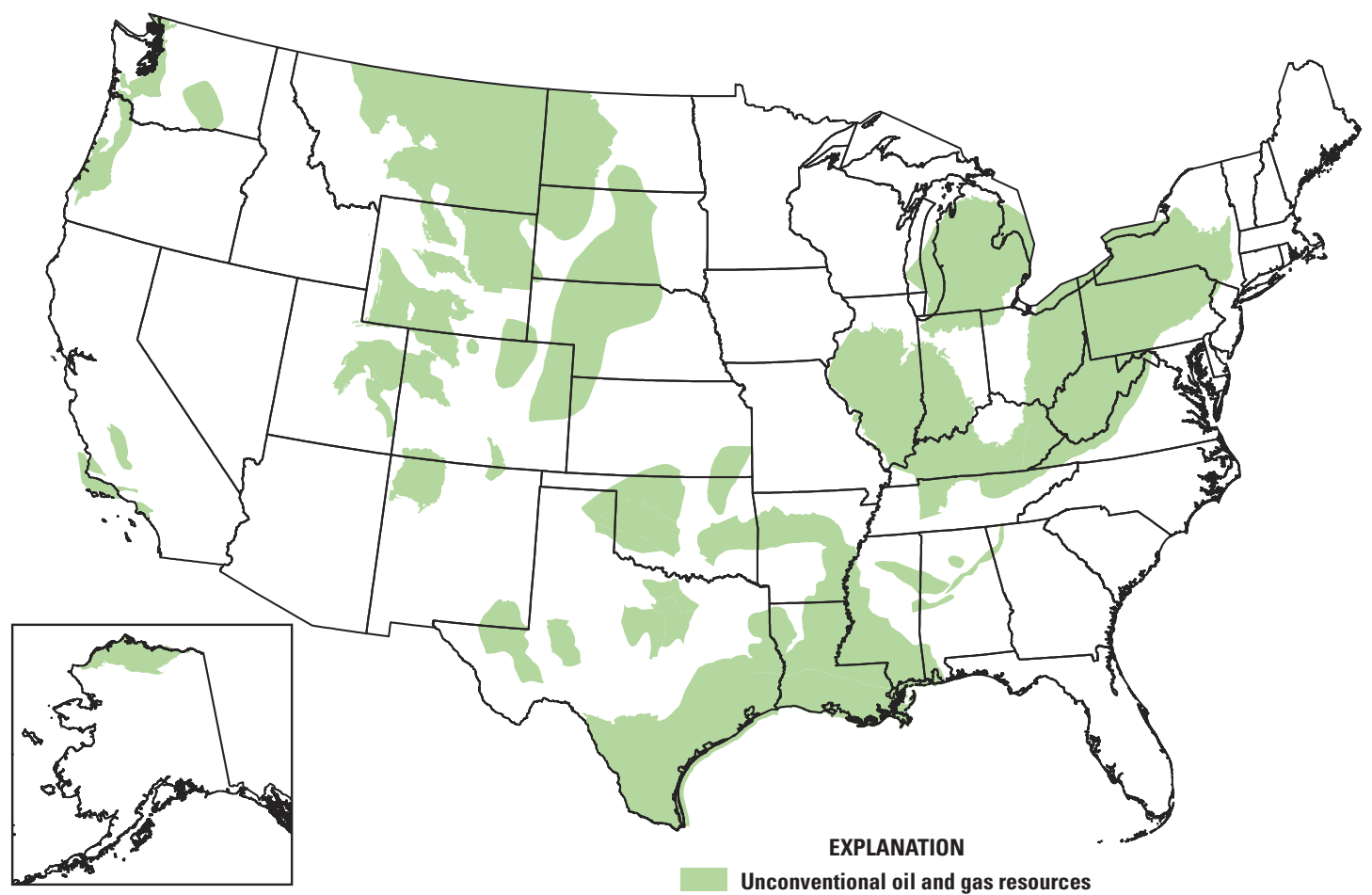

Figure 11. Major areas of unconventional oil and gas development in the United States. Modified from Susong and others (2012).

Wastewater generated from shale wells consists of drilling fluids, flowback water, and brine (Lutz and others, 2013). Drilling fluid refers to the water and additives used to cool and lubricate the drill head and remove drill cuttings. Because wells are relatively deep and directional drilling is used, substantial volumes of drilling fluid can be used during well construction. Flowback water refers to the so-called frac fluid that is returned to the surface during the initial period (typically shorter than 4 weeks) of gas or oil recovery. In contrast to conventional oil and gas production, shale wells need to be hydraulically fractured and require large volumes of frac fluid to be injected into the well. Hydraulic fracturing requires approximately 3 to $5 \mathrm{Mgal}$ of fluid per well (U.S. Department of Energy, 2009). Typically about 10 to 70 percent of the frac fluid returns to the surface as flowback water (American Petroleum Institute, 2010). Formation brines originating within and around the shale deposits are also recovered, along with drilling and flowback waters, over the lifetime of the well, and these brines constitute the largest fraction of total wastewater volume extracted from Marcellus wells (Lutz and others, 2013). All three sources of wastewater can contain high concentrations of TDS and chloride. For example, brines in western Pennsylvania contain up to $207,000 \mathrm{mg} / \mathrm{L}$ chloride (Dresel and Rose, 2010). Thus the chloride load in flowback water from each well may range from 13 tons per year (assuming the lower production volume, the lowest return percentage, and lowest brine concentration of $10,000 \mathrm{mg} / \mathrm{L}$ from Whittemore, 2007) to more than 3,000 tons per year (assuming the lower production volume, the return percentage, and the brine concentration of $207,000 \mathrm{mg} / \mathrm{L}$ from Dresel and Rose, 2010). A median load estimate for each well based on these numbers would be about 1,500 short tons per year of chloride.

Because of the potential growth of shale gas and oil development, the management and disposal of saline wastewater from shale wells presents a major challenge to the oil and gas industry and regulatory community. This is particularly true for development of the Marcellus Shale because of the size of the resource. For example, Lutz and others (2013) estimate that development of the Marcellus Shale in Pennsylvania and West Virginia has increased the total amount of wastewater in the region by 570 percent since 2004, despite the production of less wastewater per unit of gas recovered. Marcellus wells produced about 10 times more wastewater than conventional wells, but the large increase in the total volume of wastewater results largely from the massive size of the Marcellus Shale and the exponential increase in the number of new Marcellus wells drilled over the past 5 years. The U.S. Department of Energy's Energy Information Administration (2011) estimated that, as of 
2009 , only 1 to 3 percent of the technically recoverable shale gas in the United States had been produced. The size of the remaining recoverable gas resources indicates that large volumes of wastewater will continue to be generated in the future. Because the effective lifespan of shale gas wells is relatively short (on the order of 4 years), many new wells will be needed to maintain market-driven production levels (U.S. Department of Energy, Energy Information Administration, 2011). Disposal via reinjection into deep geologic formations is limited by unfavorable geologic conditions in some parts of the country, such as the area around the Marcellus Shale, creating the need for alternative disposal methods for highly saline wastewaters.

Mining and use of coal energy also may be a source of chloride to surface water and groundwater in many areas of the country. The U.S. Department of Energy, Energy Information Administration $(2012 b, c)$ indicates that coal production increased from about 500 million short tons per year in the 1940s to about 1.06 billion short tons per year in 1990 and averaged about 1.15 billion short tons per year from 2000 through 2011 . The chloride content of dry coal varies widely from trace amounts to more than $5,000 \mathrm{ppm}$; a value of about $1,000 \mathrm{ppm}$ dry coal is commonly considered to be a representative value (Raask 1985; Chriswell and O'Donnell, 1996; McCulloch and others, 1999; Tewalt and others, 2010; Kolker and others, 2012; East and Matthias, 2013). Thus annual chloride mobilization from coal production is expected to be about 1.15 million short tons per year from 2000 through 2011, which is about 3 percent of the chloride in the salt produced each year during this period (Kelly and Matos, 2013). McCulloch and others (1999) estimated that about 873 million short tons of coal was burned in the United States in 1990; this burning released about 619,000 short tons of chloride to the atmosphere and about 187,000 short tons of chloride to liquid or solid waste. In theory, chloride data from the NADP should account for chloride from emissions to the atmosphere, but data from this national network may not detect many point sources. During the past 20 years the proportion of atmospheric emissions of chloride has been reduced by exhaust scrubbing and coal washing, which would increase the proportion discharged as liquid or solid waste (Chriswell and O'Donnell, 1996; McCulloch and others, 1999). However, methods that may be used to wash and treat coal may utilize sodium chloride or potassium chloride to reduce the effects of sulfur, chloride, and mercury emissions (Dondelewski, 1977; Raask 1985; Simpson, 1986; Chriswell and O'Donnell, 1996; Kolker and others, 2012).

\section{Landfills, Incineration, and Composting}

Disposal of industrial, municipal, and construction and demolition waste to landfills, incineration, and compost can contribute chloride to the atmosphere, surface waters, and groundwaters. Kostick (1993) estimated that about 11 billion short tons of waste was generated annually in the United
States and that about 196 million short tons was municipal solid waste. He indicated that about 67 percent was sent to landfills, 17 percent was recycled or composted, and 16 percent was incinerated. Kostick (1993) indicated that 10.3 million short tons of salt (about million 6.25 short tons of chloride) produced in 1990 would eventually be disposed to compost, landfill, or incineration; this amount represents about 23 percent of the total reported consumption during the year. Kostick (1993) segregated this amount from the estimated 34.76 million short tons directly dispersed to the environment. The EPA estimated that 208.27 million short tons of municipal solid waste was generated in 1990 (U.S. Environmental Protection Agency, 2014a); 14 percent of this municipal waste was recycled, 2 percent was composted, 14.2 was incinerated, and 69.8 percent was sent to landfills. The EPA also estimated that 250.42 million short tons of municipal solid waste was generated in 2010 (U.S. Environmental Protection Agency, 2014a); 25.9 percent of this municipal waste was recycled, 8.1 percent was composted, 11.7 percent was incinerated, and 53.8 percent was sent to landfills. Although Kostick (1993) did not include the solid waste stream in the totals that were dispersed to the environment, some portion of this waste was likely released.

Incineration of waste produces hydrochloric acid $(\mathrm{HCl})$ that may be released to the atmosphere, discharged as wastewater to surface water or groundwater from wet exhaust scrubbing processes, or captured and landfilled by dry exhaust scrubbing processes (Uchida and others, 1988; DesrochesDucarne and others, 1998; McCulloch and others, 1999; Guo and others, 2000; Mussatti, 2002). McCulloch and others (1999) indicated that about 117,000 short tons of chloride was released from municipal-waste-burning plants to the atmosphere within or near population centers in the United States in 1990 and that this chloride would be deposited in close proximity to the source. Such sources may not be identified by the relatively sparse NADP monitoring network, so local data or local estimates may be needed to augment NADP-based estimates.

Landfill and compost-pile sites are point sources of water and other constituents in the watershed. If runoff from such sites is a problem, the sites may appear as local point sources. If leakage to groundwater is a problem, contaminant plumes may enter surface-water bodies as a diffuse source of constituents. The quantity and quality of leachate leaking into surface waters and groundwaters at a given site depend on many factors, including the age of the waste and site, site design, the use of safeguards such as liners, the degree of waste compaction, climate variability, and the characteristics of the waste or composted materials (Renou and others, 2008; Carey and others, 2013). Leaky landfills or compost facilities may be a long-term source of chloride and other constituents to aquifers and streams because of long groundwater travel times (Mullaney and others, 2009). Haarstad and Mæhlum (2007) estimate that about $0.1-0.7$ percent of the mass of municipal solid waste is chloride and that about 40 percent of this chloride is leachable. Landfill and compost pile 
leachates commonly have high concentrations of chloride. In the literature, chloride concentrations in landfill leachates range from about 130 to $100,000 \mathrm{mg} / \mathrm{L}$ and are commonly reported as being greater than $1,000 \mathrm{mg} / \mathrm{L}$ (El-Fadel and others, 1997; Kjeldsen and others, 2002; Svensson and others, 2005; Panno and others, 2005, 2006; Haarstad and Mæhlum, 2007; Kulikowska and Klimiuk, 2008; Loncnar and others, 2010; Varank and others, 2011). In comparison, chloride concentrations in leachate from compost piles may range from about $50 \mathrm{mg} / \mathrm{L}$ to about 3,700 $\mathrm{mg} / \mathrm{L}$ (E\&A Environmental Consultants, 1998; Krogmann and Woyczechowski, 2000; Marques and Hogland, 2001; Oregon Department of Environmental Quality, 2007). Leachates may have high chloride concentrations, but depending on the age, design, and maintenance of the composting system or landfill site, these facilities may be sources of a small proportion of total chloride loads in some basins. However, if measured chlorides are misattributed to deicing chemical use, then the adverse effects caused by leachates may be overlooked because leachate also contains many constituents such as arsenic, biological and chemical oxygen demand, cyanide, nutrients, pharmaceutical compounds, and many anthropogenic organic compounds that may be endocrine disruptors, toxic, mutagenic, or have other adverse effects at very low concentrations (Kimmel and Braids, 1974; U.S. Environmental Protection Agency, 1995; El-Fadel and others, 1997; Kjeldsen and others, 2002; Svensson and others, 2005; Panno and others, 2006; Kulikowska and Klimiuk, 2008; Buszka and others, 2009; Canton and others 2010; Loncnar and others, 2010; Ford and others, 2011; Varank and others, 2011).

\section{Constructing a Chloride Budget for a Watershed}

The magnitudes of the various water-budget components depend on the physical characteristics of the watershed, climatic conditions such as the temporal and spatial distribution of precipitation and evapotranspiration, and the extent of alteration by human activity (Healy and others, 2007; Stanton and others, 2011). To develop a chloride budget for a watershed, the water budget and sources of chloride in the basin need to be determined. Water and solute budgets constructed from literature values and available hydrologic data may provide initial planning-level estimates of concentrations and loads of chloride at a site of interest. Such estimates may be refined by using local values if necessary. In this section, watershed characteristics, waterbudget components, and methods for using this information to build a chloride budget are described. The USGS has done many water-budget studies, groundwater and surface-water modeling studies, and hydrologic mapping studies that provide water budgets or provide the information and data needed to construct these budgets in an area of interest. The results of these studies are available through the USGS Publications Warehouse (http://pubs.usgs.gov/).

Water budgets are a way to quantify the flux of water in a basin and account for all the water exchanged into and out of a control volume of any spatial scale, such as a stream, aquifer, wetland, lake, agricultural field, groundwater-supply well capture zone, or watershed. In the hydrological cycle, water moves from the atmosphere to the land surface as precipitation, infiltrates the subsurface, flows along the land surface to water bodies such as the ocean, and eventually returns to the atmosphere by evaporation (Healy and others, 2007). The changing storage and flux of the water budget in a hydrological system also becomes a natural source and carrier of water-quality constituents, such as chloride, through the environment. If the inputs, outputs, and recycling of water throughout the budget are known (or can be reliably estimated), then chloride loads and concentrations can be traced as the chloride ions move through the cycle with the water. Knowledge of the combined movement of water and chloride concentrations can help in distinguishing between natural and anthropogenic sources of constituents, helping to effectively manage the landscape.

\section{Watershed Characterization}

The physical characteristics of a watershed, such as soil properties, topographic relief, and land cover, determine its hydrologic response to precipitation events. These characteristics generally determine the apportioning of precipitation between direct runoff to surface water and infiltration to the unsaturated and saturated zones. For example, impermeable soils typically reduce infiltration and lead to more direct runoff, whereas more permeable soils have higher infiltration rates and produce higher base flows from groundwater discharge. Land cover also affects stormrunoff response and plays a large role in determining the amount of water lost to the atmosphere by evapotranspiration. The most important land-use changes in terms of hydrologic effects are losses of natural land cover (for example, forested land), intensification of agriculture, losses of wetlands, and urbanization. These changes can affect flood response, channel stability, seasonal soil moisture, groundwater levels, wetland function, water quality, and the health of aquatic ecosystems (Calder, 1993).

The stream networks in many watersheds in the United States have been altered by human activity. Alterations may be extensive and include physical alterations, flow alterations, and water-quality alterations (Armstrong and others, 2011). Physical alterations are caused by dams, road crossings, channelization, and flood-plain development. Flow alterations are caused by water withdrawals, wastewaterreturn flows, industrial uses, hydropower, and urban runoff. Water-quality alterations are caused by wastewater discharges, industrial contaminants, and runoff from urban, residential, and agricultural lands. In highly developed watersheds, these 
human stressors, in particular water withdrawals and return flows, can have a significant effect on the magnitude of the components of the basin water budget. For example, Eng and others (2013) analyzed multiple streamflow metrics for 4,196 gaged rivers across the conterminous United States and showed that increased road density and dams had the greatest effect on flows and that road density, agriculture, and wastewater discharges tended to be associated with increased flows in comparison to their natural conditions. Chloride sources are typically associated with urbanization, and thus this type of basin alteration is particularly important for understanding the fate and transport of chloride.

\section{Water Budget}

A water budget for a watershed can be constructed by applying the principle of mass conservation. A simple definition of a water budget for a watershed is that inflow equals outflow plus or minus the change in storage, and this definition can be expressed as follows:

$$
P-E T+S W_{\text {in }}-S W_{\text {out }}+G W_{\text {in }}-G W_{\text {out }}=\Delta S / \Delta t
$$

where

$$
\begin{aligned}
P & \text { is precipitation; } \\
E T & \text { is evapotranspiration; }
\end{aligned}
$$

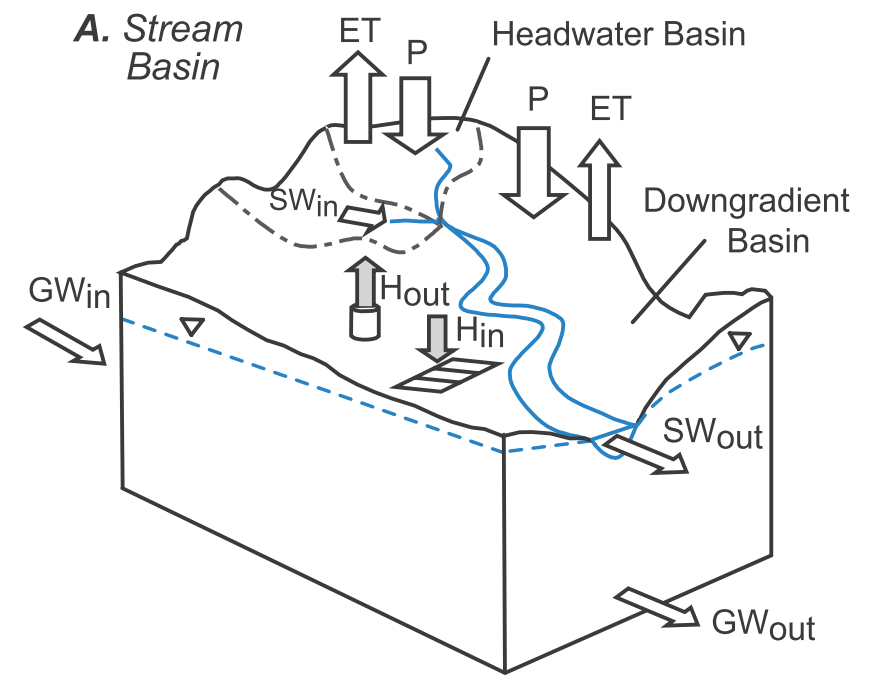

\author{
$S W_{\text {in }} \quad$ is surface-water inflow; \\ $S W_{\text {out }}^{\text {in }} \quad$ is surface-water outflow; \\ $G W_{\text {in }}^{\text {out }} \quad$ is groundwater inflow; \\ $G W_{\text {out }}^{\text {in }} \quad$ is groundwater outflow; and \\ $\Delta S / \Delta t \quad$ is the rate of change in storage (fig. 12).
}

In undeveloped watersheds the major input is precipitation, and the major outputs are evaporation and plant transpiration (evapotranspiration) and surface-water flow past the basin outlet. The portion of precipitation that reaches the ground in solid form as snow or ice can be stored temporarily or accumulate as a snowpack until melting takes place. The liquid precipitation (rainfall) is apportioned among temporary retention on vegetation or in surface depressions, infiltration into the soil, and flow over the land surface into rivulets feeding larger streams and rivers (Hornberger and others, 1998). Flow over the land surface is referred to as surface runoff or overland flow. In urban areas, surface runoff is often directed to engineered systems, such as storm sewers, that discharge to streams and rivers. Of the water that infiltrates, some is returned to the atmosphere by evapotranspiration, some flows laterally through the soil zone and discharges to streams and rivers as interflow (also referred to as subsurface stormflow), and the remaining water continues to migrate downward through the unsaturated zone to the water table, becoming groundwater. Groundwater eventually discharges into streams and rivers as base flow.

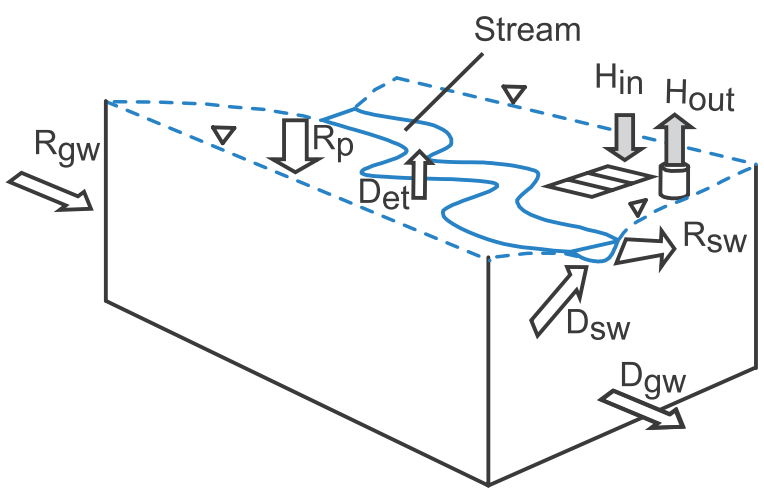

Figure 12. Components of a water budget for $A$, a stream basin and $B$, an aquifer system. The headwater basins, which receive no lateral inflow, discharge to the downgradient basin. The gray dashed lines represent subbasin drainage divides, the blue dashed lines represent the water tables of these unconfined aquifers. The land surface is not shown in part $B$ because the water table is the control-volume interface. Water-budget terms are defined in equations 2 and 3 . Modified from Weiskel and others (2007). 
In very large watersheds, it may be assumed that surfacewater and groundwater divides are coincident; consequently, groundwater inflows and outflows across the basin boundary can be neglected in the water-budget equation. In small watersheds, however, surface-water and groundwater watersheds often do not coincide; that is, the groundwater system extends beyond the surface watershed (Winter and others, 2003).

Major water-budget components are described briefly in the following subsections. Uncertainties associated with estimating these components are also discussed because errors in water-budget components may be large and can provide misleading results (Winter, 1981b).

\section{Precipitation}

Precipitation varies widely across the conterminous United States. Average annual precipitation ranges from nearly 200 inches per year (in/yr) in coastal areas of the Pacific Northwest to less than $5 \mathrm{in} / \mathrm{yr}$ in the desert Southwest (Smith, 1993). In the humid eastern half of the country, average annual precipitation typically ranges from about 30 to $60 \mathrm{in} / \mathrm{yr}$, whereas in the arid western half of the country, averages of less than $20 \mathrm{in} / \mathrm{yr}$ are common. Thus the amount of water available to watersheds also varies widely across the country. In addition to regional variability on an annual basis, precipitation also exhibits substantial short-term variability over small areas. Consequently, determining precipitation inputs to watersheds to develop water budgets typically involves some form of regionalization of point measurements (rain gages) of rainfall (Winter, 1981a,b). In northern climates, seasonal snow cover also needs to be considered.

Rain gages are typically used for measuring precipitation. Uncertainties in measuring precipitation generally are caused by the errors associated with the instrumentation and techniques used to measure rainfall and by areal averaging (regionalization) of point measurements. Most errors are related to modification of the wind field by the gage (Smith, 1993). Winter (1981a,b) estimates that instrument measurement errors are in the range of 1 to 5 percent, but errors caused by other factors such as the height of the gage above ground level can be as high as 75 percent for individual storms. Errors for longer time periods (monthly and seasonal precipitation) are smaller than for individual storm events. Radar measurement of rainfall is advantageous in some circumstances because it provides coverage of large areas with high spatial and temporal resolution. However, similar to point measurements, precipitation estimates derived from radar data are subject to errors from a variety of sources (Smith, 1993). For all methods, interception losses by surface vegetation also should be considered. These losses are often accounted for as a component of evapotranspiration losses in the watershed.

\section{Evapotranspiration}

Long-term (1971-2000) mean annual evapotranspiration varies widely across the continental United States, ranging from about $40 \mathrm{in}$. in the humid Southeast to less than 4 in. in the arid Southwest (Sanford and Selnick, 2013). The fraction of annual precipitation lost to evapotranspiration exceeds 30 percent for most of the conterminous United States; thus evapotranspiration represents a large sink for precipitation and is an important component of water-budget studies. Seasonal variability in evapotranspiration is important in areas with large annual ranges in air temperature. Evapotranspiration rates are controlled by the availability of energy and water. Potential evapotranspiration refers to a maximum rate of loss limited by available atmospheric energy, whereas actual evapotranspiration refers to a lower rate limited by available water in the watershed. In many locations, energy will limit the evapotranspiration rate for some time periods, and water will limit the rate for other periods.

Evaporation pans are the most commonly used instruments to estimate evapotranspiration and are considered to provide direct measurements. Other common methods make use of climate data to calculate potential evapotranspiration. These equations can be categorized as energy budget, aerodynamic (eddy correlation, gradient, and mass transfer), semi-empirical, and empirical methods (Rosenberry and others, 2004; Winter and others, 1995). These equations require differing amounts of climatic and thermal data, such as air temperature, relative humidity, wind speed, and various measures of solar radiation.

Evapotranspiration measurement errors can have a substantial effect on a watershed water budget. The energybudget technique is the most accurate method for estimating evapotranspiration for periods exceeding several weeks in duration, with errors in the range of 10 to 15 percent (Winter, 1981a,b). However, this technique requires extensive instrumentation and is not widely used for watershed studies. More commonly used methods such as the Penman, JensenHaise, Hamon, and Thornthwaite methods make use of climate data that are available from weather stations (Rosenberry and others, 2004; Winter and others, 1995). Errors associated with these methods are difficult to quantify. Evapotranspiration may also be determined indirectly as the residual of a water balance for a watershed when the other components of the water-balance have been determined. This approach provides an areal average of evapotranspiration for the watershed, but the estimate can contain significant error because the change in water storage in the watershed over short (monthly) time scales cannot be measured reliably (Shuttleworth, 1993). Similarly to error in estimating precipitation, error in measuring evapotranspiration also arises from areal averaging of point measurements, particularly for watersheds with highly variable land cover. Overall, evapotranspiration at the watershed scale is less reliably estimated than precipitation and streamflow. 


\section{Streamflow}

Streamflow refers here to the open-channel flow at the outlet point of a watershed of interest. Streamflow is usually measured by constricting the flow through a rated device such as a flume or weir or by measuring flow velocity and stage in an open channel. Measurement errors for rated devices are usually low (less than 5 percent). Errors for open-channel measurements depend on many factors and are generally higher than for rated devices; errors can exceed 10 percent in some circumstances (Winter, 1981a,b; Harmel and others, 2006). An individual streamflow measurement is a point value in space and time. Temporal variations in streamflow are commonly determined by continuous measurements of stream stage. This method requires the development of an empirical stage-discharge relationship (a rating curve) over a wide range of flows (Rantz, 1982a,b). In general, errors in streamflow measurements are related to instrumentation and to the techniques used to determine the spatial and temporal distribution of discharge (Winter, 1981a,b; Harmel and others, 2006).

Nonchannelized flows (surface runoff, infiltration, and groundwater discharge) that generate streamflow are often important processes for transporting chloride to stream channels. Detailed water budgets that included these processes have been developed in some studies. For example, Sanford and others (2012) quantified water-budget components such as surface runoff, base flow, recharge, and riparian evapotranspiration for 48 watersheds in Virginia. Collection of continuous streamflow data and chemical hydrograph separation techniques were used to estimate the surface-runoff and base-flow components of streamflow in these watersheds. However, in many basin studies, these nonchannelized flow components, which are highly variable in time and space, are not measured, and watershed water budgets are based on longterm average streamflow as the basin outflow term.

In watershed-scale studies, concentrations of chloride are usually measured in streams rather than directly in surface runoff and groundwater. One disadvantage of this approach is that stream samples integrate the effects of multiple transport processes and sources in the watershed. However, improved resolution may be achieved by measuring concentrations in the surface-runoff (stormflow) and base-flow components of stream discharge (Smith, 2013). Stormflow encompasses all processes of surface and shallow subsurface runoff that generate peak flows in response to precipitation events. Base flow is composed largely of groundwater and represents precipitation that infiltrated though the unsaturated zone to the water table. Concentrations in stormflow and base flow are indicative of sources in the watershed and can often be related to the amount of urban land use in the watershed (Heisig, 2000; Smith, 2013). Other approaches to delineate streamflow components include continuous streamflow monitoring with application of base-flow separation techniques (Sanford and others, 2012). If a water-quality constituent that correlates to chloride concentration, such as specific conductance, is also measured continuously, then long-term mean chloride loads associated with surface runoff and base flow can also be estimated.

\section{Human Water Use}

Hydrologic systems can be highly affected by human water use (Weiskel and others, 2007; Johnston, 1999). Both withdrawals and return flows can alter the water budgets of watersheds and, therefore, need to be represented in the waterbudget equation (fig. 12). To represent human-induced inflows and outflows, the basic water-budget equation for a watershed (eqn. 2) can be modified and expressed as follows:

$$
\begin{aligned}
& P-E T+S W_{\text {in }}-S W_{\text {out }}+G W_{\text {in }}-G W_{\text {out }}+H W_{\text {in }}-H W_{\text {out }}= \\
& \Delta S / \Delta t,
\end{aligned}
$$

where

$$
\begin{gathered}
H W_{\text {in }} \text { and } H W_{\text {out }} \text { represent the total human-induced inflows } \\
\text { and outflows, respectively, from all } \\
\text { sources, and all other terms are as defined } \\
\text { previously. }
\end{gathered}
$$

Other more indirect human-induced alterations such as landcover change, dam construction, and climate change also can affect water budgets of hydrologic systems (Weiskel and others, 2007). Water use may also change the timing and magnitude of streamflows at the reach scale, resulting in adverse effects on aquatic habitat and water quality.

Human water-use regimes can be broadly characterized by four end members (Weiskel and others, 2007): naturalflow-dominated (undeveloped), human-flow-dominated (churned), withdrawal-dominated (depleted), and return-flow dominated (surcharged). These conditions reflect the magnitude of the human-induced inflows and outflows in relation to natural flows and available water in the basin. Humanflow-dominated systems are characterized by high withdrawals and return flows that are roughly in balance such that the basin water balance is minimally altered by human water use. However, the high intensity of human water use can affect the mass balance of chloride. Uncertainty in estimating the effect of human water use on a basin water budget is related to the availability and quality of water-use data. Withdrawal and return-flow data are often poorly estimated or unavailable.

Estimates of water use in the United States indicate that about 408 billion gal/d were withdrawn for human uses in 2000 , with 83.3 billion gal/d from fresh groundwater and 262 billion gal/d from surface water (Hutson and others, 2004). Withdrawals are dominated by thermoelectric power, which represents about 48 percent of the total withdrawals for human use. Water for thermoelectric power is used in generating electricity with stream-driven turbine generators, causing increased evaporation by direct evaporative cooling or by increasing the temperature of discharged water. Irrigation water, representing 34 percent of the total water use, is the 
second largest human water withdrawal. The water is applied by an irrigation system to sustain plant growth in agricultural and horticultural practices, especially in the western United States where annual precipitation is typically less than $20 \mathrm{in}$. and insufficient to support crops. The development of agricultural land for irrigation causes changes in the seasonal and long-term groundwater levels, infiltration, evapotranspiration, groundwater recharge, streamflow, stream stage, and stream temperatures. The immediate effects of irrigation are seasonal. Evapotranspiration is lower while soil-moisture and net recharge are higher in the spring, when newly planted fields are bare. Evapotranspiration and soil-moisture storage are higher in the summer, as fields are irrigated, but the net recharge is lower. Long-term pumping of groundwater also lowers the water level, which in turn lowers the levels of lakes and streams, causing increased water temperatures (Weeks and Stangland, 1971). Public-supply water withdrawals were more than 43 billion gal/d (Hutson and Others, 2004). Public-supply water withdrawals were about 11 percent of the total human water use in 2000 (the third largest of the human withdrawals). In 2000, 85 percent of the United States population received their water from a public supply, with the majority of this water coming from surface-water sources such as reservoirs (Hutson and others, 2004).

\section{Chloride Budget}

Studies that quantify sources of chloride can be used to ascribe the loads of chloride to natural or anthropogenic sources to assess current conditions and establish TMDLs (for example, Peters and Turk, 1981; Panno and others, 2006; Peters and others, 2006; Heinz and others, 2008; California Regional Water Quality Control Board, 2008; Carollo Engineers, 2009; Novotny and others, 2009; Trowbridge and others, 2010; Kelly and others, 2012). However, unless longterm data are available (for example, Jaworski and Hetling, 1996), such studies provide a snapshot rather than the true condition of the watershed. Studies that couple water budgets, source loading, and measurements of water flow and quality (for example, LaBaugh and others, 1995, 1997; Bukaveckas and others, 1998; Eisele and others, 2001; Yechieli and Wood, 2002; Ito and others, 2005) can be used to assess prior conditions, the current status, and potential outcomes. Accurate information about sources, flows, and concentrations is needed to guide resource management decisions (Winter, 1981a,b).

Water and chloride budgets can be created on the watershed scale or on a local scale. For example, a water and solute budget may be done for the contributing area of a public-supply well to determine the potential sources of contaminants and potential trends in the water-quality from the well. As indicated in figure 13, the fate of water and deicing solutes from the pavement through the hydrosphere can be complex (Gupta and others, 1981). Some of the deicer melts snow and ice on the pavement, and the meltwater runs off to the local land surface or through a drainage system to a receiving water or BMP. This meltwater may discharge to streams or infiltrate to groundwater. Some of the deicer may be plowed or splashed off the highway to infiltrate roadside soils, deposit on roadside vegetation, or be reentrained in the atmosphere. Deicers that dry on the road may later be mobilized by traffic and entrained in the atmosphere. Deicers that run off may enter soil water to be discharged as groundwater or stormwater later in the year. Once deicers are in surface water and groundwater they may be captured for water supply and be discharged with wastewaters. Thus addition of chloride from deicing and other sources may amplify chloride concentrations as the water moves through the environment. Detailed information for quantifying the flows, concentrations, and loads in any one of these hydrologic compartments is encyclopedic; a detailed description of such methods is beyond the scope of the current study. However, information and important considerations for monitoring are provided, with selected examples and references to more detailed information.

A chloride budget can be constructed by applying the principle of mass conservation. A simple definition of a chloride budget for a control volume is that inflow equals outflow plus or minus the change in storage, and this definition can be expressed as follows:

$$
\begin{aligned}
& P+D_{\text {in }}-D_{\text {out }}+G C_{\text {in }}+S W_{\text {in }}-S W_{\text {out }}+G W_{\text {in }}-G W_{\text {out }}+ \\
& H L_{\text {in }}-H L_{\text {out }}+H W_{\text {in }}-H W_{\text {out }}=\Delta S / \Delta t,
\end{aligned}
$$

where

$\begin{aligned} P & \text { is precipitation; } \\ D_{\text {in }} & \text { is dry-deposition influxes; } \\ D_{\text {out }} & \text { is dust entrainment exports; } \\ G C_{\text {in }} & \text { is geochemical release; } \\ S W_{\text {in }} & \text { is surface-water inflow; } \\ S W_{\text {out }} & \text { is surface-water outflow; } \\ G W_{\text {in }} & \text { is groundwater inflow; } \\ G W_{\text {out }} & \text { is groundwater outflow; } \\ H L_{\text {in }} & \text { is human imports; } \\ H L_{\text {out }} & \text { is human exports; } \\ H W_{\text {in }} & \text { is human-induced inflow; } \\ H W_{\text {out }} & \text { is human-induced outflows; and } \\ \Delta S / \Delta t & \text { is the rate of change in storage (fig. 12). }\end{aligned}$

The chloride budget is, by and large, a function of the water budget for a watershed or control volume. However, loadings from human activities can substantially increase the chloride flux and in many cases are contributing to increased chloride storage in aquifers underlying watersheds of interest. The information provided in the sections describing sources of chloride can be used with a water budget to estimate a chloride budget for an area of interest.

The first eight terms in the equation represent natural inflow and outflow volumes in the water budget. However, the associated inflow and outflow loads may contain both natural and anthropogenic sources of chloride. The precipitation 


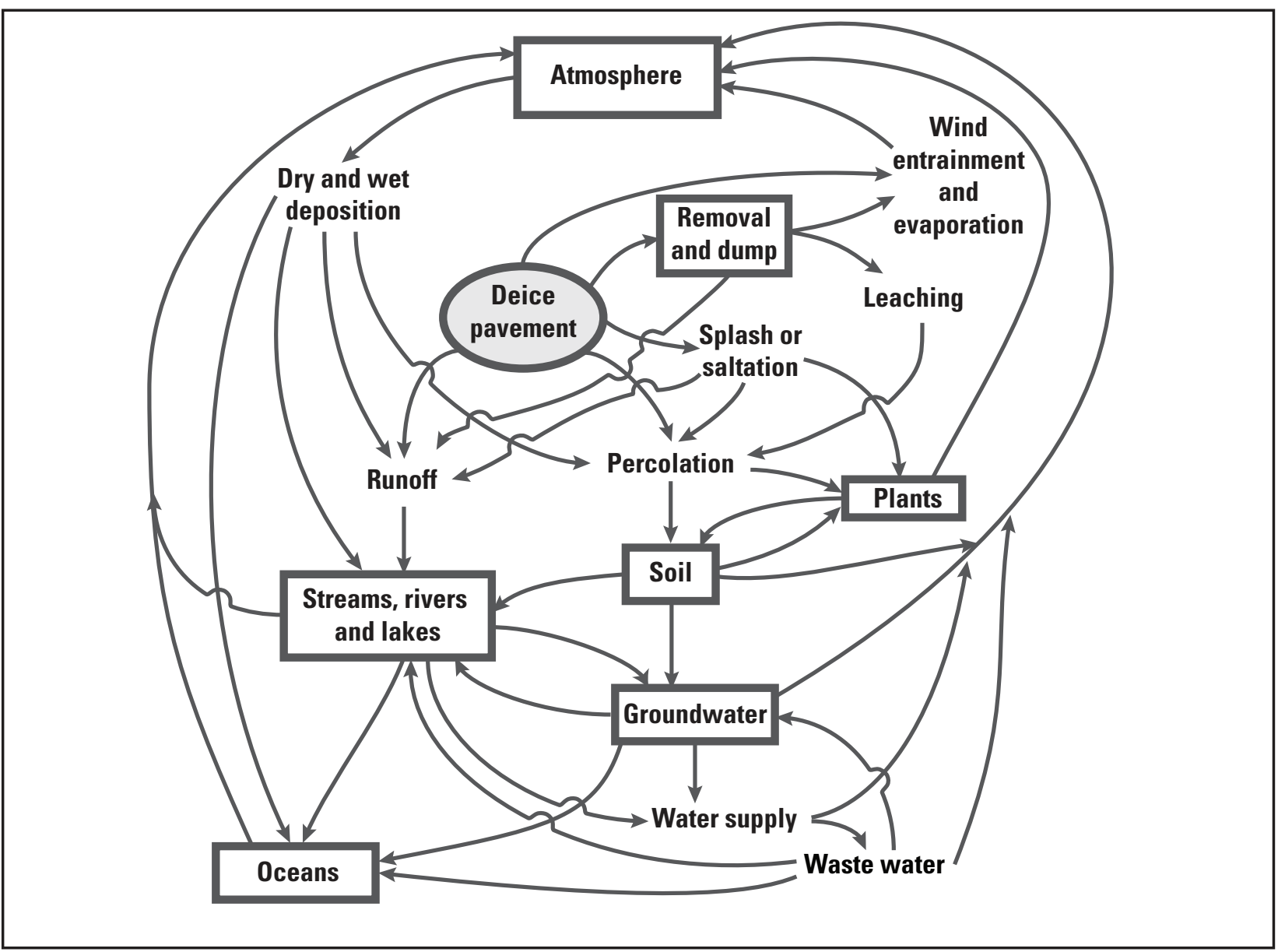

NOT TO SCALE

Figure 13. Environmental reservoirs and pathways for the storage and transport of water and solutes from deicing operations. Chloride reservoirs are shown as text in boxes. Modified from Gupta and others (1981).

load is the precipitation volume times the local chloride concentration. The evapotranspiration term does not appear in the chloride budget because evapotranspiration of water may increase chloride concentrations but does not increase the chloride loads. The $D_{i n}$ term includes natural sources of chloride and some human loadings that have been reentrained from neighboring areas. Conversely, the $D_{\text {out }}$ term includes natural and human chloride deposits that are entrained by the wind and deposited in neighboring areas. The $G C_{i n}$ term includes solubilization of chloride from soil, sediment, and bedrock deposits. The $S W_{\text {in }}$ and $S W_{\text {out }}$ terms include inflows and outflows of chloride in surface waters naturally flowing in and out of the basin, respectively. The $G W_{\text {in }}$ and $G W_{\text {out }}$ terms include inflows and outflows of chloride in groundwaters naturally flowing in and out of the basin, respectively. The effect of deep saline groundwater may be counted as $G W_{i n}$ if the control volume is a surficial aquifer and the overlying surface waters or may be counted as $G C_{i n}$ if the deep saline aquifer is included in the control volume.

The last four terms on the left side of the equation represent human-induced chloride fluxes. $H L_{i n}$ is human imports, and $H L_{\text {out }}$ is human exports; these terms denote chloride that is imported to or exported from the control volume from sources that are not included in the water budget. For example, Stites and Kraft (2001) estimate imports of chloride to a farm field in fertilizer and exports from the field in the harvested crops. Other imports in this category may include deicing chemicals, water and wastewater-treatment chemicals, food and consumer products, animal feed, welldrilling fluids, and domestic or industrial waste. Exports from the basin may include crops, livestock, manure fertilizers, sludge from wastewater treatment, and domestic or industrial waste. The $H W_{\text {in }}$ is human-induced inflows, and $H W_{\text {out }}$ is human-induced outflows from the control volume. Humaninduced inflows may include chloride loads with water that 
is imported for public supply or irrigation. Human-induced inflows also may include chloride from saltwater intrusion or energy-production brines that are pumped up from the underlying strata. Human-induced inflows may also include chloride in wastewater. Human induced outflows include water that is withdrawn from the control volume for export. In some cases, however, it may be convenient to account for $H L_{i n}$ and $H L_{\text {out }}$ as internal $H W_{\text {in }}$ and $H W_{\text {out }}$ cycling. For example, it may be difficult to estimate the chloride loads added to wastewater, but available data on wastewater quality and water use can be used to estimate loads added to wastewater that is withdrawn and returned within the same control volume. The section in this report on sources of chloride demonstrates the use of direct loading estimates and loading estimates based on measured water quality.

\section{Monitoring Chloride in the Environment}

Decisionmakers face many different issues concerning the characteristics and effects of chloride from many potential sources. Water and solute budgets constructed from literature values and available hydrologic data may provide initial planning-level estimates of concentrations and loads of chloride at a site of interest. NWIS provides ready access to millions of water-quality analyses from almost 400,000 sites nationwide (http://waterdata.usgs.gov/nwis). The USGS, in cooperation with the FHWA, developed a suite of programs to facilitate data mining and analysis of data from NWIS (Granato, 2006; Granato and others, 2009). The USGS also provides free online access to more than 100,000 publications (including technical reports, resource maps, standard methods, hydrologic software, and other products) written by USGS scientists over more than a century (http://pubs.usgs.gov/). Many of these reports are useful for defining surface-water and groundwater flow and quality in an area, and many are useful for defining different water-quality problems nationally, regionally, and locally.

In many cases, however, site-specific data may be needed to support the planning and decision-making process or to meet legal or regulatory information needs. In such cases, site-specific knowledge of the concentrations and loads of chlorides from transportation facilities and other natural and anthropogenic sources (and the physical and chemical processes that govern the generation and transport of chloride) is important for decisionmakers, planners, and highway engineers in assessing and mitigating possible adverse impacts of chloride on water supplies and the Nation's receiving waters. This section is intended to introduce important concepts for monitoring chloride rather than being a comprehensive monitoring manual. References are provided to assist the search for more detailed guidance and to provide examples of monitoring efforts; a multivolume manual may be required to provide the details needed for monitoring any one component of the hydrologic cycle with proper methods and quality assurance (QA) and quality control (QC) practices. Depending on the situation, data may be needed to quantify concentrations and loads of chloride in atmospheric deposition, soil water, groundwater, runoff, streamflow, and in ponds, lakes or reservoirs.

In a review of water-quality data collected by Federal, State, and local water-quality monitoring entities, Hren and others (1987) defined five characteristics necessary to establish that data are useful. To be useful, data must be (1) representative of the system under study, (2) available for public use as original data, (3) collected from a readily located sampling site (to assess data comparability and to interpret results of geographic/climatological variations), (4) associated with sufficient QA information (to indicate the validity, reliability, and compatibility of data from different sources), and (5) available in useful computer files (to increase reliable compilation and manipulation of large volumes of data). These criteria were developed to screen data from diverse programs for inclusion in a database that could provide consistent, technically sound water-quality data representing broad geographic areas through time (Hren and others, 1987).

\section{Quality Assurance and Quality Control}

Quality assurance and quality control (QA/QC) programs are used to detect and control errors and to maintain and document the reliability and uncertainty of results (Jones, 2003). Historically, QA/QC programs have been recognized as an essential component of laboratory analysis, but the usefulness of data for decision-making is affected by many external factors (Brown and others, 1991). QA/QC requirements to document that data from laboratory and field sampling activities are valid, current, and technically supportable have been increasing over the last 3 decades. The Intergovernmental Task Force on Monitoring Water Quality (ITFM) has defined strict guidelines for the collection, analysis, and documentation of water-quality information. The issues involved in achieving data comparability are consistent with operating in a well-defined quality system for physical, chemical and biological measures in the field and in the laboratory (Intergovernmental Task Force on Monitoring Water Quality, 1995a,b). The ITFM requires that sample-collection procedures and analysis methods need to be fully described, validated, and conducted by competent personnel. To document that data collection information is internally reliable and comparable to results from other groups, performance needs to be evaluated against a reference (Intergovernmental Task Force on Monitoring Water Quality, 1995b). The EPA recommends the use of quality-assurance plans within the scope of a data-quality-objectives process to document all activities needed to ensure that the data collection program will produce the type and quality of data that will be sufficient to support decisions made by using data collected (U.S. Environmental Protection Agency, 1986, 1994). 
The EPA and the ITFM have established criteria for water-quality data to be included in national databases (U.S. Department of Environmental Protection, 1994, 1996; Intergovernmental Task Force on Monitoring Water Quality, 1995a,b). To demonstrate that water-quality data are valid and technically supportable, sufficient documentation must be available to prove that the data are meaningful, representative, complete, precise, accurate, comparable, repeatable, and admissible as legal evidence (Alm and Messner, 1984; Federal Highway Administration, 1986; Intergovernmental Task Force on Monitoring Water Quality, 1995a,b; U.S. Environmental Protection Agency, 1997; Granato and others, 2003; Jones, 2003). Although the concepts intertwine, each is a distinctive part of the evaluation process. A dataset that is representative accurately and precisely characterizes a population, a process, and parameter variations at a study site. A dataset that is complete contains enough representative information to characterize the uncertainties in the data and resultant interpreted values. To be considered complete, a dataset from a monitoring study to characterize chloride concentrations and loads should characterize seasonality over more than 1 year because annual highway-runoff solute loads have been shown to vary from approximately 50 percent to 200 percent of the median from year to year over a 5-year period (Granato, 1996). Precision implies a high degree of repeatability for samples obtained under similar conditions. Accuracy implies a lack of bias (no systematic errors). Data that are comparable are taken from the same matrix, such as the water column, suspended solids, sediment, or biota, by using documented methods of sampling and analysis that are demonstrated to produce results with similar and acceptable levels of bias and variability. Datasets that are admissible as legal evidence must contain enough information to withstand any reasonable challenge to their quality and veracity.

Planning for QA/QC should be documented in a comprehensive QA plan for each monitoring project (Jones, 2003). QA/QC should be carried out as part of a comprehensive quality system that is centered in a quality management plan. It is not possible to prescribe a single set of QA/QC practices to be used in all monitoring efforts (Jones, 2003). Specific QA/QC activities are based on the risks of error associated with each monitoring activity and the likelihood and consequences of each type of error. To be effective, QA must address all aspects of the project, including project management responsibilities and resources, data-quality objectives, sampling and analysis plans, data collection protocols, data quality-control plans, data assessment procedures and requirements, and project outputs. The USGS-FHWA National Data and Methodology Synthesis Project provided a technical manual and literature review for establishing data-quality objectives and quality-management systems for monitoring concentrations and flows (Church and others, 2003; Granato and others, 2003; Jones, 2003).

\section{Use of lonic Conductance for Monitoring Chloride}

Ionic conductance, measured either as the specific conductance in water or the electromagnetic conductance of water, and geologic materials below the land surface can be used to facilitate measurements of chloride and other ionic species in water. Chloride commonly is measured as a negatively charged ionic constituent (an anion) in surface water and groundwater and as such exists in solution with other anions, cations (positively charged ions), and other charged water-quality species (Feth, 1981; Miller and others, 1988; Hem, 1992). Pure water does not conduct electricity, but the presence of ionic species in water can carry an electrical charge, thereby increasing the conductance of the aqueous solution (Harned and Owen, 1958; Lind, 1970; Smedley, 1980; Hem, 1982, 1992; Miller and others, 1988; Granato and Smith, 1999a). Specific-conductance probes, which can be used manually or under the control of a data logger, are commonly used to make large numbers of repeated measurements in a fraction of the time and cost needed to obtain, process, and analyze water-quality samples (Granato and Smith, 1999a,c; Radtke and others, 2005; Rasmussen and others, 2005; Wagner and others, 2006). Methods used to measure electromagnetic conductance are commonly used to provide information about subsurface water quality that would be difficult or impossible to obtain without installation of an extensive number of sampling points at different depths and different locations (Keys and MacCary, 1971; Zohdy and others, 1974; Williams and others, 1993; Church and Granato, 1996; Paillet and Crowder, 1996; Kunze and Sroka, 2004). Electromagnetic conductance, however, is a bulk measurement of the matrix and solutes that must be used interpretively with other information to estimate water and solutes.

\section{Specific Conductance}

Specific conductance is a measure of ionic conductance for a volume of water with a unit length, a unit width, and a defined temperature (Hem, 1982, 1992; Miller and others, 1988; Granato and Smith, 1999a; Radtke and others, 2005). In the United States, specific conductance is commonly reported as microsiemens per centimeter $(\mu \mathrm{S} / \mathrm{cm})$ at 25 degrees Celsius. Well-calibrated and well-maintained conductance probes can be expected to maintain readings within plus or minus 2 to 5 percent of the actual conductance in groundwater or ephemeral runoff flows and within plus or minus 5 to 10 percent of the actual conductance for several weeks at a time in many perennial streams (Granato and Smith, 1999c; Wagner and others, 2006; Radtke and others, 2005). Measurement of specific conductance with other physical parameters such as temperature and $\mathrm{pH}$ provides instantaneous information for manual field sampling efforts and provides a method for establishing geochemical stability for groundwater sampling efforts (Koterba and others, 1995; Granato and 
Smith, 1999a,c; Radtke and others, 2005). Measurement of specific conductance under data-logger control can provide detailed records of changes in water quality during the monitoring period (Granato and Smith, 1999a,c; Wagner and others, 2006).

Knowledge of the major-ion composition of the waters of interest can be used with specific-conductance measurements to interpret changes in chloride with conductance. Each ionic constituent has a characteristic conductance at infinite dilution that, in theory, can be used to calculate the specific conductance of dilute solutions (table 3). The principle of superposition, Kohlrausch's law, states that the specific conductance of dilute electrolytic solutions can be calculated as the sum of the equivalent ionic conductances of all anions and cations in solution (Harned and Owen, 1958; Smedley, 1980; Hem, 1982; Miller and others, 1988; Granato and Smith, 1999a). To calculate the specific conductance of an aqueous solution by superposition, one simply sums the individual conductances attributed to all major ionic constituents in solution. The individual conductance of each ionic constituent in solution is the product of the concentration times the equivalent ionic conductance at infinite dilution for that ionic constituent (Granato and Smith, 1999a). Examination of calculated specific-conductance values from analyses of water samples indicates that estimates of measured specific conductance below $1,000 \mu \mathrm{S} / \mathrm{cm}$ are a good approximation for the measured value when a complete major ion analysis is available. In this conductance range, the difference between calculated and measured specific conductance is within the error of \pm 5 percent expected for conductance probes and is often close to the error in charge balance of the laboratory analysis (Hem, 1982; Granato and Smith, 1999a). However, the calculated specific-conductance values can be adjusted by using the equations in figure 14 so that they will be within \pm 5 percent of the expected value for sodium chloride solutions in the range below $80,000 \mu \mathrm{S} / \mathrm{cm}$. Therefore, superposition may provide a good approximation throughout the specificconductance range of most natural waters. Concentration effects may not be the only cause for error in estimating specific-conductance values on the basis of water-quality data. Other factors include the effects of variations in $\mathrm{pH}$ and temperature and the effect of organic chemicals on the measured conductance (Granato and Smith, 1999a).

Relations between individual ions and their associated conductance have practical applications for estimating individual ionic concentrations from a bulk conductance value. Investigators commonly use regression relations to predict individual constituent concentrations from measurements of specific conductance, but the predictive power of such relations may depend on the contribution of the ion of interest to the total conductance. For example, Hem (1992) provides concentrations of the mean composition of the rivers of the world. Analysis of the individual conductance values and their sum indicates that these waters primarily consist of calcium and bicarbonate ions with an estimated unadjusted conductance of about $147 \mu \mathrm{S} / \mathrm{cm}$. The chloride concentration provides about 7.2 percent of the equivalents in solution (14.4 percent of anion equivalents) and about 9.9 percent of the expected conductance. If the chloride concentration were doubled by adding 11 grams of $\mathrm{NaCl}$, the conductance would change by about 16 percent, and the chloride ion would still be a minor contributor to the total conductance. It would be necessary to add $40 \mathrm{mg} / \mathrm{L}$ of $\mathrm{NaCl}$, while holding everything else constant, for chloride to be the dominant anionic contributor controlling the conductance of the solution. Gorham and others (1982) examined the chemical composition of lakes in the north-central United States and evaluated relations between specific conductance, TDS, chloride, and other major constituents for different water types. They found that chloride varied randomly in lakes with water types defined as having a specific conductance less than $501 \mu \mathrm{S} / \mathrm{cm}$ because those lakes were dominated by calcium-magnesium carbonates. The high-conductance lakes were dominated by magnesium-sodium sulfates but had appreciable chloride concentrations that increased with increases in conductance value. Therefore, knowledge of the local background water chemistry is needed to interpret relations between measured specific conductance and estimated chloride concentrations. Rainwater (1962) compiled a map of the conterminous United States with areas of similar ionic strength and water type that can be used to help interpret local conditions.

Linear regression models are statistical relationships between continuous independent variables that are used to estimate the value of one response variable from the value of another (Riggs, 1968; Hirsch and Gilroy, 1984; Hirsch and others, 1992; Helsel and Hirsch, 2002; Granato, 2006). It is important that the slope and intercept have reasonable signs and reasonable values so that the regression model will not produce an unreasonable output for a reasonable input (for example, a negative concentration value for a plausible specific conductance). This is especially important for realtime monitoring efforts. In principle, regression models should not be extrapolated beyond available input data, but in real-time monitoring efforts it takes time to obtain and analyze water samples that cover the range of instantaneous values. The residuals, which are the differences between each measured value and the associated value produced by the regression line, should be linear and of constant variance over the range of input values. Concentrations and specificconductance values can range over orders of magnitude. Reported values are scale dependent because the accuracy and precision of measurement methods are based on a percentage of the measured value and because the values commonly are reported by using two or three significant figures (Fishman and Friedman, 1989; Fishman, 1993; Brinton and others, 1996; Radtke and others, 2005; Wagner and others, 2006). Additionally, Helsel and Hirsch (2002) recommend that investigators create a boxplot of residuals by season or by month to detect seasonal differences in the response variable. This is a good practice if fluctuations in chloride are suspected to be caused by seasonal activities such as winter deicing, springtime application of $\mathrm{KCl}$ potash, or elevated wastewater 


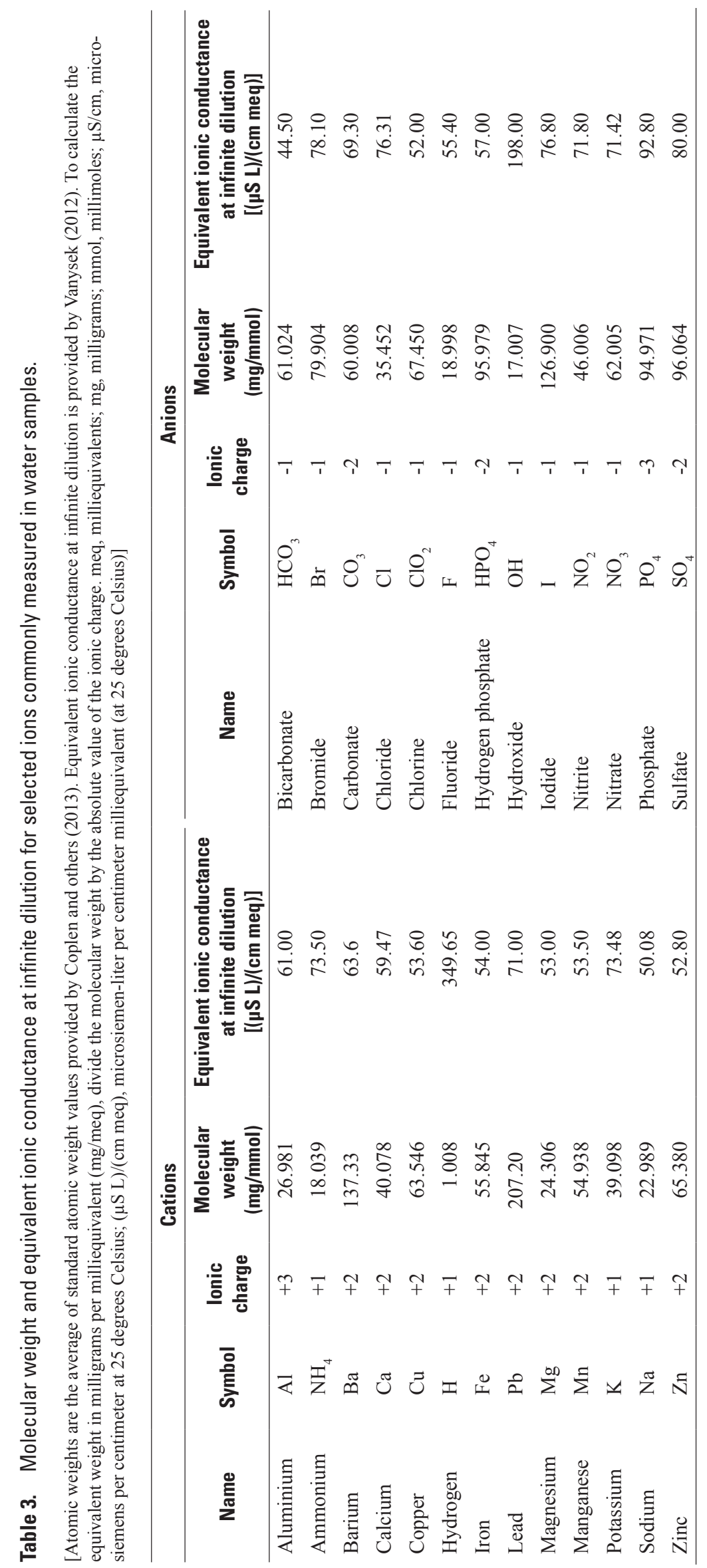




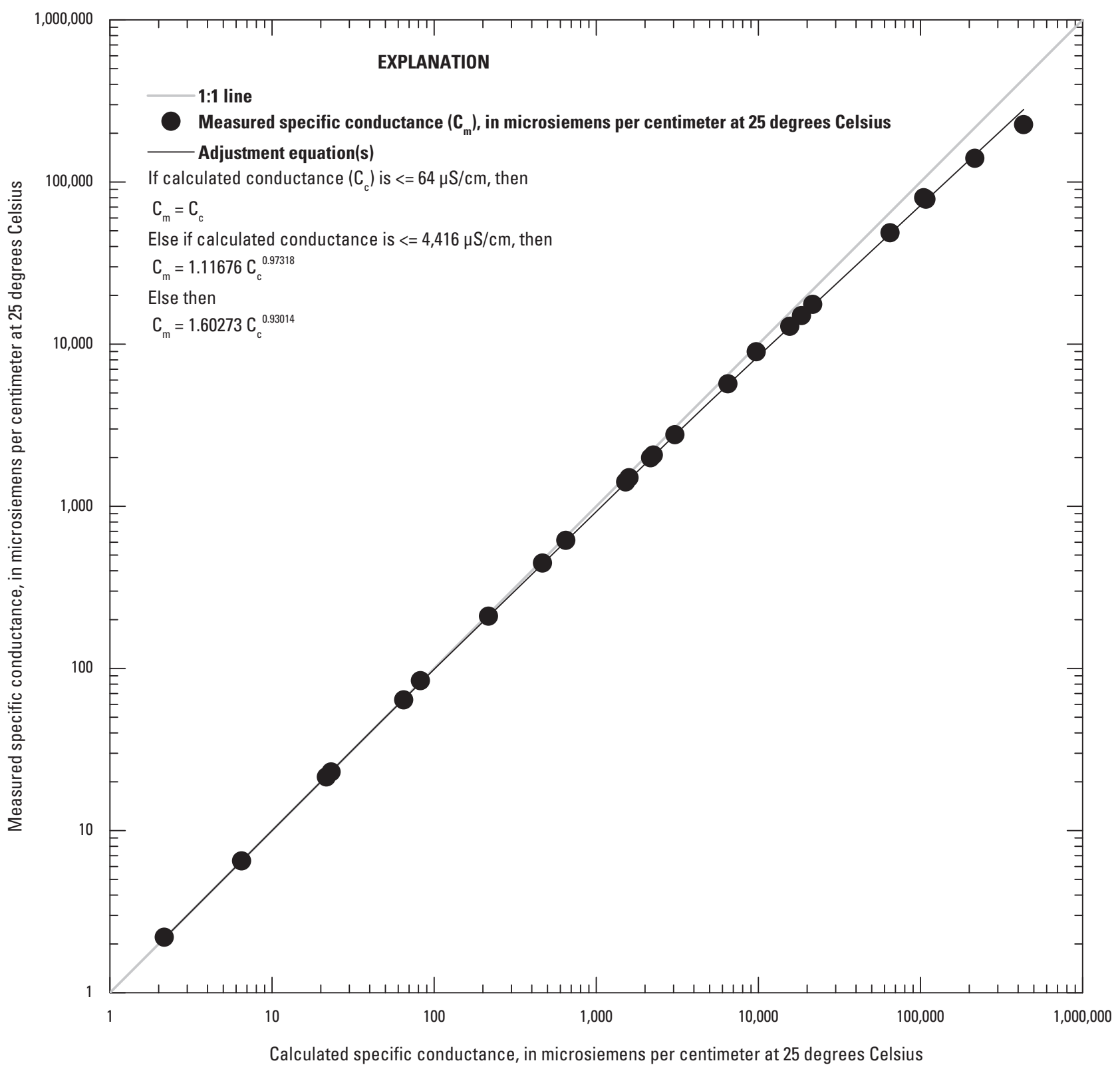

Figure 14. Empirical equations for adjusting the calculated specific conductance to a measured specific conductance for a sodium chloride solution. 
concentrations during low-flow seasons. To that end, Christensen and others (2000), Ryberg, (2006), and Brown and others (2011) used specific conductance and streamflow, as an additional variable, to improve the fit to data on the basis of examination of the residual structure.

Many investigators develop linear regression models to estimate chloride concentrations from specific conductance by using the untransformed measured values (for example, Peters and Turk, 1981; Britton and others, 1983; Cain, 1987; Blasius and Merritt, 2002; Watson and others, 2002; Novotny and others, 2007, 2008; Perera and others, 2009; Corsi and others, 2010a,b; Denner and others, 2010; Harte and Trowbridge, 2010; Trowbridge and others, 2010; Windsor and others, 2011; Morgan and others, 2012; McDonald and others, 2012; Schalk and Stasulis, 2012). All 14 of these reports have one or more equations with negative intercept values; these equations will produce negative chloride concentrations for a positive conductance value. Among these sources, nine reports measured specific-conductance values that are less than or equal to the point at which the regression will produce a negative chloride concentration. The negative intercepts occur because the solution would have a positive conductance if the chloride could be removed from a natural water sample and all the other constituents would remain. However, these untransformed regression equations do not represent the physicochemical relation between dilution and measured conductance. Also, as indicated in figure 14, the relation between the chloride concentration and the measured conductance is nonlinear, causing curvature in the residuals over a large range of conductance and chloride. Finally, because random variations in the measurements of specific conductance and concentration vary as a percentage of scale, the residuals of a regression equation developed by using the untransformed measured values would have nonconstant variance. In many cases, the ranges of measured conductance in paired values were small (within an order of magnitude), so these effects may not have been visible. In some cases, these regression equations may produce good fit statistics because the high-concentration values also are high-leverage points among the nontransformed values. For example, Blasius and Merritt (2002) show a poorly fit regression line with an r-square value of 0.9727 , which is obviously influenced by the leverage of the highest value. Corsi and others $(2010 \mathrm{a}, \mathrm{b})$ segregated their data and developed their regression with only the conductance values above about 1,400 and only the chloride values above $230 \mathrm{mg} / \mathrm{L}$ because the equations that were dominated by high-leverage values produced negative values below these thresholds. This threshold is notable because the resultant equation is only applicable for chloride concentrations above commonly used water-quality criterion of $230 \mathrm{mg} / \mathrm{L}$. Furthermore, about 52 percent of the data collected by Corsi and others (2010a,b) were below this chloride-concentration threshold.

A few researchers used polynomial equations to account for nonlinearity in the relation in the range of measured values (Howard, and Haynes, 1993; Baldys and others, 2010).
Polynomial expressions can be used to optimize the fit within a given range but are especially vulnerable to large errors when used outside the range of input data (Riggs, 1968). In theory, polynomial expressions could be developed with transformed or untransformed variables, but they commonly are developed by using untransformed variables. The higher level exponents are, in effect, a data transformation.

Many researchers also have used regression equations to estimate chloride from specific conductance by using the logarithm of both variables (Granato and Smith, 1999a; Rasmussen and others 2005, 2008; Barr Engineering Company, 2010; Kelly and others, 2010; Smith and Granato, 2010; Smith and Breault, 2011; Baldwin and others, 2012, 2013; Smith, 2013, 2014). Kelly and others (2010) noted that when they extended their log-log relation for the Upper Illinois Waterway, the results approximated the values they had for road-salt runoff. Log-log regression equations are a better approximation for infinite dilution than are untransformed equations because log-log equations will produce very small numbers but will not go to (or below) zero. The log-log regression equations are well suited for specificconductance and water-quality data because the accuracy and precision of these measurements is scale dependent. Two factors may affect the perceived performance of the log-log equations. Because high values are not high-leverage points in logarithmic space, log-log equations constructed from data with relatively few high concentrations may underrepresent extreme chloride concentrations. Log-log equations also may under predict high values because a bias correction factor is needed to adjust the equation to prevent underestimation of concentrations or loads as an artifact of transformation (Hirsch and Gilroy, 1984; Hirsch and others, 1992; Helsel and Hirsch, 2002; Granato, 2006).

Multisegment regression models may be useful for improving both untransformed and log-log regression models for estimating chloride from specific conductance. In cases where a chloride source is superimposed on the existing background water quality, there may be one relation between specific conductance and chloride in the source water and a second relation as chloride increases above background values. For example, Granato and Smith (1999a) used the composition of local precipitation to estimate the nonsalt contribution of major ions to conductance in highway runoff. Panno and others (2006) plotted groundwater chloride and conductance from shallow aquifers that represented background values and increased conductance and chloride from one or more anthropogenic sources. They estimated that there was no strong relation between conductance and chloride until the point at which specific conductance was equal to $750 \mu \mathrm{S} / \mathrm{cm}$, with a base chloride concentration of $15 \mathrm{mg} / \mathrm{L}$. Above this point they show increases attributed to a sodium-chloride solution, but with increasing variance in the scatter of points above and below the line (heteroscedasticity) as conductance increases. Perera and others (2009) noted that a one-line equation developed with untransformed variables would produce negative chloride concentrations 
within the measurement range of the data. Their data also indicate that sodium-chloride waters are causing high conductance-chloride pairs and that there is a distinctive change in slope. They developed untransformed two-line models to improve the performance of their estimates, but these equations do not preclude a negative estimate of chloride concentration. The Kendall-Theil Robust Line software (Granato, 2006), developed by the USGS in cooperation with the FHWA, was designed to facilitate the generation of multisegment regression models with a variety of data-transformation options.

In some cases, investigators have tried to use ionspecific probes to measure chloride concentrations directly instead of (or in addition to) estimates of chloride made by using specific-conductance probes, but ion-specific chloride probes have limited use in the field, especially for automated monitoring applications. Ion-specific electrodes for chloride (and other constituents) are prone to fouling, measurement variations with temperature, measurement drift over time (therefore the need for frequent calibration), and interference from other chemicals in solution (Ames and others, 1987; Smith and Granato, 2005; Windsor and Mooney, 2008; Windsor and others, 2011; Cole-Parmer, 2014; Omega, 2014). For example, chloride probe manufacturers recommend that probes be recalibrated every hour to maintain a high standard of reproducibility (Cole-Parmer, 2014; Omega, 2014).

Windsor and Mooney (2008) did a 7-day test to compare the performance of a chloride probe and a specific-conductance probe and found that the conductivity sensor drift was only 0.08 percent from the actual value and that the chloride-sensor drift was 8.4 percent from the reading after only 7 days. Ames and others (1987) and Smith and Granato (2005) developed intricate systems with climate control and a system of filters, pumps, and standard-calibration solutions to obtain stable and reliable ion-specific probe measurements in the field, but the cost of equipment, standard-calibration solutions, labor, power, and other logistical requirements exceeded the cost of automatic sample-collection efforts. Furthermore, these systems may be applicable for precipitation or groundwater monitoring, but suspended sediment, particulate matter, and biofouling from stormwater samples made the system impractical for stormwater monitoring (Smith and Granato, 2005). Other researchers who tried to use chloride probes for automatic monitoring in streams receiving highway runoff also had similar results (John R. Mullaney, U.S. Geological Survey, written commun., 2008).

\section{Electromagnetic Conductance}

Electromagnetic conductance is the electrical conductivity of the ground that is a function of the conductivity of the rock or sediment type, porosity, and ion-exchange capacity, and the quality and quantity of water within the geologic structure. The electromagnetic conductance is measured by using surface geophysical methods, which generate an electric current or a magnetic field and measure the response (fig. 15;
Zohdy and others, 1974; Mack and Maus, 1986; Knuth and others, 1990; Lesch and others, 1995; Jones and Sroka, 1997; Sharma, 1997; Paine, 2001; Risch and Robinson, 2001; Barlow, 2003; Abraham and Lucius, 2004; Lundmark and Olofsson, 2007; Canton and others, 2010; Harte and Trowbridge, 2010; Henderson and others, 2010; Earon and others, 2012; Prinos, 2014) or borehole (Keys and MacCary, 1971; Church and Friesz, 1993; Williams and others, 1993; Church and Granato, 1996; Paillet and Crowder, 1996; Williams, 1996; Sharma, 1997; Paine, 2001; Risch and Robinson, 2001; Watson and others, 2002; Barlow, 2003; Johnson and others, 2002; Johnson and others, 2005; Henderson and others, 2010; Metzger and Izbicki, 2013). Electromagnetic methods provide the means for detecting the salinity of water in the unsaturated zone and in groundwater over large areas and multiple depths that would be difficult to characterize without an extensive network of piezometers, lysimeters, and groundwater monitoring wells. These geophysical methods are used with information about the geology, hydrology, and water-quality of the area to detect variations in the quality of soil and groundwater in space and (or) time. Water-quality data may be used to develop relations between electromagnetic conductance in the area of interest and the specific conductance, TDS, or chloride in groundwaters and soil waters. Electromagnetic conductance is sometimes described by using the term "resistivity," which is the inverse of conductance. Surficial measurements can be made by using installed sensor arrays (for example, Knuth and others, 1990; Canton and others, 2010; Henderson and others, 2010; Earon and others, 2012) and mobile instruments that are carried (for example, Mack and Maus, 1986; Knuth and others, 1990; Lesch and others, 1995; Jones and Sroka, 1997; Paine, 2001; Harte and Trowbridge, 2010), towed behind vehicles (for example, Triantafilis and McBratney, 1998), towed behind water craft (for example, Manheim and others, 2002), or mounted to aircraft (for example, Paine, 2001; Barlow, 2003; Prinos, 2014).

\section{Atmospheric Deposition}

Atmospheric deposition encompasses a diverse set of sources, processes, and sinks; monitoring atmospheric deposition to estimate chloride loads to a watershed or contributing area is fraught with uncertainty (Thimonier, 1998; Krupa, 2002; Colman and others, 2003; Dämmgen and others, 2005; Wetherbee and Rhodes, 2013). The total atmospheric deposition, which is measured as bulk precipitation, consists of dry deposition and wet deposition (fig. 16). Each of these components may be further categorized as sedimenting constituents (components that will, in theory, eventually fall under the force of gravity) and nonsedimenting constituents (the aerosols and gasses that will not settle by gravity). The relationships among these categories, however, are complex. For example, water vapor is a gas that will not settle. Water droplets may form when vapor condenses on a particulate, and the droplet may cause further condensation and may 


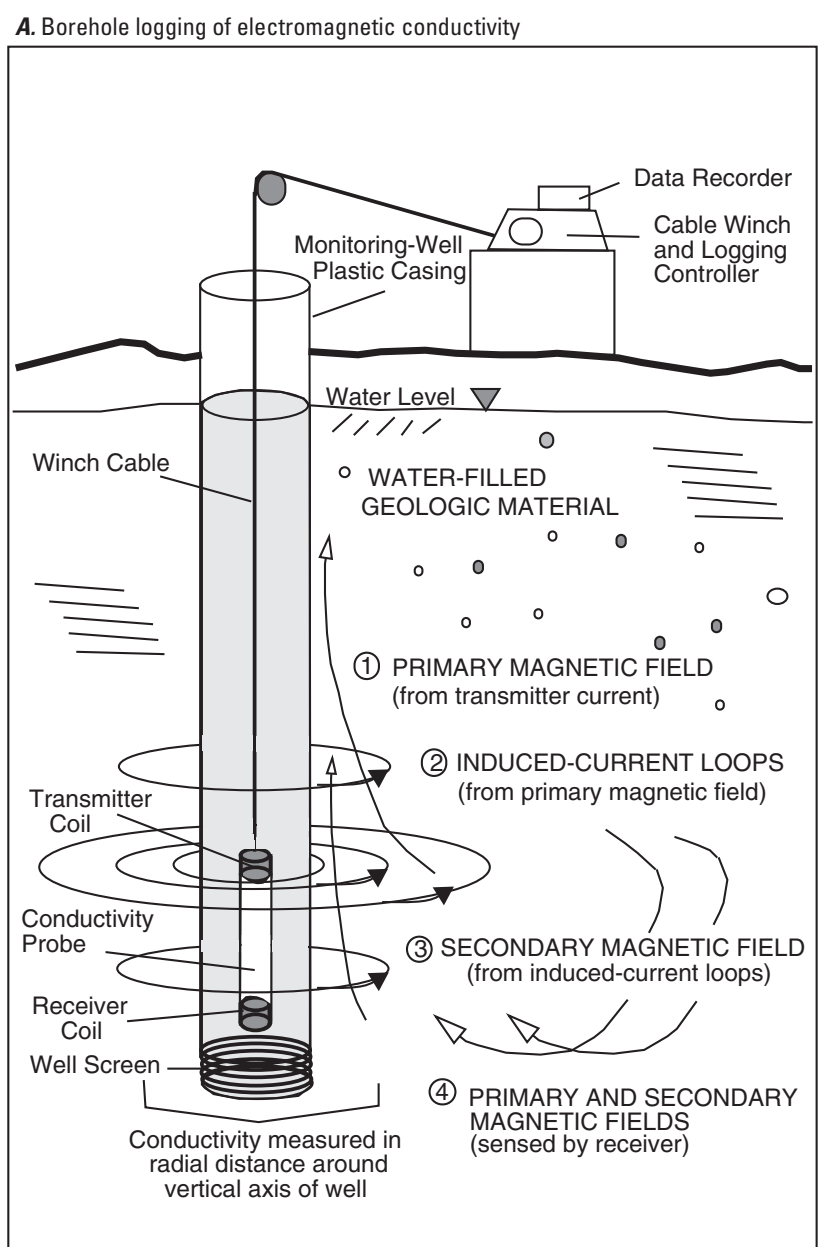

Modified from Williams and others (1993), and Mack (1993)
B. Surface survey of terrain conductivity

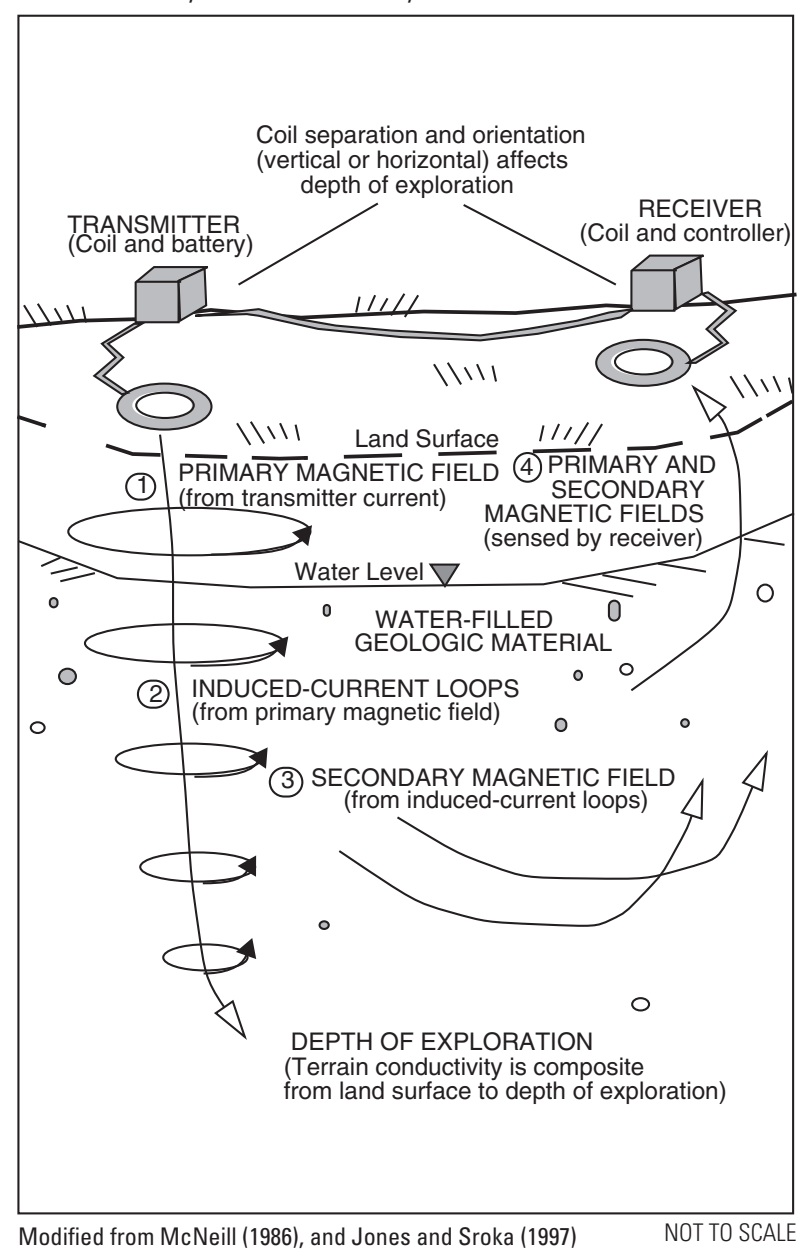

Figure 15. A, Principles of borehole logging of electromagnetic conductivity and $B$, a surface survey of terrain conductivity. Modified from Risch and Robinson (2001).

Atmospheric constituents (bulk deposition)

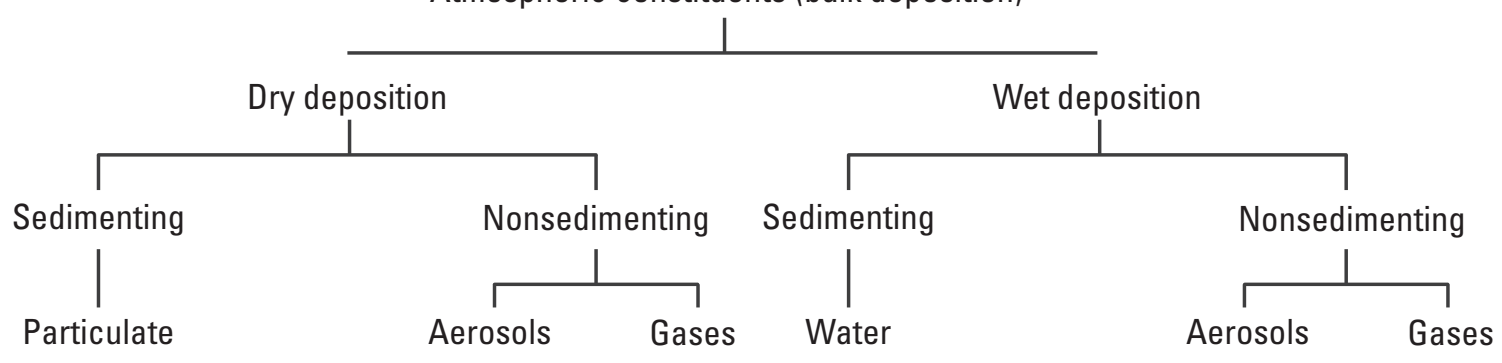

Figure 16. Conceptual categorization of the components of atmospheric deposition with respect to their deposition properties and flux detection methods. Modified from Grunhage and others (1993). 
scavenge gases, aerosols, and particulates during transport and precipitation. Conversely, small low-density particulates that would settle in a quiescent atmosphere may be kept aloft by atmospheric turbulence until they are scavenged by precipitation. Gas particles may impact vegetation, water bodies, the ground, and samplers. Methods for measurement of atmospheric deposition are designed to measure the influx of constituents from the atmosphere, but measurements may also reflect losses from sampling systems to the atmosphere.

There are many complex processes, including wind, evapotranspiration, saltation, and combustion, that may inject solids, aerosols, and gasses into the atmosphere at the site scale, the local scale, the watershed scale, the regional scale, or the global scale (Harned, 1988; Lovett and others, 2000; Colman and others, 2003). For example, Lundmark and Olofsson (2007) indicated that short-range deposition by plowing, splash, and spray was responsible for depositing 22 percent of the chloride applied to the road within 2 meters (m) of the road and 40 percent of the salt that was applied within $10 \mathrm{~m}$ of the road; almost all of the remaining 5 percent of chloride lost to splash, spray, and plowing was deposited within $100 \mathrm{~m}$ of the road. The NADP is designed to avoid the influence of local sources; this national dataset must be augmented to estimate deposition in developed areas (Wetherbee and others, 2011). Local monitoring may be needed at the site scale if a large upwind source is suspected.

The design and implementation of an atmospheric deposition monitoring program are complex; major errors can be introduced through suboptimal designs. The quality of data depends on the equipment design and the placement and operation of the samplers (Buso and others, 2000; Krupa, 2002; Colman and others, 2003; Dämmgen and others, 2005; Wetherbee and Rhodes, 2013). The sampler geometry, material, and placement will affect results. Precipitation samples commonly are very dilute solutions with weak ionic strength; they are easy to contaminate and difficult to analyze. Use of multiple collocated samplers provides a higher degree of certainty but adds substantially to the costs. Compositing samples from collocated samplers, however, is not recommended, because one contaminated sample can determine the result (Dämmgen and others, 2005). The USGS provides a QA/QC program for the NADP efforts (Nilles, 2000; Wetherbee and others, 2005, 2011; Wetherbee, and Rhodes, 2013); many elements of this program can be applied to improve local sampling. For example, it has long been known that precipitation volume data are biased low in unshielded precipitation gages, but shields have not been used in atmospheric deposition collectors for fear of contamination; the USGS QA/QC program developed a noncontaminating shield that increased the catch efficiency of wet-deposition samplers by about 39 percent (Wetherbee and Rhodes, 2013).

Bulk deposition samplers commonly are collection buckets that are always opened to the atmosphere (Buso and others, 2000; Krupa, 2002; Colman and others, 2003; Dämmgen and others, 2005; Lundmark and Olofsson, 2007).
Bulk deposition samplers are not commonly used in national atmospheric-deposition networks because the samplers are subject to undefinable contamination and losses, which are accentuated because they are always open (Krupa, 2002; Colman and others, 2003; Dämmgen and others, 2005). In some cases wet-deposition and dry-deposition sampling results are summed to estimate bulk deposition (Vet and others, 1988). In forested basins, stemflow samplers may be necessary because stemflows may represent about 10 percent of precipitation that reaches the soil column (Thimonier, 1998). Recently, ion-exchange samplers have been developed and tested to measure the quantities of ionic constituents in bulk precipitation that are washed down a funnel and through an ion-exchange column (Fenn and others, 2002; Simkin and others, 2004; Sheibley and others, 2012). These samplers can be deployed for long periods of time but are affected by the funnel's catch efficiency and the potential for contamination from bird droppings. Because it is difficult and expensive to operate a robust monitoring network, it may be best to use the NADP wet-deposition data to provide planning-level estimates of bulk deposition by using correction factors. The literature indicates that wet deposition commonly accounts for about 60 to 90 percent of the bulk deposition total for many constituents (Vet and others, 1988; Peters and Ratcliffe, 1998; Thimonier, 1998; Staelens and others, 2005; Balestrini and others, 2007; Izquierdo and Avila, 2012).

Wet-deposition samplers commonly are collection buckets or funnels that are opened when a sensor detects the onset of precipitation and closed once the sensor detects the end of precipitation (Krupa, 2002; Colman and others, 2003). Water samples are held for a sampling interval and then removed for field and (or) laboratory constituent measurements. Automated wet-deposition samplers that use ion-specific electrodes to produce real-time records of precipitation chemistry were developed in the 1980s (Ames and others, 1987; Krupa, 2002) but have not been widely adopted in practice, presumably because of the difficulties in field deployment of automated ion-specific electrodes described in the "Specific Conductance" section of this report. In theory, the bulk ion-exchange samplers described by Fenn and others (2002) and Simkin and others (2004) could be modified with a dry-period lid to monitor wet deposition.

Dry-deposition samplers commonly are collection buckets or funnels that remain open except when a sensor detects the onset of precipitation, triggering the sampler to close; dry deposition is commonly measured in conjunction with wet deposition by using a wet-dry sampler (Krupa, 2002; Colman and others, 2003). The data from dry-deposition samplers also are subject to losses and contamination because they are open to the atmosphere for a substantial amount of time. When bulk-deposition samples are compared to the sum of wet- and dry-deposition samples, there can be large variations in the estimates produced because of variability and bias in the sampling, sample handling, and analyses processes (Sherwood, 2003, 2006). 
Air-quality sampling data may be used to estimate material available for deposition or to adjust regional atmospheric monitoring results to reflect local conditions. The EPA's ambient air quality monitoring program is carried out by State and local agencies and consists of three major categories of monitoring stations: State and local air monitoring stations, with about 4,000 stations nationwide; national air monitoring stations, with about 1,080 stations nationwide; and special purpose monitoring stations (SPMSs), which are not permanently established stations, that measure the criteria pollutants (U.S. Environmental Protection Agency, 2013a). The EPA provides a five-volume set of information for running air monitoring stations that produce representative data (U.S. Environmental Protection Agency, 2013b). The SPMS network may provide the opportunity for monitoring air quality at sites of interest for chloride monitoring studies

Saltation is the hopping motion of large particles (sand size or greater) across the land surface. In the natural environment, saltation is driven by wind (Harned, 1988; Shao and others, 1993; Zobeck and others, 2002). Atmospheric deposition samplers are placed well above ground to prevent the sampling of such particles. Saltation can generate particulates that will later settle if the large particles impact an erodible surface, which can kick up fine dust for short- or long-range wind transport (Shao and others, 1993; Zobeck and others, 2002). On highways, roadways, and parking lots saltation may be driven by the natural prevailing wind, by turbulence caused by vehicle traffic, by tire action, or by sand and salt spreaders (Harned, 1988). Increasingly, State DOTs are prewetting salt before application to reduce saltation from the pavement to the roadside environment; these measures are estimated to reduce salt loss by about 87 percent (New Hampshire Department of Environmental Services, 2013). Saltation samplers consist of slotted containers, which may be fixed or designed to rotate with the prevailing wind (Shao and others, 1993; Zobeck and others, 2002).

\section{Vadose Zone}

The vadose zone includes the material between the land surface and the groundwater interface, which is defined as the point at which the saturated hydraulic head equals atmospheric pressure (Tindall and others, 1999; Looney and Falta, 2000; Heath, 2004; Fares and others, 2009). The vadose zone also is commonly referred to as the unsaturated zone, but the vadose zone may be partially or completely saturated during recharge events. The vadose zone commonly is described as consisting of three zones: the soil zone, the intermediate zone, and the capillary fringe. The soil zone is the uppermost meter or two of soil and has relatively high permeability because of the presence of roots and voids. The intermediate zone is relatively undisturbed and is commonly stratified with depth. The capillary fringe is at the boundary of the aquifer, where capillary action of water and sediment pull water up out of the saturated zone; water in the unsaturated zone exists under negative hydraulic pressure. Under unsaturated conditions, a substantial amount of water may remain as a film on sediment surfaces, as capillary water in cracks in the sediment grains, and as capillary water in the pores between sediment grains. The specific retention values for granite bedrock, gravel, sand, soil, and clay are about $0.01,1,3,15$, and 48 percent, respectively (Heath, 2004). When recharge occurs, the stratified horizontal layers of sediment tend to retard vertical flow because of differences in grain size, pore size, and particle sorting, which can cause large differences in vertical and horizontal hydraulic conductivity. As a result, infiltrating water tends to flow through preferential flow paths that may alternate between horizontal and vertical directions. Thus, the hydrologic properties of the vadose zone and the occurrence of intermittent flows that may mix waters from sequential storms complicate sampling and interpretation of data from the vadose zone (Tindall and others, 1999; Looney and Falta, 2000; Fisher and Healy, 2008; Fares and others, 2009; Graham and Lin, 2011; Perkins and others, 2011).

Soil cores are one method that is commonly used to assess the occurrence of water and solutes in the unsaturated zone (Boll and others, 1992; Landon and others, 1999; Looney and Falta, 2000; Boulding and Ginn, 2003; Lundmark and Olofsson, 2007; Cunningham and others, 2008; Fares and others, 2009; Perkins and others, 2011). Cores are weighed, dried, and weighed again to ascertain the water content. Dried core materials can be mixed with deionized water, shaken, and the resulting solution can be filtered to obtain a chloride concentration (Lundmark and Olofsson, 2007). It can be difficult to capture the chemistry of infiltrating water because it is difficult to sample the preferential flow paths by random coring (Perkins and others, 2011) and because cores tend to capture the less mobile soil waters (Landon and others, 1999). Coring can provide valuable information about the stratigraphy of soils and the distribution of water and solutes at one place in space and time, but repeated coring efforts in small areas at research sites can disturb the soil column and create preferential flow paths through the unsaturated zone (Lundmark and Olofsson, 2007).

Monitoring the flow of water and solutes in the unsaturated zone is complex and difficult (Peters and Healy, 1988; Boll and others, 1992; Rimmer and others, 1994; Stone and Robl, 1996; Landon and others, 1999; Looney and Falta, 2000; Boulding and Ginn, 2003; Fares and others, 2009; Peranginangin and others, 2009; Thomas and others, 2013). Vadose-zone pore-water samplers include suction-cup lysimeters, gravity pan lysimeters, suction wick lysimeters, wick pan lysimeters, and agricultural tile lines. For example, Landon and others (1999) used isotope ratios to estimate that 95 to 100 percent of water collected by wick samplers and 15 to 95 percent of water collected by suction lysimeters was mobile soil water. Boll and others (1992) indicated that pan samplers produce samples only when the soil above the sampler is saturated, and suction samplers produce samples only from saturated soils and from the large pores of unsaturated soils. Similarly, Peranginangin and others 
(2009) noted that gravity and wick pan lysimeters had high collection efficiencies at high soil moisture levels, wick pan samplers could obtain samples under saturated conditions and lower moisture contents, and cup samplers had low collection efficiencies over a wide range of conditions. Agricultural tile lines will produce concentrations and flows under saturated conditions, but use of tile samplers is limited by topography (Boll and others, 1992). It is difficult to emplace any sampler without disturbing the natural flow paths through the soil; in some cases a trench is dug and the samplers are inserted in the sidewall of the trench. Dahan and others (2006) developed a deep vadose zone monitoring system that combines timedomain reflectometry sensors for continuous measurement of water content and suction-cup samplers for water-quality measurements; this system is inserted in a diagonal borehole between the land surface and the water table to minimize disturbance of soils above the sampling array.

An array of surface and borehole geophysical methods such as electrical, electromagnetic, nuclear, acoustic, seismic, and ground-penetrating radar techniques are used to identify lithological features and to monitor the flow of water and solutes in the vadose zone (Looney and Falta, 2000; Boulding, and Ginn, 2003; Abraham and Lucius, 2004). Such methods can provide information over relatively large areas, in comparison to pore-water sampling, without disturbing the soil column. Multiple geophysical methods may be needed because the sediment, dry pore space, wet pore space, water, and solutes all contribute to different types of geophysical measurements. Soil cores and pore-water sampling efforts also may be needed to interpret the geophysical data collected at a given site. Differences between repeated geophysical measurements may be useful for interpreting ongoing processes at a site of interest. For example, Lundmark and Olofsson (2007) used direct-current resistivity measurements to estimate the distribution of chloride in the unsaturated zone along different transects near the highway. The distribution of bedrock, clay, and sandy soil was too complex for estimating chloride concentrations, but differences between measurements before and after the winter season indicated areas in which preferential salt migration was occurring. Lundmark and Olofsson (2007) recommended this method for repeated profiling at a study site because it is inexpensive, can be done in a short time, and does not alter the soil column.

\section{Groundwater}

Groundwater, which is water in the saturated zone under the land surface, occurs throughout the United States (Domenico and Schwartz, 1998; Heath, 2004; Eberts and others, 2013). Increasing chlorides in domestic and public groundwater supplies have been the focus of investigations for almost 50 years (Dowst, 1967; Coogan, 1971; Pollock and Toler, 1973; Eberts and others, 2013). More recently, groundwater studies have been done to address the fact that infiltrating chloride from wastewater, agricultural sources, and deicing applications may represent a large and increasing source of chloride to surface water and groundwater throughout each year (Panno and others, 2006; Kelley and others, 2008; Casey and others, 2013; Perera and others, 2013). This is an important realization because the widespread adoption of low-impact-development practices that use infiltration of runoff to reduce problems with surface-water quality and flow will accelerate chloride contamination of groundwater, which may become a year-round source of elevated stream concentrations (Casey and others, 2013).

If increasing chloride or specific conductance is detected in public-supply wells, comprehensive studies may be needed to properly identify the different contributors. In most cases, assumptions about the source of water to public-supply wells on the basis of topography are likely to be misleading. Contributing areas to wells can be complex, especially if there are nearby surface-water bodies, if there are multiple wells, or if the wells are in a complex hydrogeologic setting (Reilly and Pollock, 1993; Franke and others, 1998; Friesz and Stone, 2007; Eberts and others, 2013). For example, Izbicki (2000) found that elevated specific conductance and chloride in several public-supply wells along the Blackstone River in Massachusetts were primarily the result of induced surfacewater infiltration by withdrawals from the wells. During low flows, the Upper Blackstone Water Pollution Abatement District wastewater-treatment plant is the primary source of water in the Blackstone River near these wells. For one publicsupply well in Millbury, Massachusetts, topographic analysis and conventional wisdom would suggest that the source of chloride was deicing salts from two State highways that are within $600 \mathrm{ft}$ of the well and a large shopping mall within $1,000 \mathrm{ft}$ of the well. This assumption could prompt expensive and unsuccessful mitigation measures and would not protect the public from the host of wastewater contaminants, such as pharmaceuticals, that are not identified in commonly used drinking-water analyses (Reif and others, 2012).

The movement of water and the transport of solutes through the ground is complex. An understanding of the hydrogeology within and outside of one or more well clusters that are installed to evaluate a specific problem or to monitor changing conditions at a site of interest is needed to obtain a proper understanding of measurements taken from wells. The USGS has done many local, regional, and national studies that provide the methods, data and information needed to monitor and model chloride in groundwater. The USGS Regional Aquifer-System Analysis program was done to define the hydrogeology and provide background information on geology, hydrology, and geochemistry of the Nation's 25 largest groundwater systems. Sun and others (1997) provide a bibliography of the 1,105 reports that result from various studies of the program, which is organized by aquifer system. The USGS Groundwater Resources Program is an ongoing effort designed to provide the interdisciplinary scientific information needed to assess and quantify the Nation's groundwater resources (U.S. Geological Survey, 2013d). The focus of this program is on groundwater availability in 15 large aquifer 
systems. The USGS National Water Quality Assessment program is conducting monitoring and modeling to assess the status and trends of groundwater quality within 20 of the Nation's principal aquifer systems (U.S. Geological Survey, 2013d). Data, interpretations, and models from these national programs and hundreds of local groundwater investigation studies by USGS water science centers in each State should provide sufficient understanding of the effects of local climate, groundwater recharge, hydrogeology, and groundwater quality for planning and interpreting local groundwater investigations. For example, daily data from 6,554 groundwater monitoring sites and measurements from 852,024 wells are available online from NWIS (http://waterdata.usgs.gov/nwis).

The USGS also completed studies that provide methods needed to monitor and model chloride in groundwater. This series of studies demonstrates the use of hydrogeologic data, groundwater-quality data, and surface and borehole geophysics to detect and quantify flows, concentrations, and loads of chloride in groundwater (Church and Friesz, 1993; Williams and others, 1993; Church and others, 1996; Kunze and Sroka, 2004; Harte and Trowbridge, 2010; Schalk and Stasulis, 2012). The USGS National Water-Quality Assessment Program developed protocols for setting up a monitoring-well network (Lapham and others, 1995) and for obtaining defensible samples from monitoring wells (Koterba and others, 1995). The USGS also provides protocols for calibration of instruments and for filtering and processing of samples (USGS, 2013c). Use of such methods and protocols can improve data quality and can result in monitoring data that are consistent with tens of thousands of groundwater measurements collected from thousands of wells; , these measurements are available on NWIS.

The costs associated with installing and monitoring multiple wells at a given site commonly result in the installation of one well or a few wells with long screens to sample the entire depth of the aquifer. Church and Granato (1996) demonstrated that it would be difficult or impossible to obtain representative samples from long-screen wells and that the long-screen well may act as a conduit spreading a contaminant plume over the depth of the well. These field experimental results confirmed the modeling predictions made by Reilly and others (1989). Church and Granato (1996) concluded that use of electromagnetic induction logs in fully cased wells that span the depth of the aquifer can be used to identify zones of high conductivity or changing conductivity, which may indicate the presence of a contaminant plume. This information can be used with other hydrogeological and geophysical information to locate short-screen monitoring wells. Figure 17 shows the implementation of this type of design in two well arrays upgradient and downgradient of State Route 25 in southeastern Massachusetts. Other studies also have shown that groundwater quality can change substantially over small vertical distances; in such cases, multiport sampling wells have been proposed to be used where possible (Gibs and others, 1993; Delin and Landon, 1996).
The USGS also has implemented the filter-press method to identify different water-quality zones as the well is drilled by extracting water from sediment core samples for onsite analysis (Lusczynski, 1961). Lusczynski (1961) used titration to directly measure chloride, but specific conductance may be a quick and simple alternative for identifying variations in water quality. This method also may be used to put in a fully cased deep well while informing placement of subsequent short-screen sampling wells.

Because groundwater travels much more slowly than surface water, it has long been thought that annual, quarterly, or monthly groundwater sampling was sufficient for characterizing groundwater quality; however, results from automated monitoring efforts have demonstrated that substantial changes in concentration may occur over a few days, especially with time-varying sources of water-quality constituents (Granato and Smith, 1999a,c, 2001, 2002; Savoie and others, 2004). Smith and Granato (1998) showed that measurements made by a passive specific-conductance probe in a stagnant well did not represent the magnitude or changes in water quality measured by using approved groundwater sampling protocols. They developed a real-time monitoring system named Robowell that automatically pumps and purges a well in accordance with USGS manual-sampling protocols on an hourly, daily, or weekly schedule (Granato and Smith, 1999b,c, 2000, 2001); the utility of this system was demonstrated on several field sites. Robowell is well suited for monitoring variable point or nonpoint sources of chloride in groundwater because it can monitor water levels and quality in one or more adjacent wells and notify the user when conditions change by a user-defined threshold. Monitoring results also can be made available in real time for remote monitoring and sampling-system activation. Use of remote sampling-system activation can substantially reduce sampling costs because the Robowell unit can purge the well and collect samples before the sampling team arrives to collect the bottles.

Base-flow monitoring is an alternative to sampling wells for characterization of groundwater quality because it is difficult to completely characterize groundwater quality at the basin scale even with a large number of monitoring wells (Heisig, 2000; Clune and Denver, 2012). The water sampled from each well commonly is derived from a space within a few centimeters of the well screen. Groundwater wells are expensive to emplace and monitor. In comparison, sampling base flow, which is defined as the streamflow that represents groundwater discharge that occurs between periods of stormflow, provides an integrated sample from the entire upstream area. Base-flow sampling is relatively fast and inexpensive, especially in small tributary streams, for which it is well suited. A combination of base-flow sampling and groundwater monitoring can provide more detailed information about various sources and the lagtimes between recharge and discharge from different areas (Clune and Denver, 2012).

Heisig (2000) provides a good example of a base-flow sampling program that was designed to characterize the 

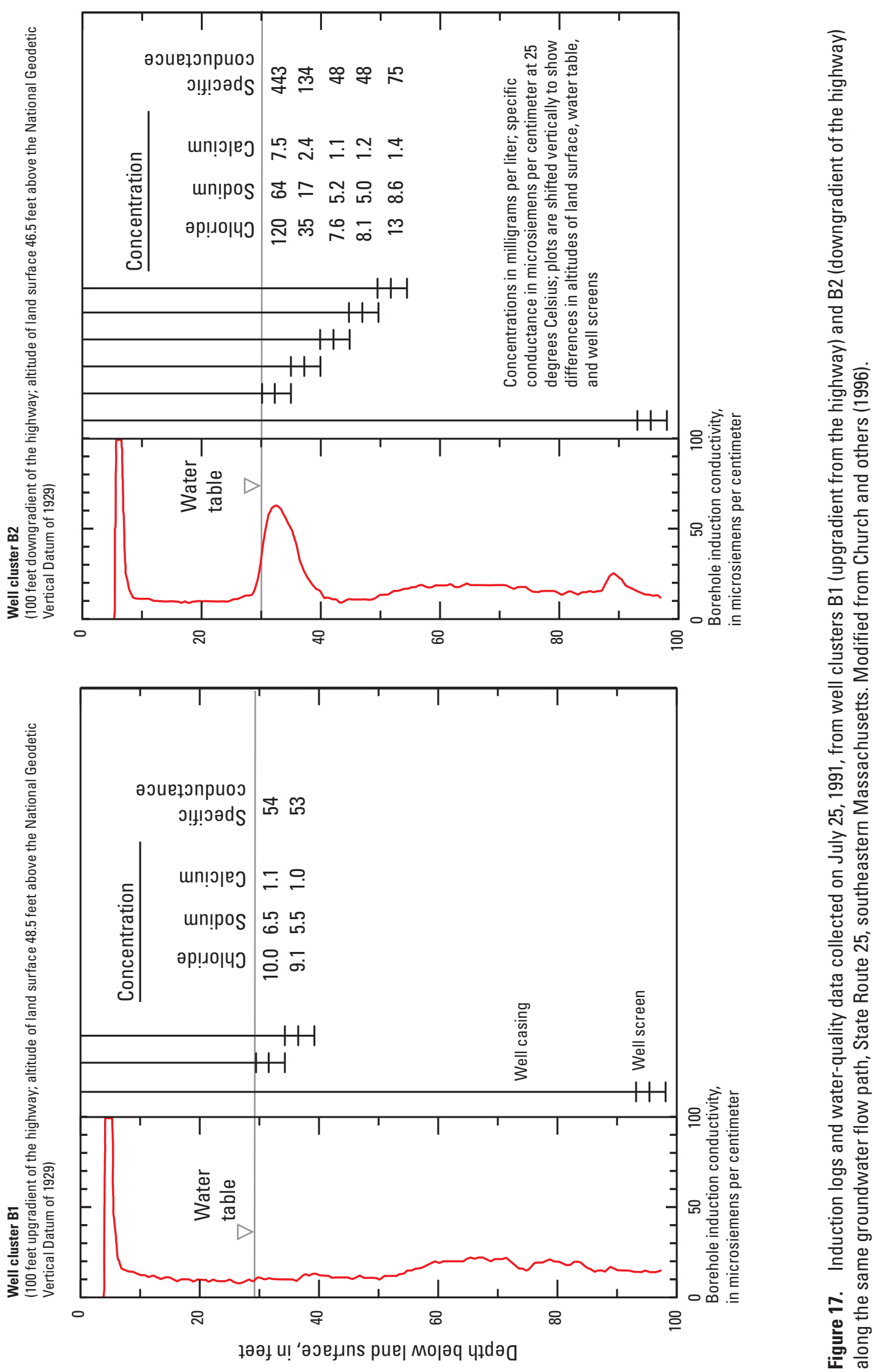
quality of groundwater from different land-use areas. Heisig (2000) measured water-quality properties and constituents in base flow from 33 small basins (with drainage areas ranging from 0.06 to 1.55 square miles) within the Croton watershed in southeastern New York. He used land-use data with the water-quality data to evaluate sources of constituents in base flow. He found that specific conductance, chloride, and nitrate were highest in the unsewered residential basins. Chloride was highly correlated with salt application rates and two-lane road density; he also found high correlations between nitrates and unsewered housing density. He attributed the chloride to road deicing and the nitrates to septic-system discharges, despite the facts that chloride concentrations can be high in septic effluent (especially if water softeners are being used) and that the chloride concentrations were lower in the sewered basin. One would expect that housing density and two-lane road density would be highly correlated, especially in suburban areas. Also, wastewater may be a source of chloride in sewered basins because sewer pipes commonly leak into the underlying aquifer; leakage rates are estimated to be between 1 and 13 percent of dry weather flows (Rutsch and others, 2006). For example, Eisen and Anderson (1979) found elevated chloride, ammonium, and fecal bacteria in monitoring wells downgradient of a highway and a sewered area near sewer pipes; they note that the initial road-salt assumption would not indicate the presence of nitrogen and bacteria in the well water. Hyer (2007) used base-flow sampling with a combination of inexpensive and expensive water-quality analysis techniques to identify methods for detecting sewage inputs to receiving waters and to identify sewage sources in the Accotink Creek Basin in Virginia. Hyer (2007) found elevated specific conductance and chloride concentrations in waters affected by sewage inputs. Although Heisig's (2000) interpretation of sources of chloride did not attribute any chloride to wastewater sources, careful use of base-flow monitoring results with land-use information for a large number of basins can be a useful way for evaluating groundwater quality in a large area.

\section{Surface Runoff}

Surface runoff includes sheet flow on pervious and impervious surfaces, flow in drainage systems, flow into or out from structural BMPs, and flow in normally dry channels. Surface runoff may include the following:

- infiltration excess (Hortonian) overland flow, which occurs on impervious surfaces and in pervious areas when precipitation intensity or runoff from adjacent impervious areas exceeds the infiltration capacity of these areas;

- saturation overland flow, which occurs in pervious areas when the groundwater table rises to the land surface so that precipitation and groundwater contribute to surface runoff; and
- meltwater flow, which occurs when solar energy, temperature, increasing salinity, or some other process melts accumulated ice or snow (Ward, 1984; Strecker and others, 2001; Smith, 2002; Church and others, 2003; Smith and Granato, 2010; Granato, 2010a).

Surface-runoff monitoring is difficult because runoff occurs intermittently, and when it does occur, the flow rates and concentrations can change by orders of magnitude in a matter of minutes. Automated monitoring and sampling methods that commonly are used for monitoring stormwater runoff are, with some modification, suitable for monitoring chloride concentrations in runoff (Alley, 1977; Federal Highway Administration, 1985; Spangberg and Niemczynowicz, 1992; U.S. Environmental Protection Agency, 1992a; Church and others, 1996; Granato and Smith, 1999a, McFarland and Hauck, 2001; Strecker and others, 2001; Smith, 2002; Harmel and others, 2003; Natural Resources Conservation Service, 2003; Wagner and others, 2006; Geosyntec Consultants and Wright Water Engineers, 2009; Smith and Granato, 2010; California Department of Transportation, 2013).

Some published protocols allow for grab sampling of runoff flows, but automated monitoring and sampling equipment are needed to quantitatively characterize flows, concentrations, and loads of surface-runoff constituents. Automated monitoring is necessary because rapid changes in the flow and concentrations of runoff may occur within minutes. For example, figure 18 shows the range of chloride concentrations estimated from specific-conductance values measured at one-minute intervals in highway runoff during salt-affected runoff events. During the runoff event on January 2, 2006, estimated chloride values increased from less than 2 to more than $500 \mathrm{mg} / \mathrm{L}$ within 4 minutes, exceeded $6,000 \mathrm{mg} / \mathrm{L}$ within 5 minutes, and exceeded $7,500 \mathrm{mg} / \mathrm{L}$ within 6 minutes of the onset of runoff. Concentrations decreased to less than $500 \mathrm{mg} / \mathrm{L}$ within 28 minutes and were back below the $230 \mathrm{mg} / \mathrm{L}$ criterion within 30 minutes of the onset of runoff. Similarly, during the runoff event on February 25, 2006, the estimated chloride values increased from less than 10 to more than $1,000 \mathrm{mg} / \mathrm{L}$ within 1 minute and exceeded $10,000 \mathrm{mg} / \mathrm{L}$ within 8 minutes of the onset of runoff and were back below the $230 \mathrm{mg} / \mathrm{L}$ criterion within 69 minutes of the onset of runoff. It is unlikely that a grab-sampling program would produce representative samples, and it would be impossible for a sampling team to obtain comparative grab samples if they needed to sample multiple sites during the same storm event. Furthermore, the safety of grab-sampling teams may be compromised by adverse road conditions, limited visibility, and snow and ice removal operations during the winter storms that are of greatest interest for chloride monitoring studies. This is especially true because the highest concentrations of chloride are expected to occur shortly after the application of deicing chemicals.

Use of instantaneous measurements of flow and specific conductance coupled with automatic sampling systems is necessary to quantify flows, concentrations, and loads of chloride in runoff (Church and others, 1996; Granato and 


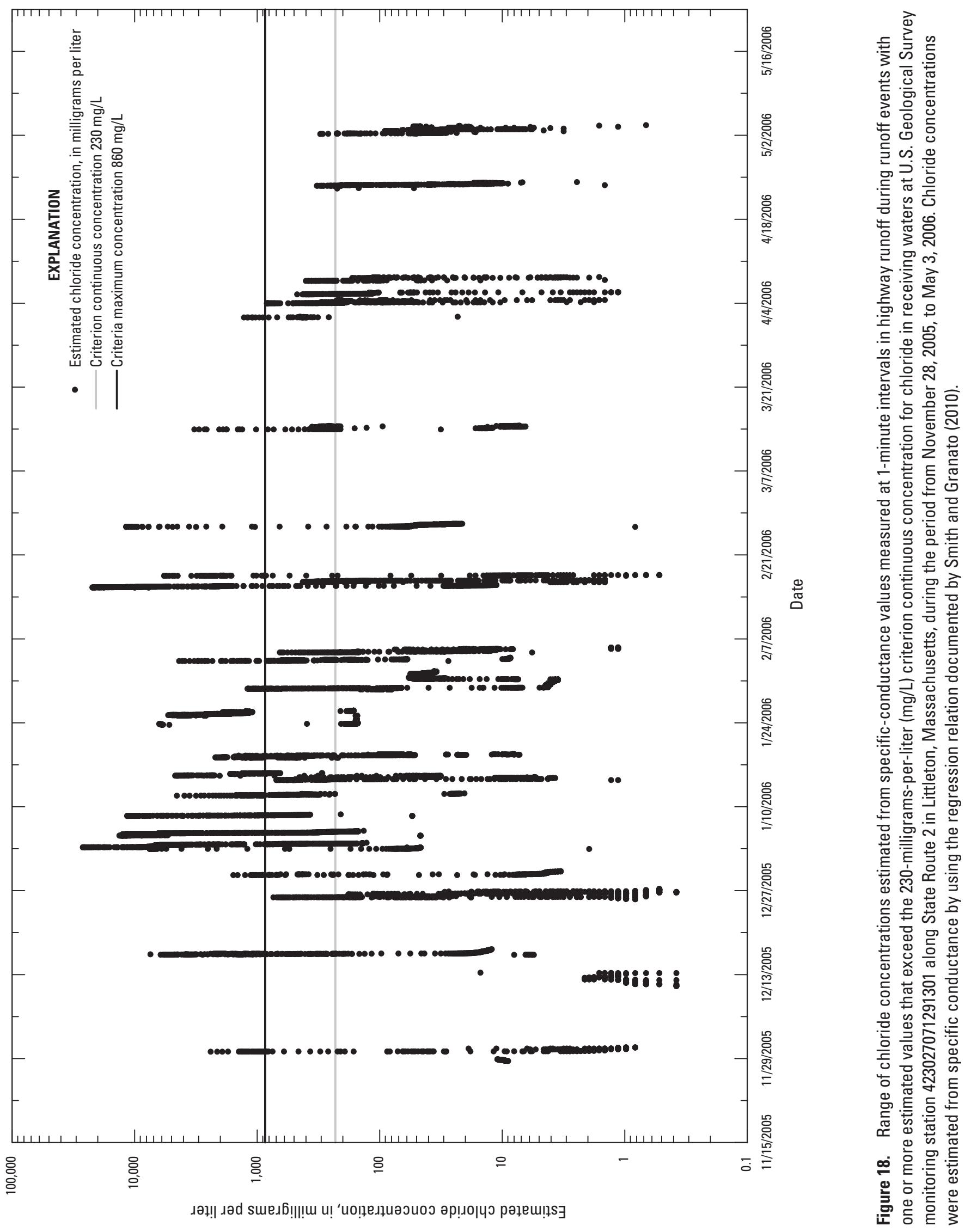


Smith, 1999a; Smith and Granato, 2010). Church and others $(1999,2003)$ describe methods for monitoring stormflows and the accuracy and precision of different methods. As described in the section on "Use of Ionic Conductance for Monitoring Chloride," relations between specific conductance and chloride concentrations can be used to provide robust estimates of chloride concentrations at short measurement intervals (Granato and Smith, 1999a; Smith and Granato, 2010). Flow-weighted composite sampling methods commonly are used to develop event-mean concentrations (EMCs) of runoff constituents. If, however, the monitoring program objective is to define concentrations and loads of dissolved salts, then specific-conductance measurements can be used to trigger the automatic sampler to obtain a series of discrete samples throughout the range of measured conductance. Flow in small sewers may be well mixed, but proper orientation of sample intakes and use of structures such as passive mixers or flumes will improve the representativeness of data collected with automatic samplers and fixed-point water-quality probes (Spangberg and Niemczynowicz, 1992; Edwards and Glysson, 1999; Smith, 2002; Bent and others, 2003; Smith and Granato, 2010). For stormwater-monitoring studies, the real-time measurements of flow and conductance can be used to assess the representativeness of the EMC sampling program. For example, Smith and Granato (2010) were able to establish that the flow-weighted stormwater samples were representative by comparing the 5-20 concentrations measured in storm samples collected at each site with the 72-149 concentration values estimated from measured specific conductance and flow during the monitored storms at each site.

Data from other automated monitoring instruments may be used by investigators with instantaneous measurements of flow and specific conductance to monitor conditions at a site of interest and interpret the water-quality records and samples that were collected. Commonly used air and water-temperature sensors can be used to assess the condition of the measurement section; however, ice buildup at the measurement section may affect the quality of measurements. Air and water temperature also may indicate that runoff is from a melt event rather than a precipitation event. Solar energy sensors such as a pyrheliometer, pyranometer, or a net radiometer may indicate the source of runoff as melt water even if air temperature sensors indicate freezing conditions at the air-temperature sensor location.

Additional equipment and increased station maintenance are required for winter monitoring efforts in comparison to monitoring efforts in the warm seasons (Kilpatrick and Schneider, 1983; Siccama and Denny, 2001; Bent and others, 2003; Church and others, 2003; Natural Resources Conservation Service, 2003; Wagner and others, 2006; Mentz and others, 2011; Busch and Mentz, 2012; Natural Resources Conservation Service, 2012; Hulstrand, 2014). Freezing conditions complicate monitoring efforts because of the following factors:

- ice can affect the hydraulic geometry of flow-measurement locations;
- snow and ice can cause backwater submerging weirs or flumes or other equipment;

- ice can clog sampling tubes and pumps;

- ice can damage equipment; and

- snow and ice can reroute flows away from probes and sampling intakes.

If the objective is to monitor runoff from impervious surfaces, the placement of monitoring sites in the drainage system below ground level where geothermal energy increases temperatures may decrease the occurrence of ice problems (Church and others, 1996; Granato and Smith, 1999a; Smith, 2002; Smith and Granato, 2010). If electric power is available, conductive and radiant heaters may help to keep instruments, tubes, and the measurement section free of ice. In the absence of subterranean monitoring locations and (or) electrical power, gas heaters may be used to keep the monitoring station ice free (Kilpatrick and Schneider, 1983; Siccama and Denny, 2001; Natural Resources Conservation Service, 2003; Mentz and others, 2011; Busch and Mentz, 2012). If heaters are used, then the monitoring location must be sheltered to minimize snow buildup and retain the heat necessary to reduce or eliminate ice formation. However, the shelter design must accommodate the range of possible flows.

\section{Streams and Rivers}

In this report, streams and rivers are defined as perennial or intermittent channelized surface-water flows with measurable horizontal flow velocities. The term "streamflow" is used to describe flows in both streams and rivers. Streamflow monitoring is difficult because flow rates and concentrations can change by orders of magnitude in a matter of minutes. For example, figure 19 shows variations in flow and specific conductance in Unnamed Tributary 1 in Stony Brook Reservoir watershed (Massachusetts) during the fall of 2006 and winter of 2007. During the fall, runoff dilutes the base flow, causing a decrease in specific conductance during the storm event. Elevated specific-conductance values indicate deicing-chemical washoff, then dilution from runoff during the winter event. Streamflow monitoring also may be difficult because flow velocities and constituent concentrations may vary across the channel and with depth. As such, automated monitoring and sampling methods that commonly are used for monitoring stormwater runoff also are necessary for defining the magnitude and variations of flows, concentrations, and loads of constituents of concern in streams and rivers (Christensen and others, 2000; Natural Resources Conservation Service, 2003; Rasmussen and others, 2005, 2008; Harmel and others, 2006; Clark and Davidson, 2009; Coon and others, 2009; Denner and others, 2010; Trowbridge and others, 2010; Brown and others, 2011; Smith and Breault, 2011; Baldwin and others, 2012; Smith, 2013). 


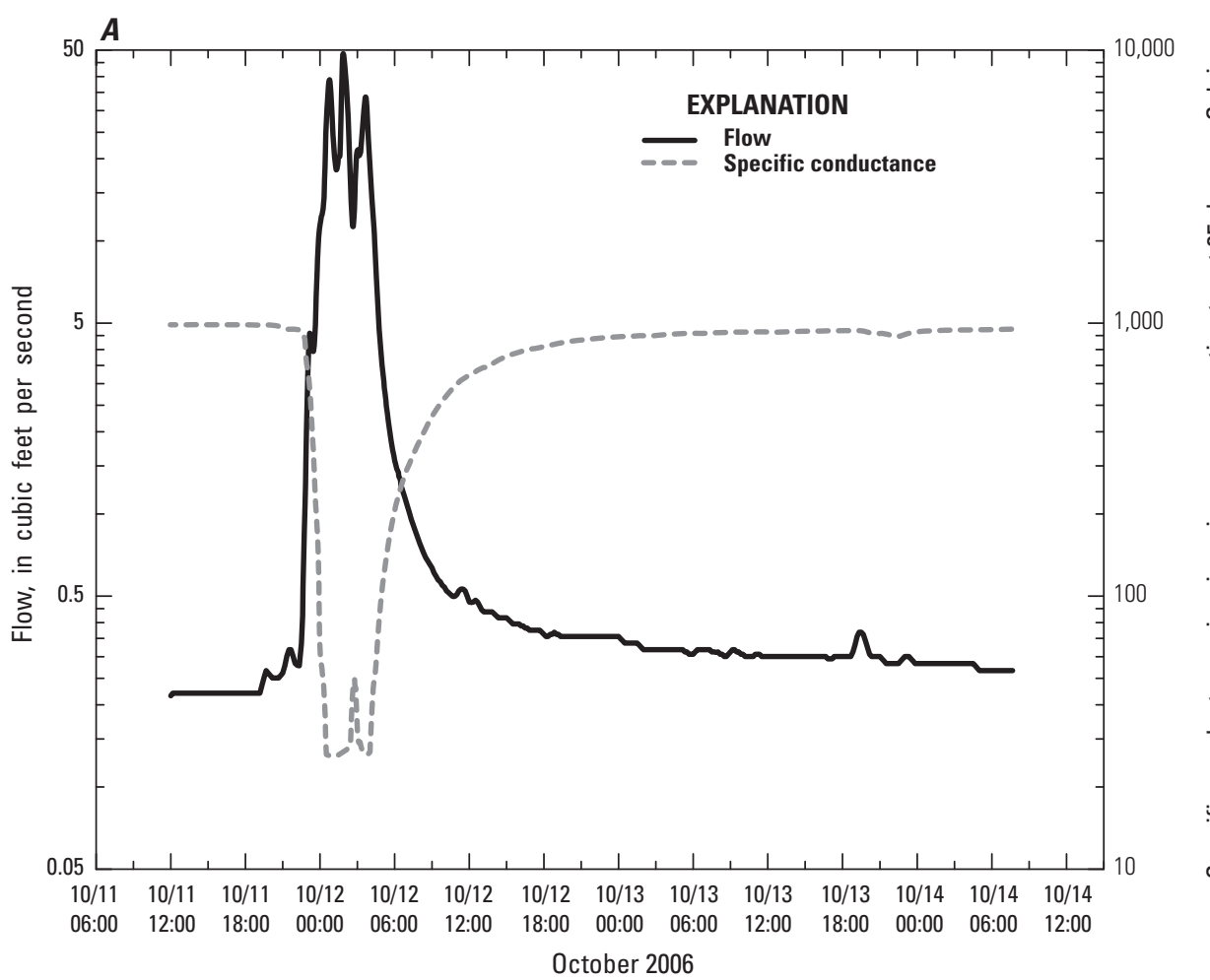

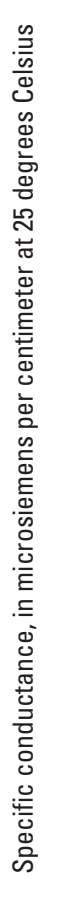

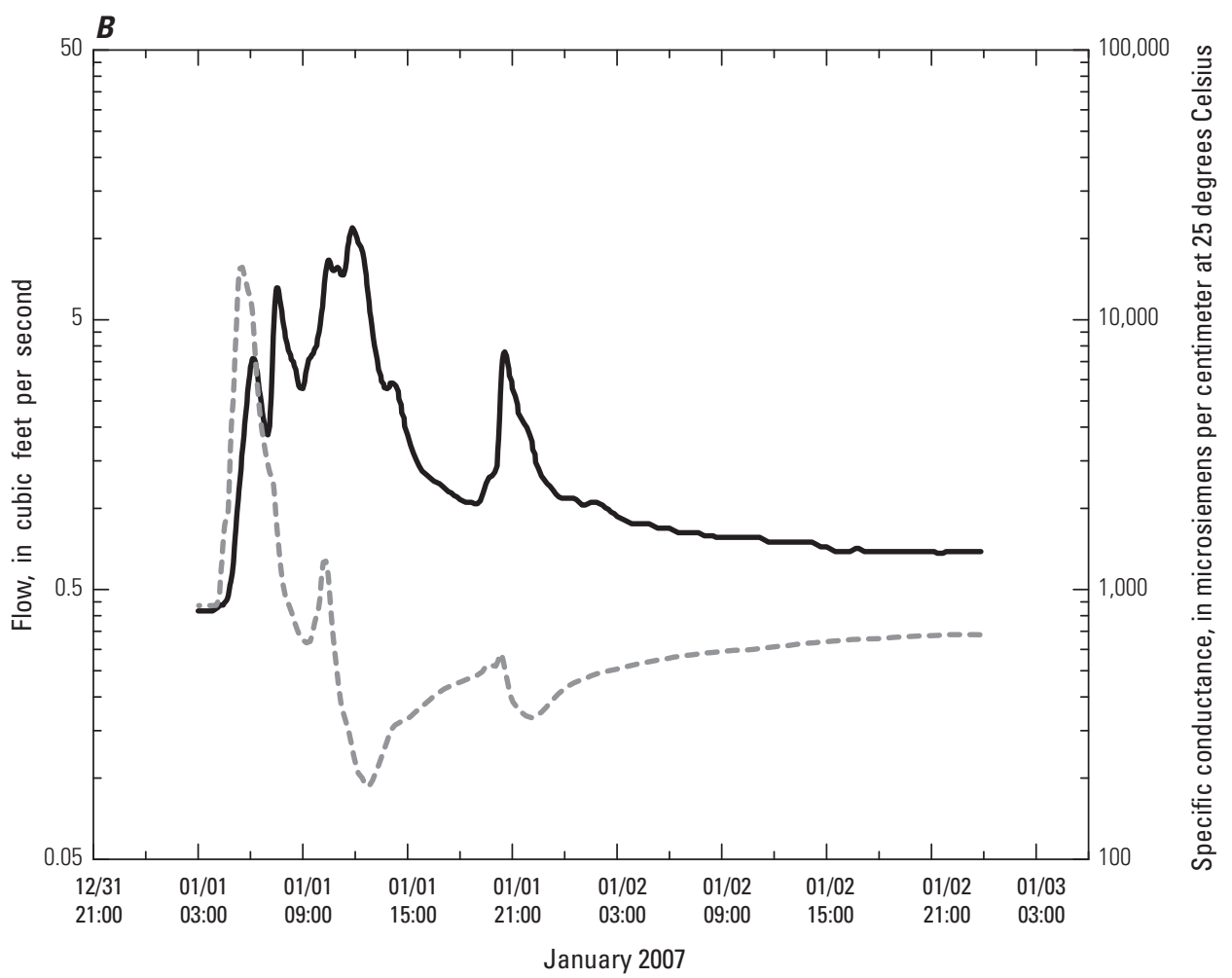

Figure 19. Records of flow and specific conductance during $A$, fall and $B$, winter storm runoff at U.S. Geological Survey streamgage 01104455, Unnamed Tributary 1, Stony Brook Reservoir watershed, Massachusetts, water year 2007. Modified from Smith (2013). 


\section{Methods for Evaluating Potential Sources of Chloride in Surface Waters and Groundwaters}

Real-time water-quality monitoring probes and automatic samplers can obtain instantaneous measurements and concurrent samples as streamflows and concentrations change, but cross-sectional variations in concentrations and flows must be considered to ensure that the point measurement and sampling location is representative of streamwater quality or that the point values can be adjusted to represent the flowweighted mean values (Zarriello and others, 1985; Natural Resources Conservation Service, 2003; Harmel and others, 2006; Wagner and others, 2006; Coon and others, 2009; Baldwin and others, 2012; Rasmussen and others, 2008; Rasmussen and others, 2009). Commonly used water-quality monitoring probes, such as turbidity, specific conductance, $\mathrm{pH}$, and dissolved oxygen probes, can be used to do equalwidth-increment or equal-discharge-increment monitoring (Edwards and Glysson, 1999; Natural Resources Conservation Service, 2003; Rasmussen and others, 2009; Stone and others, 2012) to assess the representativeness of the fixed monitoring probe(s) and automatic-sampler intake(s). The USGS also has published protocols for streamflow measurement (Rantz, 1982a,b; Sauer, 2002; Sauer and Turnipseed, 2010; Turnipseed and Sauer, 2010), real-time water-quality monitoring (Wagner and others, 2006; Rasmussen and others, 2009; Stone and others, 2012), and water-quality sampling (Webb and others, 1998; Ward and Harr, 1990; Mueller and others, 1997; Edwards and Glysson, 1999) that are applicable for monitoring chloride in streams and rivers.

\section{Ponds, Lakes, and Reservoirs}

In this report, ponds, lakes, and reservoirs are defined as bodies of water surrounded by land with small horizontal flow velocities between the inlet and the outlet. Depending on their sizes, run-of-the-river impoundments may behave like lakes during low flows and like streams during high flows. Definitive lake monitoring requires an understanding of the hydrology and limnology of the lake or reservoir being studied (Winter, 1981a,b; U.S. Environmental Protection Agency, 1985; Thomann and Mueller, 1987; Moore and Thornton, 1988; Bubeck and Burton, 1989; Ward and Harr, 1990; Buso and others, 2000; Natural Resources Conservation Service, 2003; Cooke and others, 2005; Muller and Gachter, 2010; Koterba and others, 2011). One important variable is the average residence time of the lake or reservoir, which is defined as the water flux through the lake divided by the lake volume. The residence time characterizes the lake or reservoir by normalizing it with respect to basin size and climate. In many areas of the United States, knowledge of the stratification of the lake or reservoir also is important for monitoring and interpreting water-quality data. Variations in the density of water caused by temperature and in some cases large concentrations of TDS cause stratification of the water column during the winter and summer, which creates three distinct water-quality zones. These zones are the following:
- the epilimnion, which is an oxygenated zone near the surface of the lake;

- the metalimnion, which is a thin zone of water between the epilimnion and the hypolimnion that is characterized by large temperature, density and dissolved oxygen gradients; and

- the hypolimnion, which is characterized as having the highest density and lowest dissolved oxygen concentrations.

If the lake is stratified by temperature, a change in the seasons commonly will cause a period of complete mixing in the spring and fall. If, however, the lake is stratified by variations in TDS, such as large inflows of deicing salts or wastewater effluent, these mixing events may be delayed or may not occur in a given year (Bubeck and Burton, 1989).

Although they are commonly lumped into one category, there are substantial differences between natural lakes and man-made reservoirs that can affect the system's response to different loading scenarios. For example, on average, reservoirs tend to have larger drainage areas, surface areas, maximum depths, mean depths, areal water loading rates, and drainage-area to surface-area ratios than natural lakes; reservoirs, on average, have lower hydraulic residence times than natural lakes (Thornton and others, 1980; Cooke and others, 2005). Reservoirs also tend to have an inflow tributary that dominates the hydrology of the lake and sets up a riverine zone, a transitional zone, and a lacustrine zone, which are dominated by different thermal and physicochemical processes. In comparison, natural lakes tend to have relatively smaller tributaries and have proportionally larger interactions with groundwater inflows and outflows. However, properties and behavior of reservoirs and natural lakes tend to converge with similar residence times (Cooke and others, 2005).

Lakes and reservoirs commonly are modeled as being fully mixed, but concentrations may vary considerably because of spatial and temporal variability in the quality of inflows and vertical variability caused by thermal and chemical stratification (Winter, 1981b; Thomann and Mueller, 1987; Bubeck and Burton, 1989; Cooke and others, 2005). Therefore, data from multiple sampling locations and from different depths at each sampling location commonly are necessary to quantify the concentrations of lake-water constituents (Hem, 1992; Thomann and Mueller, 1987; Bubeck and Burton, 1989; Ward and Harr, 1990; Natural Resources Conservation Service, 2003; Koterba and others, 2011). Traditionally, lake sampling was done to generate water-quality samples for laboratory analyses, with costs for sample collection and analysis limiting the number of sampling points. Lake monitoring efforts were designed to use randomly selected locations or few transects. Currently, however, multiparameter water-quality probes can be used to collect continuous data, which can be used to inform the decision to collect water samples for analysis. For example, Atkinson and Maybe (2006) mounted a fin-stabilized 
water-quality monitoring probe to a boat and made eight monthly towed-array surveys of Lake Texoma on the Oklahoma-Texas border to generate over 600 specificconductance measurements that were georeferenced by using a global positioning system (GPS) unit. Novotny and others (2008) used monitoring probes to do 173 specific conductivity/ temperature profiles with a $0.5-\mathrm{m}$ resolution in the 13 lakes in the Minneapolis-St. Paul Twin Cities Metropolitan Area at 4- to 6-week intervals over a 46-month period. Bubeck and Burton (1989) used a water-quality monitoring probe to do vertical profiling at selected sites in Irondequoit Bay on Lake Ontario to guide collection of samples for water-quality analyses. Initially Bubeck and Burton (1989) used a Van Dorp sampler (Ward and Harr, 1990) to obtain discrete water samples from the selected depths, but they switched to a pump sampler with the inlet tube attached to the probe to facilitate sample collection in concert with real-time measurements of water quality with depth. Novotny and Stefan (2012) used a buoy system to record temperature and specific conductance every 2 minutes from an array of probes suspended on a line from the surface to the bottom of the lake to document the evolution of vertical temperature and salinity gradients in Tanners Lake in Oakdale, Minnesota.

Collecting samples within a lake may provide information on the status and trends of lake water quality, but samples from precipitation and surface-water and groundwater inflows may be needed to identify the sources of problems and therefore the proper mitigation measures (Winter, 1981a,b; Bubeck and Burton, 1989; Peters, 1991; Doerr and others, 1994; LaBaugh and others, 1997; Rice and others, 2007; Eyles and Meriano, 2010; Likens and Buso, 2010; Koterba and others, 2011; Smeltzer and others, 2012). Many of the methods used for monitoring the inflows to a lake or reservoir are outlined in previous subsections of this report. The methods used for monitoring the quality and flow of groundwater in the lake basin are described, but monitoring groundwater discharge into the reservoir requires special methods. The quality and quantity of groundwater entering a lake commonly are difficult to ascertain because inflows and outflows can have large variations spatially and temporally (Winter, 1981a,b; Winter and others, 2003). Inputs of groundwater may range from an insignificant proportion of inflows in large riverine lakes or reservoirs to the vast majority of inflows for glacial kettle lakes without perennial surface-water tributaries (Winter, 1981a,b; LaBaugh and others, 1997; Muller and Gachter, 2010). The source and quality of groundwater may represent local conditions, regional flow fields, or local and regional groundwater flows. Diverse methods may be used to locate and sample discharge zones. For example, McCobb and others (2003) used groundwater-flow model simulations, seepage-meter observations, and measured hydraulic gradients to locate the discharge area of a sewage plume in Ashumet Pond, Cape Cod, Massachusetts and sampled the area with temporary slotted-steel well-point samplers. Toran and others (2010) used geophysical surveys along the coast of Mirror Lake in New Hampshire to identify variations in inflows and followed these surveys by sampling from piezometers and seepage meters in the lakebed to identify and quantify the quality and quantity of the inflow of a salt plume from the local groundwater system.

\section{Summary}

Chloride is a major ion in most natural waters, but many anthropogenic sources are increasing concentrations of chloride in many receiving waters. Although natural concentrations in continental waters may be as high as 200,000 milligrams per liter (mg/L), concentrations that are suitable for freshwater ecology, human consumption, and agricultural and industrial water uses commonly are on the order of 10 to $1,000 \mathrm{mg} / \mathrm{L}$. The purpose of this report is to provide information about potential sources of chloride, water and solute budgets, and methods for collecting water-quality data to help identify potential sources. Scientists, engineers, regulators, and decisionmakers need this information to evaluate potential sources of chloride in areas where chloride may have adverse ecological effects or may degrade water supplies used for drinking water, agriculture, or industry. Knowledge of potential sources can help decisionmakers identify the best mitigation measures to reduce the total background chloride load, thereby reducing the potential for water-quality exceedences caused by superposition on rising background concentrations. Also, knowledge of potential sources may help decisionmakers identify the potential for the presence of contaminants that have toxic, carcinogenic, mutagenic, or endocrine-disrupting effects at concentrations that are lower by orders of magnitude than the chloride concentrations in the source water.

There are many natural and anthropogenic sources of chloride in the waters of the United States. Natural sources include atmospheric deposition, evaporative concentration of precipitation, deep saline groundwater, and chemical weathering. Saltwater intrusion at supply wells is an example of a natural source of chloride that is introduced into the freshwater realm by the human action of pumping at coastal wells or deep irrigation wells above deep saline groundwater. Anthropogenic sources include deicing chemicals, chlorides used for dust control and stabilization, water treatment and wastewater, agricultural sources, energy production, and landfills. Deicing salt frequently is identified as the sole source of anthropogenic chloride, but only about 30 percent of the salt consumed and released to the environment is from deicing. Furthermore, several studies in Southern States where the use of deicing salt is minimal also show rising concentrations of chloride and strong correlations between these concentrations and imperviousness and road density. This is because imperviousness and road density also are strongly correlated to population density. The term "road salt" is a misnomer because deicers applied to parking lots, sidewalks, and driveways can be a substantial source 
of chloride in some catchments because these land covers are comparable to roadways as a percentage of the total impervious area and commonly receive higher salt application rates than some roadways.

The magnitudes of the various water-budget components depend on the physical characteristics of the watershed, climatic conditions such as temporal and spatial distribution of precipitation and evapotranspiration, and the extent of alteration by human activity. To develop a chloride budget for a watershed, the water budget and sources of chloride in the basin need to be determined. Water budgets are a way to quantify the flux of water in a basin and account for all the water exchanged into and out of a control volume of any spatial scale such as a stream, aquifer, wetland, lake, agricultural field, watershed, groundwater-supply well capture zone. Chloride budgets are needed to ascribe the measured concentrations to natural and anthropogenic sources, to understand processes that may affect current and future concentrations, and to quantify the status and trends in an area of interest. Studies that quantify sources of chloride can be used to ascribe the loads of chloride to natural or anthropogenic sources to assess current conditions and establish total maximum daily loads.

Decisionmakers face many different issues concerning the characteristics and effects of chloride from many potential sources. Water and solute budgets constructed from literature values and available hydrologic data may provide initial planning-level estimates of concentrations and loads of chloride at a site of interest. In many cases, however, site-specific data may be needed to support the planning and decision-making process or to meet legal or regulatory information needs. In such cases, site-specific knowledge of the concentrations and loads of chlorides from transportation facilities and other natural and anthropogenic sources and knowledge of the physical and chemical processes that govern the generation and transport of chloride is important for decisionmakers, planners, and highway engineers who assess and mitigate possible adverse impacts of chloride on water supplies and the Nation's receiving waters.

\section{References Cited}

Abraham, J.D., and Lucius, J.E., 2004, Direct current resistivity profiling to study distribution of water in the unsaturated zone near the Amargosa Desert research site, Nevada: U.S. Geological Survey Open-File Report 2004$1319,16 \mathrm{p}$.

Alhajjar, B.J., Chesters, Gordon, and Harkin, J.M., 1990, Indicators of chemical pollution from septic systems: Ground Water, v. 28, no. 4, p. 559-568.
Alley, W.M., 1977, Guide for collection, analysis, and use of urban stormwater data-A conference report, held at Easton, Maryland, November 28-December 3, 1976: New York, American Society of Civil Engineers, 115 p.

Alley, W.M., 2003, Desalination of ground water-Earth science perspectives: U.S. Geological Survey Fact Sheet 075-03, 4 p.

Alm, A.L., and Messner, H.M., 1984, Policy and program requirements to implement the mandatory quality assurance program: U.S. Environmental Protection Agency Order $5360.1,9 \mathrm{p}$.

AMEC Environment and Infrastructure, 2013, Clean Air Status and Trends Network (CASTNET) - 2011 annual report: U.S. Environmental Protection Agency EPA Contract No. EP-W-09-028, 103 p., accessed October 22, 2013, at http://epa.gov/castnet/javaweb/docs/annual_ report_2011.pdf.

American Petroleum Institute, 2010, Water management associated with hydraulic fracturing: American Petroleum Institute Guidance Document HF2, 40 p.

American Society of Agricultural and Biological Engineers, 2006, Manure production and characteristics: St. Joseph, Mich., American Society of Agricultural and Biological Engineers Standard ASAE D384.2-MAR2005, p. 709-727.

Ames, D.L., Roberts, L.E., and Webb, A.H., 1987, An automatic rain gauge for continuous, real time determination of rainwater chemistry: Atmospheric Environment, v. 21, no. 9 , p. 1947-1955.

Armstrong, D.L., and Griffin, K.P., 1998, Production and use of potassium: Better Crops with Plant Food, v. 82, no. 3, p. 6-8.

Armstrong, D.S., Richards, T.A., and Levin, S.B., 2011, Factors influencing riverine fish assemblages in Massachusetts: U.S. Geological Survey Scientific Investigations Report 2011-5193, 59 p.

Arnold, C.L., Jr., and Gibbons, C.J., 1996, Impervious surface coverage-The emergence of a key environmental indicator: Journal of the American Planning Association, v. 62, no. 2, p. 243-258.

Arnon, Shai, Ofer, Dahan, Elhanany, Sara, Cohen, Keren, Pankratov, Irena, Gross, Amit, Ronen, Zeev, Baram, Shahar, and Shore, L.S., 2008, Transport of testosterone and estrogen from dairy-farm waste lagoons to groundwater: Environmental Science and Technology, v. 42, no. 15, p. 5521-5526.

Atkinson, S.F., and Maybe, J.A., 2006, Near real-time monitoring and mapping of specific conductivity levels across Lake Texoma, USA: Environmental Monitoring and Assessment, v. 120, p. 449-460. 
Baldwin, A.K., Graczyk, D.J., Robertson, D.M., Saad, D.A., and Magruder, Christopher, 2012, Use of real-time monitoring to predict concentrations of select constituents in the Menomonee River drainage basin, Southeast Wisconsin, 2008-9: U.S. Geological Survey Scientific Investigations Report 2012-5064, 18 p.

Baldwin, A.K., Robertson, D.M., Saad, D.A., and Magruder, Christopher, 2013, Refinement of regression models to estimate real-time concentrations of contaminants in the Menomonee River drainage basin, southeast Wisconsin, 2008-11: U.S. Geological Survey Scientific Investigations Report 2013-5174, 113 p.

Baldys, Stanley, III, Churchill, C.J., Mobley, C.A., and Coffman, D.K., 2010, Bromide, chloride, and sulfate concentrations and loads at U.S. Geological Survey streamflow-gaging stations 07331600 Red River at Denison Dam, 07335500 Red River at Arthur City, and 07336820 Red River near DeKalb, Texas, 2007-09: U.S. Geological Survey Scientific Investigations Report 2010-5120, 30 p.

Balestrini, Raffaella, Arisci, Silvia, Brizzio, M.C., Mosello, Rosario, Rogora, Michela, and Tagliaferri, Antonio, 2007, Dry deposition of particles and canopy exchangeComparison of wet, bulk and throughfall deposition at five forest sites in Italy: Atmospheric Environment, v. 41, p. 745-756.

Barbot, Elise, Vidic, N.S., Gregory, K.B., and Vidic, R.D., 2013, Spatial and temporal correlation of water quality parameters of produced waters from Devonian-age shale following hydraulic fracturing: Environmental Science and Technology, v. 47, p. 2562-2569.

Barlow, L.K., Hutchins, L.M., and DeSimone, L.A., 2009, Water withdrawals, use, and wastewater return flows in the Concord River Basin, eastern Massachusetts, 1996-2000: U.S. Geological Survey Scientific Investigations Report 2008-5158, 123 p.

Barlow, P.M., 2003, Ground water in freshwater-saltwater environments of the Atlantic coast: U.S. Geological Survey Circular 1262, 113.

Barlow, P.M., and Reichard, E.G., 2010, Saltwater intrusion in coastal regions of North America: Hydrogeology Journal, v. 18 , p. 247-260.

Barlow, P.M., and Wild, E.C., 2002, Bibliography on the occurrence and intrusion of saltwater in aquifers along the Atlantic coast of the United States: U.S. Geological Survey Open-File Report 02-235, 35 p.

Barr Engineering Company, 2010, Nine Mile Creek Watershed chloride Total Maximum Daily Load report: Minnesota Pollution Control Agency TMDL Report wq-iwii-08e, 49 p.
Battaglin, W.A., and Goolsby, D.A., 1995, Spatial data in geographic information system format on agricultural chemical use, land use, and cropping practices in the United States: U.S. Geological Survey Water-Resources Investigations Report 94-4176, 87 p.

Benefield, L.A., 2002, Residential flow rates: Washington State Department of Health Rule Development Committee issue research report, accessed June 10, 2014, at http://www.doh.wa.gov/portals/1/Documents/Pubs/337-103. pdf.

Bent, G.C., Gray, J.R., Smith, K.P., and Glysson, G.D., 2003, A synopsis of technical issues for monitoring sediment in highway and urban runoff, in Granato, G.E., Zenone, Chester, and Cazenas, P.A., eds., National highway runoff water-quality data and methodology synthesis, v. ITechnical issues for monitoring highway runoff and urban stormwater: Federal Highway Administration FHWAEP-03-054, p. 111-163.

Bent, G.C., Zarriello, P.J., Granato, G.E., Masterson, J.P., Walter, D.A., Waite, A.M., and Church, P.E., 2009, Simulated effects of water withdrawals and land-use changes on streamflows and groundwater levels in the Pawcatuck River Basin, southwestern Rhode Island and southeastern Connecticut: U.S. Geological Survey Scientific Investigations Report 2009-5127, 254 p.

Berger, L.L., and Cunha, T.J., 2006, Salt and trace minerals for livestock, poultry and other animals: Alexandria, Va., Salt Institute, $139 \mathrm{p}$.

Best, M.G., 1982, Igneous and metamorphic petrology: New York, W.H. Freeman, 630 p.

Biesecker, J.E., and Leifeste, D.K., 1975, Water quality of hydrologic bench marks - An indicator of water quality in the natural environment: U.S. Geological Survey Circular 460-E, 21 p.

Bills, T.D., Marking, L.L., and Howe, G.E., 1993, Sensitivity of juvenile striped bass to chemicals used in aquaculture: U.S. Fish and Wildlife Service Resource Publication 192, $11 \mathrm{p}$.

Blasius, B.J., and Merritt, R.W., 2002, Field and laboratory investigations on the effects of road salt $(\mathrm{NaCl})$ on stream macroinvertebrate communities: Environmental Pollution, v. 120, p. 219-231.

Bolander, Peter, and Yamada, Alan, 1999, Dust palliative selection and application guide: U.S. Forest Service Report 9977-1207-SDTDC, 20 p.

Boll, Jan, Steenhuis, T.S., and Selker, J.S., 1992, Fiberglass wicks for sampling of water and solutes in the vadose zone: Soil Science Society of America Journal, v. 56, no. 3, p. 701-707. 
Boulding, J.R., and Ginn, J.S., 2003, Practical handbook of soil, vadose zone, and ground-water contaminationAssessment, prevention, and remediation: Boca Raton, Fla., CRC Press, $728 \mathrm{p}$.

Bowen, H.J.M., 1966, Trace elements in biochemistry: London, Academic Press, 241 p.

Boyd, C.E., 1998, Water quality for pond aquaculture: Auburn University Department of Fisheries and Allied Aquacultures Research and Development Series 43, 37 p.

Boyd, C.E., 2008, Chlorine effective disinfectant in aquaculture: Global Aquaculture Advocate, November/December, p. 52-53.

Brinton, T.I., Antweiler, R.C., and Taylor, H.E., 1996, Method for the determination of dissolved chloride, nitrate, and sulfate in natural water using ion chromatography: U.S. Geological Survey Open-File Report 95-426A.

Britton, L.J., Goddard, K.E., and Briggs, J.C., 1983, Quality of rivers of the United States, 1976 water year-Based on the National Stream Quality Accounting Network (NASQAN): U.S. Geological Survey Open-File Report 80-594, 423 p.

Brown, C.J., Mullaney, J.R., Morrison, Jonathan, and Mondazzi, Remo, 2011, Preliminary assessment of chloride concentrations, loads, and yields in selected watersheds along the Interstate 95 corridor, southeastern Connecticut, 2008-09: U.S. Geological Survey Open-File Report 2011-1018, $41 \mathrm{p}$.

Brown, R.D., Marinenko, George, and Egan, D.E., 1991, Quality assurance as viewed by a data user, in Friedman, David, ed., Waste testing and quality assurance: Philadelphia, Pa., American Society for Testing Materials, ASTM STP 1075, v. 3, p. 391-404.

Bubeck, R.C., and Burton, R.S., 1989, Changes in chloride concentrations, mixing patterns, and stratification characteristics of Irondequoit Bay, Monroe County, New York, after decreased use of road-deicing salts, 1974-1984: U.S. Geological Survey Water-Resources Investigations Report 87-4223, 52 p.

Buckler, D.R., and Granato, G.E., 1999, Assessing biological effects from highway-runoff constituents: U.S. Geological Survey Open-File Report 99-240, 45 p.

Bukaveckas, P.A., Likens, G.E., Winter, T.C., and Buso, D.C., 1998, A comparison of methods for deriving solute flux rates using long-term data from streams in the mirror lake watershed: Water, Air, and Soil Pollution, v. 105, no. 1-2, p. 277-293.

Bundy, L.G., 1985, Corn fertilization: Madison, Wis., University of Wisconsin-Extension publication A3340, 7 p., accessed May 16, 2014, at http://www.soils.wisc.edu/ extension/pubs/A3340.pdf.
Burggraf, Fred, Collings, W.R., and Stewart, L.C., 1932, The effectiveness of calcium chloride as a dust palliative and its value to general road maintenance: Proceedings of the Highway Research Board, v. 11, p. 375-387.

Burkart, M.R., and Stoner, J.D., 2007, Nitrate in aquifers beneath agricultural systems: Water Science and Technology, v. 56, no. 1, p. 59-69.

Busch, Dennis, and Mentz, Randy, 2012, Lessons learnedMonitoring edge-of-field runoff from agricultural land at University of Wisconsin Platteville's Pioneer Farm: National Nonpoint Source Monitoring Workshop, 20th, Tulsa, Okla., 2012, accessed June 22, 2014, at http://www.bae.ncsu.edu/programs/extension/wqg/nmp conf/2012_tulsa/41uwplatteville.pdf.

Buso, D.C., Likens, G.E., and Eaton, J.S., 2000, Chemistry of precipitation, streamwater, and lakewater from the Hubbard Brook Ecosystem Study_A record of sampling protocols and analytical procedures: U.S. Forest Service General Technical Report NE-275, 52 p.

Buszka, P.M., Yeskis, D.J., Kolpin, D.W., Furlong, E.T., Zaugg, S.D., and Meyer, M.T., 2009, Waste-indicator and pharmaceutical compounds in landfill-leachate-affected ground water near Elkhart, Indiana, 2000-2002: Bulletin of Environmental Contamination and Toxicology, v. 82, no. 6, p. 653-659.

Buttner, J.K., Soderberg, R.W., and Terlizzi, D.E., 1993, An introduction to water chemistry in freshwater aquaculture: Northeast Regional Aquaculture Center Fact Sheet 1701993, 4 p.

Cain, Doug, 1987, Relations of specific conductance to streamflow and selected water-quality characteristics of the Arkansas River Basin, Colorado: U.S. Geological Survey Water-Resources Investigations Report 87-4041, 93 p.

Calder, I.R., 1993, Hydrologic effects of land-use change, chap. 13 of Maidment, D.R., ed., Handbook of hydrology: New York, McGraw-Hill, [variously paged].

California Department of Transportation, 2013, Caltrans stormwater monitoring guidance manual: State of California Department of Transportation Document CTSW-OT-13999.43.01, $443 \mathrm{p}$.

California Fertilizer Foundation, 2011, Plant nutrientsPotassium: Sacramento, Calif., California Fertilizer Foundation, $2 \mathrm{p}$. 
California Regional Water Quality Control Board, 2008, Upper Santa Clara River chloride TMDL reconsideration, conditional site specific objectives for chloride, and interim wasteload allocations for sulfate and total dissolved solids: Los Angeles, Calif., California Regional Water Quality Control Board-Los Angeles Region, 59 p., accessed June 17, 2014, at http://www.waterboards.ca.gov/ rwqcb4/board_decisions/basin_plan_amendments/technical_documents/69_New/2008_1203/Revised_Draft_Staff_ Report.pdf.

California State Legislature, 2005, Article 1. Water Softeners: California Health and Safety Code, $\S \S 116775-116795$, accessed July 4, 2014, at http://www.leginfo.ca.gov/ cgi-bin/displaycode?section=hsc\&group=116001$117000 \&$ file $=116775-116795$.

Cañedo-Argüelles, Miguel, Kefford, B.J., Piscart, Christophe, Prat, Narcís, Schäfer, R.B., and Schulz, Claus-Jürgen, 2013, Salinisation of rivers-An urgent ecological issue: Environmental Pollution, v. 173, p. 157-167.

Canessa, Peter, and Hermanson, R.E., 1994, Irrigation management practices to protect ground water and surface water quality state of Washington: Washington State University Cooperative Extension Report EM4885, 194 p.

Canton, Mathieu, Anschutz, Pierre, Naudet, Véronique, Molnar, Nathalie, Mouret, Aurélia, Franceschi, Michel, Naessens, Fabien, and Poirier, Dominique, 2010, Impact of solid waste disposal on nutrient dynamics in a sandy catchment: Journal of Contaminant Hydrology, v. 116, p. $1-15$.

Carey, R.O., Hochmuth, G.J., Martinez, C.J., Boyer, T.H., Dukes, M.D., Toor, G.S., and Cisar, J.L., 2013, Evaluating nutrient impacts in urban watersheds - Challenges and research opportunities: Environmental Pollution, v. 173, p. 138-149.

Carey, R.O., Hochmuth, G.J., Martinez, C.J., Boyer, T.H., Nair, V.D., Dukes, M.D., Toor, G.S., Shober, A.L., Cisar, J.L., Trenholm, L.E., and Sartain, J.B., 2012, A review of turfgrass fertilizer management practices-Implications for urban water quality: HortTechnology, v. 22, p. 280-291.

Carollo Engineers, Inc., 2009, San José/Santa Clara Water Pollution Control Plant master plan-Task no. 3, Project memorandum no. 8, Projected wastewater flows and characteristics-Final draft: Walnut Creek, Calif., City of San José, 30 p., accessed June 17, 2014, at https://www.sanjoseca.gov/Archive/ViewFile/Item/1543.

Casey, R.E., Lev, S.M., and Snodgrass, J.W., 2013, Stormwater ponds as a source of long-term surface and ground water salinization: Urban Water Journal, v. 10, no. 3, p. 145-153.
Castillo, A.R., St-Pierre, N.R., Silva del Rio, Noelia, and Weiss, W.P., 2013, Mineral concentrations in diets, water, and milk and their value in estimating on-farm excretion of manure minerals in lactating cows: Journal Dairy Science, v. 96 , p. $3388-3398$.

Chafin, D.T., and Butler, D.L., 2002, Dissolved-solids-load contributions of the Pennsylvanian Eagle Valley Evaporite to the Colorado River, west-central Colorado, in Kirkham, R.M., Scott, R.B., and Judkins, T.W., eds., Late Cenozoic evaporite tectonism and volcanism in west-central Colorado: Boulder, Colo., Geological Society of America Special Paper 366, p. 149-155.

Chisala, B.N., and Lerner, D.N., 2008, Distribution of sewer exfiltration to urban groundwater: Proceedings of the Institution of Civil Engineers Water Management, v. 161, no. WM6, p. 333-341.

Christensen, V.G., Jian, Xiaodong, and Ziegler, A.C., 2000, Regression analysis and real-time water-quality monitoring to estimate constituent concentrations, loads, and yields in the Little Arkansas River, south-central Kansas, 1995-99: U.S. Geological Survey Water-Resources Investigations Report 2000-4126, 36 p.

Chriswell, C.D., and O'Donnell, J.A., 1996, Method of treating coal to reduce sulphur and chlorine emissions: U.S. Patent 5,505,746, 6 p.

Church, P.E., Armstrong, D.S., Granato, G.E., Stone, V.J., Smith, K.P., and Provencher, P.L., 1996, Effectiveness of highway-drainage systems in preventing contamination of ground water by road salt, Route 25 , southeastern Massachusetts-Description of study area, data collection programs, and methodology: U.S. Geological Survey OpenFile Report 96-317, 72 p.

Church, P.E., and Friesz, P.J., 1993, Delineation of a roadsalt plume in groundwater, and traveltime measurements for estimating hydraulic conductivity by use of boreholeinduction logs: International Symposium on Geophysics for Minerals, Geotechnical, and Environmental Applications, 5th, Tulsa, Okla., The Minerals and Geotechnical Logging Society, 1993 [proceedings], p. Y1-Y16.

Church, P.E., and Granato, G.E., 1996, Bias in groundwater data caused by well-bore flow in long-screen wells: Ground Water, v. 34, no. 2, p. 262-273.

Church, P.E., Granato, G.E., and Owens, D.W., 1999, Basic requirements for collecting, documenting, and reporting precipitation and stormwater-flow measurements: U.S. Geological Survey Open File Report 99-255, 30 p. 
Church, P.E., Granato, G.E., and Owens, D.W., 2003, Basic requirements for collecting, documenting, and reporting precipitation and stormwater-flow measurements, in Granato, G.E., Zenone, Chester, and Cazenas, P.A., eds., National highway runoff water-quality data and methodology synthesis, v. I-Technical issues for monitoring highway runoff and urban stormwater: Federal Highway Administration Report FHWA-EP-03-054, p. 47-79.

Claassen, H.C., and Halm, D.R., 1996, Estimates of evapotranspiration or effective moisture in Rocky Mountain watersheds from chloride ion concentrations in stream baseflow: Water Resources Research, v. 32, p. 363-372.

Clark, C.E., and Veil, J.A., 2009, Produced water volumes and management practices in the United States: Argonne, Ill., U.S. Department of Energy, Argonne National Laboratory, ANL/EVS/R-09/1, 60 p.

Clark, M.L., and Davidson, S.L., 2009, Specific conductance and dissolved-solids characteristics for the Green River and Muddy Creek, Wyoming, water years 1999-2008: U.S. Geological Survey Scientific Investigations Report 2009-5168, 18 p.

Clune, J.W., and Denver, J.M., 2012, Residence time, chemical and isotopic analysis of nitrate in the groundwater and surface water of a small agricultural watershed in the Coastal Plain, Bucks Branch, Sussex County, Delaware: U.S. Geological Survey Scientific Investigations Report 2012-5235, $15 \mathrm{p}$.

Colborn, Theo, Kwiatkowski, Carol, Schultz, Kim, and Bachran, Mary, 2010, Natural gas operations from a public health perspective: Human and Ecological Risk Assessment, v. 17 , p. 1039-1056.

Cole-Parmer, 2014, Replaceable membrane chloride ion electrodes instruction manual: Cole-Parmer manual, 22 p., accessed June 30, 2014, at http://www.coleparmer.com/ Assets/manual_pdfs/27506-12Chloridereplaceable.pdf.

Coles, J.F., Cuffney, T.F., McMahon, Gerard, and Beaulieu, K.M., 2004, The effects of urbanization on the biological, physical, and chemical characteristics of coastal New England streams: U.S. Geological Survey Professional Paper 1695, $47 \mathrm{p}$.

Coles, J.F., McMahon, Gerard, Bell, A.H., Brown, L.R., Fitzpatrick, F.A., Scudder Eikenberry, B.C., Woodside, M.D., Cuffney, T.F., Bryant, W.L., Cappiella, Karen, FraleyMcNeal, Lisa, and Stack, W.P., 2012, Effects of urban development on stream ecosystems in nine metropolitan study areas across the United States: U.S. Geological Survey Circular 1373, 138 p.
Colman, J.A., Rice, K.C., and Willoughby, T.C., 2001, Methodology and significance of studies of atmospheric deposition in highway runoff: U.S. Geological Survey Open-File Report 01-259, 64 p.

Colman, J.A., Rice, K.C., and Willoughby, T.C., 2003, Methodology and significance of studies of atmospheric deposition in highway runoff, in Granato, G.E., Zenone, Chester, and Cazenas, P.A., eds., National highway runoff water-quality data and methodology synthesis, v. ITechnical issues for monitoring highway runoff and urban stormwater: Federal Highway Administration Report FHWA-EP-03-054, p. 47-79.

Conrads, P.A., Roehl, E.A., Jr., Daamen, R.C., and Cook, J.B., 2013, Simulation of salinity intrusion along the Georgia and South Carolina coasts using climate-change scenarios: U.S. Geological Survey Scientific Investigations Report 2013-5036, 92 p., and 5 apps., http://pubs.usgs.gov/ sir/2013/5036.

Coogan, C.J., 1971, The increase in chloride experienced in Massachusetts water supplies: New England Water Works Association Journal, v. 85, no. 2, p. 173-178.

Cooke, G.D., Welch, E.B., Peterson, and Nichols, S.A., 2005, Restoration and management of lakes and reservoirs (3d ed.): New York, CREC Press, 591 p.

Coon, W.F., Hayhurst, B.A., Kappel, W.M., Eckhardt, D.A.V., and Szabo, C.O., 2009, Water-quality characterization of surface water in the Onondaga Lake Basin, Onondaga County, New York, 2005-08: U.S. Geological Survey Scientific Investigations Report 2009-5246, 67 p.

Coplen, T.B., Brand, W.A., Meija, J., Gröning, M., Holden, N.E., Berglund, M., De Bièvre, P., Loss, R.D., Prohaska, T., and Walczyk, T., 2013, Atomic weights of the elements 2013 (xls): Commission on Isotopic Abundances and Atomic Weights, accessed April 1, 2015, at http://www.ciaaw.org/pubs/TSAW2013_xls.xls.

Corsi, S.R., Graczyk, D.J., Geis, S.W., Booth, N.L., and Richards, K.D., 2010a, A fresh look at road salt-Aquatic toxicity and water-quality impacts on local, regional, and national scales: Environmental Science and Technology, v. 44 , p. $7376-7382$.

Corsi, S.R., Graczyk, D.J., Geis, S.W., Booth, N.L., and Richards, K.D., 2010b, Supporting Information-A fresh look at road salt-Aquatic toxicity and waterquality impacts on local, regional, and national scales: Environmental Science and Technology, v. 44, p. 73767382. 
Crandall, C.A., 2000, Distribution, movement, and fate of nitrate in the surficial aquifer beneath citrus groves, Indian River, Martin, and St. Lucie Counties, Florida: U.S. Geological Survey Water-Resources Investigations Report 2000-4057, 69 p.

Culligan International Company, 2012, Culligan ${ }^{\circledR}$ high efficiency automatic water softener owners guide: Rosemont, Ill., Culligan International Company manual 01021076, 82 p., accessed April 1, 2015, at http://www.culligan.com/uploadedFiles/Culligancom/ Content/Products/Water_Softeners/HE_Softener_ OwnersGuide_01021076.pdf.

Cunningham, M.A., Snyder, Eric, Yonkin, Daniel, Ross, Morgan, and Elsen, Toren, 2008, Accumulation of deicing salts in soils in an urban environment: Urban Ecosystems, v. 11, p. 17-31.

Dahan, Ofer, Rimon, Yaara, Tatarsky, Boaz, and Talby, Ruti, 2006, Deep vadose zone monitoring system: West Lafayette, Ind., Purdue University, Paper ID TDR 46, 15 p., https://engineering.purdue.edu/TDR/Papers.

Dämmgen, Ulrich, Erisman, J.W., Cape, J.N., Grünhage, Ludger, and Fowler, David, 2005, Practical considerations for addressing uncertainties in monitoring bulk deposition: Environmental Pollution, v. 134, no. 3, p. 535-548.

Delin, G.N., and Landon, M.K., 1996, Multiport well design for sampling of ground water at closely spaced vertical intervals: Ground Water, v. 34, no. 6, p. 1098-1104.

Dennehy, K.F., 2004, National perspective on saline aquifers, in Proceedings - 49th Annual New Mexico Water Conference [2004] — Water desalination and reuse strategies for New Mexico: Las Cruces, N. Mex., New Mexico Water Resources Research Institute Report 336, p. 11-15, accessed November 6, 2013, at http://wrri.nmsu.edu/publish/watcon/ proc49/proc49.html.

Dennehy, K.F., Litke, D.W., Tate, C.M., Qi, S.L., McMahon, P.B., Bruce, B.W., Kimbrough, R.A., and Heiny, J.S., 1998, Water quality in the South Platte River Basin, Colorado, Nebraska, and Wyoming, 1992-95: U.S. Geological Survey Circular 1167, 38 p.

Denner, J.C., Clark, S.F., Jr., Smith, T.E., and Medalie, Laura, 2010, Effects of highway road salting on the water quality of selected streams in Chittenden County, Vermont, November 2005-2007: U.S. Geological Survey Scientific Investigations Report 2009-5236, 43 p.

Deo, R.P., and Halden, R.U., 2013, Pharmaceuticals in the built and natural water environment of the United States: Water, v. 5, p. 1346-1365.
DeSilva, F.J., 2003, Nitrate removal by ion exchange: Water and Wastes Digest Web site, accessed July 4, 2014, at http://www.waterinfocenter.com.

DeSimone, L.A., 2009, Quality of water from domestic wells in principal aquifers of the United States, 1991-2004: U.S. Geological Survey Scientific Investigations Report 2008-5227, 139 p.

Desroches-Ducarne, Estelle, Marty, Eric, Martin, Gérard, Delfosse, Lucien, 1998, Co-combustion of coal and municipal solid waste in a circulating fluidized bed: Fuel, v. 77 , no. 12 , p. $1311-1315$.

Dindorf, Carolyn, and Fortin, Connie, 2008, Winter parking lot and sidewalk maintenance manual: St. Paul, Minn., Minnesota Pollution Control Agency, 47 p.

Doerr, S.M., Effler, S.W., Whitehead, K.A., Auer, M.T., Perkins M.G., and Heidtke, T.M., 1994, Chloride model for polluted Onondaga Lake: Water Research, v. 28, no. 4, p. 849-861.

Domenico, P.A., and Schwartz, F.W., 1998, Physical and chemical hydrogeology ( $2 \mathrm{~d}$ ed.): New York, John Wiley \& Sons, 528 p.

Dondelewski, 1977, Hydrodesulfurization of coal and the like: U.S. Patent 4,127,390, 4 p.

Dowst, R.B., 1967, Highway chloride applications and their effects on water supplies: Journal of the New England Water Works Association, v, 81, no. 1, p. 63-67.

Dresel, P.E., and Rose, Q.W., 2010, Chemistry and origin of oil and gas well brines in western Pennsylvania: Pennsylvania Geological Survey Open-File Oil and Gas Report 10-01.0, 48 p.

Driscoll, F.G., 1986, Groundwater and wells (2d ed.): St. Paul, Minn., Johnson Division, 1,089 p.

Driver, N.E., and Tasker, G.D., 1990, Techniques for estimation of storm-runoff loads, volumes and selected constituent concentrations in urban watersheds in the United States: U.S. Geological Survey Water-Supply Paper 2363, 44 p.

E\&A Environmental Consultants, 1998, Evaluation of compost facility runoff for beneficial reuse, phase 2: Seattle, Wash., Clean Washington Center Final Report CM-98-1, $35 \mathrm{p}$.

Earon, Robert, Olofsson, Bo, and Renman, Gunno, 2012, Initial effects of a new highway section on soil and groundwater: Water, Air, and Soil Pollution, v. 223, p. 5413-5432. 
East, Joe, and Matthias, Robert, 2013, National Coal Resources Data System (NCRDS) database: U.S. Geological Survey database, accessed July 1, 2014, at http://energy.usgs.gov/Tools/NationalCoalResourcesDataSystem/tabid/280/Agg816_SelectTab/1/Default.aspx.

Ebeling, J.M., Ogden, S.R., Sibrell, P.L., and Rishel, K.L., 2004, Application of chemical coagulation aids for the removal of suspended solids (TSS) and phosphorus from the microscreen effluent discharge of an intensive recirculating aquaculture system: North American Journal of Aquaculture, v. 66, p. 198-207.

Eberts, S.M., Thomas, M.A., and Jagucki, M.L., 2013, The quality of our Nation's waters-Factors affecting publicsupply-well vulnerability to contamination-Understanding observed water quality and anticipating future water quality: U.S. Geological Survey Circular 1385, 120 p.

Edwards, T.K., and Glysson, G.D., 1999, Field methods for measurement of fluvial sediment: U.S. Geological Survey Techniques of Water-Resources Investigations, book 3 , chap. C2, 89 p.

Ege, J.R., 1985, Maps showing distribution, thickness, and depth of salt deposits of the United States: U.S. Geological Survey Open-File Report 85-28, 11 p., 3 pls.

Eisele, M., Kiese, R., Krämer, A., and Leibundgut, C., 2001, Application of a catchment water quality model for assessment and prediction of nitrogen budgets: Physics and Chemistry of the Earth, Part B: Hydrology, Oceans and Atmosphere, v. 26, no. 7-8, p. 547-551.

Eisen, Craig, and Anderson, M.P., 1979, The effects of urbanization on ground-water quality-A case study: Ground Water, v. 17 , no. 5 , p. $456-462$.

El-Fadel, Mutasem, Findikakis, A.N., and Leckie, J.O., 1997, Environmental impacts of solid waste landfilling: Journal of Environmental Management, v. 50, p. 1-25.

El Gamal, A.R., 2014, Chlorination in aquaculture operations: Fish Consulting Group Web page, accessed April 01, 2015, at http://fishconsult.org/wp-content/uploads/2013/05/Chlorination-in-aquaculture-operations.pdf.

Eng, Ken, Wolock, D.M., and Carlisle, D.M., 2013, River flow changes related to land and water management practices across the conterminous United States: Science of The Total Environment, v. 463-464, p. 414-422.

Environment Canada, 2001, Priority substances list assessment report-Road salts: Environment Canada, Minister of Public Works and Government Services, 170 p.

Environment Canada, 2012, Five-year review of progressCode of Practice for the Environmental Management of Road Salts: Environment Canada report En14-54/2012E, $84 \mathrm{p}$.
Eugster, H.P., 1980, Geochemistry of evaporitic lacustrine deposits: Annual Review of Earth and Planetary Sciences, v. 8 , p. 35-63.

Exum, L.R., Bird, S.L., Harrison, James, and Perkins, C.A., 2005, Estimating and projecting impervious cover in the southeastern United States: U.S. Environmental Protection Agency EPA/600/R-05/061, 126 p.

Eyles, Nick, and Meriano, Mandana, 2010, Road-impacted sediment and water in a Lake Ontario watershed and lagoon, City of Pickering, Ontario, Canada-An example of urban basin analysis: Sedimentary Geology, v. 224, p. 15-28.

Fairfax County Water Authority, 2014, Water Quality Analytical Reports: Fairfax, Va., Fairfax County Water Authority Web page, accessed July 4, 2014, at http://www.fairfaxwater.org/water/imar.htm.

Falcone, James, 2011, GAGES-II: Geospatial Attributes of Gages for Evaluating Streamflow: U.S. Geological Survey geospatial dataset, accessed July 5, 2014, at http://water.usgs.gov/GIS/metadata/usgswrd/XML/gagesII_Sept2011.xml.

Fanning, J.L., Schwarz., G.E., and Lewis, W.C., 2001, A field and statistical modeling study to estimate irrigation water use at benchmark farms study sites in southwestern Georgia, 1995-96: U.S. Geological Survey Water-Resources Investigations Report 00-4292, 32 p.

Fares, Ali, Deb, S.K., and Fares, Samira, 2009, Review of vadose zone soil solution sampling techniques: Environmental Reviews, v. 17, p. 215-234.

Fay, Laura, and Kociolek, Angela, eds., 2009, Road dust management and future needs-2008 conference proceedings: Federal Highway Administration FHWA-CFL/ TD-09-001, $52 \mathrm{p}$.

Fay, Laura, Shi, Xianming, and Huang, Jiang, 2013, Strategies to mitigate the impacts of chloride roadway deicers on the natural environment: National Cooperative Highway Research Program Synthesis 449, 96 p.

Federal Highway Administration, 1985, Water-quality monitoring and data collection, sec. 6 of Highway runoff water-quality training course-Student handbook: U.S. Federal Highway Administration, variously paged.

Federal Highway Administration, 1986, Highway runoff water quality training course-Student workbook: McLean, Va., U.S. Federal Highway Administration, 919 p.

Federal Highway Administration, 2012, Highway statistics 2012: Federal Highway Administration, Office of Highway Policy Information Web page, accessed July 1, 2014, at http://www.fhwa.dot.gov/policyinformation/statistics/2012/. 
Federal Highway Administration, 2013, Snow and ice: Federal Highway Administration, Office of Operations Web page, accessed July 14, 2014, at http:/ops.fhwa.dot.gov/weather/ weather_events/snow_ice.htm.

Fenn, M.E., Poth, M.A., and Arbaugh, M.J., 2002, A throughfall collection method using mixed bed ion exchange resin columns: The Scientific World, v. 2, p. 122-130.

Feth, J.H., 1970, Saline groundwater resources of the conterminous United States: Water Resources Research, v. 6, p. 1454-1457.

Feth, J.H., 1981, Chloride in natural continental water-A review: U.S. Geological Survey Water-Supply Paper 2175, $30 \mathrm{p}$.

Feth, J.H., and others, 1965, Preliminary map of the conterminous United States showing depth to and quality of shallowest ground water containing more than 1,000 parts per million dissolved solids: U.S. Geological Survey Hydrologic Investigations Atlas HA-199, 1 pl.

Fisher, L.H., and Healy, R.W., 2008, Water movement within the unsaturated zone in four agricultural areas of the United States: Journal of Environmental Quality, v. 37, no. 3, p. 1051-1063.

Fishman, M.J., ed., 1993, Methods of analysis by the U.S. Geological Survey National Water Quality LaboratoryDetermination of inorganic and organic constituents in water and fluvial sediments: U.S. Geological Survey OpenFile Report 93-125, 217 p.

Fishman, M.J., and Friedman, L.C., 1989, Methods for determination of inorganic substances in water and fluvial sediments: U.S. Geological Survey Techniques of WaterResources Investigations, book 5, chap. A1, 545 p.

Fixen, P.E., Bruulsema, T.W., Johnston, A.M., Mikkelsen, R.L., Murrell, T.S., Snyder, C.S., and Stewart, W.M., 2006, The fertility of North American soils: Peachtree Corners, Ga., Potash and Phosphate Institute, Reference 06078, 4 p.

Ford, R.G., Acree, S.D., Lien, B.K., Scheckel, K.G., Luxton, T.P., Ross, R.R., Williams, A.G., and Clark, Patrick, 2011, Delineating landfill leachate discharge to an arsenic contaminated waterway: Chemosphere, v. 85, no. 9, p. 1525-1537.

Fortin, Connie, and Dindorf, Carolyn, 2012, Minnesota snow and ice control field handbook for snowplow operators $(2 \mathrm{~d}$ revision): St. Paul, Minn., University of Minnesota Local Road Research Board, Manual Number 2005-01 REV, 33 p.

Franke, O.L., Reilly, T.E., Pollock, D.W., and LaBaugh, J.W., 1998, Estimating areas contributing recharge to wells, lessons from previous studies: U.S. Geological Survey Circular 1174, 14 p.
Frape, S.K., Blyth, A., Blomqvist, R., McNutt, R.H., and Gascoyne, M., 2003, Deep fluids in the continents- II. Crystalline rocks, in Holland, H.D., and Turekian, K.K., eds., Treatise on geochmistry, v. 5.16: Oxford, England, Elsevier, p. 541-560.

Frape, S.K., and Fritz, Peter, 1982, The chemistry and isotopic composition of saline groundwaters from the Sudbury Basin, Ontario: Canadian Journal of Earth Sciences, v. 19, p. 645-661.

Friesz, P.J., and Stone, J.R., 2007, Simulation of ground-water flow and areas contributing recharge to production wells in contrasting glacial valley-fill settings, Rhode Island: U.S. Geological Survey Scientific Investigations Report 20075133, $51 \mathrm{p}$.

Fu, Liping, Omer, Raqib, and Liaqat, Zara, 2013, A survey of current state of practice for winter maintenance of parking lots and sidewalks, in the Compendium of Papers for the Transportation Research Board 92nd Annual Meeting [2013]: Washington, D.C., Transportation Research Board, CD-ROM, 14 p.

Gaggiani, N.G., 1991, Effects of land disposal of municipal sewage sludge on soil, streambed sediment, and groundand surface-water quality at a site near Denver, Colorado: U.S. Geological Survey Water-Resources Investigations Report 90-4106, 163 p.

Gaillardet, Jérôme, Dupré, Bernard, Louvat, Pascale, and Allegre, C.J., 1999, Global silicate weathering and $\mathrm{CO}_{2}$ consumption rates deduced from the chemistry of large rivers: Chemical Geology, v. 159, p. 3-30.

Garrison, Noah, Kloss, Christopher, and Lukes, Robb, 2011, Capturing rainwater from rooftops-An efficient water resource management strategy that increases supply and reduces pollution: Washington, D.C., Natural Resources Defense Council, 25 p.

Geosyntec Consultants and Wright Water Engineers, 2009, Urban stormwater BMP performance monitoring: Geosyntec Consultants and Wright Water Engineers manual, [variously paged], accessed January 1, 2014, at http://www.bmpdatabase.org/monitoring-guidance. html\#MonitoringGuidance.

German, E.R., 1990, Effect of spray irrigation of treated wastewater on water quality of the surficial aquifer system, Reedy Creek Improvement District, central Florida: U.S. Geological Survey Water-Resources Investigations Report 88-4174, 43 p.

Gesford, A.L., and Anderson, J.A., eds., 2007, Environmentally sensitive maintenance for dirt and gravel roads: U.S. Environmental Protection Agency Report EPA-PA-2005v1.1, $360 \mathrm{p}$. 
Ghassemi, Fereidoun, Jakeman, A.J., and Nix, H.A., 1995, Salinisation of land and water resources-Human causes, extent, management and case studies: Sydney, Australia, University of New South Wales Press, 526 p.

Gibs, Jacob, Brown, G.A., Turner, K.S., MacLeod, C.L., Jelinski, J.C., and Koehnlein, S.A., 1993, Effects of smallscale vertical variations in well-screen inflow rates and concentrations of organic compounds on the collection of representative ground-water-quality samples: Ground Water, v. 31, no. 2, p. 201-208.

Gilbertson, C.B., Nye, J.C., Clark, R.N., and Swanson, N.P., 1981, Controlling runoff from livestock feedlots-A state of the art: U.S. Department of Agriculture, Agriculture Information Bulletin Number 441, 24 p.

Gleason, R.A., Chesley-Preston, Tara, Preston, T.M., Smith, B.D., Tangen, B.A., and Thamke, J.N., 2011, Examination of brine contamination risk to aquatic resources from petroleum development in the Williston Basin: U.S. Geological Survey Fact Sheet 2011-3047, 4 p.

Gleason, R.A., and Tangen, B.A., eds., 2014, Brine contamination to aquatic resources from oil and gas development in the Williston Basin, United States: U.S. Geological Survey Scientific Investigations Report 2014-5017, 127 p.

Godwin, K.S., Hafner, S.D., and Buff, M.F., 2003, Long-term trends in sodium and chloride in the Mohawk River, New York-The effect of fifty years of road-salt application: Environmental Pollution, v. 124, p. 273-281.

Gong, S.L., Barrie, L.A., and Blanchet, J.P., 1997a, Modeling sea-salt aerosols in the atmosphere-1. Model development: Journal of Geophysical Research, v. 102, no. D3, p. 3805-3818.

Gong, S.L., Barrie, L.A., Prospero, J.M., Savoie, D.L., Ayers, G.P., Blancet, J.P., and Spacek, L., 1997b, Modeling sea-salt aerosols in the atmosphere-2. Atmospheric concentrations and fluxes: Journal of Geophysical Research, v. 102, no. D3, p. 3819-3830.

Gootee, B.F., 2013, An evaluation of carbon dioxide sequestration potential in the Luke Basin, south-central Arizona: Arizona Geological Survey Open-File Report OFR-13-05, 14 p., accessed October 31, 2013, at http://repository.azgs. az.gov/sites/default/files/dlio/files/nid1521/ofr-13-05_luke_ basin_sequestration_v1.pdf.

Gorham, Eville, Dean, W.E., and Sanger, J.E., 1982, The chemical composition of lakes in the north-central United States: U.S. Geological Survey Open-File Report 82-149, $65 \mathrm{p}$.

Gorman, H.S., 1999, Efficiency, environmental quality, and oil field brines-The success and failure of pollution control by self-regulation: Business History Review, v. 73, p. 601-640.
Graedel, T.E., and Keene, W.C., 1996, The budget and cycle of Earth's natural chlorine: Pure and Applied Chemistry, v. 68, no. 9, p. 1689-1697.

Graham, C.B., and Lin, H.S., 2011, Controls and frequency of preferential flow occurrence-A 175-event analysis: Vadose Zone Journal, v. 10, no. 3, p. 816-831.

Granato, G.E., 1996, Deicing chemicals as a source of constituents in highway runoff: Washington, D.C., Transportation Research Board, National Research Council, Transportation Research Record 1533, p. 50-58.

Granato, G.E., 2006, Kendall-Theil Robust Line (KTRLineversion 1.0)-A visual basic program for calculating and graphing robust nonparametric estimates of linearregression coefficients between two continuous variables: U.S. Geological Survey Techniques and Methods, book 4, chap. A7, $31 \mathrm{p}$.

Granato, G.E., 2010a, Methods for development of planninglevel estimates of stormflow at unmonitored sites in the conterminous United States: Washington, D.C., Federal Highway Administration FHWA-HEP-09-005, 90 p.

Granato, G.E., 2010b, Overview of methods used to estimate imperviousness in a drainage basin-Appendix 6 of Granato, G.E., 2010, Methods for development of planninglevel estimates of stormflow at unmonitored sites in the conterminous United States: Washington, D.C., Federal Highway Administration FHWA-HEP-09-005, 90 p.

Granato, G.E., Bank, F.G., and Cazenas, P.A., 2003, Data quality objectives and criteria for basic information, acceptable uncertainty, and quality-assurance and quality-control documentation, in Granato, G.E., Zenone, Chester, and Cazenas, P.A., eds., National highway runoff water-quality data and methodology synthesis, v. I-Technical issues for monitoring highway runoff and urban stormwater: Federal Highway Administration FHWA-EP-03-054, p. 3-21.

Granato, G.E., Carlson, C.S., and Sniderman, B.S., 2009, Methods for development of planning-level stream-waterquality estimates at unmonitored sites in the conterminous United States: Washington, D.C., Federal Highway Administration FHWA-HEP-09-003, 53 p.

Granato, G.E., and Cazenas, P.A., 2009, Highway-Runoff Database (HRDB Version 1.0) - A data warehouse and preprocessor for the stochastic empirical loading and dilution model: Washington, D.C., Federal Highway Administration FHWA-HEP-09-004, $57 \mathrm{p}$.

Granato, G.E., and Smith, K.P., 1999a, Estimating concentrations of road-salt constituents in highway runoff from measurements of specific conductance: U.S. Geological Survey Water-Resources Investigations Report 99-4077, 22 p. 
Granato, G.E., and Smith, K.P., 1999b, Robowell-A reliable and accurate automated data collection process applied to reactive wall monitoring on Cape Cod at the Massachusetts Military Reservation, in Morganwalp, D.W., and Buxton, H.T., eds., 1999, U.S. Geological Survey Toxic Substances Hydrology Program_-Proceedings of the Technical Meeting, Charleston, South Carolina, March 8-12, 1999Volume 3-Subsurface Contamination from Point Sources: U.S. Geological Survey Water-Resources Investigations Report 99-4018C, p. 447-455.

Granato G.E., and Smith, K.P., 1999c, Robowell: An automated process for monitoring groundwater quality using established sampling protocols. Groundwater Monitoring and Remediation, v. 19, no. 4, p. 81-89.

Granato, G.E., and Smith, K.P., 2000, Automated groundwater monitoring system and method: U.S. Patent 6,021,664, 31 p.

Granato, G.E., and Smith, K.P., 2001, Automated groundwater monitoring with Robowell-Case studies and potential applications, in Jensen, J.O., and Burggraf, L.W., eds., Chemical and biological early warning monitoring for water, food, and ground-Proceedings 4574: Bellingham, Washington, Society of Photo-Optical Instrumentation Engineers, Photonics Boston, October 28, 2001, p. 32-41.

Granato, G.E., and Smith, K.P., 2002, Robowell-Providing accurate and current water-level and water-quality data in real time for protecting the Nation's groundwater resources: U.S. Geological Survey Fact Sheet 053-02, 6 p.

Granato, G.E., Zenone, Chester, and Cazenas, P.A., eds., 2002, National Highway Runoff Water-Quality Data and Methodology Synthesis_-Volume 1. Technical issues for monitoring highway runoff and urban stormwater: Washington, D.C., Federal Highway Administration FHWA-EP-03-054, 479 p.

Grasby, S.E., and Betcher, R.N., 2002, Regional hydrogeochemistry of the carbonate rock aquifer, southern Manitoba: Canadian Journal of Earth Sciences, v. 39, p. 1053-1063.

Greene, K.E., Ebbert, J.C., and Munn, M.D., 1994, Nutrients, suspended sediment, and pesticides in streams and irrigation systems in the Central Columbia Plateau in Washington and Idaho, 1959-1991: U.S. Geological Survey WaterResources Investigations Report 94-4215, 64 p.

Gregory, M.B., and Calhoun, D.L., 2007, Physical, chemical, and biological responses of streams to increasing watershed urbanization in the Piedmont Ecoregion of Georgia and Alabama-Chapter B of Effects of urbanization on stream ecosystems in six metropolitan areas of the United States: U.S. Geological Survey Scientific Investigations Report 2006-5101-B, 104 p.
Grunhage, Ludger, Dammgen, Ulrich, Hertstein, Udo, and Jager, H.J., 1993, Response of grassland ecosystem to air pollutants - I. Experimental concept and site of the braunschweig grassland investigation program: Environmental Pollution, v. 81, no. 2, p. 163-171.

Guo, X.F., Yang, X.L., Li, H.B., Chen, Y.A., and Xie, K.C., 2000, Combustion characteristics of PVC: Journal of Fuel Chemistry and Technology, v. 28, no. 1, p. 70.

Gupta, M.K., Agnew, R.W., and Kobriger, N.P., 1981, Constituents of highway runoff — Volume I-State-of-the-art report: Federal Highway Administration Final Report FHWA/RD-81/042, 121 p.

Gustavson, T.C., Smpkins, W.W., Alhades, Alan, and Hoadley, Ann, 1982, Evaporite dissolution and development of karst features on the rolling plains of the Texas Panhandle: Earth Surface Processes and Landforms, v. 7, p. 545-563.

Haarstad K., and Mæhlum, T., 2007, Electrical conductivity and chloride reduction in leachate treatment systems: Journal of Environmental Engineering, v. 133, no. 6, p. 659-664.

Hamilton, P.A., and Helsel, D.R., 1995, Effects of agriculture on ground-water quality in five regions of the United States: Ground Water, v. 33, no. 2, p. 217-226.

Hamlin, H.S., 2006, Salt domes in the Gulf Coast aquifer, in Mace, R.E., Davidson, S.C., Angle, E.S., and Millican, W.F. III, eds., Aquifers of the Gulf Coast of Texas: Texas Water Development Board Report 365, p. 217-230.

Hamlin, H.S., Smith, D.A., and Akhter, M.S., 1988, Hydrogeology of Barbers Hill salt dome, Texas coastal plain: The University of Texas at Austin, Bureau of Economic Geology, Report of Investigations No. 176, 41 p.

Hansen, M.C., 1995, The Scioto Saline-Ohio’s early salt industry: Ohio Department of Natural Resources, Division of Geological Survey GeoFacts no. 7, 2 p., accessed November 1, 2013, at http://www.dnr.state.oh.us/Portals/10/ pdf/GeoFacts/geof07.pdf.

Harman, J., Robertson, W.D., Cherry, J.A., and Zanini, L., 1996, Impacts on a sand aquifer from an old septic system-Nitrate and phosphate: Ground Water, v. 34, no. 6, p. 1105-1114.

Harmel, R.D., Cooper, R.J., Slade, R.M., Haney, R.L., and Arnold, J.G., 2006, Cumulative uncertainty in measured streamflow and water quality data for small watersheds: Transactions of American Society of Agricultural and Biological Engineers, v. 49, no. 3, p. 689-701.

Harmel, R.D., King, K.W., and Slade, R.M., 2003, Automated storm water sampling on small watersheds: Applied Engineering in Agriculture, v. 19, no. 6, p. 667-674. 
Harned, D.A., 1988, Effects of highway runoff on streamflow and water quality in the Sevenmile Creek Basin, a rural area in the Piedmont Province of North Carolina, July 1981 to July 1982: U.S. Geological Survey Water-Supply Paper $2329,105 \mathrm{p}$.

Harned, D.A., McMahon, Gerard, Spruill, T.B., and Woodside, M.D., 1995, Water-quality assessment of the AlbemarlePamlico drainage basin, North Carolina and VirginiaSummary of water-quality data for suspended sediment, nutrients, and pesticides: U.S. Geological Survey Open-File Report 95-191, $131 \mathrm{p}$.

Harned, H.S., and Owen, B.B., 1958, The physical chemistry of electrolytic solutions ( $3 \mathrm{~d}$ ed.): New York, Reinhold, $803 \mathrm{p}$.

Harrison, J.F., and Michaud, C.F., 2005, Home water treatment system discharges to on-site wastewater systems: Water Conditioning and Purification, v. 47, no. 12, p. 34-39.

Harte, P.T., and Trowbridge, P.R., 2010, Mapping of roadsalt-contaminated groundwater discharge and estimation of chloride load to a small stream in southern New Hampshire, USA: Hydrological Processes, v. 24, p. 2349-2368.

Harvey, F.E., Ayers, J.F., and Gosselin, D.C., 2007, Ground water dependence of endangered ecosystems: Nebraska's eastern saline wetlands: Ground Water, v. 45, p. 736-752.

Healy, R.W., Winter, T.C., LaBaugh, J.W., and Franke, L.O., 2007, Water budgets - Foundations for effective waterresources and environmental management: U.S. Geological Circular 1308, 90 p.

Heath, R.C., 2004, Basic ground-water hydrology (revised ed.): U.S. Geological Survey Water-Supply Paper 2220, $86 \mathrm{p}$.

Heinz, Stefan, Novotny, Eric, Sander, Andrew, and Mohseni, Omid, 2008, Study of environmental effects of de-icing salt on water quality in the Twin Cities metropolitan area, Minnesota: Minnesota Department of Transportation Report $\mathrm{MN} / \mathrm{RC} 2008-42,88 \mathrm{p}$.

Heisig, P.M., 2000, Effects of residential and agricultural land uses on the chemical quality of baseflow of small streams in the Croton Watershed, southeastern New York: U.S. Geological Survey Water-Resources Investigations Report 99-4173, 15 p.

Helsel, D.R., and Hirsch, R.M., 2002, Statistical methods in water resources - Hydrologic analysis and interpretation: Techniques of Water-Resources Investigations of the U.S. Geological Survey, book 4, chap. A3, 510 p.

Hem, J.D., 1982, Conductance-A collective measure of dissolved ions, in Minear, R.A., and Keith, L.A., eds., Water Analysis, v. 1, part 1. Inorganic Species: New York, Academic Press, p. 137-161.
Hem, J.D., 1992, Study and interpretation of the chemical characteristics of natural water (3d ed.): U.S. Geological Survey Water-Supply Paper 2254, 263 p.

Henderson, R.D., Unthank, M.D., Zettwoch, D.D., and Lane, J.W., Jr., 2010, Brine delineation and monitoring with electrical resistivity tomography and electromagnetic borehole logging at the Fort Knox well field near West Point, Kentucky, in Symposium on the Application of Geophysics to Engineering and Environmental Problems, April 11-15, 2010, Keystone, Colorado, proceedings: Denver, Colo., Environmental and Engineering Geophysical Society, 10 p.

Hibbs, Barry, and Merino, Mercedes, 2007, Discovering a geologic salinity source in the Rio Grande aquifer: Southwest Hydrology, v. 6, p. 20-23.

Hill, B.J., Berthe, F.D., Lightner, D.V., and Saís, R.E., 2013, Chapter 1.1.3 - Methods for disinfection of aquaculture establishments, in Manual of diagnostic tests for aquatic animals: Paris, France, World Organization for Animal Health, $39 \mathrm{p}$.

Hirsch, R.M., and Gilroy, E.J., 1984, Methods of fitting a straight line to data-Examples in water resources: Water Resources Bulletin, v. 20, no. 5, p. 705-711.

Hirsch, R.M., Helsel, D.R., Gilroy, E.J., and Cohn, T.A., 1992, Chapter 17-Statistical analysis of hydrologic data, in Maidment, D.R., ed., Handbook of hydrology: New York, McGraw-Hill, p. 17.1-17.55.

Hitchon, Brian, Levinson, A.A., and Reeder, S.W., 1969, Regional variations of river water composition resulting from halite solution, Mackenzie River drainage basin, Canada: Water Resources Research, v. 5, p. 1395-1403.

Hladik, M.L., Focazio, M.J., and Engle, Mark, 2014, Discharges of produced waters from oil and gas extraction via wastewater treatment plants are sources of disinfection by-products to receiving streams: Science of the Total Environment, v. 466-467, p. 1085-1093.

Hooda, P.S., Edwards, A.C., Anderson, H.A., and Miller, A.A., 2000, A review of water quality concerns in livestock farming areas: Science of the Total Environment, v. 250, no. 1-3, p. 143-167.

Hope, Diane, Anderson, James, Grimm, N.B., and Clary, Michael, 2001, Wet and dry deposition of major nutrients across the CAP LTER ecosystem: Central Arizona-Phoenix Long-Term Ecological Research (CAP LTER) Third Annual Poster Symposium, Tempe, Ariz., Arizona State University, January 19, 2001, accessed October 21, 2013, at http://caplter.asu.edu/docs/symposia/symp2001/Hopeetal_ atmdep.pdf. 
Horn, M.K., and Adams, J.A.S., 1966, Computer-derived geochemical balances and element abundances: Geochimica et Cosmochimica Acta, v. 30, p. 279-297.

Hornberger, G.M., Raffensperger, J.P., Wiberg, P.L., and Eshleman, K.N., 1998, Elements of physical hydrology: Baltimore, Maryland, The Johns Hopkins University Press, $302 \mathrm{p}$.

Howard, K.W.F., and Haynes, Janet, 1993, Groundwater contamination due to road de-icing chemicals-Salt balance implications: Geoscience Canada, v. 20, no. 1, p. 1-8.

Howard, K.W.F., and Maier, Herb, 2007, Road de-icing salt as a potential constraint on urban growth in the Greater Toronto Area, Canada: Journal of Contaminant Hydrology, v. 91, p. 146-170.

Hren, J., Chaney, T.H., Norris, J.M., and Childress, C.J.O., 1987, Water-quality data-collection activities in Colorado and Ohio-Phase I-Inventory and evaluation of 1984 programs and costs: U.S. Geological Survey Water-Supply Paper 2295-A, $71 \mathrm{p}$.

Hudak, P.F., 2000, Sulfate and chloride concentrations in Texas aquifers: Environment International, v. 26, no. 1-2, p. 55-61.

Hudak, P.F., 2003, Oil production and groundwater quality in the Edwards-Trinity Plateau aquifer, Texas: The Scientific World Journal, v. 3, 13, p. 1147-1153.

Hull, L.C., and Bishop, C.W., 2003, Fate of magnesium chloride brine applied to unpaved roads to suppress dust at the INEEL subsurface disposal area: Idaho National Engineering and Environmental Laboratory Report INEEL/ EXT-01-01173, $60 \mathrm{p}$.

Hull, L.C., and Bishop, C.W., 2004, Fate of brine applied to unpaved roads at a radioactive waste subsurface disposal area: Vadose Zone Journal, v. 3, p. 190-202.

Hulstrand, Douglas, 2014, Cold weather flow monitoring with flumes: Open Channel Flow, January 15, 2014, accessed June 23, 2014, at http://www.openchannelflow.com/blog/ article/cold-weather-flow-monitoring-with-flumes.

Hunt, R.J., Borchardt, M.A., Richards, K.D., and Spencer, S.K., 2010, Assessment of sewer source contamination of drinking water wells using tracers and human enteric viruses: Environmental Science and Technology, v. 44, p. 7956-7963.

Hurlbut, C.S. Jr., and Klein, C., 1977, Manual of mineralogy (19th ed.): New York, John Wiley and Sons, 532 p.

Hutson, S.S., Barber, N.L., Kenny, J.F., Linsey, K.S., Lumia, D.S., and Maupin, M.A., 2004, Estimated use of water in the United States in 2000, U.S. Geological Survey Circular $1268,46 \mathrm{p}$.
Hyer, K.E., 2007, A multiple-tracer approach for identifying sewage sources to an urban stream system: U.S. Geological Survey Scientific Investigations Report 2006-5317, 89 p.

Illinois Department of Natural Resources, 2009, When salt was gold: Illinois Department of Natural Resources Outdoor Illinois, October 2009, p. 11-13, accessed November 1, 2013, at http://www.dnr.illinois.gov/OI/Documents/Oct09Salt.pdf.

Intergovernmental Task Force on Monitoring Water Quality, 1995a, The strategy for improving water-quality monitoring in the United States: U.S. Geological Survey Final Report, $25 \mathrm{p}$.

Intergovernmental Task Force on Monitoring Water Quality, $1995 \mathrm{~b}$, The strategy for improving water-quality monitoring in the United States: U.S. Geological Survey Technical Appendixes, $117 \mathrm{p}$.

Israel, D., Showers, W.J., Fountain, M., and Fountain, J., 2005, Nitrate movement in shallow groundwater from swine-lagoon-effluent spray fields managed under current application regulations: Journal of Environmental Quality, v. 34 , p. $1828-1842$.

Ito, Mari, Mitchell, M.J., Driscoll, C.T., and Roy, K.M., 2005, Nitrogen input-output budgets for lake-containing watersheds in the Adirondack region of New York: Biogeochemistry, v. 72 , no. 3, p. 283-314.

Ivahnenko, Tamara, 2009, Estimated Colorado golf course irrigation water use, 2005: U.S. Geological Survey OpenFile Report 2008-1267, 25 p.

Izbicki, J.A., 2000, Water resources of the Blackstone River Basin, Massachusetts: U.S. Geological Survey WaterResources Investigations Report 93-4167, 115 p.

Izquierdo, Rebeca, and Avila, Anna, 2012, Comparison of collection methods to determine atmospheric deposition in a rural Mediterranean site (NE Spain): Journal of Atmospheric Chemistry, v. 69, no. 4, p. 351-368.

Jackson, D.D., 1905, The normal distribution of chlorine in the natural waters of New York and New England: U.S. Geological Survey Water-Supply Paper 144, 31 p.

Jackson, R.B., and Jobbagy, E.G., 2005, From icy roads to salty streams: Proceedings of the National Academy of Sciences, v. 102, no. 41, p. 14487-14488.

Janiczek, J.R., 2005, Application of oil field brine (brine)Application of brines for ice and dust control and soil and road stabilization: Michigan Department of Environmental Quality Water Bureau Groundwater Discharge General Permit 2215-05-5, 7 p., accessed July 9, 2014, at http://www.deq.state.mi.us/documents/deq-wmd-gwpRule2215OilFieldBrine-1.pdf. 
Jasinski, S.M., Kramer, D.A., Ober, J.A., and Searls, J.P., 1999, Fertilizers-Sustaining global food supplies: U.S. Geological Survey Fact Sheet 99-155, 4 p.

Jaworski, N.A., and Hetling, L.J., 1996, Water quality trends of Mid-Atlantic and northeast watersheds over the past 100 years, in U.S. Environmental Protection Agency Watershed '96, June 8-12, 1996, Baltimore, Maryland, proceedings: Alexandria, Virginia, Water Environment Federation, p. 980-983.

Johns, W.D., and Huang, W.H., 1967, Distribution of chlorine in terrestrial rocks: Geochemica et Cosmochimica Acta, v. 31, p. $35-49$.

Johnson, C.D., Haeni, F.P., Lane, J.W., and White, E.A., 2002, Borehole-geophysical investigation of the University of Connecticut landfill, Storrs, Connecticut: U.S. Geological Survey Water-Resources Investigations Report 01-4033, $187 \mathrm{p}$.

Johnson, C.D., Joesten, P.K., and Mondazzi, R.A., 2005, Borehole-geophysical and hydraulic investigation of the fractured-rock aquifer near the University of Connecticut landfill, Storrs, Connecticut, 2000 to 2001: U.S. Geological Survey Water-Resources Investigations Report 03-4125, $133 \mathrm{p}$.

Johnson, K.S., 1981, Dissolution of salt on the east flank of the Permian Basin in the southwestern U.S.A: Journal of Hydrology, v. 54, p. 75-93.

Johnson, K.S., 1997, Subsidence hazards due to evaporite dissolution in the United States: Environmental Geology, v. 48, p. $395-409$.

Johnson, K.S., Gonzales, Serge, and Dean, W.E., 1989, Distribution and geologic characteristics of anhydrite deposits in the United States, in Dean, W.E., and Johnson, K.S., eds, Anhydrite deposits of the United States and characteristics of anhydrite important for storage of radioactive wastes: U.S. Geological Survey Bulletin 1794, p. 9-90.

Johnson, T.D., and Belitz, Kenneth, 2012, A remote sensing approach for estimating the location and rate of urban irrigation in semi-arid climates: Journal of Hydrology, v. $414-415$, p. $86-98$.

Johnston, R.H., 1999, Hydrologic budgets of regional aquifer systems of the United States for predevelopment and development conditions: U.S. Geological Survey Professional Paper 1425, $34 \mathrm{p}$.

Joint Departments of the Army, Navy, and Air Force, 1995, Maintenance and repair of surface areas: Joint Departments of the Army, Navy, and Air Force TM 5-624/NAVFAC DM MO-102/AFJMAN 321040, [variously paged].
Jones, A.L., and Sroka, B.N., 1997, Effects of highway deicing chemicals on shallow unconsolidated aquifers in Ohio, interim report, 1988-93: U.S. Geological Survey WaterResources Investigations Report 97-4027, 139 p.

Jones, B.E., 2003, Principles and practices for quality assurance and quality control, in Granato, G.E., Zenone, C., and Cazenas, P.A., eds., National highway runoff water-quality data and methodology synthesis, v. I-Technical issues for monitoring highway runoff and urban stormwater: Federal Highway Administration FHWA-EP-03-054, p. 25-46.

Jones, David, Kociolek, Angela, Surdahl, Roger, Bolander, Peter, Drewes, Bruce, Duran, Matthew, Fay, Laura, Huntington, George, James, David, Milne, Clark, Nahra, Mark, Scott, Andrew, Vitale, Bob, and Williams, Bethany, 2013, Unpaved road dust management-A successful practitioner's handbook: Federal Highway Administration FHWA-CFL/TD-13-001, 94 p.

Jordan, P.R., Jones, B.F., and Petri, L.R., 1964, Chemical quality of surface waters and sedimentation in the Saline River Basin, Kansas: U.S. Geological Survey Water-Supply Paper 1651, $90 \mathrm{p}$.

Jorgensen, D.G., Helgesen, J.O., and Imes, J.L., 1993, Regional aquifers in Kansas, Nebraska, and parts of Arkansas, Colorado, Missouri, New Mexico, Oklahoma, South Dakota, Texas, and Wyoming - Geohydrologic framework: U.S. Geological Survey Professional Paper 1414-B, 72 p.

Kalkhoff, S.J., 1982, Specific conductance and dissolved chloride concentrations of freshwater aquifers and streams in petroleum producing areas in Mississippi: U.S. Geological Survey Open-File Report 82-353, 33 p.

Kalkhoff, S.J., 1993, Brine contamination of ground water and streams in the Baxterville oil field area, Lamar and Marion Counties, Mississippi: U.S. Geological Survey WaterResources Investigations Report 93-4147, 37 p.

Karr, J.D., Showers, W.J., Gilliam, J.W., and Andres, A.S., 2001, Tracing nitrate transport and environmental impact from intensive swine farming using delta nitrogen-15: Journal of Environmental Quality, v. 30, p. 1163-1175.

Kassotis, C.D., Tillitt, D.E., Davis, J.W., Hormann, A.M., and Nagel, S.C., 2014, Estrogen and androgen receptor activities of hydraulic fracturing chemicals and surface and ground water in a drilling-dense region: Endocrinology, v. 155, no. 3, p. 897-907.

Katz, B.G., Eberts, S.M., and Kauffman, L.J., 2011, Using $\mathrm{Cl} / \mathrm{Br}$ ratios and other indicators to assess potential impacts on groundwater quality from septic systems - A review and examples from principal aquifers in the United States: Journal of Hydrology, v. 397, p. 151-166. 
Katz, B.G., and Griffin, D.W., 2008, Using chemical and microbiological indicators to track the impacts from the land application of treated municipal wastewater and other sources on groundwater quality in a karstic springs basin: Environmental Geology, v. 55, p. 801-821.

Keene, W.C., Khalil, M.A.K., Erickson, D.J., McCulloch, Archie, Graedel, T.E., Lobert, J.M., Aucott, M.L., Gong, S.L., Harper, D.B., Kleiman, Gary, Midgley, Pauline, Moore, R.M., Seuzaret, Christophe, Sturges, W.T., Benkovitz, C.M., Koropalov, Valentin, Barrie, L.A., and Li, Y.F., 1999, Composite global emissions of reactive chlorine from anthropogenic and natural sources-Reactive chlorine emissions inventory: Journal of Geophysical Research, v. 104, no. D7, p. 8429-8440.

Kelley, V.R., Lovett, G.M., Weathers, K.C., Findlay, S.E.G., Strayer, D.L., Burns, D.J., and Likens, G.E., 2008, Longterm sodium chloride retention in a rural watershedLegacy effects of road salt on streamwater concentration: Environmental Science and Technology, v. 42, no. 2, p. $410-415$.

Kellog, R.L., 2000, Potential priority watersheds for protection of water quality from contamination by manure nutrients, in Proceedings of the Animal Residuals Management Conference 2000, November 12-14, Kansas City, Missouri: Alexandria, Va., Water Environment Federation, 20 p.

Kellog, R.L., Lander, C.H., Moffit, D.C., and Gollehon, Noel, 2000, Manure nutrients relative to the capacity of cropland and pastureland to assimilate nutrients - Spatial and temporal trends for the United States: U.S. Department of Agriculture Natural Resources Conservation Service Report nps00-0579, 140 p.

Kelly, T.D., and Matos, G.R., comps., 2013, Historical statistics for mineral and material commodities in the United States (2013 version): U.S. Geological Survey Data Series 140, accessed July 3, 2014, at http://minerals.usgs.gov/minerals/pubs/historical-statistics/.

Kelly, V.R., Lovett, G.M., Weathers, K.C., Findlay, S.E.G., Strayer, D.L., Burns, D.J., and Likens, G.E., 2008, Longterm sodium chloride retention in a rural watershedLegacy effects of road salt on streamwater concentration: Environmental Science and Technology, v. 42, no. 2, p. $410-415$.

Kelly, W.R., Panno, S.V., and Hackley, Keith, 2012, The sources, distribution, and trends of chloride in the waters of Illinois: Illinois State Water Survey Bulletin B-74, 59 p.

Kelly, W.R., Panno, S.V., Hackley, K.C., Hwang, Hue-Hwa, Martinsek, A.T., and Markus, Momcilo, 2010, Using chloride and other ions to trace sewage and road salt in the Illinois Waterway: Applied Geochemistry, v. 25, p. 661673.
Kelting, D.L., Laxson, C.L., and Yerger, E.C., 2012, Regional analysis of the effect of paved roads on sodium and chloride in lakes: Water Research, v. 46, p. 2749-2758.

Kenny, J.F., Barber, N.L., Hutson, S.S., Linsey, K.S., Lovelace, J.K., and Maupin, M.A., 2009, Estimated use of water in the United States in 2005: U.S. Geological Survey Circular 1344, 52 p.

Kenny, J.F., and Juracek, K.E., 2012, Description of 2005-10 domestic water use for selected U.S. cities and guidance for estimating domestic water use: U.S. Geological Survey Scientific Investigations Report 2012-5163, 31 p.

Kestler, M.A., 2009, Stabilization selection guide for aggregate and native-surfaced low volume roads: U.S. Forest Service Report 0877 1805-SDTDC, 156 p.

Ketcham, S.A., Minsk, L.D., Blackburn, R.R., and Fleege, E.J., 1996, Manual of practice for an effective anti-icing program a guide for highway winter maintenance personnel: Federal Highway Administration FHWA-RD-95-202, 70 p.

Keys, W.S., and MacCary, L.M., 1971, Application of borehole geophysics to water-resources investigations: U.S. Geological Survey Techniques of Water-Resources Investigations, book 2, chap. E1, 126 .

Kharaka, Y.K., and Hanor, J.S., 2003, Deep fluids in the continents - I. Sedimentary basins, in Holland, H.D., and Turekian, K.K., eds., Treatise on geochemistry, v. 5.16: Oxford, England, Elsevier, p. 1-48.

Kharaka, Y.K., Thordsen, J.J., Kakouros, Evangelos, and Herkelrath, W.N., 2005, Impacts of petroleum production on ground and surface waters - Results from the OsageSkiatook Petroleum Environmental Research A site, Osage County, Oklahoma: Environmental Geosciences, v. 12, no. 2, p. 127-138.

Kidd, R.E., and Lambeth, D.S., 1995, Hydrogeology and ground-water quality in the Black Belt area of west-central Alabama, and estimated water use for aquaculture, 1990: U.S. Geological Survey Water-Resources Investigations Report 94-4074, 52 p.

Kilpatrick, F.A., and Schneider, V.R., 1983, Use of flumes in measuring discharge: U.S. Geological Survey Techniques of Water-Resources Investigations, book 3, chap. A14, 46 p.

Kimmel, G.E., and Braids, O.C., 1974, Leachate plumes in a highly permeable aquifer: Ground Water, v. 12, no. 6, p. 388-393.

Kirk, M.F., Crossey, L.J., Takacs-Vesbach, Cristina, Newell, D.L., and Bowman, R.S., 2009, Influence of upwelling saline groundwater on iron and manganese cycling in the Rio Grande floodplain aquifer: Applied Geochemistry, v. 24, p. $426-437$. 
Kjeldsen, Peter, Barlaz, M.A., Rooker, A.P., Baun, Anders, Ledin, Anna, and Christensen, T.H., 2002, Present and longterm composition of MSW landfill leachate-A review: Critical Reviews in Environmental Science and Technology, v. 32, no. 4, p. 297-336.

Knuth, Martin, Jackson, J.L., and Whittemore, D.O., 1990, An integrated approach to identifying the salinity source contaminating a ground-water supply: Ground Water, v. 28, no. 2, p. 207-214.

Kolker, Allan, Quick, J.C., Senior, C.L., and Belkin, H.E., 2012, Mercury and halogens in coal-Their role in determining mercury emissions from coal combustion: U.S. Geological Survey Fact Sheet 2012-3122, 6 p.

Kolpin, D.W., Furlong, E.T., Meyer, M.T., Thurman, E.M., Zaugg, S.D., Barber, L.B., and Buxton, H.T., 2002, Pharmaceuticals, hormones, and other organic wastewater contaminants in U.S. Streams, 1999-2000-A national reconnaissance: Environmental Science and Technology, v. 36, no. $6,1202-1211$.

Konikow, L.F., and Person, Mark, 1985, Assessment of longterm salinity changes in an irrigated stream-aquifer system: Water Resources Research, v. 21, no. 11, p. 1611-1624.

Kostick, D.S., 1993, The material flow of salt: U.S. Bureau of Mines Information Circular 9343, 32 p.

Koterba, M.T., Waldron, M.C., and Kraus, T.E.C., 2011, The water-quality monitoring program for the Baltimore reservoir system, 1981-2007-Description, review and evaluation, and framework integration for enhanced monitoring: U.S. Geological Survey Scientific Investigations Report 2011-5101, 133 p.

Koterba, M.T., Wilde, F.D., and Lapham, W.W., 1995, Ground-water data-collection protocols and procedures for the National Water-Quality Assessment Program-Collection and documentation of water-quality samples and related data: U.S. Geological Survey Open-File Report 95-399, $114 \mathrm{p}$.

Kraft, G.J., Browne, B.A., DeVita, W.M., and Mechenich, D.J., 2008, Agricultural pollutant penetration and steady state in thick aquifers: Ground Water, v. 46, no. 1, p. 41-50.

Krapac, I.G., Dey, W.S., Roy, W.R., Jellerichs, B.G., and Smyth, C., 2000, Groundwater quality near livestock waste pits, in Moore, J.A., ed., Proceedings of the 8th International symposium on animal, agricultural and food processing wastes, October 9-11, 2000, Des Moines, Iowa: St. Joseph, Mich., American Society of Agricultural Engineers publication 701P0002, p. 710-718.
Krogmann, Uta, and Woyczechowski, Heike, 2000, Selected characteristics of leachate, condensate and runoff released during composting of biogenic waste: Waste Management and Research, v. 18 , no. 3, p. 235-248.

Krupa, S.V., 2002, Sampling and physico-chemical analysis of precipitation-A review: Environmental Pollution, v. 120, p. 565-594.

Kulikowska, Dorota, and Klimiuk, Ewa, 2008, The effect of landfill age on municipal leachate composition: Bioresource Technology, v. 99, p. 5981-5985.

Kunze, A.E., and Sroka, B.N., 2004, Effects of highway deicing chemicals on shallow unconsolidated aquifers in Ohio-Final report: U.S. Geological Survey Scientific Investigations Report 2004-5150, 187 p.

Kuroda, P.K., and Sandell, E.B., 1953, Chlorine in igneous rocks: Bulletin of the Geological Society of America, v. 64, p. $879-896$.

LaBaugh, J.W., Rosenberry, D.O., and Winter, T.C., 1995, Groundwater contribution to the water and chemical budgets of Williams Lake, Minnesota, 1980-1991: Canadian Journal of Fisheries and Aquatic Sciences, v. 52, no. 4, p. 754-767.

LaBaugh, J.W., Winter, T.C., and Rosenberry, D.O., Schuster, P.F., Reddy, M.M., and Aiken, G.R., 1997, Hydrological and chemical estimates of the water balance of a closed-basin lake in north central Minnesota: Water Resources Research, v. 33 , no. 12 , p. $2799-2812$.

Lamb, Dennis, and Bowersox, Van, 2000, The National Atmospheric Deposition Program-An overview: Atmospheric Environmnent, v. 34, p. 1661-1663.

Land, L.S., and Prezbindowski, D.R., 1981, The origin and evolution of saline formation water, Lower Cretaceous carbonates, south-central Texas, U.S.A.: Journal of Hydrology, v. 54 , p. $51-74$.

Landon, M.K., Delin, G.N., Komor, S.C., and Regan, C.P., 1999, Comparison of the stable-isotopic composition of soil water collected from suction lysimeters, wick samplers, and cores in a sandy unsaturated zone: Journal of Hydrology, v. 224 , no. $1-2$, p. $45-54$.

Langevin, C.D., 2009, SEAWAT-A computer program for simulation of variable-density groundwater flow and multispecies solute and heat transport: U.S. Geological Survey Fact Sheet 2009-3047, 2 p.

Langevin, C.D., and Zygnerski, Michael, 2013, Effect of sealevel rise on salt water intrusion near a coastal well field in southeastern Florida: Groundwater, v. 51, no. 5, p. 781-803. 
Lapham, W.W., Wilde, F.D., and Koterba, M.T., 1995, Ground-water data-collection protocols and procedures for the national water-quality assessment program-Selection, installation, and documentation of wells, and collection of related data: U.S. Geological Survey Open-File Report 95-398, 71 p.

Lee, J.G., and Heaney, J.P., 2003, Estimation of urban imperviousness and its impacts on storm water systems: Journal of Water Resources Planning and Management, v. 129, no. 5 , p. 419-426.

Lerner, D.N., 2002, Identifying and quantifying urban recharge-A review. Hydrogeology Journal, v. 10, no. 1, p. 143-52.

Lesch, S.M., Rhoades, J.D., and Strauss, D.J., 1995, Spatial prediction of soil salinity using electromagnetic induction techniques - 1. Statistical prediction models - A comparison of multiple linear regression and cokriging: Water Resources Research, v. 31, no. 2, p. 373-386.

Levin, S.B., and Zarriello, P.J., 2013, Estimating irrigation water use in the humid eastern United States: U.S. Geological Survey Scientific Investigations Report 2013-5066, $32 \mathrm{p}$.

Li, Guiying, An, Taicheng, Chen, Jiaxin, Sheng, Guoying, Fu, Jiamo, Chen, Fanzhong, Zhang, Shanqing, and Zhao, Huijun, 2006, Photoelectrocatalytic decontamination of oilfield produced wastewater containing refractory organic pollutants in the presence of high concentration of chloride ions: Journal of Hazardous Materials, v. B138, p. 392-400.

Likens, G.E., and Bormann, F.H., 1995, Biogeochemistry of a forested ecosystem ( $2 \mathrm{~d}$ ed.): New York, Springer-Verlag, $159 \mathrm{p}$.

Likens, G.E., and Buso, D.C., 2010, Salinization of Mirror Lake by road salt: Water Air Soil Pollution, v. 205, p. 205214.

Lind, C.J., 1970, Specific conductance as a means of estimating ionic strength: U.S. Geological Survey Professional Paper 700-D, p. D272-280.

Lindsey, B.D., and Rupert, M.G., 2012, Methods for evaluating temporal groundwater quality data and results of decadal-scale changes in chloride, dissolved solids, and nitrate concentrations in groundwater in the United States, 1988-2010: U.S. Geological Survey Scientific Investigations Report 2012-5049, 46 p.

Loncnar, Mojca, Zupancic Marija, Bukovec, Peter, and Justin, M.Z., 2010, Fate of saline ions in a planted landfill site with leachate recirculation: Waste Management, v. 30, p. 110118.

Looney, B., and Falta, R., 2000, Vadose zone-Science and technology solutions: Columbus, Ohio, Battle Press, 1540 p.
Lopes, T.J., and Dionne, S.G., 1998, A review of semivolatile and volatile organic compounds in highway runoff and urban stormwater: U.S. Geological Survey Open-File Report 98-409, 67 p.

Louisiana State University Agricultural Center, 2007, Winterize lawn with potash, not nitrogen: Baton Rouge, La., Louisiana State University Agricultural Center Web page, accessed January 20, 2012, at http://www.lsuagcenter.com/ en/lawn_garden/home_gardening/lawn/Winterize + Lawn $+W$ ith + Potash+Not+Nitrogen.htm.

Lovelace, J.K., 2009, Methods for estimating water withdrawals for aquaculture in the United States, 2005: U.S. Geological Survey Scientific Investigations Report 2009-5042, $13 \mathrm{p}$.

Lovett, G.M., Bowser, J.J., and Edgerton, E.S., 1997, Atmospheric deposition to watersheds in complex terrain: Hydrological Processes, v. 11, p. 645-654.

Lovett, G.M., Likens, G.E., Buso, D.C., Driscoll, C.T., and Bailey, S.W., 2005, The biogeochemistry of chlorine at Hubbard Brook, New Hampshire, USA: Biogeochemistry, v. 72, p. 191-232.

Lovett, G.M., Traynor, M.M., Pouyat, R.V., Carreiro, M.M., Zhu, W.X., and Baxter, J.W., 2000, Atmospheric deposition to oak forests along and urban-rural gradient: Environmental Science and Technology, v. 34, p. 4294-4300.

Lundmark, Annika, and Olofsson, Bo, 2007, Chloride deposition and distribution in soils along a deiced highway-Assessment using different methods of measurement: Water Air Soil Pollution, v. 182, p. 173-185.

Lusczynski, N.J., 1961, Filter-press method of extracting water samples for chloride analysis: U.S. Geological Survey Water-Supply Paper 1544-A, 8 p.

Lutz, B.D., Lewis, A.N., and Doyle, M.W., 2013, Generation, transport, and disposal of wastewater associated with Marcellus Shale gas development: Water Resources Research, v. 49, p. 647-656.

Lynch, T.J., 2010, Beneficial use Determination-Brine for dust control: New York State Department of Environmental Conservation Permit \# 8A-729, 9 p., accessed July 9, 2014, at http://www.ithacajournal.com/assets/pdf/CB177057720. PDF.

Macfarlane, P.A., Whittemore, D.O., Townsend, M.A., Doveton, J.H., Hamilton, V.J., Coyle, W.G., III, Wade, A., Macpherson, G.L., and Black, R.D., 1990, The Dakota Aquifer Program annual report, FY89: Kansas Geological Survey Open-File Report 90-27, accessed July 9, 2014, at http://www.kgs.ku.edu/Dakota/vol3/fy89/index.htm. 
Mack, T.J., 1993, Detection of contaminant plumes by borehole geophysical logging: Ground Water Monitoring and Remediation, v. 13, no. 1, p 107-114.

Mack, T.J., and Maus, P.E., 1986, Detection of contaminant plumes in ground water of Long Island, New York, by electromagnetic terrain-conductivity surveys: U.S. Geological Survey Water-Resources Investigations Report 86-4045, $39 \mathrm{p}$.

Madison Wisconsin Salt Use Subcommittee, 2006, Report of the salt use subcommittee to the commission on the environment on road salt use and recommendations-Draft report: Madison, Wis., Salt Use Subcommittee to the Commission on the Environment, $19 \mathrm{p}$.

Manheim, F.T., Krantz, D.E., Snyder, D.S., and Sturgis, Brian, 2002, Streamer resistivity surveys in Delmarva coastal bays, in Symposium on the Application of Geophysics to Environmental and Engineering Problems (SAGEEP 2002), Las Vegas, Nev., February 10-14, 2002, proceedings: Las Vegas, Nev., Environmental and Engineering Geophysical Society, Paper 13GSL5, 17 p.

Marques, M., and Hogland, W., 2001, Stormwater run-off and pollutant transport related to the activities carried out in a modern waste management park: Waste Management and Research, v. 19, no. 1, p. 20-34.

Massachusetts Department of Transportation, 2012, MassDOT snow and ice control program-Public Review Draft: Massachusetts Department of Transportation Environmental Status and Planning Report EOEA\#11202, 125 p.

Maybeck, Michael, 1987, Global chemical weathering of surficial rocks estimated from river dissolved loads: American Journal of Science, v. 287, p. 401-428.

McCobb, T.D., Leblanc, D.R., Walter, D.A., Hess, K.M., Kent, D.B., and Smith, R.L., 2003, Phosphorus in a ground-water contaminant plume discharging to Ashumet Pond, Cape Cod, Massachusetts, 1999: U.S. Geological Survey WaterResources Investigations Report 02-4306, 69 p.

McCulloch, Archie, Aucott, M.L., Benkovitz, C.M., Graedel, T.E., Kleiman, Gary, Midgley, P.M., and Li, Yi-Fan, 1999, Global emissions of hydrogen chloride and chloromethane from coal combustion, incineration and industrial activities-Reactive Chlorine Emissions Inventory: Journal of Geophysical Research, v. 104, no. D7, p. 8391-8403.
McDonald, K.H., Ongley, L., Woods, B., and Lee Pinard, T., 2012, The pinch of salt-Monitoring analysis and winter maintenance strategies within the Long Creek Watershed in Morse, Brian, and Doré, Guy, eds., Cold Regions Engineering 2012 - Sustainable Infrastructure Development in a Changing Cold Environment: American Society of Civil Engineers, Proceedings of the 15th International Specialty Conference on Cold Regions Engineering, Quebec City, Canada, August 19-22, 2012, p. 281-291.

McEachern, Rod, Wist, William, and Lehr, J.H., 2009, Water softening with potassium chloride-Process, health, and environmental benefits: New York, John Wiley \& Sons, $240 \mathrm{p}$.

McFarland, Anne, and Hauck, Larry, 2001, Strategies for monitoring nonpoint source runoff: Stephenville, Tex., Texas Institute for Applied Environmental Research Report TR0115, $83 \mathrm{p}$.

McGinley, P.M., 2008, Modeling the influence of land use on groundwater chloride loading to lakes: Journal of Lake and Reservoir Management, v. 24, no. 2, p. 112-121.

McMahon, Gerard, Tervelt, Larinda, and Donehoo, William, 2007, Methods for estimating annual wastewater nutrient loads in the southeastern United States: U.S. Geological Survey Open-File Report 2007-1040, 81 p.

McNeill, J.D., 1986, Geonics EM39 borehole conductivity meter-Theory and operation: Mississauga, Ontario, Canada, Geonics Limited, Technical Note TN-20, 11 p.

McQuillan, Dennis, 2007, Groundwater contamination by septic tank effluents in Proceedings-51st Annual New Mexico Water Conference [2006] — Water quality for the 21st century: Las Cruces, N. Mex., New Mexico Water Resources Research Institute Report 340, accessed February 7, 2012, at http://wrri.nmsu.edu/publish/watcon/proc51/ mcquillan.pdf.

Medalie, Laura, 2012, Temporal and spatial trends of chloride and sodium in groundwater in New Hampshire, 1960-2011: U.S. Geological Survey Open-File Report 2012-1236, 25 p.

Meegoda, J.N., Marhaba, T.F., and Ratnaweera, P., 2004, Strategies to mitigate salt runoff from salt storage and salt truck maintenance facilities: Practice Periodical of Hazardous, Toxic, and Radioactive Waste Management, v. 8, no. 4, p. $247-252$. 
Mentz, Randy, McGinley, Paul, Penn, Mike, and Busch, Dennis, 2011, Snow, ice, and runoff-Winter runoff monitoring methods and results from the University of Wisconsin-Platteville Pioneer Farm: The American Society of Agronomy, Crop Science Society of America, and Soil Science Society of America, Annual Meeting, San Antonio, Texas, October 16-19, 2011, accessed June 20, 2014, at https://a-c-s.confex.com/crops/2011am/webprogram/ Paper67620.html.

Metzger, L.F., and Izbicki, J.A., 2013, Electromagneticinduction logging to monitor changing chloride concentrations: Ground Water, v. 51, no. 1, p. 108-121.

Meyer, Deanne, and Inson, P.R., 2007, Dairy nutritionists' roles in nutrient use-Recommendations for feed nutrient records analyses: Davis, Calif., University of California, Division of Agriculture, 5 p., accessed July 19, 2014, at http://anrcatalog.ucdavis.edu/pdf/8278.pdf.

Michaud, C.F., 2002a, Factors affecting the brine efficiency of softeners - Revisited-The quest for perfection: Water Conditioning and Purification, v. 44, no. 2, p. 82-85.

Michaud, C.F., 2002b, Oxidation-Oxidizers, age and softening resins 2000: Water Conditioning and Purification, v. 42, no. 8 , p. 26-29.

Michigan Department of Environmental Quality, 2014, Sodium and chloride and water softeners: Michigan Department of Environmental Quality Fact Sheet, 4 p., accessed July 4, 2014, at http:/www.deq.state.mi.us/ documents/deq-wmd-gwp-SodiumChlorideWaterSofteners. pdf.

Michigan Department of Transportation, 2006, Emerging technologies in winter road maintenance-Improving safety while minimizing environmental impacts: Michigan Department of Transportation, 5 p., accessed April 5, 2015, at https://www.michigan.gov/documents/stormwatermgt/ MDOT_MS4_Emerging_Technologies_in_Winter_Road Maintenance_208451_7.pdf.

Miller, J.J., Handerek, B.P., Beasley, B.W., Olson, E.C.S., Yanke, L.J., Larney, F.J., McAllister, T.A., Olson, B.M., L.B., Selinger, D.S., Chanasyk, and Hasselback, Paul, 2004, Quantity and quality of runoff from a beef cattle feedlot in southern Alberta: Journal of Environmental Quality, v. 33, p. 1088-1097.

Miller, R.L., Bradford, W.L., and Peters, N.E., 1988, Specific conductance-Theoretical considerations and application to analytical quality control: U.S. Geological Survey WaterSupply Paper 2311, 16 p.
Minnesota Department of Transportation, 2011, 2010-2011 annual winter maintenance report at a glance: St. Paul, Minn., Minnesota Department of Transportation, accessed January 1, 2014, at http://www.dot.state.mn.us/maintenance/ pdf/research/winterataglance.pdf.

Minnesota Pollution Control Agency, 1999, Effects of septic systems on ground water quality-Baxter, Minnesota: St. Paul, Minn., Minnesota Pollution Control Agency, 37 p.

Monlux, Steve, and Mitchell, Michael, 2006, Surfaceaggregate stabilization with chloride materials: U.S. Forest Service Report 0677 1805-SDTDC, 23 p.

Moore, Lynn, and Thornton, Kent, eds., 1988, Lake and reservoir restoration guidance manual: U.S. Environmental Protection Agency EPA 440/5-88-002, [variously paged].

Morgan, R.P., II, Kline, K.M., Kline, M.J., Cushman, S.F., Sell, M.T., Weitzell, R.E., Jr., and Churchill, J.B., 2012, Stream conductivity_Relationships to land use, chloride, and fishes in Maryland streams: North American Journal of Fisheries Management, v. 32, no. 5, p. 941-952.

Moyer, D.L., Anderholm, S.K., Hogan, J.F., Phillips, F.M., Hibbs, B.J., Witcher, J.C., Matherne, A.M., and Falk, S.E., 2013, Knowledge and understanding of dissolved solids in the Rio Grande-San Acacia, New Mexico, to Fort Quitman, Texas, and plan for future studies and monitoring: U.S. Geological Survey Open-File Report 2013-1190, 55 p.

Mueller, D.K., and Helsel, D.R., 1996, Nutrients in the Nation's waters - Too much of a good thing?: U.S. Geological Survey Circular 1136, 24 p.

Mueller, D.K., Martin, J.D., and Lopes, T.J., 1997, Qualitycontrol design for surface-water sampling in the National Water-Quality Assessment Program: U.S. Geological Survey Open-File Report 97-223, 17 p.

Mullaney, J.R., Lorenz, D.L., and Arntson, A.D., 2009, Chloride in groundwater and surface water in areas underlain by the glacial aquifer system, northern United States: U.S. Geological Survey Scientific Investigations Report 2009-5086, 41 p.

Muller, Beat, and Gachter, Rene, 2010, Increasing chloride concentrations in Lake Constance - Characterization of sources and estimation of loads: Aquatic Sciences, v. 74, p. 101-112.

Munger, J.W., and Eisenreich, S.J., 1983, Continental-scale variations in precipitation chemistry: Environmental Science and Technology, v. 17, no. 1, p. 32A-42A.

Munn, M.D., Gilliom, R.J., Moran, P.W., and Nowell, L.H., 2006, Pesticide toxicity index for freshwater aquatic organisms (2d ed.): U.S. Geological Survey Scientific Investigations Report 2006-5148, 81 p. 
Mussato, B.T., Gepraegs, O.K., Seabrook, P.T., Davidson, J.P., Charlton, R.S., Parker, R.D., Keep, D.G., Lewis, W.M., Jr., and Chollar, Brian, 2007, Guidelines for the selection of snow and ice control materials to mitigate environmental impacts: Washington, D.C., Transportation Research Board, National Cooperative Highway Research Program Report 577,228 p.

Mussatti, D.C., 2002, The EPA air pollution control cost manual: U.S. Environmental Protection Agency Report EPA/452/B-02-001, 1,400 p.

Nantung, T.E., 2001, Evaluation of zero velocity deicer spreader and salt spreader protocol: West Lafayette, Ind., Indiana Department of Transportation Report FHWA/IN/ JTRP-2000/24, 42 p.

National Agricultural Statistics Service, 2011, Agricultural Chemical Use Program - Corn, upland cotton and fall potatoes 2010: U.S. Department of Agriculture, National Agricultural Statistics Service, 4 p.

National Agricultural Statistics Service, 2013, Agricultural Chemical Use Program Quick Stats database: U.S. Department of Agriculture, National Agricultural Statistics Service, accessed July 12, 2014, at http://www.nass.usda. gov/Surveys/Guide_to_NASS_Surveys/Chemical_Use/.

National Atmospheric Deposition Program, 2012, National Atmospheric Deposition Program 2011 annual summary: University of Illinois at Urbana-Champaign, Illinois State Water Survey, NADP Data Report 2012-01, 24 p., accessed October 18, 2012, at http://nadp.sws.uiuc.edu/lib/ dataReports.aspx.

National Research Council Committee on Animal Nutrition, 1994, Nutrient requirements of poultry (9th revised ed.): Washington, D.C., National Academies Press, 176 p.

National Research Council Committee on Animal Nutrition, 2000, Nutrient requirements of beef cattle (7th revised ed.): Washington, D.C., National Academies Press, 248 p.

National Research Council Committee on Animal Nutrition, 2001, Nutrient requirements of dairy cattle ( 7 th revised ed.): Washington, D.C., National Academies Press, 408 p.

National Research Council Committee on Animal Nutrition, 2007a, Nutrient requirements of horses (6th revised ed.): Washington, D.C., National Academies Press, 360 p.

National Research Council Committee on Animal Nutrition, 2007b, Nutrient requirements of small ruminants - Sheep, goats, cervids, and new world camelids: Washington, D.C., National Academies Press, 384 p.

National Research Council Committee on Animal Nutrition, 2012, Nutrient requirements of swine (11th revised ed.): Washington, D.C., National Academies Press, 400 p.
Natural Resources Conservation Service, 2001, Estimating Leaching Fraction Requirements: Natural Resources Conservation Service Report 143-010763, 1 p., http://www.nrcs.usda.gov/Internet/FSE_DOCUMENTS/ nrcs143_010763.pdf.

Natural Resources Conservation Service, 2003, National water quality handbook: Natural Resources Conservation Service Report 450-VI-NWQH, [variously paged].

Natural Resources Conservation Service, 2012, Edge-of-field water quality monitoring data collection and evaluation: Natural Resources Conservation Service Conservation Activity Code 201, 43 p.

New Hampshire Department of Environmental Services, 2008, Hardness in Drinking Water: New Hampshire Department of Environmental Services Fact Sheet WD-DWGB3-6, 4 p., accessed July 4, 2014, at http://des.nh.gov/ organization/commissioner/pip/factsheets/dwgb/documents/ dwgb-3-6.pdf.

New Hampshire Department of Environmental Services, 2009, Ion exchange treatment of drinking water: New Hampshire Department of Environmental Services Fact Sheet WDDWGB-2-12, 6 p., accessed July 4, 2014, at http://des.nh.gov/organization/commissioner/pip/factsheets/ dwgb/documents/dwgb-2-12.pdf.

New Hampshire Department of Environmental Services, 2013, New Hampshire Salt reduction best management practices - Technologies/best management practices for salt reduction: New Hampshire Department of Environmental Services Web page, accessed December, 12, 2013, at http://des.nh.gov/organization/divisions/water/wmb/was/ salt-reduction-initiative/tech-assist-bmp-practices.htm.

Nilles, M.A., 2000, Atmospheric Deposition Program of the U.S. Geological Survey: U.S. Geological Survey Fact Sheet $112-00,6$ p.

Nimiroski, M.T., and Waldron, M.C., 2002, Sources of sodium and chloride in the Scituate Reservoir drainage basin, Rhode Island: U.S. Geological Survey Water-Resources Investigations Report 02-4149, 16 p.

North Carolina Department of Agriculture and Consumer Services, 2012, A homeowner's guide to fertilizer: Raleigh, N.C., North Carolina Department of Agriculture and Consumer Services Web page, accessed January 24, 2012, at http://www.ncagr.gov/cyber/kidswrld/plant/label.htm.

Norton, D.R., and Friedman, Irving, 1985, Chloride flux out of Yellowstone National Park: Journal of Volcanology and Geothermal Research, v. 25, p. 231-250. 
Novotny, E.V., Murphy, Dan, and Stefan, H.G., 2007, Road salt effects on the water quality of lakes in the Twin Cities Metropolitan Area: Minneapolis, Minn., St. Anthony Falls Laboratory Project Report 505, 48 p.

Novotny, E.V., Murphy, Dan, and Stefan, H.G., 2008, Increase of urban lake salinity by road deicing salt: Science of the Total Environment, v. 406, p. 131-144.

Novotny, E.V., Sander, A.R., Mohseni, Omid, and Stefan, H.G., 2009, Chloride ion transport and mass balance in a metropolitan area using road salt: Water Resources Research, v. 45, W12410, 13 p., accessed April 1, 2015, at http://dx.doi.org/10.1029/2009WR008141.

Novotny, E.V., and Stefan, H.G., 2012, Road salt impact on lake stratification and water quality: Journal of Hydraulic Engineering, v. 138, no. 12, p. 1069-1080.

Ohno, T., 1990, Levels of total cyanide and $\mathrm{NaCl}$ in surface waters adjacent to road salt storage facilities: Environmental Pollution, v. 67, no. 2, p. 123-132.

Ohrel, R.L., 2000, Rating deicing agents-salt still stands firm: Watershed Protection Techniques, v. 1, no. 4, p. 217-220.

Oliva, Priscia, Viers, Jerome, and Dupre, Bernard, 2003, Chemical weathering in granitic environments: Chemical Geology, v. 202, p. 225-256.

Omega, 2014, ISE-8760 and ISE-8770 chloride ion selective electrodes: Omega Engineering, Inc., Operator's Manual M791/0892, 20 p., accessed June 30, 2014, at http://www.omega.com/manuals/manualpdf/M0791.pdf.

Omer, Raqib, Mirtorabi, Ramona, Fu, Liping, and Liaqat, Zara, 2014, Monitoring and analysis of winter maintenance operations for parking lots, in the Compendium of Papers for the Transportation Research Board 93rd Annual Meeting 2014: Washington, D.C., Transportation Research Board, CD-ROM, 17 p.

Oregon Department of Environmental Quality, 2007, Compost leachate research: Oregon Department of Environmental Quality Report 0791022.00, 32 p.

Ostendorf, D.W., Hinlein, E.S., and Choi, S., 2012, Reduced road salt spillage owing to indoor delivery and loading: Journal of Environmental Engineering, v. 128, p. 223-228.

Ostendorf, D.W., Hinlein, E.S., Rotaru, C., and DeGroot, D.J., 2006, Contamination of groundwater by outdoor highway deicing agent storage: Journal of Hydrology, v. 326, p. 109-121.

Otton, J.K., 2006, Environmental aspects of produced-water salt releases in onshore and estuarine petroleum-producing areas of the United States-A bibliography: U.S. Geological Survey Open-File Report 2006-1154, 223 p.
Paillet, F.L., and Crowder, R.E., 1996, A generalized approach for the interpretation of geophysical well logs in groundwater studies theory and application: Ground Water, v. 34, no. 5 , p. 883-898.

Paine, J.G., 2001, Determining salinization extent, identifying salinity sources, and estimating chloride mass using surface, borehole, and airborne electromagnetic induction methods: Water Resources Research, v. 39, no. 3, 10 p., accessed April, 1, 2015, at http://dx.doi.org/10.1029/2001WR000710.

Paine, J.G., Nance, H.S., Collins, E.W., and Niemann, K.L., 2007, Quantifying contributions to stream salinity using electromagnetic induction and hydrochemistry in a small Texas coastal-plain basin: Applied Geochemistry, v. 22, p. 2207-2224.

Panno, S.V., Hackley, K.C., Hwang, H.H., Greenberg, S.E., Krapac, I.G., Landsberger, S., and O'Kelly, D.J., 2005, Database for the characterization and identification of $\mathrm{Na}-\mathrm{Cl}$ sources in natural waters of Illinois: Illinois State Geological Survey Open File Series 2005-1, 15 p.

Panno, S.V., Hackley, K.C., Hwang, H.H., Greenberg, S.E., Krapac I.G., Landsberger, S., and O'Kelly, D.J., 2006, Characterization and identification of $\mathrm{Na}-\mathrm{Cl}$ sources in ground water: Ground Water, v. 44, no. 2, p. 176-187.

Panno, S.V., Kelly, W.R., Hackley, K.C., and Weibel, C.P., 2007, Chemical and bacterial quality of aeration-type waste water treatment system discharge: Ground Water Monitoring and Remediation, v. 27, no. 2, p. 71-76.

Pastor, J., and Hernández, A.J., 2012, Heavy metals, salts and organic residues in old solid urban waste landfills and surface waters in their discharge areas-Determinants for restoring their impact: Journal of Environmental Management, v. 95, p. S2-S49.

Patterson, R.A., 1997, Domestic wastewater and the sodium factor, in Bedinger, M.S., Johnson, A.I., and Fleming, J.S., eds., Site characterization and design of on-site septic systems Conference, New Orleans, Louisiana, January, 16, 1997, Proceedings: American Society for Testing and Materials STP 1324, p. 23-35.

Paul, A.P., Seiler, R.L., Rowe, T.G., and Rosen, M.R., 2007, Effects of agriculture and urbanization on quality of shallow ground water in the arid to semiarid western United States, 1993-2004: U.S. Geological Survey Scientific Investigations Report 2007-5179, $56 \mathrm{p}$.

Peavy, H.S., Rowe, D.R., and Tchobanoglous, George, 1985, Environmental engineering: New York, McGraw-Hill, $719 \mathrm{p}$. 
Pennsylvania Department of Environmental Protection, 2013, Roadspreading of brine for dust control and road stabilization: Commonwealth of Pennsylvania 8000-FS-DEP1801, 2 p.

Peranginangin, N.P., Richards, B.K., and Steenhuis, T.S., 2009, Assessment of vadose zone sampling methods for detection of preferential herbicide transport: Hydrology and Earth System Sciences Discussions, v. 6, p. 7247-7285.

Perera, Nandana, Gharabaghi, Bahram, and Noehammer, Peter, 2009, Stream chloride monitoring program of city of Toronto-Implications of road salt application: Water Quality Research Journal of Canada, v. 44, no. 2, p. 132-140.

Perkins, K.S., Nimmo, J.R., Rose, C.E., and Coupe, R.H., 2011, Field tracer investigation of unsaturated zone flow paths and mechanisms in agricultural soils of northwestern Mississippi, USA: Journal of Hydrology, v. 396, no. 1-2, p. $1-11$.

Peters, C.A., and Healy, R.W., 1988, The representativeness of pore water samples collected from the unsaturated zone using pressure-vacuum lysimeters: Ground Water Monitoring Review, v. 8, p. 96-101.

Peters, N.E., 1984, Evaluation of environmental factors affecting yields of major dissolved ions of streams in the United States: U.S. Geological Survey Water-Supply Paper 2228, $39 \mathrm{p}$.

Peters, N.E., 1991, Chloride cycling in two forested lake watersheds in the west-central Adirondack Mountains, New York, USA: Water, Air, and Soil Pollution, v. 59, p. 201215.

Peters, N.E., and Ratcliffe, E.B., 1998, Tracing hydrologic pathways using chloride at the Panola Mountain Research Watershed, Georgia, USA. Water, Air and Soil Pollution, v. 105 , no. $1 / 2$, p. $263-275$.

Peters, N.E., Shanley, J.B., Aulenbach, B.T., Webb, R.M., Campbell, D.H., Hunt, R., Larsen, M.C., Stallard, R.F., Troester, J., and Walker, J.F., 2006, Water and solute mass balance of five small, relatively undisturbed watersheds in the U.S.: Science of the Total Environment, v. 358, no. 1-3, p. 221-242.

Peters, N.E., and Turk, J.T., 1981, Increases in sodium and chloride in the Mohawk River, New York, from the 1950s to the 1970s attributed to road salt: Journal of the American Water Resources Association, v. 17, no. 4, 586-598.

Pettyjohn, W.A., 1971, Water pollution by oil-field brines and related industrial wastes in Ohio: The Ohio Journal of Science, v. 71, no. 5, p. 257-269.
Piechota, Thomas, van Ee, Jeff, Batista, Jacimaria, Stave, Krystyna, and James, David, eds., 2004, Potential environmental impacts of dust suppressants - "Avoiding another Times Beach"-An expert panel summary, Las Vegas, Nevada, May 30-31, 2002: U.S. Environmental Protection Agency Report EPA/600/R-04/031, 79 p.

Pierce, W.G., and Rich, E.I., 1962, Summary of rock salt deposits in the United States as possible storage sites for radioactive waste materials: U.S. Geological Survey Bulletin 1148, $91 \mathrm{p}$.

Plummer, L.N., Bexfield, L.M., Anderholm, S.K., Saford, W.E., and Busenberg, Eurybiades, 2004, Geochemical characterization of ground-water flow in the Santa Fe Group aquifer system, Middle Rio Grande Basin, New Mexico: U.S. Geological Survey Water-Resources Investigations Report 2003-4131, 395 p.

Pollock, S.J., and Toler, L.G., 1973, Effects of highway deicing salts on ground water and water supplies in Massachusetts: Highway Research Record 425, p. 17-22.

Prinos, S.T., 2014, Using state-of-the-art technology to evaluate saltwater intrusion in the Biscayne aquifer of Miami-Dade County, Florida: U.S. Geological Survey Fact Sheet 2014-3050, 6 p.

Raask, Erich, 1985, Mineral impurities in coal combustion-Behavior, problems, and remedial measures: Berlin, Springer-Verlag, 485 p.

Radtke, D.B., Davis, J.V., and Wilde, F.D., 2005, 6.3 Specific electrical conductance (ver. 1.2, August 2005): U.S. Geological Survey Techniques of Water-Resources Investigations, book 9, chap. A6, sec. 6.5, August 2005, accessed June 30, 2014, at http://pubs.water.usgs.gov/twri9A6/.

Rainwater, F.H., 1962, Stream composition of the conterminous United States: U.S. Geological Survey Hydrologic Investigations Atlas HA-61, 3 pls.

Ranganathan, Vishnu, and Hanor, J.S., 1988, Density-driven groundwater flow near salt domes: Chemical Geology, v. 74, p. 173-188.

Rantz, S.E., and others, 1982a, Measurement and computation of streamflow_-v. 1, Measurement of stage and discharge: U.S. Geological Survey Water-Supply Paper 2175, p. 1-284.

Rantz, S.E., and others, 1982b, Measurement and computation of streamflow—v. 2, Computation of discharge: U.S. Geological Survey Water-Supply Paper 2175, p. 285-631. 
Rasmussen, P.P., Gray, J.R., Glysson, G.D., and Ziegler, A.C., 2009, Guidelines and procedures for computing time-series suspended-sediment concentrations and loads from in-stream turbidity-sensor and streamflow data: U.S. Geological Survey Techniques and Methods, book 3, chap. C4, 52 p.

Rasmussen, T.J., Lee, C.J., and Ziegler, A.C., 2008, Estimation of constituent concentrations, loads, and yields in streams of Johnson County, northeast Kansas, using continuous waterquality monitoring and regression models, October 2002 through December 2006: U.S. Geological Survey Scientific Investigations Report 2008-5014, 103 p.

Rasmussen, T.J., Ziegler, A.C., and Rasmussen, P.P., 2005, Estimation of constituent concentrations, densities, loads, and yields in lower Kansas River, northeast Kansas, using regression models and continuous water-quality monitoring, January 2000 through December 2003: U.S. Geological Survey Scientific Investigations Report 2005-5165, 117 p.

Rauzi, S.L., 2002, Arizona has salt!: Tucson, Arizona, Arizona Geological Survey, Circular 30, January 2002, 36 p.

Reif, A.G., Crawford, J.K., Loper, C.A., Proctor, Arianne, Manning, Rhonda, and Titler, Robert, 2012, Occurrence of pharmaceuticals, hormones, and organic wastewater compounds in Pennsylvania waters, 2006-09: U.S. Geological Survey Scientific Investigations Report 2012-5106, 99 p.

Reilly, T.E., Dennehy, K.F., Alley, W.M., and Cunningham, W.L., 2008, Ground-water availability in the United States: U.S. Geological Survey Circular 1323, 70 p. [Also available at http://pubs.usgs/gov/circ/1323.]

Reilly, T.E., Franke, O.L., and Bennett, G.D., 1989, Bias in groundwater samples caused by wellbore flow: Journal of Hydraulic Engineering, v. 115, no. 2, p. 270-276.

Reilly, T.E., and Pollock, D.W., 1993, Factors affecting areas contributing recharge to wells in shallow aquifers: U.S. Geological Survey Water-Supply Paper 2412, 21 p.

Renou, S., Givaudan, J.G., Poulain, S., Dirassouyan, F., and Moulin, P., 2008, Landfill leachate treatment-Review and opportunity: Journal of Hazardous Materials, v. 150, p. $468-493$.

Rhoads, J.D., 1992, Management of saline/sodic soils: U.S. Department of Agriculture, Soil Conservation Service and U.S. Salinity Laboratory, 137 p., accessed May 17, 2014, at http:/www.nrcs.usda.gov/Internet/FSE_DOCUMENTS/ stelprdb1044792.pdf 5/17/2014.
Rhode Island Department of Environmental Management, 2012, Best management practices for the discharge of residential water softener backwash brine in unsewered areas: Rhode Island Department of Environmental Management Office of Water Resources document, 3 p., accessed July 4, 2014, at http:/www.dem.ri.gov/programs/ benviron/water/permits/privwell/pdfs/backwash.pdf.

Rice, C.A., Abbott, M.M., and Zielinski, R.A., 2007, Use of dissolved chloride concentrations in tributary streams to support geospatial estimates of $\mathrm{Cl}$ contamination potential near Skiatook Lake, northeastern Oklahoma: Applied Geochemistry, v. 22, p. 2193-2206.

Rice, K.C., Bennett, M.R., and Shen, Jian, 2011, Simulated changes in salinity in the York and Chickahominy Rivers from projected sea-level rise in Chesapeake Bay: U.S. Geological Survey Open-File Report 2011-1191, 31 p.

Riggs, H.C., 1968, Some statistical tools in hydrology: U.S. Geological Survey Techniques of Water-Resources Investigations, book 4, chap. A1, 39 p.

Rimmer, Alon, Steenhuis, T.S., Selker, J.S., and Albrecht, G.J., 1994, Wick samplers-An evaluation of solute travel times: Soil Science, v. 159, no. 4, p. 235-243.

Risch, M.R., and Robinson, B.A., 2001, Use of borehole and surface geophysics to investigate ground-water quality near a road-deicing salt-storage facility, Valparaiso, Indiana: U.S. Geological Survey Water-Resources Investigations Report 2000-4070, 63 p.

Ritter, W.F., Scarborough, R.W., and Chirnside, A.E.M., 1993, Nitrate leaching under irrigated corn: Journal of Irrigation and Drainage Engineering, v. 119, no. 3, 544-553.

Robertson, W.D., Van Stempvoort, D.R., Solomon, D.K., Homewood, J., Brown S.J., Spoelstra, J., and Schiff, S.L., 2013, Persistence of artificial sweeteners in a 15-yearold septic system plume: Journal of Hydrology, v. 477, p. $43-54$.

Rodvang, S.J., Mikalson, D.M., and Ryan, M.C., 2004, Changes in ground water quality in an irrigated area of southern Alberta: Journal of Environmental Quality, v. 33, p. $476-487$.

Ronen, Daniel, and Magaritz, Mordeckai, 1985, High concentration of solutes at the upper part of the saturated zone (water table) of a deep aquifer under sewage-irrigated land: Journal of Hydrology, v. 80, p. 311-323.

Rose, Seth, 2007, The effects of urbanization on the hydrochemistry of base flow within the Chattahoochee River Basin: Journal of Hydrology, v. 341, no. 1-2, p. 42-54. 
Rosen, M.R., 1994, The importance of groundwater in playas - A review of playa classifications and the sedimentology and hydrology of playas: Geological Society of America Special Paper 289, p. 1-18.

Rosenberry, D.O., Stannard, D.I., Winter, T.C., and Martinez, M.L., 2004, Comparison of 13 equations for determining evapotranspiration from a prairie wetland, Cottonwood Lake area, North Dakota, USA: Wetlands, v. 24, no. 3, p. 483-497.

Roy, A.H., and Shuster, W.D., 2009, Assessing impervious surface connectivity and applications for watershed management: Journal of the American Water Resources Association, v. 45, no. 1, p. 198-209.

Rubin, Jonathan, Gårder, P.E., Morris, C.E., Nichols, K.L., Peckenham, J.M., Mitchell, G.J., McKee, Peggy, Stern, Adam, and Johnson, T.O., 2010, Maine winter roads-Salt, safety, environment and cost: Orono, Maine, University of Maine, Margaret Chase Smith Policy Center and School of Economics, 142 p., accessed July 5, 2014, at http://www. umaine.edu/files/2010/02/Winter-Road-Maint-Final.pdf.

Ruddy, B.C., Lorenz, D.L., and Mueller, D.K., 2006, Countylevel estimates of nutrient inputs to the land surface of the conterminous United States, 1982-2001: U.S. Geological Survey Scientific Investigations Report 2006-5012, 17 p.

Ruhl, J.F., 1999, Quantity and quality of seepage from two earthen basins used to store livestock waste in southern Minnesota during the first year of operation, 1997-98: U.S. Geological Survey Water-Resources Investigations Report 99-4206, 35 p.

Rutsch, M., Rieckermann, J., and Krebs, P., 2006, Quantification of sewer leakage-A review: Water Science and Technology, v. 54, no. 6-7, p. 135-144.

Ryberg, K.R., 2006, Continuous water-quality monitoring and regression analysis to estimate constituent concentrations and loads in the Red River of the North, Fargo, North Dakota, 2003-05: U.S. Geological Survey Water-Resources Investigations Report 2006-5241, 35 p.

Saffigna, P.G., and Keeney, D.R., 1977, Nitrate and chloride in ground water under irrigated agriculture in central Wisconsin: Groundwater, v. 15, no. 2, p. 170-177.

Salt Institute, 2006, The salt storage handbook-A practical guide for storing and handling deicing salt: Alexandria, Virginia, Salt Institute, 18 p.

Salt Institute, 1991, The snowfighter's handbook-A practical guide for snow and ice control: Alexandria, Virginia, Salt Institute Publication SI-1991R, 22 p.
Sander, Andrew, Novotny, Eric, Mohseni, Omid, and Stefan, Heinz, 2007, Inventory of road salt uses in the Minneapolis/ St. Paul metropolitan area: University of Minnesota, St. Anthony Falls Laboratory Report 503, 46 p.

Sanders, T.G., and Addo, J.Q., 1993, Effectiveness and environmental impact of road dust suppressants: Fargo, N. Dak., Mountain-Plains Consortium Report 94-28, 33 p.

Sanders, T.G., and Addo, J.Q., 2009, Road dust suppresssants research results, in Fay, Laura, and Kociolek, Angela, eds., 2009, Road dust management and future needs - 2008 conference proceedings: Federal Highway Administration FHWA-CFL/TD-09-001, 52 p.

Sando, S.K., Vecchia, A.V., Barnhart, E.P., Sando, T.R., Clark, M.L., and Lorenz, D.L., 2014, Trends in major-ion constituents and properties for selected sampling sites in the Tongue and Powder River watersheds, Montana and Wyoming, based on data collected during water years 19802010: U.S. Geological Survey Scientific Investigations Report 2013-5179, p. 123.

Sanford, W.E., Nelms, D.L., Pope, J.P., and Selnick, D.L., 2012, Quantifying components of the hydrologic cycle in Virginia using chemical hydrograph separation and multiple regression analysis: U.S. Geological Survey Scientific Investigations Report 2011-5198, 78 p.

Sanford, W.E., and Selnick, D.L., 2013, Estimation of evapotranspiration across the conterminous United States using a regression with climate and land-cover data: Journal of the American Water Resources Association, v. 49, no. 1, p. 217-230.

Sassan, D.A., and Kahl, S.K., 2007, Salt loading due to private winter maintenance practices: Plymouth, N.H., Plymouth State University, Center for the Environment, 20 p., accessed July 19, 2014, at http://des.nh.gov/organization/ divisions/water/wmb/was/salt-reduction-initiative/so-i93impaired/documents/salt-loading-final-report.pdf.

Satti, S.R., Jacobs, J.M., and Irmak, Suat, 2004, Agricultural water management in a humid region-Sensitivity to climate, soil and crop parameters: Agricultural Water Management, v. 70, p. 51-65.

Sauer, V.B., 2002, Standards for the analysis and processing of surface-water data and information using electronic methods: U.S. Geological Survey Water-Resources Investigations Report 2001-4044, 91 p.

Sauer, V.B., and Turnipseed, D.P., 2010, Stage measurement at gaging stations: U.S. Geological Survey Techniques and Methods, book 3, chap. A7, 45 p. 
Savoie, J.G., Kent, D.B., Smith, R.L., LeBlanc, D.R., and Hubble, D.W., 2004, Changes in groundwater quality near two granular-iron permeable reactive barriers in a sand and gravel aquifer, Cape Cod, Massachusetts, 1997-2000: U.S. Geological Survey Water-Resources Investigations Report 03-4309, 84 p.

Schalk, C.W., and Stasulis, N.W., 2012, Relations among water levels, specific conductance, and depths of bedrock fractures in four road-salt-contaminated wells in Maine, 2007-9: U.S. Geological Survey Scientific Investigations Report 2012-5205, 47 p.

Schepers, J.S., and Francis, D.D., 1982, Chemical water quality of runoff from grazing land in Nebraska-Influence of grazing livestock: Journal of Environmental Quality, v. 11, no. 3 , p. 351-354.

Schirmer, Mario, Leschik, Sebastian, and Musolff, Andreas, 2013, Current research in urban hydrogeology-A review: Advances in Water Resources, v. 51, p. 280-291.

Schueler, Tom, 2005, Snow, road salt and the Chesapeake Bay: Ellicott City, Md., Center for Watershed Protection, 5 p., accessed January 2, 2014, at http://www.cwp.org/ Resource_Library/Special_Resource_Management/ColdClimate/snow_roadsalt_chesbay.pdf.

Schulte, E.E., and Kelling, K.A., 1999, Understanding plant nutrients - Soil and applied potassium: Madison, Wis., University of Wisconsin Cooperative Extension Publication A2S21, 2 p.

Searls, J.P., 2000, Potash: U.S. Geological Survey Commodity Statistics and Information, 11 p., accessed July 4, 2014, at http://minerals.usgs.gov/minerals/pubs/commodity/ potash/560400.pdf.

Seiler, R.L., 1997, Methods to identify areas susceptible to irrigation-induced selenium contamination in the western United States: U.S. Geological Survey Fact Sheet 038-97, 4 p.

Seiler, R.L., Skorupa, J.P., Naftz, L., and Nolan, B.T., 2003, Irrigation-induced contamination of water, sediment, and biota in the western United States - Synthesis of data from the National Irrigation Water Quality Program: U.S. Geological Survey Professional Paper 1655, 123 p.

Seiler, R.L., Skorupa, J.P., and Peltz, L.A., 1999, Areas susceptible to irrigation-induced selenium contamination of water and biota in the western United States: U.S. Geological Survey Circular 1180, 36 p.

Seinfeld, J.H., and Pandis, S.N., 2006, Atmospheric chemistry and physics_-From air pollution to climate change ( $2 \mathrm{~d}$ ed.): Hoboken, N.J., John Wiley \& Sons, 1,232 p.
Shao, Y., Raupach, M.R., and Findlater, P.A., 1993, Effect of saltation bombardment on the entrainment of dust by wind: Journal of Geophysical Research, v. 98, no. D7, p. 1271912726 .

Sharma, P.V., 1997, Environmental and engineering geophysics: Cambridge, United Kingdom, Cambridge University Press, $475 \mathrm{p}$.

Sharp, Z.D., and Draper, D.S., 2013, The chlorine abundance of Earth-Implications for a habitable planet: Earth and Planetary Science Letters, v. 369-370, p. 71-77.

Sheibley, R.W., Foreman, J.R., Moran, P.W., and Swarzenski, P.W., 2012, Atmospheric deposition, water-quality, and sediment data for selected lakes in Mount Rainer, North Cascades, and Olympic National Parks, Washington, 2008-10: U.S. Geological Survey Data Series 721, 34 p.

Shepard, J.P., Mitchell, M.J., Scott, T.J., Zhang, Y.M., and Raynal, D.J., 1989, Measurements of wet and dry deposition in a northern hardwood forest: Water, Air, and Soil Pollution, v. 48, p. 225-238.

Sherwood, D.A., 2003, Water Resources of Monroe County, New York, Water Years 1997-99, with emphasis on water quality in the Irondequoit Creek Basin-Atmospheric deposition, ground water, streamflow, trends in water quality, and chemical loads to Irondequoit Bay: U.S. Geological Survey Water-Resources Investigations Report 02-4221, 55 p.

Sherwood, D.A., 2006, Water resources of Monroe County, New York, water years 2000-02-Atmospheric deposition, ground water, streamflow, trends in water quality, and chemical loads in streams: U.S. Geological Survey Scientific Investigations Report 2005-5107, 55 p.

Shipley, F.S., 1991, Oil field-produced brines in a coastal stream - Water quality and fish community recovery following long term impacts: The Texas Journal of Science, v. 43 , p. 51-64.

Showers, W.J., Genna, B., Mcdade, T., Bolich, R., and Fountain, J.C., 2008, Nitrate contamination in groundwater on an urbanized dairy farm: Environmental Science and Technology, v. 42, no. 13, p. 4683-4688.

Shuttleworth, W.J., 1993, Evaporation, chap. 4 of Maidment, D.R., ed., Handbook of hydrology: New York, McGrawHill, [variously paged].

Siccama, Thomas, and Denny, Ellen, 2001, What is a weir and how does it work?: Hubbard Brook Research Foundation, accessed June 20, 2014, at http://www.hubbardbrook.org/ w6_tour/weir-stop/weirwork.htm.

Siegel, D.I., Lesniak, K.A., Stute, Martin, and Frape, Shaun, 2004, Isotopic geochemistry of the Saratoga springsImplications for the origin of solutes and source of carbon dioxide: Geology, v. 32, p. 257-260. 
Simkin, S.M., Lewis, D.N., Weathers, K.C., Lovett, G.M., and Schwarz, K., 2004, Determination of sulfate, nitrate, and chloride in throughfall using ion-exchange resins: Water, Air, and Soil Pollution, v. 153, p. 343-354.

Simpson, C.H., 1986, Method for removing pyritic, organic and elemental sulfur from coal: U.S. Patent 4,569,678, 14 p.

Slonecker, E.T., and Tilley, J.S., 2004, An evaluation of the individual components and accuracies associated with the determination of impervious area: GIScience and Remote Sensing, v. 41, no. 2, p. 165-184.

Smedley, S.I., 1980, The interpretation of ionic conductivity in liquids: New York, Plenum Press, 195 p.

Smeltzer, Eric, Shambaugh, Angela, and Stangel, Pete, 2012, Environmental change in Lake Champlain revealed by longterm monitoring: Journal of Great Lakes Research, v. 38, p. 6-18.

Smith, G.I., Jones, C.L., Culbertson, W.C., Ericksen, G.E., and Dyni, J.R., 1973, Evaporates and brines, in Brobst, D.A., and Pratt, W.P., eds., United States mineral resources: U.S. Geological Survey Professional Paper 820, p. 197-215.

Smith, J.A., 1993, Precipitation, chap. 3 of Maidment, D.R., ed., Handbook of hydrology: New York, McGraw-Hill, [variously paged].

Smith, K.P., 2002, Effectiveness of three best management practices for highway-runoff quality along the Southeast Expressway, Boston, Massachusetts: U.S. Geological Survey Water-Resources Investigations Report 02-4059, 62 p.

Smith, K.P., 2013, Water-quality conditions and constituent loads and yields in the Cambridge drinking-water source area, Massachusetts, water years 2005-07: U.S. Geological Survey Scientific Investigations Report 2013-5039, 73 p.

Smith, K.P., 2014, Streamflow, water quality, and constituent loads and yields, Scituate Reservoir drainage area, Rhode Island, water year 2012: U.S. Geological Survey Open-File Report 2013-1274, 30 p.

Smith, K.P., and Breault, R.F., 2011, Streamflow, water quality, and constituent loads and yields, Scituate Reservoir drainage area, Rhode Island, water year 2010: U.S. Geological Survey Open-File Report 2011-1076, 26 p.

Smith, K.P., and Granato G.E., 1998, Technology transfer opportunities-Automated groundwater monitoring, a proven technology: U.S. Geological Survey Fact Sheet 122-98, 2 p.

Smith, K.P., and Granato, G.E., 2005, Automated selfcalibrating water quality monitoring sensor housing assembly: U.S. Patent 6,936,156, 9 p.
Smith, K.P., and Granato, G.E., 2010, Quality of stormwater runoff discharged from Massachusetts highways, 2005-07: U.S. Geological Survey Scientific Investigations Report 2009-5269, 198 p.

Spangberg, A., and Niemczynowicz, J., 1992, High resolution measurements of pollution wash-off from an asphalt surface: Nordic Hydrology, v. 23, no. 4, p. 245-256.

Sprague, L.A., and Battaglin, W.A., 2004, Wastewater chemicals in Colorado's streams and ground water: U.S. Geological Survey Fact Sheet 2004-3127, 4 p.

Sproul, Michael, and Adams, M.J., 2011, Winter maintenance at a glance - 2010-2011-Meeting challenges with best practices: Wisconsin Department of Transportation Transportation Fact Sheet, 8 p., accessed July 5, 2014, at http://www.dot.wi.gov/travel/road/docs/winter-maint-report. pdf

Sproul, Michael, and Adams, M.J., 2013, Winter maintenance at a glance - 2012-2013-Learning to use less salt without compromising safety: Wisconsin Department of Transportation Fact Sheet 8 p., accessed July 5, 2014, at http://www.dot.wisconsin.gov/travel/road/docs/20122013annualminireport.pdf.

Staelens, Jeroen, De Schrijver, An, Van Avermaet, Philip, Genouw, Gerrit, and Verhoest, Niko, 2005, A comparison of bulk and wet-only deposition at two adjacent sites in Melle (Belgium): Atmospheric Environment, v. 39, p. 7-15.

Stanton, J.S., Qi, S.L., Ryter, D.W., Falk, S.E., Houston, N.A., Peterson, S.M., Westenbroek, S.M., and Christenson, S.C., 2011, Selected approaches to estimate water-budget components of the High Plains, 1940 through 1949 and 2000 through 2009: U.S. Geological Survey Scientific Investigations Report 2011-5183, 79 p.

Steele, M.K., and Aitkenhead-Peterson, J.A., 2011, Longterm sodium and chloride surface water exports from the Dallas/Fort Worth region: Science of the Total Environment, v. 409, p. 3021-3032.

Stefan, Heinz, Novotny, Eric, Sander, Andrew, and Mohseni, Omid, 2008, Study of environmental effects of de-icing salt on water quality in the Twin Cities metropolitan area, Minnesota: Minnesota Department of Transportation MN/ RC 2008-42, 88 p.

Stites, Will, and Kraft, G.J., 2001, Nitrate and chloride loading to groundwater from an irrigated north-central U.S. sandplain vegetable field: Journal of Environmental Quality, v. 30 , no. 4 , p. $1176-1184$.

Stone, D.M., and Robl, J.L., 1996, Construction and performance of rugged ceramic cup soil water samplers: Soil Science Society of America Journal, v. 60, p. 417-420. 
Stone, Kevin, 2009, Canadian minerals yearbook (CMY)2009_Potash: Natural Resources Canada Web page, accessed July 12, 2014, at http://www.nrcan.gc.ca/miningmaterials/markets/canadian-minerals-yearbook/2009/8492? destination=node $/ 4286$.

Stone, M.L., Rasmussen, T.J., Bennett, T.J., Poulton, B.C., and Ziegler, A.C., 2012, Protocols for collection of streamflow, water-quality, streambed-sediment, periphyton, macroinvertebrate, fish, and habitat data to describe stream quality for the Hydrobiological Monitoring Program, Equus Beds Aquifer Storage and Recovery Program, city of Wichita, Kansas: U.S. Geological Survey Open-File Report 2012$1055,55 \mathrm{p}$.

Strecker, Eric, Mayo, Lynn, Quigley, Marcus, and Howell, James, 2001, Guidance manual for monitoring highway runoff water quality: Federal Highway Administration Report FHWA-EP-01-022, 206 p.

Sun, R.J., Weeks, J.B., and Grubb, H.F., 1997, Bibliography of the Regional Aquifer-System Analysis (RASA) Program of the U.S. Geological Survey, 1978-96: U.S. Geological Survey Water-Resources Investigation Report 97-4074, 63 p.

Suro, R.O., 1992, Abandoned oil and gas wells become pollution portals: The New York Times, May 3, 1992, accessed April 1, 2015, at http://www.nytimes.com/1992/05/03/us/ abandoned-oil-and-gas-wells-become-pollution-portals. html.

Susong, D.D., Gallegos, T.J., and Oelsner, G.P., 2012, Water quality studied in areas of unconventional oil and gas development, including areas where hydraulic fracturing techniques are used, in the United States: U.S. Geological Survey Fact Sheet 2012-3049, 4 p.

Svensson, B.M., Mathiasson, L., Martensson, L., and Bergstrom, S., 2005, Artemia salina as test organism for assessment of acute toxicity of leachate water from landfills: Environmental Monitoring and Assessment, v. 102, p. 309321.

Swann, LaDon, 1992, A basic overview of aquaculture: West Lafayette, Ind., Purdue University, Illinois-Indiana Sea Grant Program Technical Bulletin Series 102, 10 p.

Swann, LaDon, 2014, A fish farmer's guide to understanding water quality in aquaculture: West Lafayette, Ind., Purdue University, accessed May 23, 2014, at https://www.extension.purdue.edu/extmedia/as/as-503.html.

Tchobanoglous, George, Burton, F.L., and Stensel, H.D., 1991, Wastewater engineering - Treatment, disposal, and reuse (3d ed.): Boston, Metcalf and Eddy, 1,334 p.
Tewalt, S.J., Belkin, H.E., SanFilipo, J.R., Merrill, M.D., Palmer, C.A., Warwick, P.D., Karlsen, A.W., Finkelman, R.B., and Park, A.J., comps., 2010, Chemical analyses in the World Coal Quality Inventory, version 1: U.S. Geological Survey Open-File Report 2010-1196, 4 p.

Thamke, J.N., and Craigg, S.D., 1997, Saline-water contamination in Quaternary deposits and the Poplar River, East Poplar oil field, northeastern Montana: U.S. Geological Survey Water-Resources Investigations Report 97-4000, $37 \mathrm{p}$.

Thieler, E.R., and Hammar-Klose, E.S., 1999, National assessment of coastal vulnerability to future sea-level rise-Preliminary results for the U.S. Atlantic coast: U.S. Geological Survey Open-File Report 99-593, accessed June 28, 2014, at http://pubs.usgs.gov/of/of99-593/.

Thieler, E.R., and Hammar-Klose, E.S., 2000a, National assessment of coastal vulnerability to future sea-level risePreliminary results for the U.S. Gulf of Mexico Coast: U.S. Geological Survey Open-File Report 00-179, accessed June 28, 2014, at http://pubs.er.usgs.gov/publication/ ofr00179.

Thieler, E.R., and Hammar-Klose, E.S., 2000b, National assessment of coastal vulnerability to future sea-level risePreliminary results for the U.S. Pacific Coast: U.S. Geological Survey, Open-File Report 00-178, accessed June 28, 2014, at http://pubs.er.usgs.gov/publication/ofr00178.

Thimonier, Anne, 1998, Measurement of atmospheric deposition under forest canopies-Some recommendations for equipment and sampling design: Environmental Monitoring and Assessment, v. 52, p. 353-387.

Thomann, R.V., and Mueller, J.A., 1987, Principles of surface water quality modeling and control: New York, Harper and Row, $644 \mathrm{p}$.

Thomas, E.M., Lin, Henry, Duffy, C.J., Sullivan, P.L., Holmes, G.H., Brantley, S.L., and Jin, Lixin, 2013, Spatiotemporal patterns of water stable isotope compositions at the Shale Hills Critical Zone Observatory-Linkages to subsurface hydrologic processes: Vadose Zone Journal, v. 12, no. 4, $16 \mathrm{p}$.

Thomas, J.M., Welch, A.H., and Dettinger, M.D., 1996, Geochemistry and isotope hydrology of representative aquifers in the Great Basin region of Nevada, Utah, and adjacent states: U.S. Geological Survey Professional Paper 1409-C, $100 \mathrm{p}$.

Thomas, M.A., 2000, The effect of residential development on ground-water quality near Detroit, Michigan: Journal of the American Water Resources Association, v. 36, no. 5, 1023-1038. 
Thornton, K.W., Kennedy, R.H., Carroll, J.H., Walker, W.W., Gunkel, R.C., and Ashby, S., 1980, Reservoir sedimentation and water quality - An heuristic model, in Stefan, H.G., ed., Proceedings of the Symposium on Surface Water Impoundments, June 2-5, 1980, Minneapolis, Minnesota: American Society of Civil Engineers, Environmental and Water Resources Institute, p. 654-664.

Tindall, J.A., Kunkel, J.R., and Anderson, D.E., 1999, Unsaturated zone hydrology for scientists and engineers: Upper Saddle River, N.J., Prentice Hall, 624 p. [Also available at http://wwwbrr.cr.usgs.gov/projects/GW_Unsat/ Unsat_Zone_Book/index.html.]

Toetz, Dale, 2006, Nitrate in ground and surface waters in the vicinity of a concentrated animal feeding operation: Archive for Hydrobiology, v. 166, no. 1, p. 67-77.

Tomaszewski, D.J., and Lovelace, J.K., 2007, Effects of Hurricane Katrina's storm surge on the quality of shallow aquifers near the northern shoreline of Lake Pontchartrain, southeastern Louisiana, in Farris, G.S., Smith, G.J., Crane, M.P., Demas, C.R., Robbins, L.L., and Lavoie, D.L., eds., Science and the storms-The USGS response to the hurricanes of 2005: U.S. Geological Survey Circular 1306, p. 213-220.

Toran, Laura, Johnson, Melanie, Nyquist, Jonathan, and Rosenberry, Donald, 2010, Delineating a road-salt plume in lakebed sediments using electrical resistivity, piezometers, and seepage meters at Mirror Lake, New Hampshire, U.S.A: Geophysics, v. 75, no. 4, p. WA75-WA83.

Transportation Research Board, 1991, Highway deicingComparing salt and calcium magnesium acetate: Washington, D.C., Transportation Research Board, Committee on the Comparative Costs of Rock Salt and Calcium Magnesium Acetate (CMA) for Highway Deicing, Special Report 235, 180 p.

Transportation Research Board, 2004, Snow removal and ice control technology: Washington, D.C., Transportation Research Board Circular E-C063, 665 p.

Triantafilis, J., and McBratney, A.B., 1998, Development of a mobile electromagnetic sensing system for soil salinity assessment in irrigated cotton fields, in The ninth Australian cotton conference: Australian Cotton Growers Research Association conference, Broadbeach, Queensland, Australia, August 12-14, 1998, p. 61-64.
Trowbridge, P.R., 2007, Data report for the Total Maximum Daily Loads for chloride for waterbodies in the vicinity of the I-93 corridor from Massachusetts to Manchester NH-Policy-Porcupine Brook, Beaver Brook, Dinsmore Brook, North tributary to Canobie Lake: New Hampshire Department of Environmental Services NHDES-RWD-07-40, accessed August 13, 2013, at http://des.nh.gov/organization/divisions/water/wmb/tmdl/ documents/chloride_data_report.pdf.

Trowbridge, P.R., Kahl, J.S., Sassan, D.A., Heath, D.L., and Walsh, E.M., 2010, Relating road salt to exceedances of the water quality standard for chloride in New Hampshire streams: Environmental Science and Technology, v. 44, no. 13 , p. 4903-4909.

Turnipseed, D.P., and Sauer, V.B., 2010, Discharge measurements at gaging stations: U.S. Geological Survey Techniques and Methods, book 3, chap. A8, 87 p.

Tuttle, M.L., and Grauch, R.I., 2009, Salinization of the upper Colorado River-Fingerprinting geologic salt sources: U.S. Geological Survey Scientific Investigations Report 2009-5072, 62 p.

Uchida, Shigo, Kamo, Hiroshi, and Kubota, Hiroshi, 1988, The source of $\mathrm{HCl}$ emission from municipal refuse incinerators: Industrial and Engineering Chemistry Research, v. 27, no. 11, 1988, p. 2188-2190.

U.S. Census Bureau, 2011, Historical census of housing tables - Sewage disposal: U.S. Census Bureau, Housing and Household Economic Statistics Division, accessed July 4, 2014, at http://www.census.gov/hhes/www/housing/census/ historic/sewage.html.

U.S. Department of Agriculture, 2009, 2007 census of agriculture - United States summary and state dataVolume 1. Geographic area series-Part 51: U.S. Department of Agriculture, National Agricultural Statistics Service Publication AC-07-A-51, 739 p.

U.S. Department of Agriculture, 2010, Farm and ranch irrigation survey (2008)_-Volume 3: U.S. Department of Agriculture, National Agricultural Statistics Service Report AC-07-SS-1, 268 p.

U.S. Department of Agriculture, 2014a, Crops and plants: U.S. Department of Agriculture census of agriculture 2012, accessed May 26, 2014, at http://www.agcensus.usda.gov/ Publications/2012/Online_Resources/Ag_Atlas_Maps/ Crops_and_Plants/.

U.S. Department of Agriculture, 2014b, Livestock and animals: U.S. Department of Agriculture census of agriculture 2012, accessed May 26, 2014, at http://www.agcensus.usda.gov/Publications/2012/Online Resources/Ag_Atlas_Maps/Livestock_and_Animals/. 
U.S. Department of Agriculture, 2014c-Publications: U.S. Department of Agriculture census of agriculture, accessed May 26, 2014, at http://www.agcensus.usda.gov/ Publications/.

U.S. Department of Agriculture, 2014d, Census of Aquaculture 2012: U.S. Department of Agriculture Web page, accessed May 26, 2014, at http://www.agcensus.usda.gov/ Publications/2002/Aquaculture/.

U.S. Department of Defense, 2012, Domestic wastewater treatment: U.S. Department of Defense Unified Facilities Criterion 3-240-02, 33 p.

U.S. Department of Energy, 2009, Modern shale gas development in the United States-A primer: U.S. Department of Energy DoE-FG26-04NT15455, 116 p.

U.S. Department of Energy, Energy Information Administration, 2011, Review of emerging resourcesU.S. shale gas and shale oil plays: U.S. Department of Energy, Energy Information Administration, 82 p.

U.S. Department of Energy, Energy Information Administration, 2012a, Annual energy outlook 2012: U.S. Department of Energy, Energy Information Administration DOE/ EIA-0383(2012), 240 p.

U.S. Department of Energy, Energy Information Administration, 2012b, Annual energy review 1982-2010: U.S. Department of Energy, Energy Information Administration Web page, accessed July 2, 2014, at http:/www.eia.gov/ coal/data.cfm.

U.S. Department of Energy, Energy Information Administration, 2012c, Annual energy review: U.S. Department of Energy, Energy Information Administration Web page, accessed July 2, 2014, at http://www.eia.gov/totalenergy/ data/annual/.

U.S. Environmental Protection Agency, 1974, Manual for deicing chemicals - Storage and handling: U.S. Environmental Protection Agency, Environmental Protection Technology Series, EPA 670-/2-74-033, 88 p.

U.S. Environmental Protection Agency, 1985, Water quality assessment-A screening procedure for toxic and conventional pollutants in surface and ground water, part 2 [revised]: U.S. Environmental Protection Agency Report EPA/600/6-85/002b, 494 p.

U.S. Environmental Protection Agency, 1986, Development of data quality objectives: Washington, D.C., U.S. Environmental Protection Agency, 12 p.

U.S. Environmental Protection Agency, 1988, Ambient water quality criteria for chloride_-1988: U.S. Environmental Protection Agency 440/5-88-001, 47 p., accessed December 17, 2007, at http:/www.epa.gov/ost/pc/ ambientwqc/chloride1988.pdf.
U.S. Environmental Protection Agency, 1992a, National Pollutant Discharge Elimination System storm water sampling guidance document: U.S. Environmental Protection Agency Report EPA 883-B-92-001, 177 p.

U.S. Environmental Protection Agency, 1992b, Secondary drinking water regulations-Guidance for nuisance chemicals: U.S. Environmental Protection Agency EPA 810/K-92-001, accessed June 13, 2006, at http://www.epa.gov/safewater/consumer/2ndstandards.html.

U.S. Environmental Protection Agency, 1994, Guidance for the data quality objectives process EPA QA/G-4, final report: U.S. Environmental Protection Agency EPA/600/R-96/055, 72 p.

U.S. Environmental Protection Agency, 1995, Construction and demolition waste landfills: U.S. Environmental Protection Agency, 39 p., accessed May 10, 2014, at http://www.epa.gov/epawaste/hazard/generation/sqg/const/ cdrpt.pdf.

U.S. Environmental Protection Agency, 1996, Guidance for data quality assessment-Practical methods for data analysis EPA QA/G-9, final report: Washington, D.C., U.S. Environmental Protection Agency EPA/600/R-96/084, $164 \mathrm{p}$.

U.S. Environmental Protection Agency, 1997, Monitoring guidance for determining the effectiveness of nonpoint source controls: Washington, D.C., U.S. Environmental Protection Agency EPA 841-B-96-004, 378 p.

U.S. Environmental Protection Agency, 1998, Fact sheet on the Federal Register notice for stage 1 disinfectants and disinfection byproducts rule: U.S. Environmental Protection Agency Fact Sheet EPA 815-F-98-010, 2 p.

U.S. Environmental Protection Agency, 1999a, Minimizing effects from highway deicing: U.S. Environmental Protection Agency Storm Water Management Fact Sheet EPA 832-F-99-016, 8 p.

U.S. Environmental Protection Agency, 1999b, Wastewater technology fact sheet - Chlorine disinfection: U.S. Environmental Protection Agency Fact Sheet EPA 832-F-99-062, $7 \mathrm{p}$.

U.S. Environmental Protection Agency, 2002, Onsite wastewater treatment systems manual: U.S. Environmental Protection Agency EPA 625/R-00/008, 376 p.

U.S. Environmental Protection Agency, 2004, Technical development document for the final effluent limitations guidelines and new source performance standards for the concentrated aquatic animal production point source category: U.S. Environmental Protection Agency EPA821-R-04-012, [variously paged]. 
U.S. Environmental Protection Agency, 2008, Septic systems fact sheet: U.S. Environmental Protection Agency Fact Sheet EPA 832-F-08-057, 1 p.

U.S. Environmental Protection Agency, 2009, Occurrence of contaminants of emerging concern in wastewater from nine publicly owned treatment works: U.S. Environmental Protection Agency EPA-821-R-09-009, 85 p.

U.S. Environmental Protection Agency, 2012a, Aquaculture: U.S. Environmental Protection Agency National Pollutant Discharge Elimination System, accessed July 5, 2014, at http://cfpub.epa.gov/npdes/home.cfm?program_id=520.

U.S. Environmental Protection Agency, 2012b, NPDES Permit Program basics: U.S. Environmental Protection Agency National Pollutant Discharge Elimination System, accessed July 5, 2014, at http://cfpub.epa.gov/npdes/home. cfm?program_id $=45$.

U.S. Environmental Protection Agency, 2013a, Acid rain: U.S. Environmental Protection Agency Web page, accessed October 21, 2013, at http://www.epa/gov/acidrain/index. html.

U.S. Environmental Protection Agency, 2013b, The ambient air monitoring program: U.S. Environmental Protection Agency Web page, accessed December 13, 2013, at http://www.epa.gov/airquality/qa/monprog.html.

U.S. Environmental Protection Agency, 2013c, Literature review of contaminants in livestock and poultry manure and implications for water quality: U.S. Environmental Protection Agency EPA 820-R-13-002, 125 p.

U.S. Environmental Protection Agency, 2013d, Technology Transfer Network, Ambient Monitoring Technology Information Center: U.S. Environmental Protection Agency quality assurance guidance documents, accessed April 1, 2015, at http://www.epa.gov/ttnamti1/.

U.S. Environmental Protection Agency, 2014a, Municipal solid waste generation, recycling, and disposal in the United States-Tables and figures for 2012: U.S. Environmental Protection Agency EPA-530-F-14-001, accessed May 10, 2014, at http://www.epa.gov/waste/nonhaz/municipal/ msw99.htm.

U.S. Environmental Protection Agency, 2014b, Permit Compliance System (PCS) and Integrated Compliance Information System (ICIS) databases in Envirofacts: U.S. Environmental Protection Agency Web site, accessed July 5, 2014, at http://www.epa.gov/enviro/facts/pcs-icis/ search.html.
U.S. Geological Survey, 2013a, Geologic units containing phonolite: U.S. Geological Survey Mineral Resources On-Line Spatial Data Web site, accessed October 25, 2013, at http://mrdata.usgs.gov/geology/state/sgmc-lith. php?text=phonoalite.

U.S. Geological Survey, 2013b, Geologic units containing syenite: U.S. Geological Survey Mineral Resources On-Line Spatial Data Web site, accessed October 25, 2013, at http://mrdata.usgs.gov/geology/state/sgmc-lith. php?text=syenite.

U.S. Geological Survey, 2013c, National field manual for the collection of water-quality data: U.S. Geological Survey Techniques of Water-Resources Investigations, book 9, chaps. A1-A9, http://pubs.water.usgs.gov/twri9A.

U.S. Geological Survey, 2013d, Regional groundwater studies: U.S. Geological Survey Web page, accessed December 23, 2013, at http://water.usgs.gov/ogw/gwrp/activities/regional. html.

U.S. Geological Survey, 2014a, USGS publications warehouse: U.S. Geological Survey Web site, accessed July 4, 2014, at http://pubs.er.usgs.gov/.

U.S. Geological Survey, 2014b, USGS water-quality data for the nation: U.S. Geological Survey National Water Information System Web site, accessed July, 4, 2014, at http://waterdata.usgs.gov/nwis/qw.

University of Arizona Cooperative Extension, 1991, Manure use and management-Animal waste management: University of Arizona Cooperative Extension fact sheet, accessed January 20, 2012, at http://ag.arizona.edu/ animalwaste/farmasyst/awfact8.html.

Unruh, J.R., Davisson, M.L., Criss, R.E., and Moores, E.M., 1992, Implications of perennial saline springs for abnormally high fluid pressures and active thrusting in western California: Geology, v. 20, p. 431-434.

Van Denburgh, A.S., and Feth, J.H., 1965, Solute erosion and chloride balance in selected river basins of the western conterminous United States: Water Resources Research, v. 1, p. $537-541$.

van Weert, Frank, van der Gun, Jac, and Reckman, Josef, 2009, Global overview of saline groundwater occurrence and genesis: International Groundwater Resources Assessment Center ReportGP 2009-1, accessed November 8, 2013, at http://www.un-igrac.org/ publications/342.

Vanysek, Petr, 2012, Ionic conductivity and diffusion at infinite dilution, in William M. Haynes, ed., CRC handbook of chemistry and physics (93d ed.): Boca Raton, Fla., CRC Press, p. 5-77-5-79. 
Varank, G., Demir, A., Top, S., Sekman, E., Akkaya, E., Yetilmezsoy, K., and Bilgili, M.S., 2011, Migration behavior of landfill leachate contaminants through alternative composite liners: Science of the Total Environment, v. 409, p. 3183-3196.

Vaughn, J.M., Landry, E.F., and Thomas, M.Z., 1983, Entrainment of viruses from septic tank leach fields through a shallow, sandy soil aquifer: Applied and Environmental Microbiology, v. 45, no. 5, p. 1474-1480.

Vengosh, Avner, Jackson, R.B., Warner, Nathaniel, Darrah, T.H., and Kondash, Andrew, 2014, A critical review of the risks to water resources from unconventional shale gas development and hydraulic fracturing in the United States: Environmental Science and Technology, v. 48, no. 15, p. 8334-8348.

Vengosh, Avner, and Keren, Rami, 1996, Chemical modifications of groundwater contaminated by recharge of treated sewage effluent: Journal of Contaminant Hydrology, v. 23, p. 347-360.

Vengosh, Avner, and Pankratov, Irena, 1998, Chloride/bromide and chloride/fluoride ratios of domestic sewage emuents and associated contaminated ground water: Ground Water, v. 36 , no. 5 , p. $815-824$.

Vet, R.J., Sirois, Alain, Jeffries, D.S., Semkin, R.G., Foster, N.W., Hazlett, P., and Chan, C.H., 1988, Comparison of bulk, wet-only, and wet-plus-dry deposition measurements at the Turkey Lakes watershed: Canadian Journal of Fisheries and Aquatic Sciences, v. 45, no. S1, p. s26-s37.

Wagner, R.J., Boulger, R.W., Jr., Oblinger, C.J., and Smith, B.A., 2006, Guidelines and standard procedures for continuous water-quality monitors - Station operation, record computation, and data reporting: U.S. Geological Survey Techniques and Methods, book 1, chap. D3, 51 .

Wagner, R.J., Frans, L.M., and Huffman, R.L., 1996, Occurrence, distribution, and transport of pesticides in agricultural irrigation-return flow from four drainage basins in the Columbia Basin Project, Washington, 2002-04, and comparison with historical data: U.S. Geological Survey Scientific Investigations Report 2006-5005, 64 p.

Wanty, R.B., 1997, USGS research on saline waters co-produced with energy resources: U.S. Geological Survey Fact Sheet 003-97, accessed January 24, 2015, at http://pubs.usgs.gov/fs/1997/fs003-97/.

Ward, J.R., and Harr, C.A., eds., 1990, Methods for collection and processing of surface-water and bed-material samples for physical and chemical analyses: U.S. Geological Survey Open-File Report 90-140, 71 p.
Ward, M.L., Bitton, Gabriel, Townsend, Timothy, and Booth, Matthew, 2002, Determining toxicity of leachates from Florida municipal solid waste landfills using a battery-oftests approach: Environmental Toxicology, v. 17, p. 258266.

Ward, R.C., 1984, On the response to precipitation of headwater streams in humid areas: Journal of Hydrology, v. 74, p. 171-189.

Watson, L.R., Bayless, E.R., Buszka, P.M., and Wilson, J.T., 2002, Effects of highway-deicer application on groundwater quality in a part of the Calumet aquifer, northwestern Indiana: U.S. Geological Survey Water-Resources Investigations Report 01-4260, 148 p.

Webb, W.E., Radtke, D.B., and Iwatsubo, R.T., 1998, Surfacewater sampling-collection methods at flowing and stillwater sites, in Wilde, F.W., Radtke, D.B., Gibs, Jacob and Iwatsubo, R.T., eds., National field manual for the collection of water quality data: U.S. Geological Survey Techniques of Water-Resources Investigations, book 9, chap. A4.1, p. $23-59$.

Weeks, E.P., and Stangland, H.G., 1971, Effects of irrigation on streamflow in the Central Sand Plain of Wisconsin: U.S. Geological Survey Open-File Report 70-0362, 113 p.

Weiskel, P.K., Vogel, R.M., Steeves, P.A., Zarriello, P.J., DeSimone, L.A., and Ries III, K.G., 2007, Water use regimes - Characterizing direct human interaction with hydrologic systems: Water Resources Research, v. 43, W04402, 11 p., accessed April 2, 2015, at http://dx.doi.org/10.1029/2006WR005062.

Wells, K.L., 2014, The agronomics of manure use for crop production: Lexington, Ky., University of Kentucky Cooperative Extension Service Report AGR-165, 2 p., accessed July 4, 2014, at http://agrienvarchive.ca/bioenergy/ download/wells_uky_agr165.pdf.

Wetherbee, G.A., Latysh, N.E., and Burke, K.P., 2005, External quality-assurance results for the National Atmospheric Deposition Program/National Trends Network, 2002-03: U.S. Geological Survey Scientific Investigations Report 2005-5061, 59 p.

Wetherbee, G.A., Latysh, N.E., Lehmann, C.M.B., and Rhodes, M.F., 2011, Four studies on effects of environmental factors on the quality of National Atmospheric Deposition Program measurements: U.S. Geological Survey Open-File Report 2011-1170, 36 p.

Wetherbee, G.A., and Rhodes, M.F., 2013, Effects of equipment performance on data quality from the National Atmospheric Deposition Program/National Trends Network and the Mercury Deposition Network: U.S. Geological Survey Open-File Report 2013-1031, 53 p. 
Whittemore, D.O., 2007, Fate and identification of oil-brine contamination in different hydrogeologic settings: Applied Geochemistry, v. 22, p. 2099-2114.

Wigmosta, M.S., Burges, S.J., and Meena, J.M., 1994, Modeling and monitoring to predict spatial and temporal hydrologic characteristics in small catchments: University of Washington Water Resources Series Technical Report 137, 223 p.

Wilcox, D.A., 1986, The effects of deicing salts on water chemistry in Pinhook bog, Indiana: Water Resources Bulletin, v. 22, no. 1, p. 57-65.

Wilhelm, S.R., Schiff, S.L., and Robertson, W.D., 1996, Biogeochemical evolution of domestic waste water in septic systems - 2. Application of conceptual model in sandy aquifers: Ground Water, v. 34, no. 5, p. 853-864.

Williams, J.H., 1996, Application of borehole geophysics at the Retsof salt mine collapse site, western New York, in Symposium on the Application of Geophysics to Engineering and Environmental Problems, Keystone, Colo., April 28-May 1, 1996, proceedings: Englewood, Colo., Environmental and Engineering Geophysical Society, p. 813-821.

Williams, J.H., Lapham, W.W., and Barringer, T.H., 1993, Application of electromagnetic logging to contamination investigations in glacial sand-and-gravel aquifers: Ground Water Monitoring and Remediation Review, v. 13, no. 3, p. 129-138.

Wilson, J.M., and Van Briesen, J.M., 2012, Oil and gas produced water management and surface drinking water sources in Pennsylvania: Environmental Practice, v. 14, p. 301-307.

Wilson, J.M., and Van Briesen, J.M., 2013, Source water changes and energy extraction activities in the Monongahela River, 2009-2012: Environmental Science and Technology, v. 47, no. 21, p. 12575-12582.

Windsor, Cristina, and Mooney, Rob, 2008, Verifying the use of specific conductance as a surrogate for chloride in seawater matrices, in Langevin, Christian, Lebbe, Luc, Bakker, Mark, and Voss, Clifford, eds., Proceedings of the 20th Salt Water Intrusion Meeting, June 23-27, 2008, Naples, Florida: Salt Water Intrusion Meeting biennial meeting proceedings, accessed July 2, 2014, at http://www.swim-site.nl/pdf/swim20/file174-177.pdf.

Windsor, Cristina, Steinbach, Ashley, Lockwood, A.E., and Mooney, R.J., 2011, Verifying the use of specific conductance as a surrogate for chloride in seawater matrices: Fort Collins, Colo., In-Situ Inc., 7 p., accessed July 1, 2013, at http://www.in-situ.com/force_download.php?file_id=440.
Winter, T.C., 1981a, Survey of errors for estimating water and chemical balances of lakes and reservoirs: Water Science and Technology, v. 1, p. 224-233.

Winter, T.C., 1981b, Uncertainties in estimating the water balance of lakes: Journal of the American Water Resources Association, v. 17, no. 1, p. 82-115.

Winter, T.C., Rosenberry, D.O., and LaBaugh, J.W., 2003, Where does the ground water in small watersheds come from?: Ground Water, v. 41, no. 7, p. 989-1000.

Winter, T.C., Rosenberry, D.O., and Sturrock, A.M., 1995, Evaluation of 11 equations for determining evaporation for a small lake in the North Central United States: Water Resources Research, v, 31, no. 4, p. 983-993.

Wisconsin Department of Transportation, 2009, Levels of service in winter maintenance operations - A survey of State practice: Wisconsin Department of Transportation Research and Library Unit, Transportation Synthesis Report, accessed July 5, 2014, at http://www.clearroads.org/downloads/tsrlevelsofservice.pdf.

Wood, W.W., and Sanford, W.E., 1995, Chemical and isotopic methods for quantifying ground-water recharge in a regional, semiarid environment: Ground Water, v. 33, p. $456-468$.

Yanong, R.P.E., and Erlacher-Reid, Claire, 2012, Biosecurity in aquaculture, part 1-An overview: Southern Regional Aquaculture Center Publication No. 4707, 16 p.

Yates, M.V., 1985, Septic tank density and ground-water contamination: Ground Water, v. 23, no. 5, p. 586-591.

Yechieli, Y., and Wood, W.W., 2002, Hydrogeologic processes in saline systems - Playas, sabkhas, and saline lakes: EarthScience Reviews, v. 58, no. 3-4, p. 343-365.

Zarriello, P.J., Harding, W.E., Yager, R.M., and Kappel, W.M., 1985, Quantity and quality of storm runoff in the Irondequoit Creek Basin near Rochester, New York-Part 1. Data-collection network and methods, quality-assurance program, and description of available data: U.S. Geological Survey Open-File Report 84-610, 44 p.

Zhu, Chen, Winterle, J.R., and Love, E.I., 2003, Late Pleistocene and Holocene groundwater recharge from the chloride mass balance method and chlorine-36 data: Water Resources Research, v. 39, http://dx.doi.org/10.1029/2003WR001987.

Zielinski, R.A., and Budahn, J.R., 2007, Mode of occurrence and environmental mobility of oil-field radioactive material at U.S. Geological Survey research site B, Osage-Skiatook Project, northeastern Oklahoma: Applied Geochemistry, v. 22, p. 2125-2137. 
Zobeck, T.M., Stout, J.E., Van Pelt, R.S., Funk, Roger, Rajot, J.L., and Sterk, Geert, 2002, Measurement and data analysis methods for field-scale wind erosion studies, in Lee, J.A. and Zobeck, T.M., eds., 2002, Proceedings of ICAR5/ GCTE-SEN Joint Conference: Lubbock, Tex., Texas Technical University, International Center for Arid and Semiarid Lands Studies, Publication 02-2, 4 p.

Zohdy, A.A.R., Eaton, G.P., and Mabey, D.R., 1974, Application of surface geophysics to ground-water investigations: U.S. Geological Survey Techniques of Water-Resources Investigations, book 2, chap. D1, 116 p.

Zublena, J.P., Barker, J.C., and Wessen, D.P., 2012, Soil facts dairy manure as a fertilizer source: North Carolina State University Agricultural Extension Service AG-439-28

WQWM-122, 8 p., accessed January 20, 2012, at http://www.soil.ncsu.edu/publications/Soilfacts/AG-439-

28/. 

For more information concerning this report, contact: Director, New England Water Science Center

U.S. Geological Survey

10 Bearfoot Road

Northborough, MA 01532

dc_nweng@usgs.gov

or visit our Web site at:

http://ma.water.usgs.gov

http://ri.water.usgs.gov

Publishing support by:

The Pembroke Publishing Service Center. 

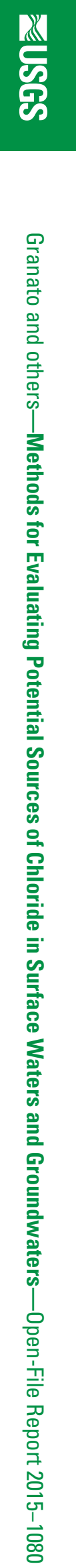